\%

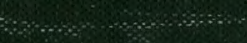
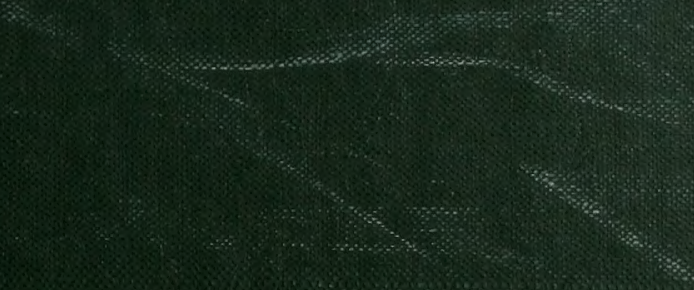

的视 


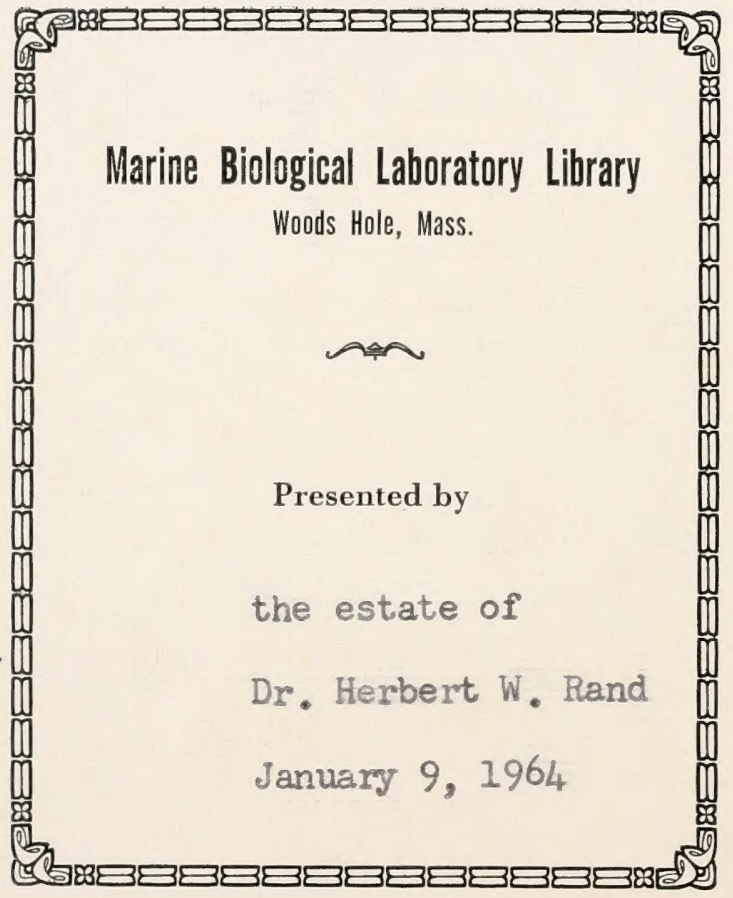



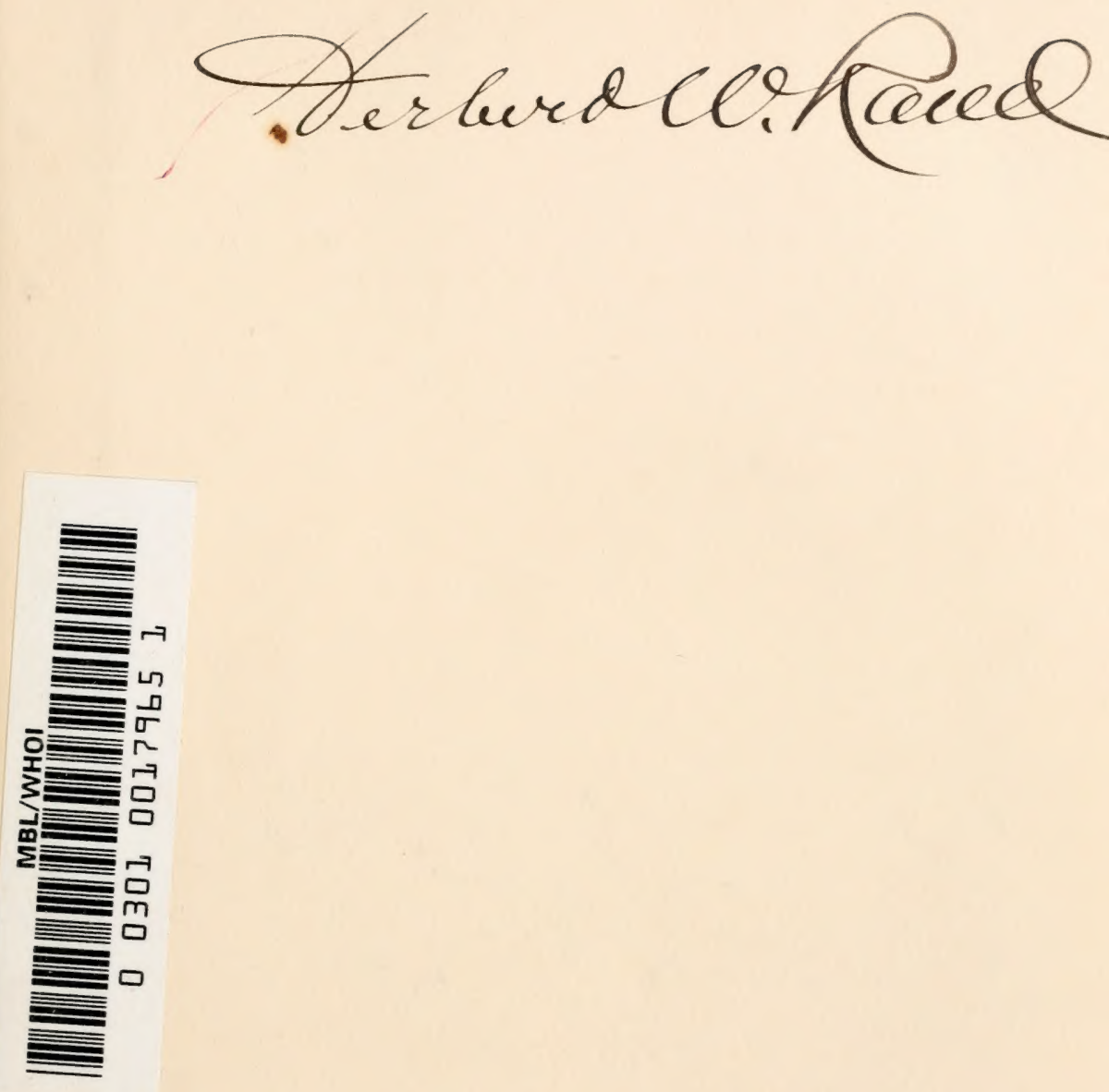








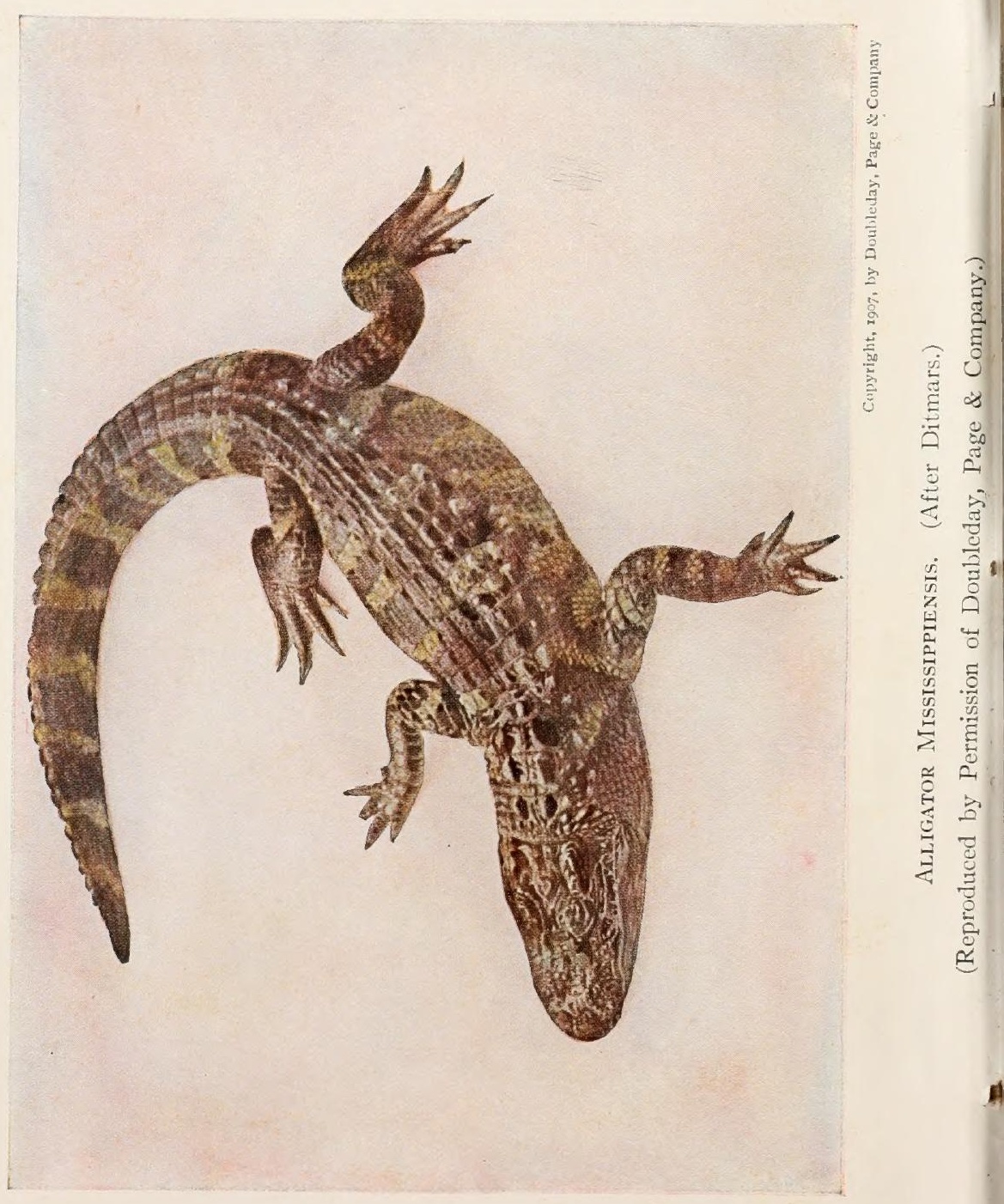




\title{
The
}

\section{Alligator and Its Allies}

\author{
By \\ Albert M. Reese, Ph.D. \\ Professor of Zoölogy in West Virginia University \\ Author of "An Introduction to Vertebrate Embryology"
}

With 62 Figures and 28 Plates

G. P. Putnam's Sons

New York and London

Tbe Tknickerbocker [presg

I9r 5 
COPYRIGHT, 1915

BY

ALBERT M. REESE

Tbe Rnickerbocker press, Hew Work 


\section{PREFACE}

THE purpose of this volume is to bring together, in convenient form for the use of students of zoölogy, some of the more important details of the biology, anatomy, and development of the Crocodilia. For obvious reasons the American Alligator is the species chiefly used.

In the first chapter the discussion of the alligator is largely the result of the personal observations of the author; the facts in regard to the less familiar forms are taken from Ditmars and others. The description of the skeleton, with the exception of short quotations from Reynolds, is the author's.

The chapter on the muscular system is a translation from Bronn's Thierreich, and the author has not verified the descriptions of that writer.

The description of the nervous system is partly the author's and partly taken from Bronn and others.

The chapters on the digestive, urogenital, respiratory, and vascular systems are practically all from descriptions by the author.

The chapter on "The Development of the Alligator" is a reprint, with slight alterations, of the paper of that title published for the author by the Smithsonian Institution. 
The bibliography, while not complete, will be found to contain most of the important works dealing with this group of reptiles.

The author is grateful to Mr. Raymond L. Ditmars and to his publishers, Messrs. Doubleday, Page \& Co., and Messrs. Sturgis \& Walton, for the use of a number of plates; to the Macmillan Company and to the United States Bureau of Fish and Fisheries for the same privilege; to the National Museum for photographs of the skull of the gavial; and to the Smithsonian Institution for the use of the plates from researches published by them and included herein.

Proper acknowledgment is made, under each borrowed figure, to the author from whom it is taken.

Morgantown, W. VA.

May I, 1915. 


\section{CONTENTS}

\section{CHAPTER I}

The Biology of the Crocodilia . . • . I I

CHAPTER II

The Skeleton

\section{CHAPTER II}

CHAPTER III

The Muscles

CHAPTER III

CHAPTER IV

The Nervous System

\section{CHAPTER V}

The Digestive System .
Chapter VI

The Urogenital System .
Chapter VII

The Respiratory System .
CHapter VIII

The Vascular System . . . . . 201

CHAPTER IX
The Development of the Alligator • . 226
Billiografhy • • • • • 343

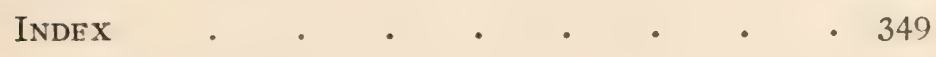





\section{ILLUSTRATIONS}

PAGE

Alligator Mississippiensis. (In color.) Frontispiece FIGURE

A. Skull of Belodon . . . . 5

I. Map Showing the Present Distribution of Crocodilia . . . . . . . . 6

2. Heads of American Alligator and CrocoDILE Facing 7

3. Alligator Joe in the Everglades . " io

4. Alligator Hunter in the Okefinokee " IO

5. Nest of C. Porosus . . . . . . 2 I

6. JACKSON SLOUGH . . . . . " 2 I

7. A Typical Alligator Hole. . . " 23

8. Alligator Nest, Made Chiefly of Grass . " 25

9. Alligator Nest, Made Chiefly of Flags . " 27

io. Two Species of Caiman . . . . " 35

i I. Two African Crocodiles . . . " 39

12. Salt Water Crocodile . . . " $4 \mathrm{I}$

13. Skull of Gavial, Ventral View . . " 43

14. Skull of Gavial, Lateral View . " " 43 vii 
viii

Illustrations

FIGURE

PAGE

15. Alligator Skins . . . . . Facing 46

i6. Entire Skeleton of Crocodile . . . 50

17. First four Cervical Vertebre of CrocoDILE . • • • . . 52

I8. Thoracic and Sacral Vertebre of CrocoDILE • • • • • • 55

19. Dorsal View of Skull of Alligator Facing 60

20. Ventral View of Skull of Alligator . "6 63

20, A. Longitudinal Section of Tooth of Crocodile . . . . . 66

2I. Lateral View of Skull of Alligator * 69

22. Posterior View of Skull of Alligator Facing 70

23. Sagittal Section of the Skull of Alligator 7 I

24. Dorsal View of Lower Jaw of Alligator Facing 74

25. The Hyoid Apparatus . . . . 77

26. The Sternum and the Associated MemBRANE BONES . . . . 79

27. The Pectoral Girdle and Anterior Limb 82

28. The Pelvis and Sacrum • . $\quad$ - 85

29. The Posterior Limb . . . • . 87

Plate I. The Shoulder Muscles • - I3O

Plate II. The Muscles of the Anterior REGION . . . . Following I30 
FIGUR:

Plate III. The Muscles of the Posterior REGION . . . . Following I3O

Plate IV. The Muscles of the Posterior REGION . . . . Following I30

Plate V. The Muscles of the Posterior REGION Following I30

30. The Brain of the Alligator . Facing 132

3I. The Brachial Plexus of C. Acutus . I 40

32. The Crural Plexus of A. Mississippiensis i 42

33. Interior of the Mouth of the Alligator.

Facing I 5 I

34. The Digestive System of the Alligator - I52

35. Outline of the Digestive Tract of the Alligator . . . . . 158

36. Covering of the Anterior Region of the Tongue . . . . . I60

37. Covering of the Posterior Region of the TONGUE . . . . . . I6I

38. Gland from the Posterior Region of the Tongue . . . . . . I 62

39. Gland from the Posterior Region of the

TONGUE . . . . . . $\quad$ I 64

40. Covering of the Roof of the Mouth - i 66

41. Transsection of the Anterior Region of THE Esophagus . . . . . I 69 
FIGURE

42. Transsection of the Posterior Region of THE Esophagus • . . . . 170

43. Epithelium of Anterior Region of EsophaGUS

44. Epithelium of Anterior Region of CEsophaGUS

45. Transsection of Wall of Pyloric Stomach . 176

46. Glands of Fundus of Stomach .

47. Transsection of Wall of Anterior Region of Small Intestine . . . . I8I

48. Transsection of Wall of Middle Region of Smalll Intestine . . . . I82

49. Transsection of Wall of Posterior Region of Small Intestine

50. Mucosa of the Anterior Region of Small INTESTINE . . . . . . I 184

5I. Transsection of the Wall of the Middle Region of the Small Intestine . . 185

52. Transsection of the Wall of the ANterior Region of THE Rectum . . . 186

53. Epithelium of the Anterior Region of the RECTUM

54. Female Urogenital System of Alligator . 193

55. Male Urogenital System of Alligator Facing 195 56. Male Organ of Alligator . . “ 195 


\section{Illustrations}

xi

FIGURE

PAGE

57. Respiratory Organs of Alligator . . I98

58. Heart of Alligator . . . Facing 202

59. Veins of the Posterior Region of Alli-

GATOR • • • • • • . 204

6o. Veins of the Anterior Region of the Alli-

GATOR • . . . . 209

61. Arteries of the Posterior Region of the

Alligator . . . . . $2 \mathrm{I} 3$

62. Arteries of the ANterior Region of the

Alligator . . . . . . 215

Plates VI to XXVIII. A Series of Figures

to Illustrate the Development of the

American Alligator . . Following 342 



\title{
THE ALLIGATOR AND ITS ALLIES
}

\section{CHAPTER I}

\author{
THE BIOLOGY OF THE CROCODILIA
}

\section{Classification}

A $\mathrm{S}$ in most groups of animals, there is conA siderable difference of opinion as to the proper classification of the Crocodilia.

One of the older textbooks (Claus and Sedgwick) divides the order Crocodilia into three sub-orders: the Teleosauria, Steneosanria, and Procalia, the last only being represented by living forms. The Procœelia or Crocodilia proper are divided into three families,- the Crocodilidce, the Alligatoride (including the caiman as well as the alligator), and the Gavialidoe.

This division into families seems to be based mainly on the shape of the head, or, at any rate, it throws those forms together that have heads of the same outline. 
It is this outline of the head that Ditmars (Reptiles of the World) uses in classifying the Crocodilia, which, he says, are all included in the single family -Crocodilida. The following list, taken from his Reptiles of the World (pp. 68-69), will give a clear idea of the number, distribution, and maximum size of the members of the order Crocodilia. More will be said of some of the members of this list later.

A. Snout extremely long and slender, extending from the head like the handle of a frying pan

Gavialis gangeticus, Indian Gavial

Tomistoma schlegeli, Malayan Gavial

B. Snout very sharp and slender; of triangular outline

Crocodilus cataphractus, Sharp-nosed Crocodile

Crocodilus johnstoni, Australian Crocodile

Crocodilus intermedius, Orinoco Crocodile

C. Snout moderately sharp; outline distinctly triangular

Crocodilus americanus, American Crocodile

Crocodilus siamensis, Siamese Crocodile

Crocodilus niloticus, Nile Crocodile

Crocodilus porosus, Salt-water Crocodile

D. Snout more oval; bluntly triangular Crocodilus robustus, Madagascar Crocodile Crocodilus rhombiferus, Cuban Crocodile Crocodilus moreletti, Guatemala Crocodile

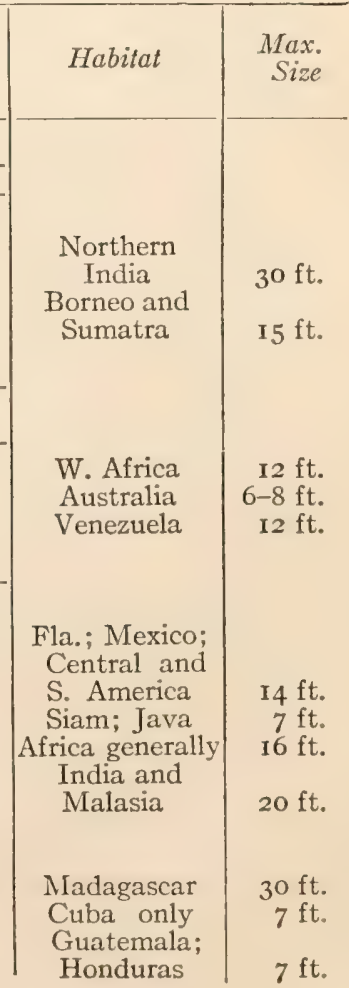




\section{The Biology of the Crocodilia}

E. Snout short and broad; conformation barely suggesting a triangular outline Crocodilus palustris, Swamp Crocodile

Osteolcmus tetrapis, Broad-nosed Crocodile

$D^{\prime}$. Outline of head similar to that of Section D

Caiman trigonotus, Rough-backed Caiman Caiman sclerops, Spectacled Caiman

Caiman palpebrosus, Banded Caiman

F. Snout very broad; bluntly rounded at tip

Caiman latirostris, ${ }^{x}$ Round-nosed Caiman

Caiman niger, ${ }^{2}$ Black Caiman

Alligator mississippiensis, American Alligator

Alligator sinensis, Chinese Alligator

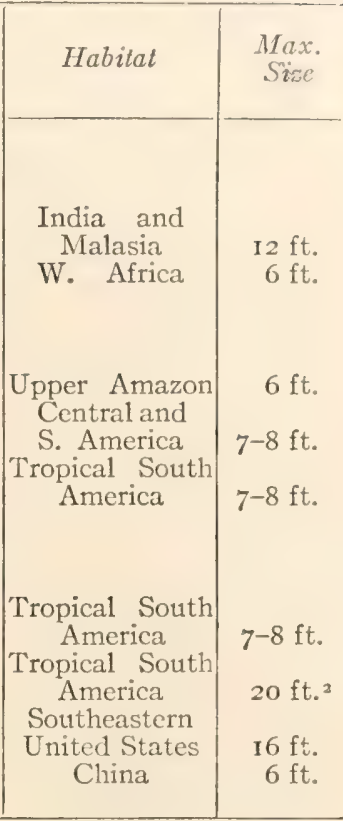

Gadow in the Cambridge Natural History (p. 45o) agrees with Boulanger in believing that the recent Crocodilia cannot be separated into different families, yet he describes seven families of Crocodilia, two of which, the Gavialidee and Crocodilide, include the living members of the order; the former includes the gavials, of course, and the latter the crocodiles, alligators, and caimans.

Though "doctors disagree" thus in regard to the scientific classification of this small group of

I These species are exceptions in their genus. The snout is blunt like that of the genus Alligator.

${ }^{2}$ Alleged to grow to this size by competent observers, 
animals, this fact does not in the least diminish the intense interest in the individual members of the order.

\section{ANCESTRY}

Although the huge dragon-like dinosaurs or "tcrrible reptiles," some of which were probably more than one hundred fcet long, became extinct during the Mesozoic epoch, perhaps millions of years before man made his appearance upon earth, we have one group of reptiles still living in certain parts of the earth of which the Mesozoic lords of creation need not feel ashamed. While most of the living Crocodilia are mere pigmies in size, compared to the Atlantosaurus, there are a few representatives of the living group, to be discussed later, that are said to reach a length of thirty feet, which length makes pigmies, in turn, of most of the other living reptiles.

Considering the extinct as well as the living Crocodilia, Gadow says it is very difficult to separate them from the Dinosauria. In the Mesozoic Crocodilia the fore limbs were much shorter and weaker than the hind limbs, as was often the case with the dinosaurs; they were almost entirely marine, but gave indications of descent from terrestrial forms.

Various facts point, thinks Gadow, "to some Theropodous Dinosaurian stock of which the Croc- 


\section{The Biology of the Crocodilia}

odilia may well form an aquatic, further developed branch" (Cambridge Natural IIistory, p. +32).
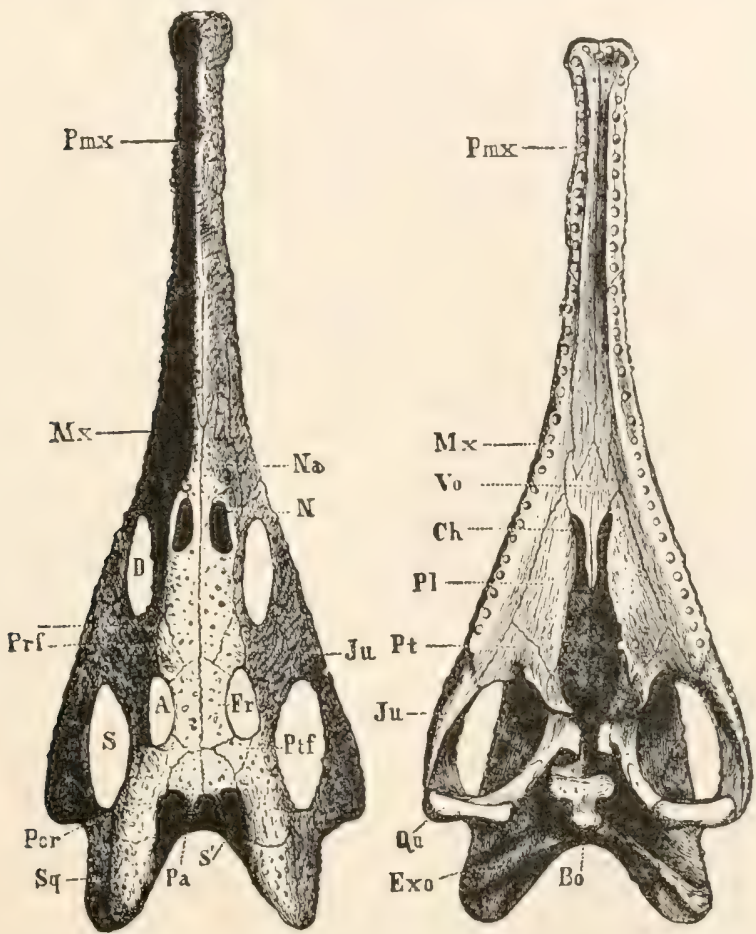

Skull of Belodon. A, from above; B, from below. A, orbit; $B$, basi-occipital; $C h$, internal nares; $D$, pre-orbital fossa; Exo. exoccipital; Fr. frontal; $J u$. jugal; La. lacrymal; $M x$. maxilla; $N a$. nasal; $P a$. parietal; $P l$. palatine; $P m x$. pre-maxilla; Por. post-orbital; $P r f$. pre-frontal; $P l$. pterygoid; $Q u$. quadrate; $S$, lateral temporal fossa: $S^{\prime}$, superior temporal fossa; Sq. squamosal; Vo. vomer. (From Zittel.)

Fig. A. A Triassic Ancestor of the Crocodilia. From Parker \& Haswell, Textbook of Zoölogy.

The direct ancestors of the Crocodilia, Gadow says, are still unknown. 


\section{Geographical Distribution}

As will be seen by examination of the table (p. 2) from Ditmars, and of Figure $\mathrm{I}$, the recent

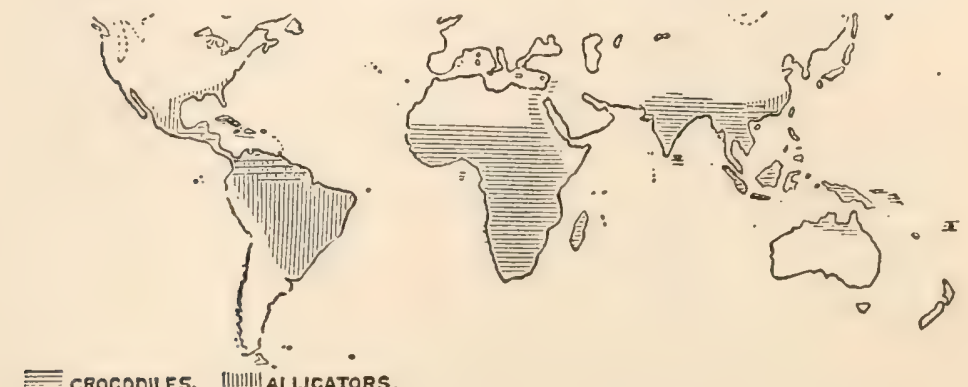

Fig. I. Map Showing Present Distribution of Crocodilia.

(After Gadow.)

Crocodilia are found in all of the great continental areas except Europe; mainly in the tropical or subtropical regions.

The alligator is found in the southwestern United States and in China.

The crocodile is the most numerous in species and is the most widely distributed of the group. It is especially characteristic of Africa and Madagascar, but is found also in Florida, Mexico, Central and South America, the West Indies, South Asia, the East Indies, and Australia.

The gavial is found in India and some of the islands of the Orient, especially Borneo and Sumatra.

The caiman occurs in southern Mexico, Central and South America. 



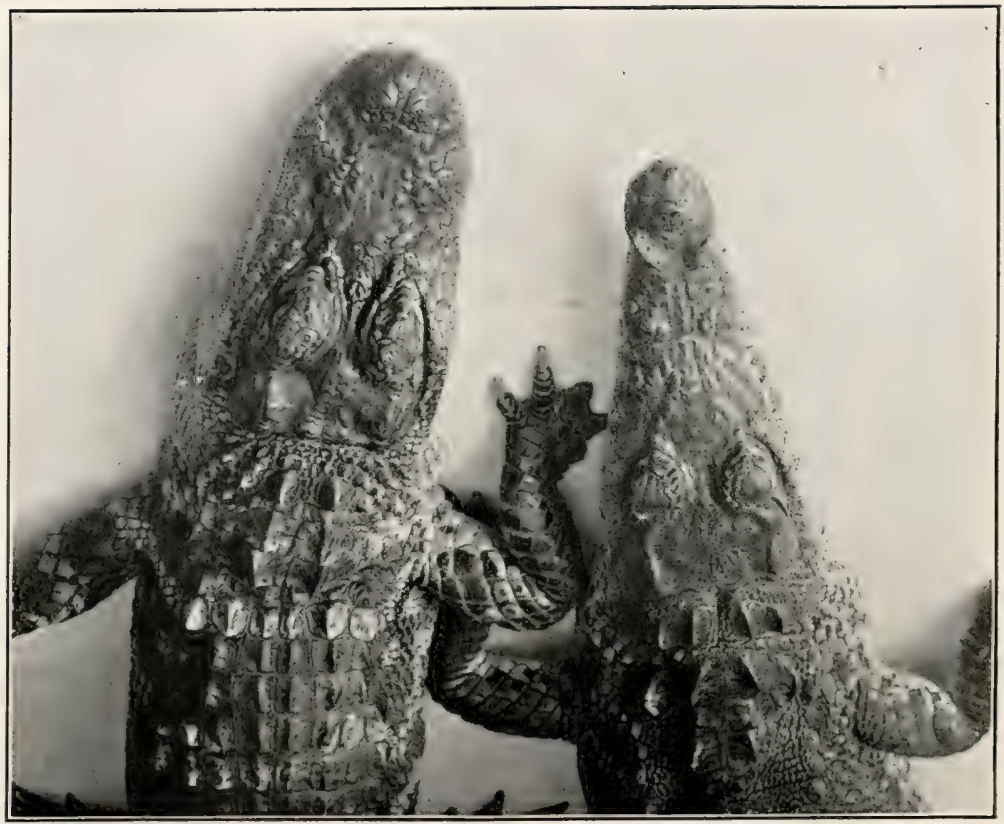

Fig. 2. Heads of American Alligator and American Crocodile; Alligator on Left. (After Ditmars.)

(Reproduced by Permission of Sturgis \& Walton Co.) 


\section{The Biology of the Crocodilia}

The distribution of individual forms will be mentioned again when they are discussed in detail.

\section{Alligator Mississippiensis}

Since this animal, generally known as the American or the Florida alligator (formerly $A$. lucius), is the one upon which most of the facts of this book are based, it will be discussed first.

At this point it may be well to answer the question that is sure to be asked by someone early in any conversation upon the Crocodilia. The writer, and doubtless every other zoölogist, has been asked countless times, "What is the difference between an alligator and a crocodile?" As a matter of fact there is, perhaps, no absolute distinction between the two groups, but there are certain features that make it easy to distinguish, say, between the American alligator and the American crocodile.

The most striking difference is in the outline of the head; the alligator has a broad, rounded snout, while that of the crocodile is narrower and more pointed (Fig. 2). Again, in the crocodile the fourth tooth from the front projects slightly outwards and fits into a notch in the side of the upper jaw, while in the alligator (also in the caiman) the corresponding tooth on each side fits into a sockct in the upper jaw and hence is hidden, except in some old animals with very long teeth, in which it may pierce the upper jaw and show from above. 
According to Ditmars, the crocodile has, as a rule, larger and more exposed teeth than the alligator. Finally, as will be brought out later, the crocodile is usually more quick and active, and also more vicious, than the alligator.

Very young alligators are nearly black, with distinct, yellow cross bands; as they grow older these markings become less distinct until in maturity the animals are of a uniform gray or dirty black color.

Habitat. The American alligator is found in the rivers and swamps of the Southern States, from the southern part of North Carolina to the Rio Grande, though Florida is usually thought of as being the region in which they particularly abound. Years ago, before the rifle of the ubiquitous tourist and so-called sportsman had gotten in its deadly work, the alligators were probably very abundant in the Southern States; but they have been so ruthlessly destroyed by native hunters for their skins, and by others for mere wanton sport, that one may travel, perhaps, for days along the rivers of the South without seeing a single 'gator.

The account quoted by Clarke from Bartram's travels of more than one hundred years ago, while probably exaggerated, gives an idea of the abundance of the alligators at that time: "The rivers at this place from shore to shore, and perhaps near a half mile above and below me, appeared to be one solid bank of fish of various kinds, push- 
ing through the narrow pass of San Juans into the little lake on their return down the river, and the alligators were in such incredible numbers, and so close together from shore to shore, that it would have been easy to have walked across their heads, had the animals been harmless." At the present time it is usually necessary to travel far from the usual routes of the Northern tourists to find alligators in any abundance.

At Palm Beach, Florida, lived, a few years ago, and probably still lives, a well-known hunter and guide, "Alligator Joe." Just what nationality he may be is difficult to determine, but that he knows that trackless waste, the Everglades, at least in the region of Palm Beach, is evident. He has an "alligator farm" near the great hotels of that famous winter resort, at which he lieeps, or did a few years ago, a large number of alligators of all sizes, as well as a number of crocodiles. For a consideration (by no means a modest one) he would take out a party of tourists for a day into the Everglades, guarantecing that he would find an alligator for them to shoot. It was rumorcd by the natives that an accomplice was always sent ahead to free the alligator at the psychological moment, after the hunters had been paddled by a devious course to the selected spot, but whether this were true or not the writer was not able to determine. It is true, however, that he and the writer paddled in a rather graceful canoe, dug out 
of a single cypress log, and waded through the Everglades for several days, searching for alligator eggs, and that we found only one nest and saw only one or two alligators (Fig. 3 ).

Doubtless in more remote parts of the Everglades the alligators are much more numerous.

During another summer the writer, with a guide, penetrated the very center of the State, to the region southeast of Lake Kissimmee, forty miles from the nearest railroad; here the alligators, and in consequence their nests, are fairly abundant, though the native hunters are, even in this remote region, rapidly thinning their ranks.

A still greater number of alligators was found, the following summer, in the Okefinokee Swamp in southern Georgia. In the center of this great waste, ten miles or more from dry land, nearly one hundred alligators, ranging from about four to eight feet in length, were killed within a week by a small party of native hunters with whom the writer was traveling (Fig. 4).

Whether this wholesale destruction by sportsman and native hunter will eventually exterminate our giant reptile, as has been the case with the buffalo and other game animals, it is impossible to say. Unless the Everglades and the Okefinokee are largely drained it seems probable that a few alligators will always remain in the most inaccessible regions.

The collection of eggs for sale and for hatching 


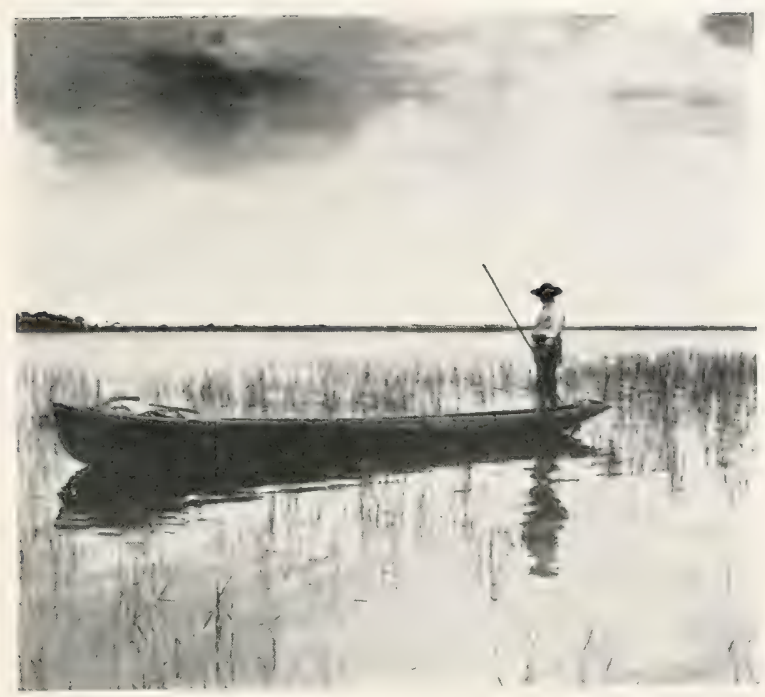

Fig. 3. Alligator Joe in the Everglades.

(From a Photograph by the Author.)

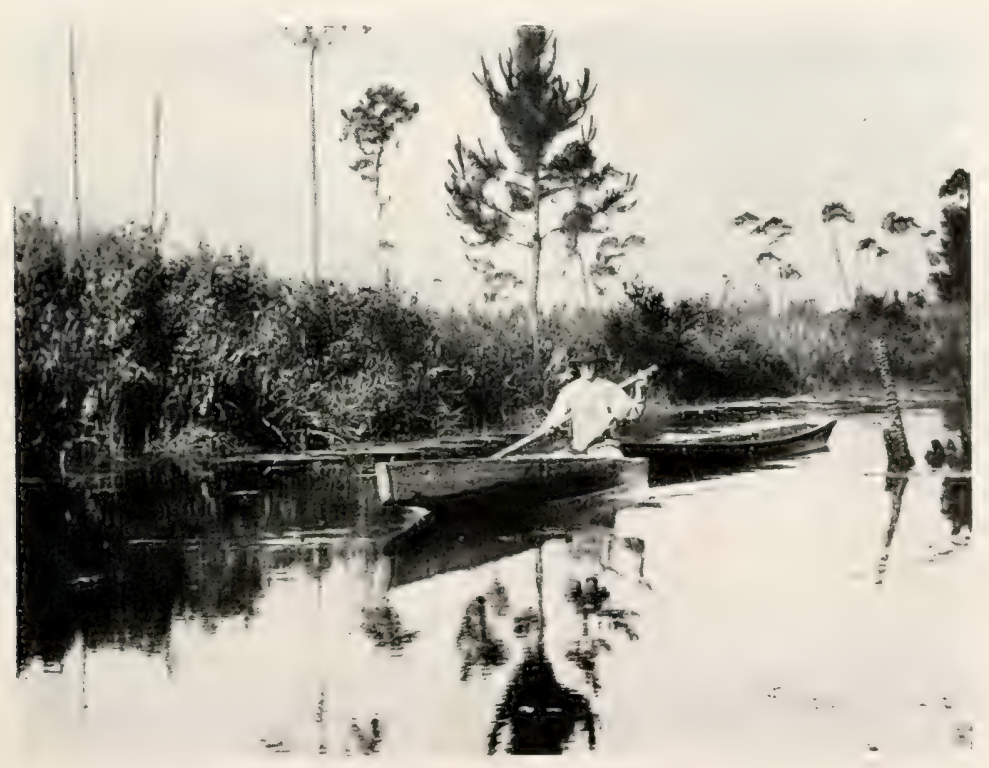

Fig. 4. Alligator Hunter in the Okefinokee.

(From a Photograph by the Author.) 



\section{The Biology of the Crocodilia}

purposes, as well as their destruction for food by bears and other animals, will also tend towards the annihilation of the species in the course of time. The economic importance of the alligator will be discussed later.

While in the old days, as has been said, the alligator was common in the larger rivers and lakes, and may even have ventured short distances into salt water, he must now frequently be satisfied to hide his great body in a "'gator hole" that is scarcely more than a puddle. These "holes" (Fig. 7) are common in central Florida and are sometimes scarcely large enough to allow the alligator to dive into them to seek the underground cave in which he hides. It is on the edge of such a hole that the nest is built, as will be described later.

Often from a small swamp or slough alligator "trails" lead off in different directions. These trails are narrow, winding gullies such as might be made by cattle in a damp pasture. If followed from the main slough the trail will usually be found to end in a "hole," in which an alligator will probably be found (Fig. 7). In a great swamp like the Everglades or the Okefinokee such holes would naturally not be found.

On one side of the hole is usually a smooth place where the vegetation is worn away; it is here that the 'gator "pulls out" to sleep in the sun; and wary must the hunter be to approach within sight 
of the animal before being seen or heard by him. At the first alarm he slides quietly or plunges quickly into the muddy water, and the hunter must wait long if he expects to see the 'gator come to the surface.

The opening of the cave is always below the surface of the water, but it is possible that there may be a subterranean chamber that is not completely filled with water. How the animal is gotten from his cave will be described later. According to some writers the alligator retires to his cave to hibernate during the cooler winter months. This is possibly true in the more northerly limits of his range. It is well known that if kept in cool water the alligator will lie dormant and refuse all food for months at a time. The writer has had young alligators in captivity, under these conditions, that refused food from late in the autumn until nearly the first of April.

The proprietor of one of the largest alligator farms in the country says: "Our alligators stop eating the first week in October and do not begin to eat until the latter part of April. We have experimented with our stock to see if we could get them to eat in the winter, and found that by keeping the water in the tanks at a certain temperature they would eat, but we found out that the warm water would make their bowels move, and that they would not eat enough to keep themselves up, as in the summer, and as a result they would be- 
come very poor and thin, so we do not force them to eat any more." The effect upon the growth of an animal of these two methods of feeding will be noted later when the age and rate of growth are discussed. The same writer says, in answer to a question about hibernation: "In their wild state they go into their dens under water and remain dormant all winter." Whether this statement is the result of actual observation the writer is not able to say, but, judging by some other statements from the same source, it is probably from hearsay. The writer, having visited the alligator haunts only in late spring and summer, has had no opportunity of studying the habits of the animal in its natural habitat during the winter season. During the heat of summer the animal does not seek the sun as he is said to do during cooler weather, but spends more time on the bank at night and during the cooler parts of the day.

That he sometimes wanders over dry land, perhaps going from hole to hole, is evident from the tracks that are sometimes seen crossing a dusty road or path. These trails are easily recognized by the clawed footprints with a line, made by the dragging tail, between them. Although most awkward on land, he can, if necessary, move very quickly. It is, however, in the water that he shows to best advantage; he is an active, powerful swimmer, his tail being used as a propeller as in the fishes. When swimming actively the legs 
are held close against the body in order that they may retard the animal's motion as little as possible. While swimming in a leisurely way the top of the head is at the surface of the water, perhaps just the nostrils and eyes projecting above the surface, so that the size of the animal can be estimated by the distance between these projecting points. One afternoon the writer and a guide, while paddling along an old canal that was dug years ago into the Okefinokee Swamp, were preceded for perhaps half a mile by a large alligator that swam just fast cnough to keep out of our reach until he came to the place where he wanted to turn off into the swamp.

Although so awkward on land, the alligator is said to be able to defend himself very effectively with his tail, which he sweeps from side to side with sufficient force, in the case of a large specimen, to knock a man off his feet. Although the writer has seen captured and helped to capture alive several alligators up to eight feet in length he has never seen this vigorous use of the tail as a weapon of defense.

While the alligator, like most other wild animals, will doubtless defend itself when cornered, it will always flee from man if possible, and the writer has frequently waded and swam in ponds and lakes where alligators lived without the least fear of attack. This might not have been possible years ago when the animals were more numerous and had not been intimidated by man and his weapons. 


\section{The Biology of the Crocodilia}

Food. The food of the adult alligator consists of fishes, birds, mammals, and possibly smaller individuals of its own species. The young eat small fish, frogs, insects, or worms.

If the animal be too large to swallow whole it is shaken and torn, the shaking being so vigorous that, according to Ditmars, the entrails of the prey may be thrown to a distance of twenty feet or more. Should two alligators seize the same prey at the same time they whirl about in opposite directions so violently that the prey is torn apart. This action may be illustrated by giving two small captive alligators a piece of tough meat; they hold on with bulldog tenacity, and each, folding its legs close to its body, will use its tail like a propeller until the animal whirls around with remarkable speed. The commotion that two ten-foot alligators would cause when thus struggling can easily be imagined. That a large alligator, if it tried, could easily drag under the water and drown a man or possibly a much larger animal is evident.

While the alligator has a valve-like fold of skin in its throat that enables it to open its mouth and crush its prey under water, it is said that it must raise its head above water in order to swallow its food. A young alligator on land will usually throw back its head when trying to swallow a large piece of meat, so that it may be simply this motion that brings the head of the alligator above the surface of the water. 
Ditmars thus describes the fate of a dog that approached too near a very large alligator: "As a dog, weighing about fifty pounds, unwarily approached the edge of this creature's tank, it was suddenly grasped and before completing its first yelp of terror was dragged beneath the surface. A few minutes later the twelve-foot saurian appeared at the top, holding the dead canine in its jaws. The dog was shifted about, amid the sound of breaking bones, and swallowed head first, and entire, after a few gulps."

Size and Growth. Although, years ago, alligators of fifteen feet length may have been common in favorable localities in the South, it is probable that few if any such monsters now exist. A twelve-foot alligator, owing to its great girth, is a huge animal and but few of this size are to be found in captivity. The largest specimen the writer has ever seen is the one in the Bronx Zoo, which is barely thirteen feet in length. At hatching the alligator is about eight inches in length.

Clarke (I 7 ) says: "The largest specimen I saw measured twelve feet in length; and none of the many hunters and natives of Florida I have met have seen any longer than thirteen feet. All the hunters agree that it is only the males that acquire the great size; no one had ever seen a female that measured over eight feet, and the majority are not over seven. The male has a heavier, more power- 
fu1 head, and during the brecding season especially is more brilliantly colored."

It is a very common belief, even among those who should be most familiar with their habits, that the growth of the alligator is remarkably slow, so that a large specimen may be described by the exhibitor as more than a century old. The same dealer in alligators quoted above says upon this subject: "You can figure about two inches a year to their growth." He also says: "We judge that an alligator about twenty-five to thirty years old will breed." Even scientific writers of reputation have not been free from this error in their writings. That the alligator may live to an extreme age, as seems to be true of some of the tortoises, is quite possible, and it is probable that after reaching a length of twelve or fifteen feet the growth is very slow.

In captivity, when kept in warm water and other favorable conditions, the alligator will grow, according to measurements taken at the New York Zoölogical Park, at the rate of about one foot a year, for about the first ten years. Under unfavorable conditions the growth may be exceedingly slow. Under favorable conditions in nature the rate of growth may exceed that given above.

Instead of requiring twenty-five to thirty years to reach sexual maturity, as quoted above, it is likely that the female may lay eggrs at five to ten years, though such a fact is difficult to determine of animals in their native haunts. 
Voice. 'The alligator, unlike most other members of its class, the Ophidia, Chelonia, and Lacertilia, has a voice, which, in an adult bull, may be heard for a mile or more. This bellowing is difficult to describe; it is something between a moan and a roar, and may be to attract the opposite sex or to serve as a challenge to other large animals. It is usually ascribed to the male, but whether confined to him or not the writer is unable to say.

In younger animals the voice is, of course, less deep and in very young individuals it is a squeak or grunt, casily imitated by hunters for the purpose of luring the animals from their hiding places.

Breeding Ilabits. Judging from the statements of native hunters the laying season of the alligator might be thought to be at any time from January to September. As a matter of fact the month of June is the time when most, if not all, of the eggs are laid. S. F. Clarke gives June $9^{\text {th }}$ and June I 7 th as the limits of the laying season in Florida, but I found at least one nest in which eggs were laid as late as June 26th: no eggs were found before the first date given by Clarke. It seemed quite certain that the laying, during the season in question, had been delayed by an extreme drought that had dried up the smaller swamps and reduced the alligator holes to mere puddles. Nests were found in considerable numbers as early as June 8 th, but no eggs were laid in any of them until the end of the dry period which occurred nearly two wceks later. 


\section{The Biology of the Crocodilia}

Almost immediately after the occurrence of the rains that filled up the swamps cggs were depositerl in all of the nests at about the same time. From the fact that all of these completed nests had stood for so long a time without eggs, and from the fact that all of the eggs from these nests contained embryos in a well-advanced state of development, it seemed evident that the egg-laying had been delayed by the unusually dry weather. Eggs taken directly from the oviducts of an alligator that was killed at this time also contained embryos that had already passed through the earlier stages of development. Thus it was that the earliest stages of development were not obtained during this summer.

It is said that during the mating season, which precedes by some time, of course, the laying season, the males are noisy and quarrelsome, and that they exhibit sexual characteristics of color by which they may be distinguished from the females. Never having been in the alligator country at this season, the writer has made no personal observations along these lines, but from the frequency with which alligators with mutilated or missing members are found it is evident that fierce encounters must sometimes take place, whatever the cause. During June and July, at least, and probably during most of the year, the alligators are very silent, an occasional bellow during the very early morning hours being the only audible cridence that one has that the big reptiles are in the 
neighborhood. Whatever may be the sexual differences during the mating season, at ordinary times the two sexes are so much alike that I have, on more than one occasion, scen experienced hunters disagree as to the supposed sex of an alligator that had just been killed.

Although I have never seen a nest actually during the process of construction, it is easy to imagine, after the examination of a large number of freshly made nests, what the process must be like.

The alligator, probably the female, as the male, after the mating season, takes no interest whatever in the propagation of his species, selects a slight elevation on or near the bank of the "hole" in which she lives. This elevation is generally, though not always, a sunny spot, and is frequently at the foot of a small tree or clump of bushes. Where the alligator is living in a large swamp she may have to go a considerable distance to find a suitable location for her nest; when her hole is scarcely more than a deep, overgrown puddle, as is often the case in the less swampy regions, she may find a good nesting place within a few feet of her cave. That the female alligator stays in the neighborhood of her nest after she has filled it with eggs seems pretty certain, but that she defends it from the attacks of other animals is extremely doubtful: certainly man is in very little danger when he robs the nest of the alligator, and, according to the statement of reliable hunters, bears are 



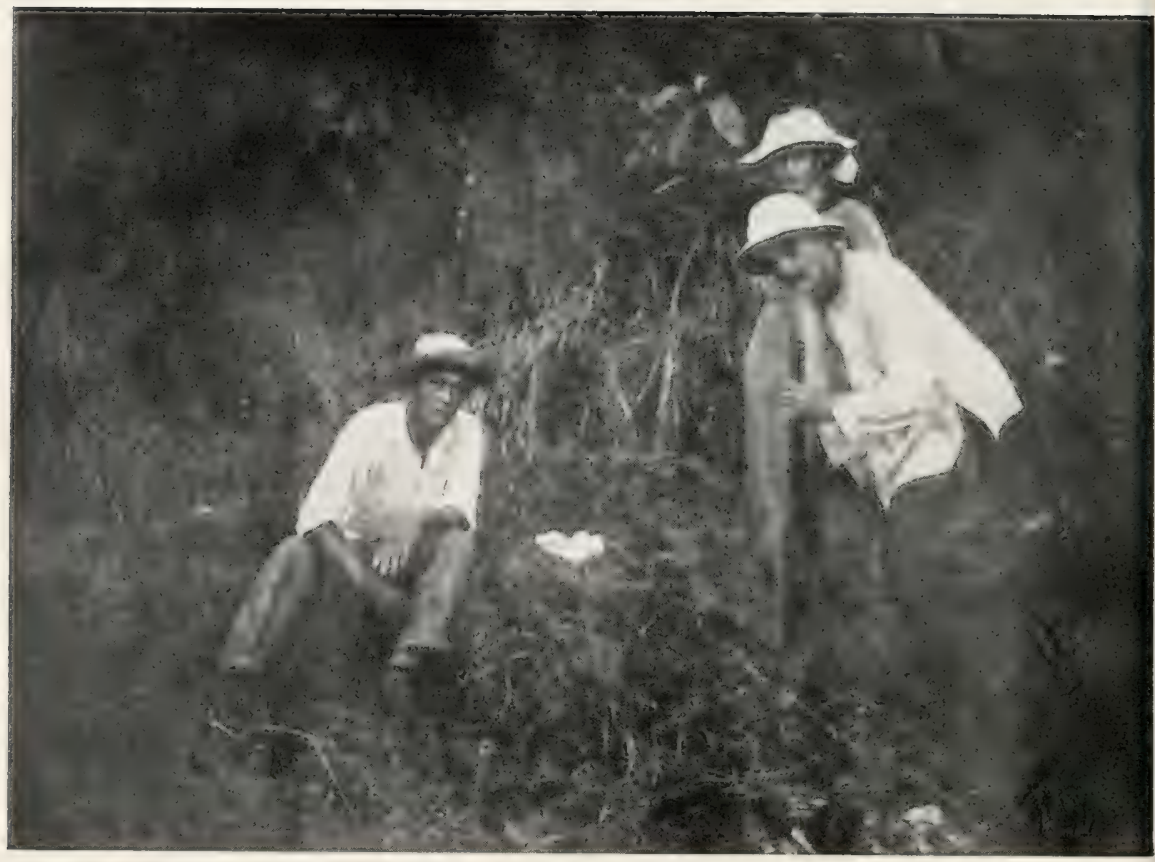

Fig. 5. A Nest of C. Porosus; Palawan, P. I.

(From a Photograph by Rowley.)

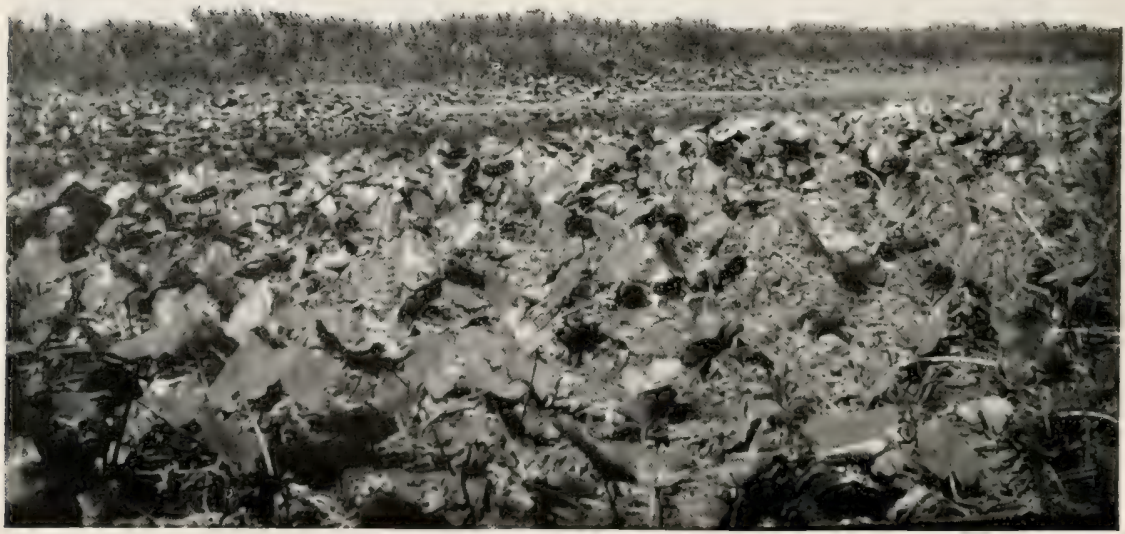

Fig. 6.-Jackson Slough; near Lake Kissmmee, Florida.

In the vicinity of this pond several alligator nests were found, either within a few yards of the edge, or on the banks of smaller "holes" which were connected with the larger pond by narrow "trails." (From a Photograph by the Author.) 


\section{The Biology of the Crocodilia}

very persistent searchers for and eaters of alligator eggs. Having selected (with how much care it is impossible to say) the location for the nest, the alligator proceeds to collect, probably biting it off with her teeth, a great mass of whatever vegetation happens to be most abundant in that immediate vicinity. This mass of flags or of marsh grass is piled into a conical or rounded heap and is packed down by the builder repeatedly crawling over it.

There is a great deal of variation in the size and form of the different nests, some being two meters or more in diameter and nearly a meter in height, while others are much smaller in diameter and so low as to seem scarcely more than an accidental pile of dead vegetation. It is probable that the nests are under construction for some time, perhaps to give time for the fresh vegetation of which they are composed to ferment and soften, and also for the material to settle into a more compact mass. The compactness of the alligator's nest was well illustrated one day when the writer used an apparently deserted nest as a vantage ground from which to take a photograph: on opening this nest it was found, after all, to contain eggs, and though some of the eggs were cracked, none of them were badly crushed. This nest although it was so low and flat that it was thought to be one that had been used during some previous season, contained forty-eight eggs, a greater number than 
was found in any other nest; while in other nests that were twice as large as this one were found less than half as many eggs, showing that there is no relation between the size of the nest and the number of eggs. The average number of eggs per nest, in the twelve nests that were noted, was thirty-one. One observer reported a nest that contained sixty eggs, but this, if true, was a very unusual case. Reports of still larger numbers of eggs in one nest probably refer to crocodiles, which are said to lay one hundred or more eggs in a nest. Although crocodiles may be found in certain parts of Florida, the writer has had no opportunity of observing their nesting habits.

The eggs are laid in the nest without any apparent arrangement. After the nest has been prepared, and has had time to settle properly, the alligator scrapes off the top, and lays the eggs in a hole in the damp, decaying vegetation; the top of the nest is again rounded off, and it is impossible to tell, without examination, whether the nest contains eggs or not.

As to whether the same nest is used for more than one season there is a difference of opinion among alligator hunters, and the writer has had no opportunity of making personal observations.

While it is usually stated that the eggs are incubated by the heat of the sun, it is held by some observers that the necessary heat is derived not from the sun but from the decomposition of the 


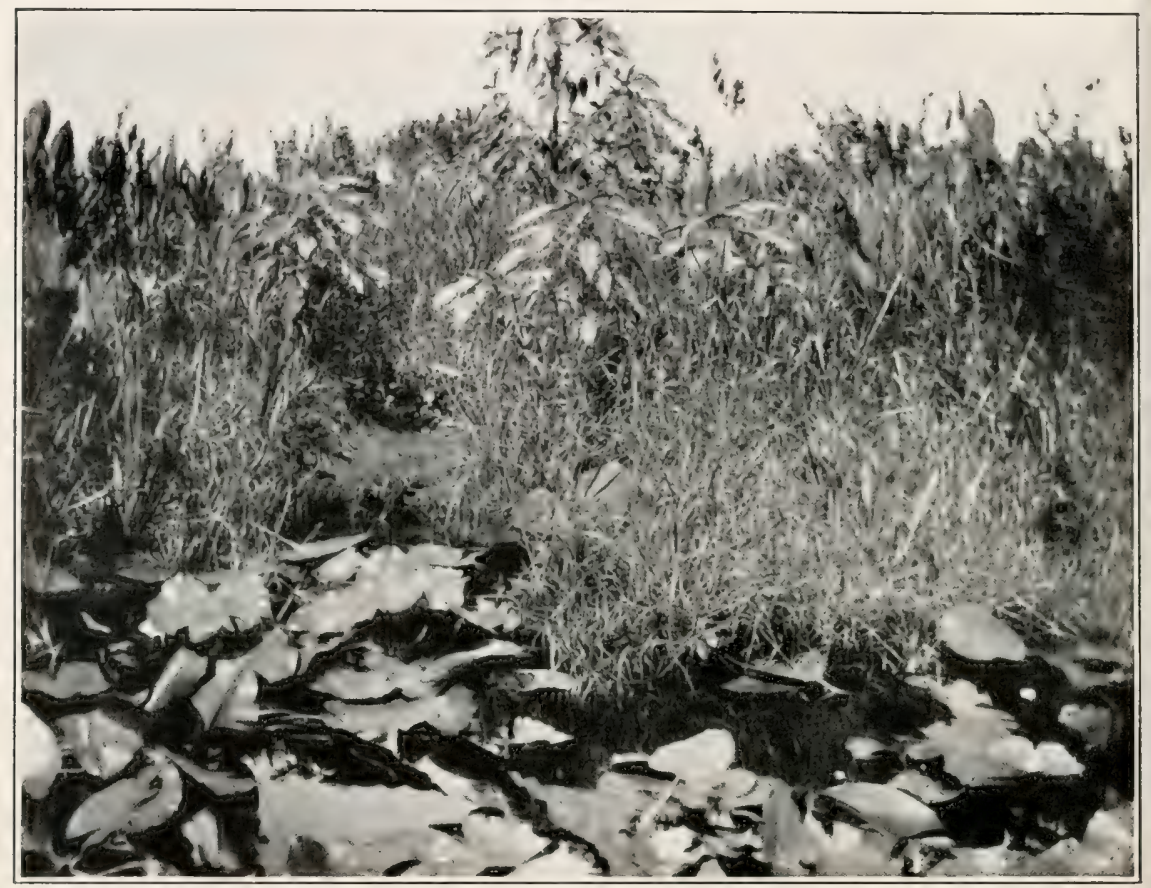

Fig. 7. A Typical 'Gator "Hole."

Only a few yards across, and surrounded by a dense growth of vegetation. On the far side is seen an opening in the surrounding grass and flags where the ground is worn smooth by the alligator in crawling out of the hole. Under the bank, probably near the place where the alligator "pulls out," is the deep cave into which the inhabitant of this hole quickly goes on the approach of danger. As this cave may be fifteen or twenty feet deep it is not an easy matter to get the animal out. When a female alligator inhabits such a hole, a nest may often be found within three or four yards of the water, though it is sometimes at a greater distance. Such a hole as this may be connected by narrow, winding "trails " with larger ponds, as noted under Fig. 6. (From a Photograph by the Author.) 


\section{The Biology of the Crocodilia}

vegetable matter of which the nest is composed. Possibly heat may be derived from both of these sources, but it seems likely that the conditions that are especially favorable to normal incubation are moisture and an even, though not necessarily an elevated, temperature. Moisture is certainly a necessary condition, as the porous shell allows such rapid evaporation that the egg is soon killed if allowed to dry. The inside of the nest is always damp, no matter how dry the outside may become under the scorching sun, so that this condition is fully met. The eggs of the Madagascar crocodile, according to Voeltzkow, ${ }^{\mathrm{I}}$ offer a marked contrast to those of the alligator. Instead of being laid in damp nests of decaying vegetation, they are laid in holes that are dug in the dry sand, and are very sensitive to moisture, the early stages, especially, being soon killed by the lcast dampness. A crocodile's nest containing eggs is shown in Figure 5. In this species of crocodile, probably C. porosus, the nest resembles that of the Florida alligator. The photograph was taken by Mr. Rowley on the edge of a small lake on the Island of Palawan, P. I. The daily range of temperature in the Southern swamps is sometimes remarkably great, so that if the eggs were not protected in some way they would often pass through a range of temperature of pos-

s Voeltzkow, A., "The Biology and Development of the Outer Form of the Madagascar Crocodile," Abhandl. Senckberg. Gesell., Bd. 26, Hit. I. 
sibly fifty degrees or more; while in the center of a great mass of damp vegetation they are probably kept at a fairly constant temperature. Unfortunately no thermometer was taken to the swamps, so that no records of the temperatures of alligator nests were obtained, but it was frequently noticed that when, at night or very early in the morning, the hand was thrust deep into the center of an alligator's nest the vegetation felt decidedly warm, while in the middle of the day, when the surrounding air was, perhaps, fifty degrees (Fahrenheit) warmer than it was just before sunrise, the inside of the same nest felt quite cool. It is probable, then, that the conditions of temperature and moisture in the center of the nest are quite uniform. One lot of eggs that had been sent from Florida to Maryland continued to incubate in an apparently normal way when packed in a box of damp sawdust, the temperature of which was about 80 degrees Fahrenheit. Another lot of eggs continued to incubate, until several young alligators were hatched, in the ordinary incubator, at a temperature of about 95 degrees Fahrenheit. ${ }^{\mathrm{I}}$

The fact that eggs taken directly from the oviducts of the cold-blooded alligator contain embryos of considerable size seems to indicate that no such elevation of temperature as is necessary with avian eggs is necessary with the eggs of the alligator.

I Reese, A. M., "Artificial Incubation of Alligator Eggs," Amer. Nat., March, 1901, pp. 193-195. 



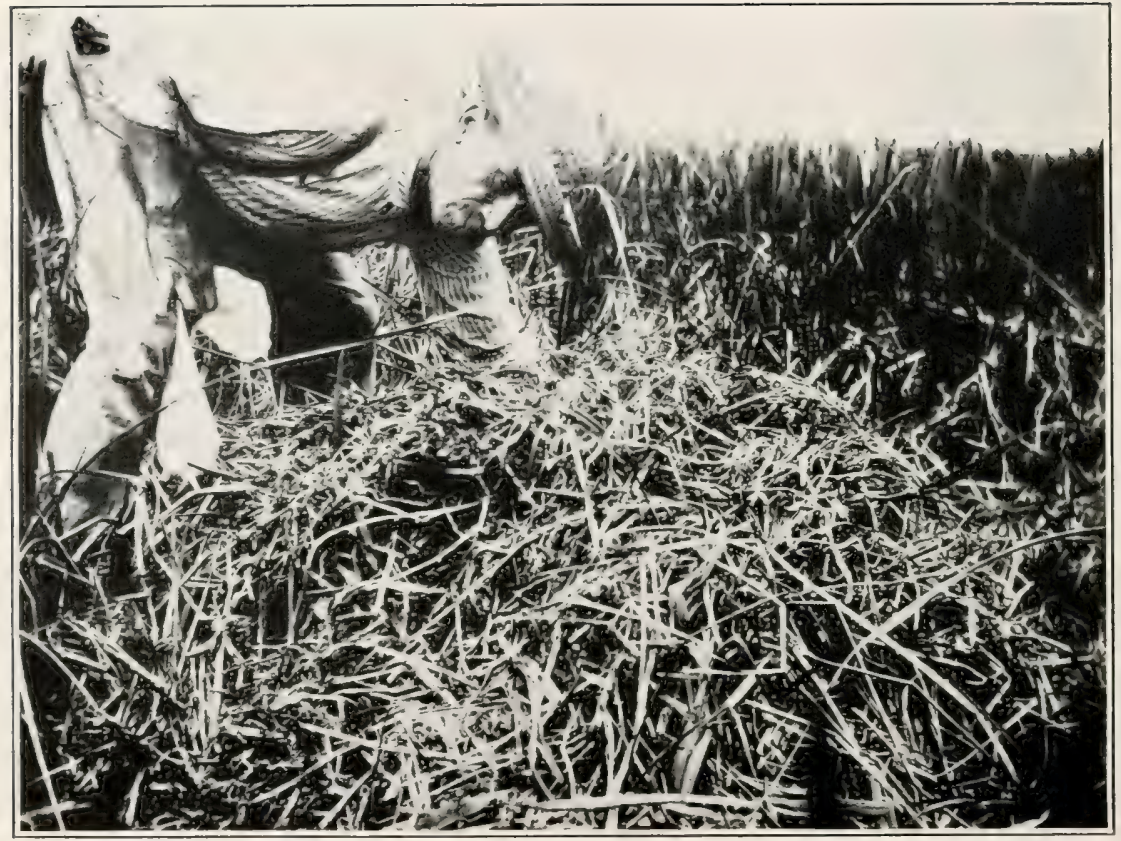

Fig. 8. A Typical Alligator's Nest, Made Chiefly of Grass.

The guide is feeling for eggs without disturbing the outside of the nest. Being made of the same material as the background, the nest does not stand out very sharply, though in nature the contrast is somewhat more marked, owing to the fact that the surrounding grass is green while the grass of which the nest is built is dead and brown. (From a Photograph by the Author.) 
The complete process of incubation probalily extends through a period of about eight weeks, but no accurate observations along this line could be made. For some hours previous to hatching the young alligators make a curious squeaking sound inside the shell, that may be heard for a distance of several yards: this sound may be for the purpose of attracting the attention of the female alligator, who will open the top of the nest in time to allow the just hatched alligators to escape: unless thus rescued, it would seem impossible for the little animals to dig their way out from the center of the closely packed mass of decaying vegetation.

At the time of hatching the alligator is, as already noted, about eight inches in length, and it seems impossible that it should have been contained in so small an egg.

The size of alligator eggs, as might be expected, is subject to considerable variation. In measuring the eggs a pair of brass calipers was used, and the long and short diameters of more than four hundred eggs were obtained. A number of eggs of average size, when weighed in mass on the scales of a country store, gave an average of $2.8 \mathrm{oz}$. per egg.

There was more variation in the long diameter of eggs than in the short diameter.

The longest egg of all those measured was 85 $\mathrm{mm}$.; the shortest was $65 \mathrm{~mm}$. The widest egg (greatest short diameter) was $50 \mathrm{~mm}$; the narrowest egg (least short diameter) was $38 \mathrm{~mm}$. 
The average long diameter was $73.742 \mathrm{~mm}$; the average short diameter was $42.588 \mathrm{~mm}$.

The greatest variation in long diameter in any one nest of eggs was $15.5 \mathrm{~mm}$.; the greatest variation in short diameter in the eggs of any one nest was II $\mathrm{mm}$.

The average variation in the long diameter of the eggs from the same nest was II.3I $8 \mathrm{~mm}$; the average variation in the short diameter of the eggs from the same nest was $5.136 \mathrm{~mm}$.

It will be seen from the above that the average variation in the long diameter of eggs from the same nest is between one sixth and one seventh of the long diameter of the average egg; while the average variation in the short diameter of the eggs from the same nest is less than one eighth of the short diameter of the average egg.

S. F. Clarke ${ }^{\mathrm{I}}$ gives the limits of the long diameter as $50 \mathrm{~mm}$. and $90 \mathrm{~mm}$., and the maximum and minimum short diameters as $45 \mathrm{~mm}$. and $28 \mathrm{~mm}$. No such extremes in size were noticed among the cight hundred or more eggs that were examined.

Economic Importance. ${ }^{2}$ More than one hundred years ago attempts were made to utilize the skin of the alligator, but it was not until about 1855 that these attempts were successful and alligator leather became somewhat fashionable and some

I Journal of Morphology, vol. v.

${ }^{2}$ The following figures are from an article by C. H. Stevenson in the Report of the Bureau of Fisheries, 1902, pp. 283-352. 



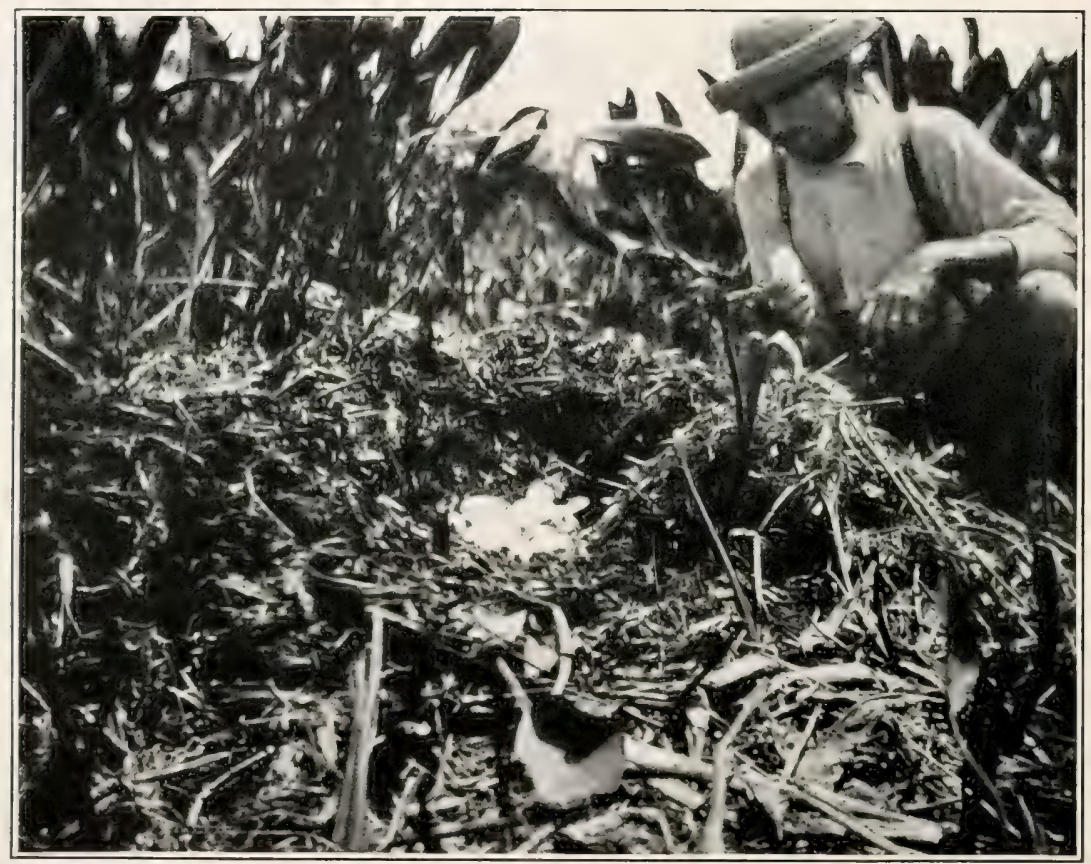

Fig. 9. An Alligator's Nest, Somewhat Smaller than the One Represented in Fig. 8, Built Chiefly of Flags.

The nest has been opened to show the irregularly arranged mass of eggs inside. The size and shape of the egg are shown by the one in the guide's hand. (From a Photograph by the Author.) 


\section{The Biology of the Crocodilia}

thousands of hides were converted into leather. The demand was short-lived, however, and was not again felt until the demand for shoe-leather during the war between the States revived the business. At the close of the war the business again failed, but about I 869 the demand became greater than ever and has continued unabated to the present time. The supply of skins from our own States proving inadequate, large numbers of skins were soon imported from Mexico and Central America. The slins from South America are so heavy that they are of little value in making leather. Of the States of the Union, Florida has been the chief producer, the most important centers for hides being Cocoa, Melbourne, Fort Pierce, Miami, and Kissimmee. Ten men at the first-named place took, in I899-I900, 2500 skins; one man took 800 skins in one year; another man collected 42 skins in one night. At Fort Pierce twelve men took 4000 skins in 1889 . In I 899, three firms at Kissimmee handled 33,600 hides. After this time the total number of hides taken and the average per man diminished greatly.

Besides being killed for their hides, the alligators have been destroyed by the thousands merely for wanton sport, so that in 1902 it was estimated that their numbers in Florida and Louisiana were less than one fifth of what they were twenty years before that time, and unless steps be taken to prevent it, the alligator hide, as an article of 
commerce, may cease to exist in our Southern States.

It has been claimed that the destruction of the alligator has allowed the cane rat and muskrat to increase to a serious extent, the former doing great damage to crops, the latter often injuring the levees to a dangerous extent. Legislation to forbid the killing of alligators of less than five feet in length has been suggested and should be passed, since animals of less size have almost no commercial value for leather.

In I902, the annual output from the tanneries of the United States approximated 280,00o skins, worth about $\$ 420,000$. Of these about fifty-six per cent. came from Mexico and Central America, twenty-two per cent. from Florida, twenty per cent. from Louisiana, and the remaining two per cent. from the other Gulf States. South American hides are not handled by the United States markets.

In I9o8, there were marketed from the South Atlantic and Gulf States 372,00o pounds of alligator hides, valued at $\$ 6 \mathrm{I}, 000$.

According to the United States Bureau of Fisheries the hunter in I89I averaged about 60 cents for the skin, while in 1902 the price averaged about 90 cents, varying between i 5 cents and $\$ 2.00$, depending on the size and condition of the skin. "Prime hides five feet long, with no cuts, scale slips, or other defects, are worth about 95 cents each, in trade, when the hunter sells them at the 


\section{The Biology of the Crocodilia}

country stores, and about \$I.IO cash, at the tanneries. Those measuring seven feet are worth \$I.55, six feet, \$I.I2; four feet, 52 cents, and three feet, 25 cents. Little demand exists for those under three feet in length" (Report Commissioncr of Fish and Fisheries, 1902, p. 345). Hides of seven feet are in most demand, those over ten feet are not much used. The income of the hunters is largely increased by the sale of otter, bear, decr, and other skins.

The different varieties of stins are described by Stevenson (74) as follows:

"There are several distinct varieties of alligator skins on the markets, the most important being the Floridian, Louisianian, and Mexican; each differs from the others in certain well-defined characteristics, and owing to these differences each variety has its special uses.

"The Florida skins are longer in the body-that is, from the fore legs to the hind legs - than those from Louisiana and Mexico, and consequently they are largely in demand by manufacturers of large handbags. They also have a number of so-called 'buttons' or 'corn marks' on the inside or under surface of an equal number of the scutes resulting from imbedded horn-like tissues in the center of those scales. These increase the difficulty in tanning the skins and detract somewhat from the appearance of the finished article, and for this reason the Florida skins are ordinarily the cheapest 
on the market. The farther south the skins are secured in Florida the greater the number of 'corn marks,' and those from the vicinity of Key West are almost valueless for this reason.

"The Louisiana skins differ from those of Florida in the absence of the 'corn marks' above noted, and from both the Florida and Mexican skins in being more pliable and in having the scales more artistically curved and shaped. Consequently they are preferred for such small articles as cardcases and pocketbooks, and usually sell at the highest prices. Skins obtained in Mississippi and Texas are similar to those secured in Louisiana, while those from Georgia and South Carolina are similar to those from Florida, except that the 'corn markings' are not so numerous. All the Florida and Louisiana skins show greater uniformity of coloring, being of a bluish black on the upper surface and a peculiar bluish white on the under side.

"In addition to an absence of the characteristics above noted the Mexican and Central American skins are distinguished by having from one to four small dots or markings like pin holes near the caudal end of each scale. The length of the Mexican skins varies greatly in proportion to the width, sometimes equaling that of the Florida skins. Those from the east coast of Mexico are the best, being lighter in color and with neat and attractively shaped scales. The west coast skins are yellowish 


\section{The Biology of the Crocodilia}

in color when in the green state, and the scales are larger and not so artistically formed. The Floricla and Louisiana skins are almost invariably split down the back, or rather along each side of the back, so as to preserve the under side in a solid piece, but most of the Mexican skins are split down the middle of the abdomen, keeping the back intact, making what is commonly known as 'horn alligator.' (See Fig. I5.)

"The skin should be removed soon after death as, in warm climates, putrefaction sets in very early and the value of the skin is depreciated. After removal, the flesh side of the skin is thoroughly rubbed with fine salt, and the skin is carefully rolled up with the salted side inside and is ready for shipment, but must be kept in a dry, cool place. Great care must be taken not to cut the hide since small cuts that are not noticeable in the raw skin may be so conspicuous in the dressed skin as to render it of much less value; a large percentage of the hides received in the markets are thus damaged.

"Formerly only the 'belly skin' was removed, by two longitudinal incisions just below the horny portion of the back; but it was later found that the thick horny skin of the back could be tanned nearly as well as the thinner belly skin, so that the entire skin is now usually removed by a longitudinal incision along the mid-ventral line, with lateral incisions along each leg to the foot (Fig. I 5). 
The entire slin is more commonly taken in Mexico and Central America than in our States.

"Although the raw skins are sold according to length, the tanned hides are sold by the width of the leather at the widest part. Standard hides sell for \$I.OO to \$I.65 per twelve inches of width. Some skins tanned and dyed in a superior manner sell for $\$ 2.00$ or more for single skins of $2 \mathrm{I} / 2$ feet in length. As a rule the Louisiana skins fetch the highest prices, and those from Florida the lowest. Imitation alligator leather is now prepared in large quantities, principally from sheepskins or the buffing from cowhides. These are tanned according to the usual process, and before the skins are finished they are embossed with the characteristic alligator markings by passing them between two rollers." (Above-mentioned report, p. 346.)

Very little of the leather is now used in making shoes, the chief demand being for handbags, music-rolls, etc.

In hunting alligators for their hides two methods are usually employed, in our Southern States at least. The common method is "fire-hunting" at night; the hunters here go, either singly or in pairs, usually in boats, sometimes on foot, with shotgun and torch. The torch may be fastened to the hunter's hat, after the manner of the miner's lamp. One more progressive hunter that I knew had, as a torch, an acetylene lamp, attached to his hat, with the tube for the gas extending down his 
back to the generator in his pocket. This lamp threw a blinding beam of light far across the swamp into the eyes of the unsuspecting 'gator, which usually remained fascinated until it could be approached to within easy range. A shotgun at close range, of course, blows off nearly the entire top of the animal's head and kills it instantly; it is then seized before it sinks out of reach and is either taken into the boat or dragged upon the bank to be collected with others in the early morning.

In daylight, with no glaring light to hypnotize it, the alligator is difficult to approach within range and it usually disappears into its cave before the hunter can get a shot at it. The daylight hunter, then, should be supplied not, of course, with a light, but with a ten- or fifteen-foot pole with a large iron hook at the end. If the alligator be vigorously prodded with this mammoth fishhook he will usually finally seize it with his mouth and can be pulled out of his hole alive. It is then an easy matter to kill him with a bullet through the base of the brain. I have seen an eight-foot alligator thus killed with a little .22 calibre "cat" rifle. An eight-foot alligator will often be all that two men can manage to drag out of his cave in this way; and, in the torrid heat of the Southern swamp, this violent exercise is not to the liking of the usually not very energetic hunter.

While the manufacture of leather gives the chief 
value to the alligator there are other ways in which it has some economic importance. Chicf of these is probably the sale of alligator goods to tourists. In I89I there were in Jacksonville, Florida, twelve dealers in live and stuffed alligators. In I890, S400 alligators were sold to tourists, the price for the live animals varying from $\$$ I 0.00 to $\$ 35$ per hundred. For individual animals of the smallest size (less than twelve inches long) the price is usually from 50 cents to $\$ \mathrm{I} .00$. For a three-foot alligator the price is generally $\$ 3-\$ 5.00$; for sizes over three feet $\$ 2.00$ per foot may be charged, though for zery large specimens the price may be from $\$ 50$ to $\$ 300$ each.

Besides the live and stuffed animals the tecth are polished and sold as souvenirs; about $45^{\circ}$ pounds of tecth were sold in $\mathrm{I} 890$, at a price varying from $\$ 1.00$ to $\$ 2.00$ per pound. From 75 to 200 teeth will make a pound.

In IS9I about forty people, in addition to the regular dealers, were engaged, in the United States, in stuffing alligators, polishing teeth, etc. The teeth are extracted by burying the head until decomposition sets in.

The tiny alligators that are most commonly sold to tourists, to be brought North, perhaps, and allowed to freeze or starve to death, may either be caught by a wire noose at the end of a fishing rod, or they may be hatched from eggs that are taken from the nests shortly before they are 



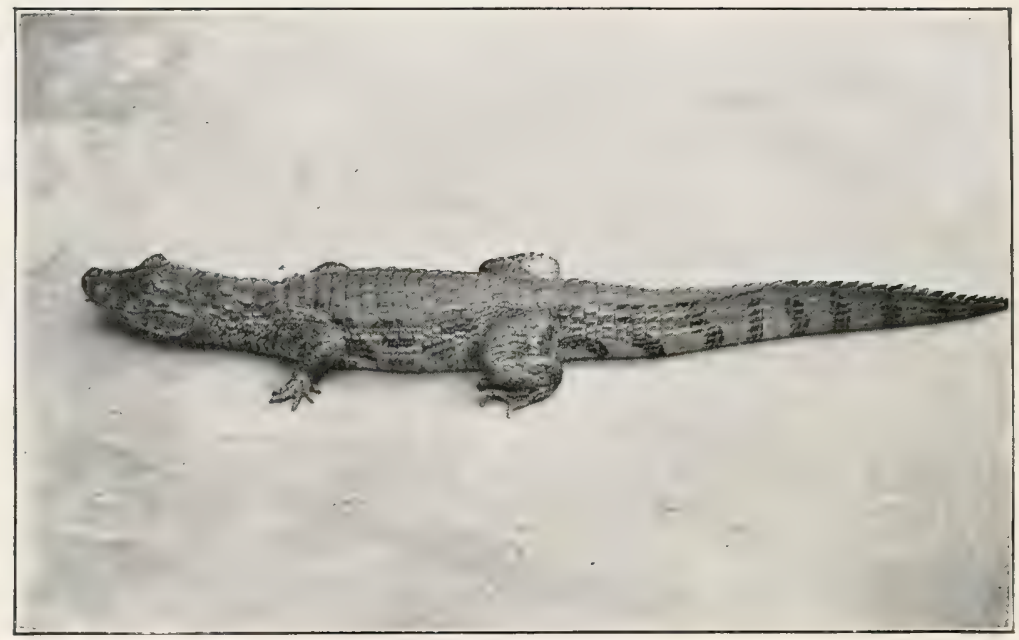

Broad-Nosed Camman. (Caiman latirostris.)

Distribution: Tropical South America.

Attains a length of about seven feet. (After Ditmars.)

(Reproduced by Permission of Sturgis \& Walton Co.)

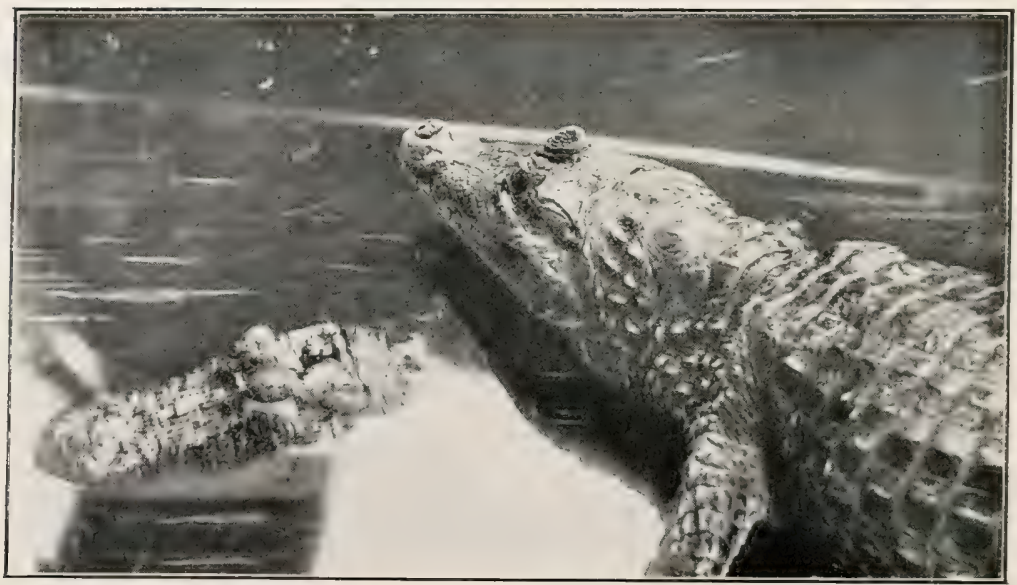

Fig. 10. Spectacled Caiman. (Caiman sclerops.) Tropical America. The length of an adult is about eight feet. (After Ditmars.) (Reproduced by Permission of Sturgis \& Walton Co.) 


\section{The Biology of the Crocodilia}

ready to hatch. Such eggs may readily be hatched by simply keeping them moist and at a fairly constant temperature, as has been previously noted. Besides the above uses Ditmars says: "The eggs are eaten in many portions of the South, and the search for eggs at the proper season furnishes profitable employment for many persons, as each nest contains a large number of eggs."

Never having eaten an alligator egg I cannot speak from personal experience of its flavor; but it has always seemed strange to me that more use is not made of the flesh of the alligator. This flesh is often said to have too strong a flavor to be palatable; I have eaten it when it had no such rank taste but was decidedly agreeable, being, as might perhaps be expected of so amphibious an animal, somewhat like both fish and flesh, yet not exactly like either. Perhaps greater care should be taken in skinning an animal that is to be used for food in order that the flesh be not tainted with the musk. It may be a lack of carc in preparation that has given rise to the impression that alligator meat is too strong to be pleasant. It is perhaps, also, the "idca" of eating a reptile that makes the meat unpopular. A half-grown boy, who was once in the swamps with me, had expressed a great aversion to alligator meat, so the guide, one day, offered him a nicely fricd piece of alligator meat, saying it was fish; the meat was eaten with evident relish and the diner was not told until after a 
second piece had disappeared what he had been eating. It always seemed strange to me that the poor people of the South should not more often vary the monotony of fat pork and corn bread with alligator steaks. Whether the meat could be smoked or salted so that it would keep in a hot climate I do not know; I am not aware of any experiments along this line.

\section{The Chinese Alligator}

Beside the American form, Alligator mississippiensis, the only other species of alligator is found in China, along the Yang-tse-Kiang River; it is Alligator sinensis. It reaches a length of six feet and externally resembles its American relative; it is greenish black above speckled with yellow; grayish below.

\section{The Caiman}

This is the nearest relative of the alligator and is found in Central America and tropical South America. As seen by the table on page 2, it is usually a small animal, though one species, the black caiman, is said to reach a length of twenty feet (Fig. I0). The nasal bones do not form a bony septum as in the alligator and the ventral armor consists of overlapping bony scutes. The canine teeth of the lower jaw fit into a pit in the upper jaw, as in the alligator. 


\section{The Biology of the Crocodilia}

They are said by some writers to be extremely abundant in the waters of the upper Amazon, migrating to the flooded forests during the rainy season and returning to the streams on the approach of the dry season. According to Ditmars there are five species of caiman of which the spectacled caiman, $C$. sclerops, and the black caiman, $C$. niger, are the most striking. The former is so named because of the spectacled appearance due to the swollen and wrinkled upper eyelids; it reaches a length of eight feet and is said to be of a treacherous disposition. The latter has a blunt snout like the alligator and is the largest of the New World crocodilians.

\section{The American Crocodile}

Of about a dozen existing species of crocodile, but one, the American crocodile, C. americamus, is found in the United States, and it is limited to the swamps and coast of southern Florida below Lake Worth; its greater sensitiveness to cold is doubtless the cause of its not being found so far north as the alligator. Its range extends south through Mexico and Central America into South America. It was first found in Florida by Dr. Hornaday in 1875 . It sometimes reaches a length of fourteen feet.

As has already been noted there is, besides certain structural differences, a marked difference in 
the dispositions of the Florida alligator and crocodile. While an alligator may snap its jaws, hiss, and swing its tail from side to side, it is not difficult for a couple of men with ropes and a pole to safely tie up a large specimen. The struggles of a crocodile are of a more serious nature. Ditmars thus describes an encounter with a captive Florida crocodile: "The writer well remembers his first acquaintance with a big fellow from Florida. Driven out of the crate the crocodile looked the picture of good nature. Standing away from what he thought to be the reach of his tail, the writer prodded the apparently sluggish brute with a stick to start it for the tank. Several things happened in quick order. With a crescentic twist of the body utterly beyond the power of an alligator, the brute dashed its tail at the writer, landing him such a powerful blow that he was lifted completely from the ground. As he left terra firma, an almost involuntary inclination caused him to hurl his body away from a pair of widely-gaping, toothstudded jaws swinging perilously near. Landing with a thud on one shoulder, though otherwise unhurt, the writer threw himself over and over, rolling from the dangerous brute that was actually pursuing him on the run, body raised high from the ground. For an instant it seemed as if the crocodile would win. As the writer sprang to his feet and glanced backward, he beheld the brute throw itself flat on its belly, open the jaws widely, 



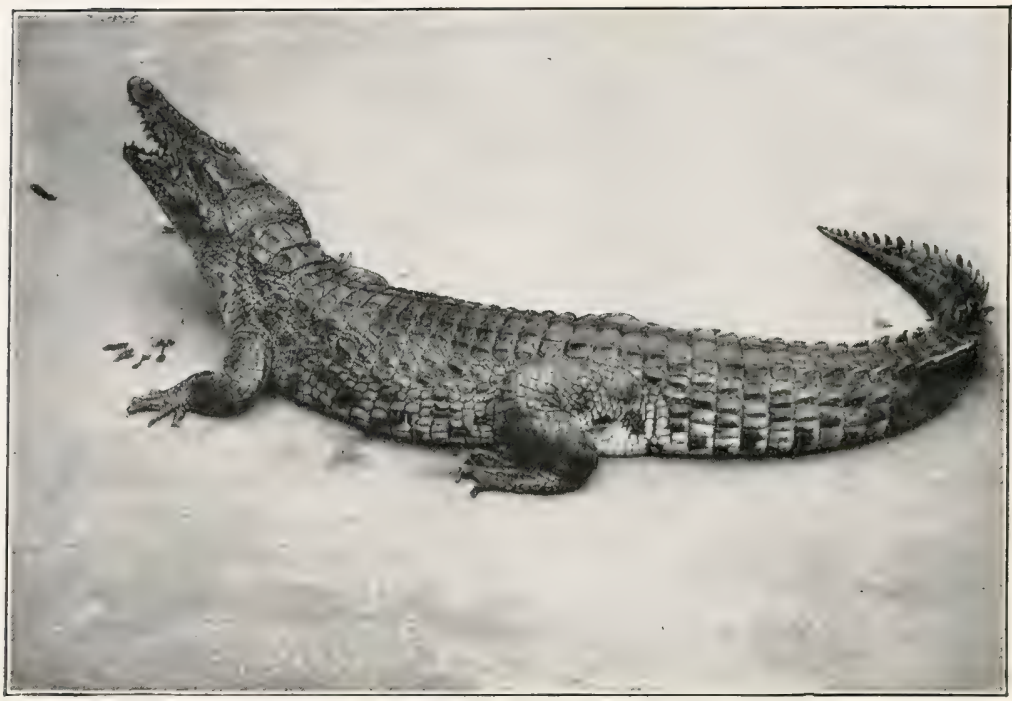

Nile Crocodile. (Crocodilus niloticus.)

Distribution: Africa generally; Madagascar.

Grows to a length of sixteen feet. (After Ditmars.)

(Reproduced by Permission of Sturgis \& Walton Co.)

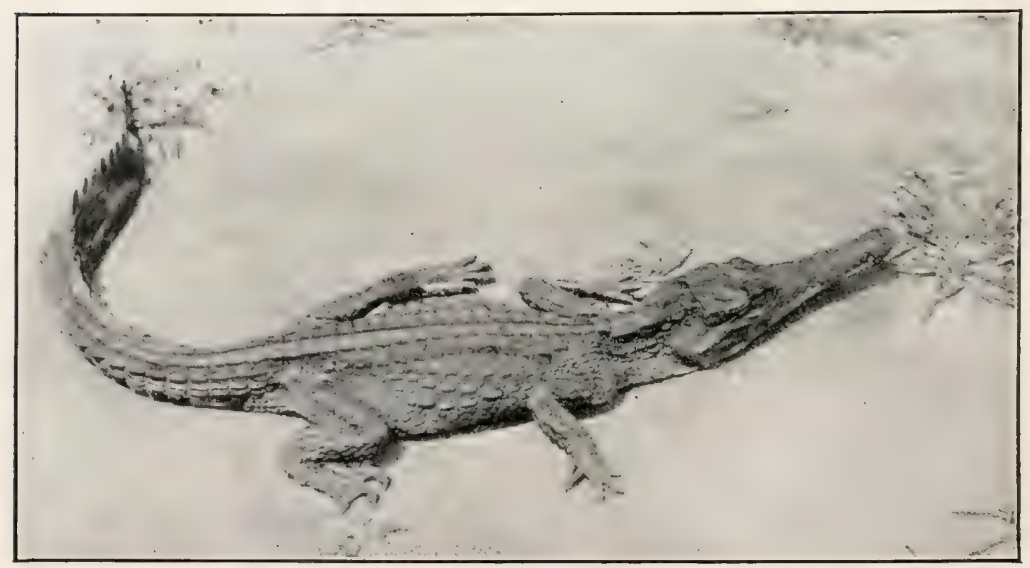

Fig. it. West African Crocodile. (Crocodilus cataphractus.)

Distribution: West Africa.

Does not attain so large a size as the Nile Crocodile. (After Ditmars.) (Reproduced by Permission of Sturgis \& Walton Co.) 
then remain motionless as a statuc. Such is the average crocodile - an active, vicious and, above all, treacherous brute." Ditmars says again, in the same book: "When the keepers of the reptile house of the New York Zoölogical Park clean out the big pool of the crocodilians, they actually walk over the backs of some of the big 'gators, so tame are these. They never become unduly familiar with the crocodiles, finding it necessary to pen the latter behind heavily barred gates--and in the process the men are often chased from the enclosure."

In contrast to this ferocious aggressiveness in captivity the American crocodile is said to be very timid and retiring when in its native habitat.

Young animals are greenish with black marking; as they become older they are of an olive color, and old specimens are dull gray.

\section{The Orinoco Crocodile, $C$. intermedius}

This is a species with a very narrow snout that is not quite so large as the preceding. It is said to be abundant in the Orinoco River and its tributaries.

Besides the two above mentioned there is a small species, C. rhombifera, found only in Cuba and hence known as the Cuban crocodile.

\section{The African or Nile Crocodile, $C$. niloticus}

This well known and much feared spccies is found throughout the continent of Africa, and is 
very common on the island of Madagascar (Fig. I I). In the lower waters of the Nile it is now nearly exterminated. It has always been a conspicuous animal in Egypt and was one of the animals held sacred by the Egyptians and preserved by them as mummies. It is discussed by Herodotus, and the "leviathan" mentioned in the Book of Job is doubtless this crocodile. In fact the name is said to be derived from the ancient Greek for lizard, just as the word alligator is said to be derived from the Spanish for lizard-el lagarto; the resemblance in form between these big saurians and their smaller relatives is evident. The alligator, being confined to America and a small part of Asia, was probably not known to the ancients.

An excellent account of the development and habits of the present species is given by Voeltzkow (78), who says it is, perhaps, the most common vertebrate in Madagascar. The largest specimen measured by this observer was thirteen feet; Ditmars gives sixteen feet as the maximum size. This man-eating crocodile, according to Ditmars, destroys more human lives than any other wild animal of the dark continent.

The story told by Herodotus of the bird, probably a species of plover, which enters the gaping mouth of the crocodile to pick off the leeches found there may be true, since there is such a bird that may be seen perching on the backs of crocodiles, and as the Crocodilia frequently lie with their 



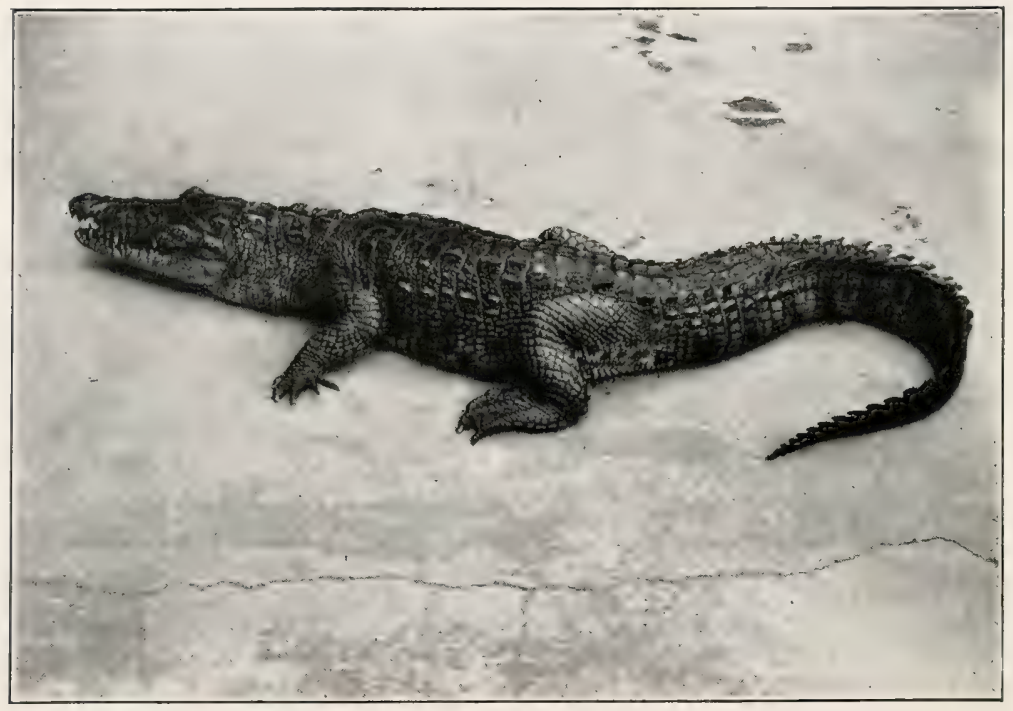

Fig. I2. Salt-Water Crocodile. (Crocodilus porosus.) Distribution: India to North Australia. Occurs at sea. Grows to a length of twenty feet. (After Ditmars.) (Reproduced by Permission of Sturgis \& Walton Co.) 


\section{The Biology of the Crocodilia}

mouths wide open it is quite possible that these birds may pick off the worms that are often found within. It is also possible that the alcrtness of these birds to danger may serve as a warning to the crocodiles with which they associate.

According to Voeltzkow these crocodiles dig caves of thirty-nine to forty feet length in the banks of the streams they inhabit, into which they retire on the approach of danger. The caves open under water and slope upward towards the surface of the ground where a few small air-holes are found. The natives locate the caves by means of the air-holes and dig out the hidden animal, first stopping up the entrance.

In Madagascar the eggs are laid in August and September and hatch in about twelve weeks; they are laid at night, usually shortly before daybreak. From twenty to thirty eggs are laid in one nest, which is merely a hole dug in the dry sand. As was said in connection with the Florida alligator, the habits of the two animals are quite different in this respect,- - the moisture that is so important in the one case is fatal to the embryo in the other. When the eggs are laid the nest is filled in with sand so that there is nothing to indicate its position except that the female crocodile is in the habit of lying on the spot where her eggs lie buried.

Like the alligator the young crocodile makes a squeaking noise shortly before hatching and the 
mother doubtless opens the nest, at this time, to allow the young to escape. A fence that Voeltzkow built around a nest was repeatedly broken down by the mother in attempting to get back to her eggs.

The character of the crocodile's egg is discussed, in comparison with that of the Florida alligator, on page 23 .

The Marsh Crocodile or Mugger, C. palustris

Found in India, Ceylon, Burmah, the Malay Peninsula, and many of the islands in that region. It has a rather broad snout, and reaches a length of twelve feet. It is a timid form and is harmless to man. It is frequently venerated by the Hindoos and is kept in a semi-domesticated condition in ponds where it is fed and becomes very tame.

In the dry season when the natural ponds are empty they sometimes migrate overland in search of water, but generally they bury themselves in the mud and lie dormant until the rains begin again.

\section{The Salt-Water Crocodile, $C$. porosus}

This is one of the largest if not the largest of living reptiles (Fig. I2). It is said by Ditmars to reach a length of twenty feet and there is a record of one specimen that was thirty-three feet in 



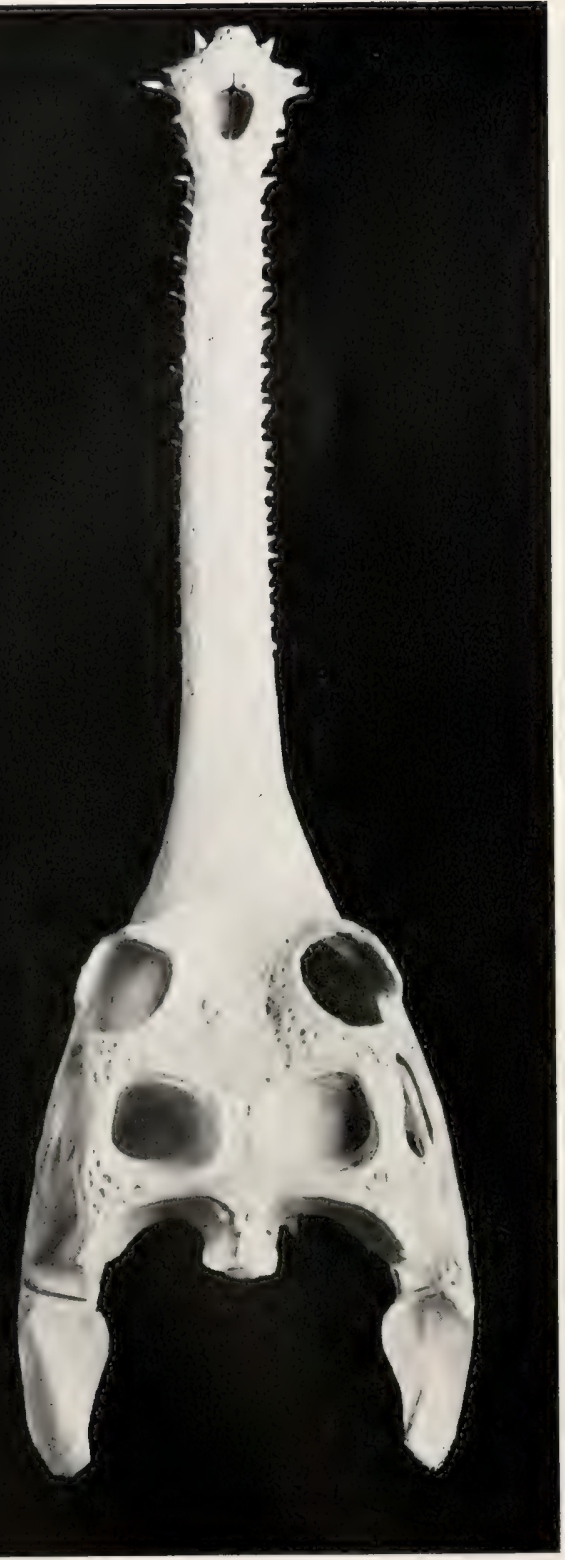

Fig. I3. Skull of Gavial. (Dorsal View.)

(Photograph from U. S. National Museum.)

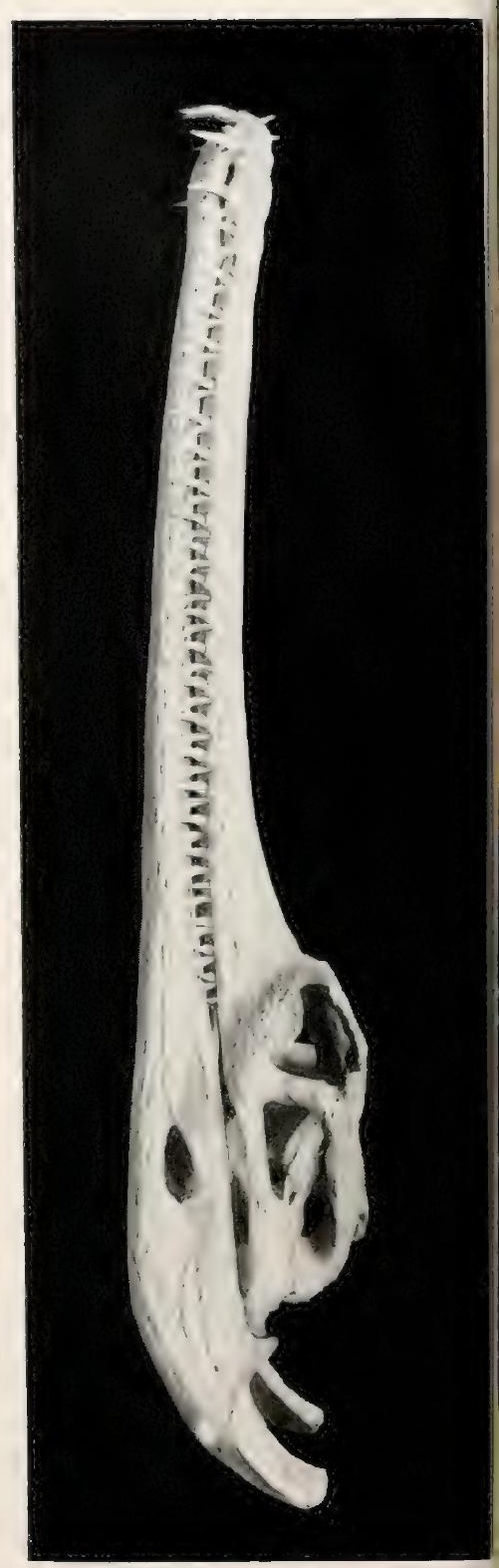

Fig. 14. SkULL OF Gavial.

(Lateral View.) ,

(Photograph from U. S. National Muscum.) 
length. It is said to be easily recognized by the prominent, longitudinal ridge that extends in front of each eye, over the prefrontal bone, and by the absence of the suboccipital scutes.

It is typically an inhabitant of tidal waters and is sometimes found swimming at sea, out of sight of land; it seldom goes inland to any great distance from the sea. It is a man-eating species and many human lives are said to be destroyed by it in India and surrounding countries. A British "blue book" states that in British India 244 deaths were caused by Crocodilia in the year I9Io.

In captivity it is savage and untamable. Ditmars, in speaking of three specimens that he had in captivity, says they were "positively the most vicious reptiles" he had ever seen.

\section{The Indian Gavial, Gavialis gangeticus}

This animal, which inhabits the Ganges and other rivers of northern India, is, with the possible exception of the preceding species, the largest of the Crocodilia; it is said to reach a length of thirty feet, which is twice that of a very large Florida alligator. As previously noted its snout is $\mathrm{ex}$ tremely long and narrow (Figs. I 3 and I4), with a large, fleshy hump at the tip, that projects above the muddy water in which the animal lies concealed.

It is a timid animal and, in spite of its huge size, dashes quickly into the water on the approach of 


\section{The Alligator and Its Allies}

man, to whom it is seldom or never dangerous. Its Indian name, gharial, from which its generic name has been corrupted, means fish-eater, since its food consists, it is said, largely if not entirely of fish.

Considering its huge size and the character of its jaws and teeth as shown in Figures I 3 and I4, it is fortunate that it prefers fish to human flesh.

Anderson (2) describes the eggs and young of the Indian gavial. He found forty eggs in a nest of sand; they were in two layers, with a foot of sand between them. The young were I5.8 inches long at hatching. He says: "The young run with amazing rapidity the moment they are out of the shell. . . . Some of them actually bit my fingers before I had time to remove the shell from their bodies." The following quotation from Oldenburg (46), for which I am indebted to Dr. Hussakof, is perhaps the earliest reference to the egg of the American alligator. It also mentions the habit that is practiced by some of the recent Crocodilia of swallowing stones to aid in digestion, as was apparently done by some of the large extinct reptiles.

"The eggs of Crocodiles and Alligators are little bigger than a Turkey's. I thought to bring one to England, but it was lost. I never broke any to see the Yolk and White; but the Shell is as firme and like in shape to a Turkey's, but not spotted. I inquired into the Stone in the Stomach of a 
The Biology of the Crocodilia

Cayman or Crocodile, and I found by the inquiry of a very observing gentleman there, that they were nothing but several Stones, which that Creature swallows for digestion. He took out of one a piece of a Rock as big as his head: out of others he had taken sixteen or twenty lesser. None regards them much there, whatever Monardes relateth." 


\section{CHAPTER II}

\section{THE SKELETON}

\section{A. The Exoskeleton}

THE exoskeleton is well devcloped in the Crocodilia, and forms a very considerable protection to its bearer. It is both dermal and epidermal in origin.

The cpidermal skeleton of the alligator consists of oblong horny scales, arranged in transverse rows; the long axes of the scales are parallel to that of the body. On the tail, except along the mid-dorsal line, and on the ventral side of the trunk and head these scales are very regular in outline and arrangement; on the sides of the head and trunk and on the legs they are much smaller and less regularly arranged, while along the mid-dorsal line of the tail, especially in its posterior half, they are elevated into tall keels that give the tail a large surface for swimming. The first three digits of both manus and pes are armed with horny claws, which also belong to the epidermal part of the exoskeleton. 


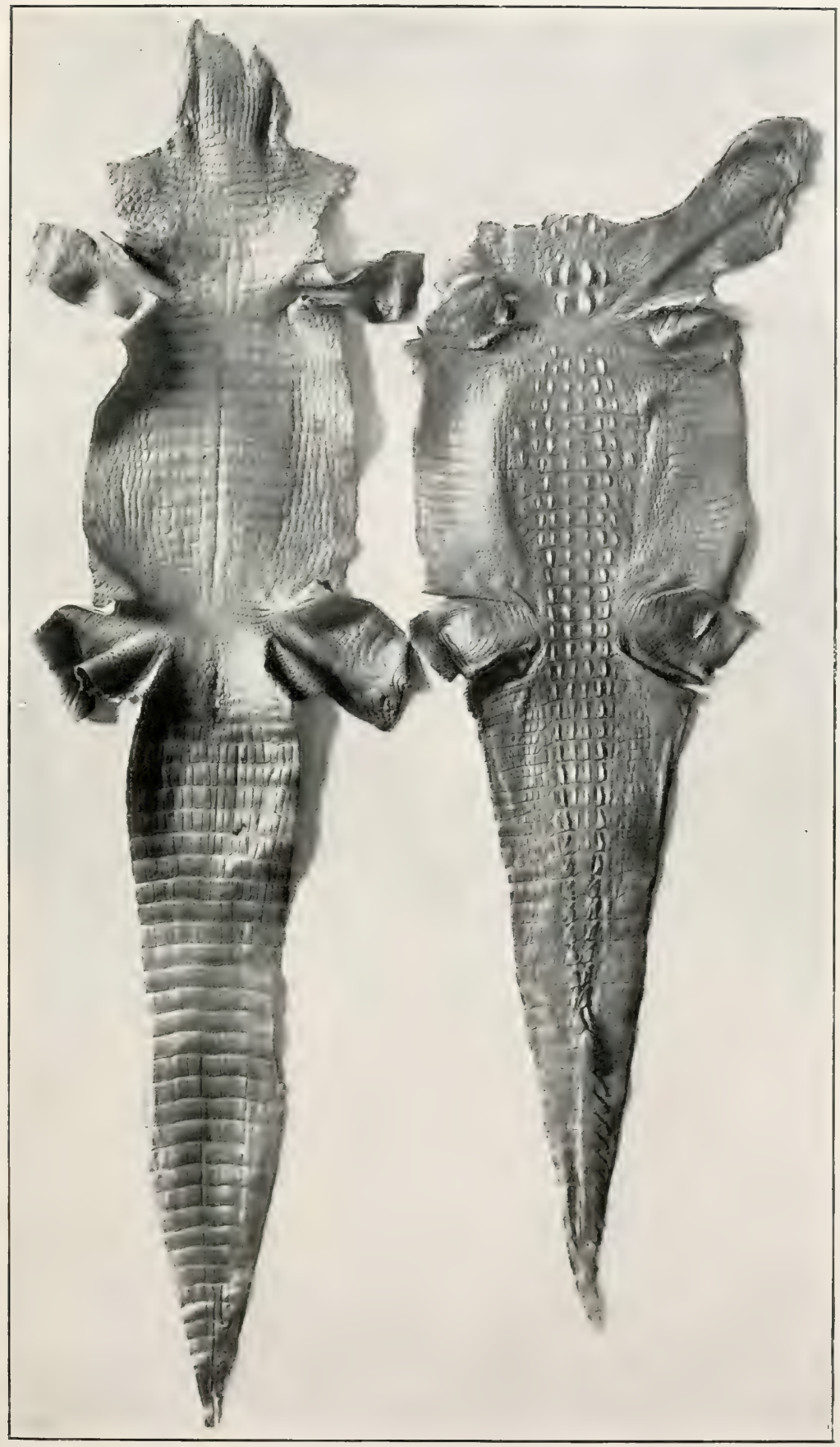

Fig. I5. Alligator Skins; Under-Surface and HorN-Back. (From Report of Commissioner of Fish and Fisheries, I902.) 

The demal exoskeleton consists of bony scutes that underlie the epidermal scales of the dorsal surface of the trunk and anterior part of the tail. The overlying scales, except in very young animals, are always rubbed off, so that the bony scales are exposed. The ventral or inner surface of the scutes is flat, while the outer surface is strongly keeled and in old animals is often rough and pitted. The plates are nearly square in outline and are closely joined together in most places.

The scutes are grouped in two fairly distinct areas known as the nuchal and the dorsal shields. The former lies just back of the head, in the region of the fore legs, and consists of four larger and a number of smaller plates (Fig. I5). The latter, or dorsal shield, extends over the back in fairly regular longitudinal rows and quite regular transverse rows. At the widest part of the trunk there are six or eight of these scutes in one transverse row. They become smaller towards the tail.

The teeth are exoskeletal structures, partly of ectodermal, partly of dermal origin. They are conical in shape, without roots, and are replaced when lost. They will be described in connection with the skull.

Musk glands, said by Gadow to be present in all Crocodilia, are found in both sexes and are derivations of the skin. One pair, each of which may be as large as a walnut, is found on the lower side of the head, one on the inside of each half of the 
mandible. The other pair is inside of the lips of the cloaca.

The IIistology of the Integument. To understand the structure of the integument of the Crocodilia it is well to begin with the embryo. A cross section of the epidermis of such an embryo will show the rete Malpighii as a single layer of short, cylindrical cells; over these are found more or less flattened, disk-shaped cells formed by transverse division of the underlying cells of the rete. On the outside lies the epitrichial layer which consists of a mosaic of polygonal cells, near the middle of each of which lies an oval nucleus. Between the epitrichial cells are small oval holes, not unlike the stomata in the epidermis of plant tissues. Bronn thinks these are not artifacts, but he does not suggest any explanation of their occurrence.

In the epidermis of young and half-grown animals the rete Malpighii is seen still as above noted. On these cylindrical cells are found flattened cells that gradually become very flat and lose their nuclei as they pass over into the horny layer.

The stratum corneum consists of strongly flattened cells in which the nuclei can no longer be clearly seen, though their location can usually be determined by the groups of pigment granules. On the cells of the more superficial layers of the stratum corneum are seen straight, dark lines, perhaps ridges caused by pressure of the over- or underlying polygonal cells. The individual cells of the horny 
layer are usually casily isolated in the belly and neck regions where they never become very thick; but in the back the cells in this layer are very numerous and fuse with each other to form the bony plates; here the rete is the only clearly differentiated layer. Whether prickle cells are present in the epidermis of the crocodile Bronn is not certain, though he thinks they probably are.

Rathke pointed out that on the surface of certain folds of the integument, especially in the region of the jaws, are found in all Crocodilia certain small, scattered, wart-like elevations, around each of which is customarily a narrow, shallow, circular groove; they usually have a dark brown but sometimes a gray or even white color. Microscopic examination shows these warts to be of epidermal origin, consisting of bright, round cells that are closely united, without visible intercellular substance. Treatment with potassium hydroxid and then with water will show sometimes, though not always, fine granular nuclei in the cells.

In probably all members of the genus Crocodilus at least is found, on the thick swelling on the right and on the left side of the neck and trunk, a small, flat pit which has the appearance of the opening of an integumental gland. The pits are present also in the scales of the throat, under the side of the neck, sides of the body, lateral and ventral surfaces of the anterior half of the tail, and the legs. They 
are near the hinder border of the scales. Only occasionally are two pits found in one scale. These pits are found in the gavials but are absent in some, probably all, alligators. A small knob projects from the center of some of the pits. These pits are not openings of glands but have about the same structure as the pits seen in the head.

The integumental bones in the Crocodilia originate in the connective tissue of the cutis. Investigations in young animals show that these bones usually take their origin in the under and middle layers of the cutis and generally work towards the periphery.

\section{B. The Endoskeleton}

I. The Vertebral Column. The vertebral column consists of about sixty-
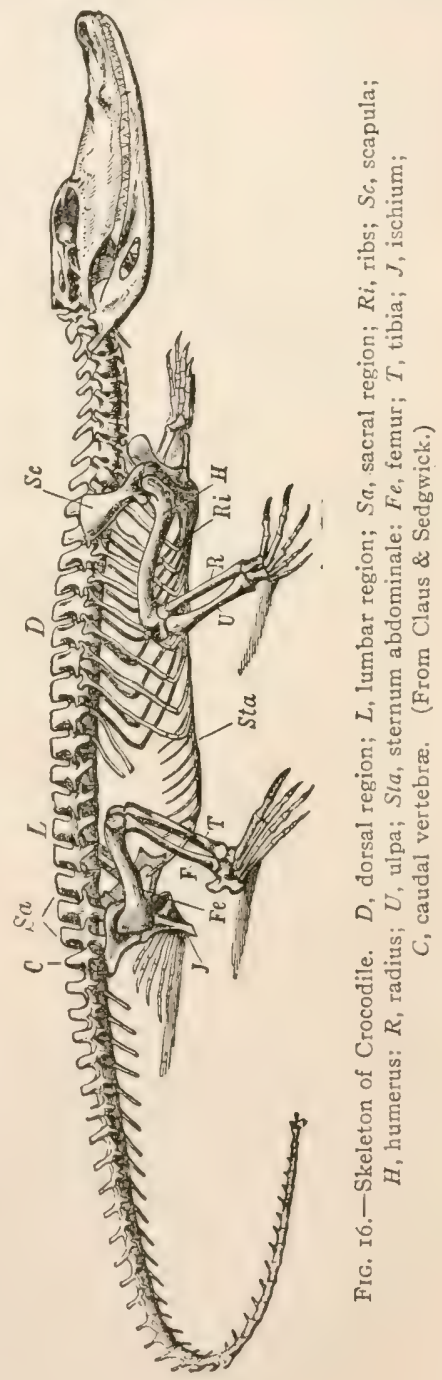
five vertebræ, which may be scparated into the usual regions; there are nine cervical, ten dorsal, five lumbar, two sacral, and about thirty-nine caudal. It is likely that the number of caudals may be subject to frequent variation; one complete slicleton had sixty-five vertebre in all, another had sixtyeight. A complete skeleton of the crocodile (specics not known) had sixty vertebræ. A thirteen-foot skeleton at Western Reserve University had only sixty-one vertebræ, but some of the caudals were evidently missing. Two skeletons of $C$. porosus in the museum at Singapore had sixty and sixty-three vertebræ respectively. A skeleton of Tomistoma schlegali in the same museum had sixty vertebrx.

The Cervical Vertebre. Since all of the cervical vertebræ bear ribs, we shall assume the distinction between them and the dorsal vertebræ to be that the ribs of the latter meet the sternum, while those of the former do not reach to the sternum. Assuming this distinction, there are, as was said above, nine cervical vertebræ.

With the exception of the first two, to be discussed later, these are all essentially alike and the fourth will be described as a type (Fig. I7). Its centrum is cylindrical or somewhat hourglass shaped, concave anteriorly and convex posteriorly; it is not completely fused with the neural arch but is united with it by sutures. From the anterior end of the ventral surface of the centrum projects downward and forward a small plow-shaped process, 
the hypapophysis. On each side of the centrum, near its anterior end, is a facet with which the lower branch (capitulum) of the rib articulates. The neural arch is strongly developed and is extended dorsally into a prominent neural spine and on each

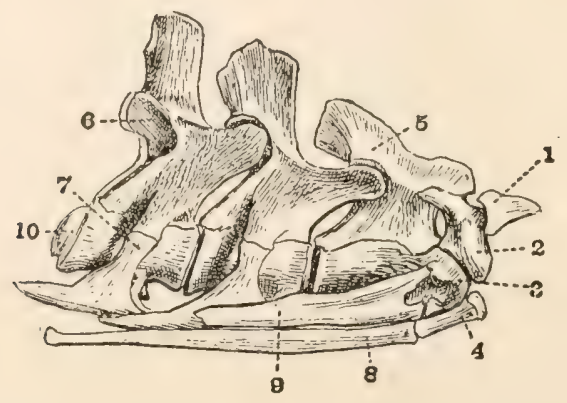

Fig. I7. First Four Cervical Vertebre of a Crocodile (C. vulgaris). (From Reynolds, partly after Von Zittel.)

1. pro-atlas.

2. Iateral portion of atlas.

3. odontoid process.

4. ventral portion of atlas.

5. neural spine of axis.

6. postzygapophysis of fourth vertebra.
7. tubercular portion of fourth cervical rib.

8. first cervical rib.

9. second cervical rib.

10. convex posterior surface of centrum of fourth vertebra.

side as a short, blunt, transverse process with which the tubercle or upper branch of the rib articulates. Posteriorly the arch is notched on each side to form the openings for the exit of the spinal nerves. Projecting dorsally and anteriorly from the arch are two short processes which bear the medially and dorsally facing prezygapophyses (Fig. I7). Just caudad to these processes are somewhat shorter 
processes that bear the laterally and ventrally facing postzygapophyses (Fig. I7, 6).

The atlus, as in other vertebrates, is highly specialized. It consists (Fig. I 7), even in the adult animal, six feet or more in length, of four distinct portions, a ventral (4), a dorsal (I), and two lateral (2) parts. The ventral portion is relatively more massive than in most animals; its anterior surface is concave and forms the main part of the articular surface for the occipital condyle of the skull. Its postero-dorsal surface articulates with the odontoid process of the axis. On its postero-lateral surfaces are the facets for articulation with the first ribs, which, unlike the other cervical ribs, have but one articular surface. Articulating dorsally with this ventral element of the atlas are the two rather heavy lateral elements which form the neural arch. Anteriorly they form the lateral parts of the articular surface for the condyle and dorsally they unite for a short distance with each other. Projecting ventrally from the posterior part of their dorsal portion are the small postzygapophyses. Ventrally and laterally they articulate with the odontoid process (Fig. I 7,3 ). Projecting dorsad and cephalad from the dorsal surface of these lateral elements is the dorsal element of the atlas (Fig. I7, I), the pro-atlas, which may not be properly a part of the vertebral column at all, since it is said to be merely a membrane bone. Gadow says it is the detached neural spine of the atlas. It is 
thin and triangular in shape, resembling in contour a large, mammalian epiglottis. It forms an arch over the space between the skull and the front of the atlas proper. Reynolds calls it the proatlas.

The Axis. The centrum differs from those following it (described above) mainly in its close articulation (not fusion) with the large odontoid process; this process not only projects into the atlas, as is usually the case, but articulates with its postero-lateral border on each side, and is distinctly visible in a lateral view of the neck (Fig. I7, $3)$. Like the rest of the cervical vertebræ the posterior surface of the centrum is convex. The neural arch of the atlas differs from those following mainly in having a much wider (in an antero-posterior direction) neural spine. The lateral processes and those bearing the prezygapophyses are also less strongly developed than on the following vertebræ.

The Thoracic Vertebrce. The first thoracic vertebra differs scarcely at all from the ninth cervical; and the tenth thoracic differs from the first lumbar only in bearing a short rib. Only the first three thoracic centra bear the hypapophyses noted in connection with the cervical vertebræ. The ribs of the first two thoracic vertebre articulate with them by two processes, as in the typical cervical vertebræ; the other ribs articulate only with the transverse process. The fourth thoracic may be 
described as a type of this region (Fig. I $8, \mathrm{~A}$ ). Its centrum is rather longer than in the first two thoracic and in the cervical vertebra and has no process for articulation with the head of the rib, otherwise it is essentially the same. Like all of

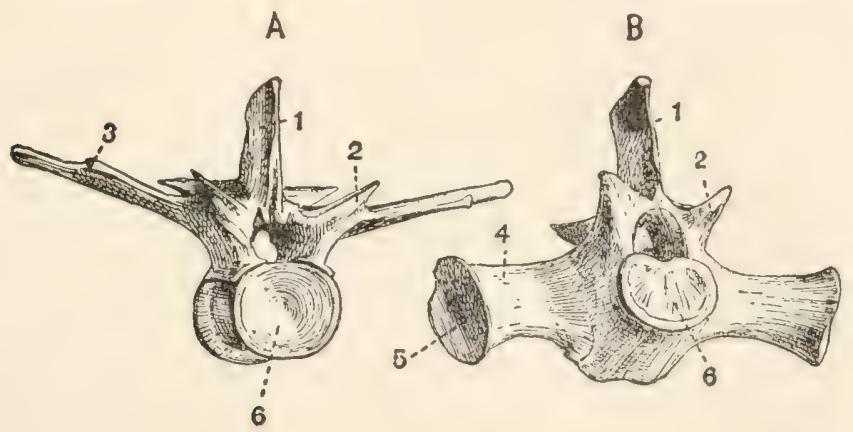

Fig. I8. ANTERior View of A, a Late Thoracic and B, the First Sacral Vertebra of a Young Crocodile (C. palustris). $\times \frac{1}{3}$. (After Reynolds.)

I. neural spine.

2. process bearing prezygapophysis.

3. facet for articulation with the capitulum of the rib.
4. sacral rib.

5. surface which is united with the ilium.

6. concave anterior face of centrum.

the vertebræ behind it and unlike those in front it is apparently completely fused with its neural arch. The neural arch is very broad (in an anteroposterior direction) and is extended dorsally as a wide neural spine (I). The neural spines of the following thoracic and the first two or three lumbar vertebræ are increasingly broad and truncated. The transverse processes are very broad, long and thin, and in the third to eighth vertebra they have 
$5^{6} \quad$ The Alligator and Its Allies

two articular surfaces, an anterior and more medial one for articulation with the head of the rib (3) and a posterior and more distal one for articulation with the tubercle of the rib. These two surfaces approach each other as the vertebræ are followed caudad until, in the last two thoracic vertebræ, they form practically one surface. The processes of the pre- and postzygapophyses spring from the arch at the base of the transverse process; the former surface is directed dorsally and medially, the latter ventrally and laterally. The intervertebral foramina are smaller and more nearly circular than in the cervical region, and are more closely surrounded by bone.

The Lumbar Vertebrce. The five lumbar vertebræ are essentially like the thoracic except that the transverse processes, which, of course, bear no ribs, are both shorter and narrower. The posterolateral border of the centrum of the last of these five vertebræ has a small surface for articulation with the antero-medial border of the transverse process of the first sacral vertebra.

The Sacral Vertebre (Fig. I8, B). These are two in number. The centrum of the first is concave in front and flat behind, instead of being convex behind, and the second is flat (instead of concave) in front, and convex behind. The neural spine and zygapophyses are as in the lumbar region. Projecting laterally from each sacral vertebra, forming a close, sutural joint with both centrum 
and neural arch, is a heavy bone shaped like a truncated pyramid (t); the base of the pyramid is ankylosed with the iliux. These bones seem to be much thickened transverse processes, but since they are not completely fused with their respective vertebræ and are said to ossify separately they should probably be called sacral ribs. The two sacral vertebræ do not seem to be any more closely united than are any other two vertebræ.

The Caudal Vertcbre (Fig. I6, C). These are characterized by the entire absence of ribs, and by the presence on all but the first and the last four or five of $\mathrm{V}$-shaped chevron bones. The first ten or twelve of these chevron bones articulate chiefly with the postero-ventral ends of the centra, but they also articulate with the antero-ventral ends of the vertebra behind themsclves; and as they are followed caudad they seem to lie directly below the intervertebral regions and to articulate equally with the vertebræ before and behind. The chevron bones gradually diminish in size from before back. The neural processes of the first four or five caudals are broad, like those of the more anterior regions, but caudad to this point they become narrower and more pointed, though they retain the same height until about the last ten or twelve vertebræ. Towards the tip of the tail the dorsal spines diminish in height and finally disappear. The transverse processes of the first five 
or six of the caudals are long and narrow. They gradually diminish in length until the eighteenth caudal, back of which they are no longer to be seen. The zygapophyses are mostly about the same as in the more anterior vertebræ, but towards the posterior end of the tail the postzygapophyses come to lie between rather than above the prezygapophyses. The noural canal diminishes, of course, in size towards the tip of the tail until it is no longer present, the last five or six vertebræ consisting only of the centra.

\section{The Skull.}

The sku1l of the alligator is very massive and has scveral peculiarities. I. The bones of the dorsal surface are rough and pitted, especially in old animals. 2. The jaws are enormously large in proportion to the brain cavity, and are armed with many large teeth. 3. The mandibular articulation is some distance caudad to the occipital condyle. 4. The interorbital septum is mainly cartilaginous. 5. There is a complicated system of Eustachian passages connecting with the back of the mouth by a single opening. 6. The posterior nares are placed very far back and the palate is correspondingly long.

The skull as a whole may be divided into three regions: the cranium, the lower jaw, and the hyoid; these will be described in the order given.

The Cranium. As a matter of convenience the 
bones will be described as seen from the different aspects-dorsal, ventral, lateral, posterior, and in sagittal section-without particular regard to their grouping into segments or regions.

The Dorsal Aspect (Fig. 19). At the extreme posterior end of the median line lies the parietal (23), double in the embryo but a single bone in the adult. It forms a part of the roof of the cranial cavity and articulates anteriorly with the frontal, laterally with the postfrontals, squamosals, and, according to Reynolds, with alisphenoids, pro-otics and epiotics, and ventrally with the supraoccipital. It forms the median boundary of each of the two supratemporal fossa (sf).

On each side of the parietal and forming the posterior corners of the rectangular postero-dorsal region of the skull are the squamosals ( 7$)$. Each squamosal articulates medially with the parietal, anteriorly with the postfrontal, and ventrally with the quadrate and exoccipital. It forms part of the posterior and lateral boundaries of the supratemporal fossa and a part of the roof of the external auditory meatus.

Articulating with the anterior border of the squamosals and forming the anterior corners of the rectangular region mentioned above are the postfrontals (6). The postfrontal articulates medially with the parietal and frontal, and ventrally with the alisphenoid and a small part of the quadrate. It sends, in a ventro-lateral direc- 
tion, a thick process that unites with a similar process from the jugal to form the postorbital bar (pb) which lies between the orbit (o) and the temporal fossa (tf). The postfrontal forms the anterolateral boundary of the supratemporal fossa.

Articulating posteriorly and laterally with the parietal and the postfrontals, and forming the highest point of the skull, is the single frontal bone (24), which, like the parietal, is paired in the embryo. It is a heavy bone whose dorsal surface is flattened posteriorly, deeply concave in the middle region, and drawn out into a long projection anteriorly. It forms part of the roof of the cranial cavity and articulates ventro-laterally with the alisphenoid and anteriorly with the prefrontals and nasals. It forms a part of the median boundary of the orbit.

The prefrontal (4) is an elongated bone in the latero-median border of the orbit. Medially and anteriorly it articulates with the frontal and nasal, laterally with the maxillary and lachrymal, and ventrally, by a heavy process, with the pterygoid.

The nasal (25) is a long narrow bone forming the greater part of the roof of the nasal passage. Along the median line of the skull it articulates with its fellow; posteriorly with the frontal; laterally with the prefrontal and maxillary; and anteriorly with the premaxilla. In the crocodile, caiman, and gavial it also articulates with the lachrymal. In the alligator the anterior ends of the 


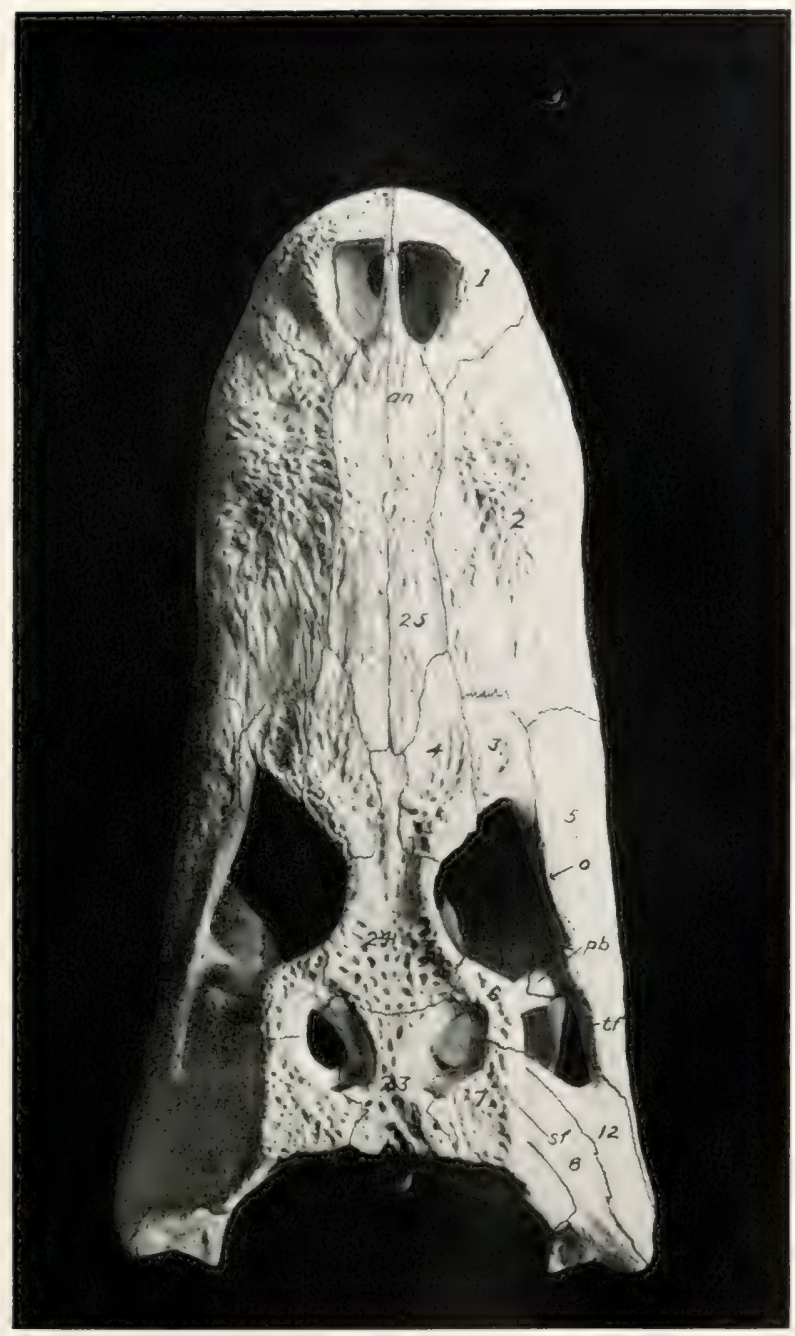

Fig. 19. Dorsal View of the Skull of the Alligator (A. Mississippiensis).

I. premaxilla.

2. maxilla.

3. lachrymal.

4. prefrontal.

5. jugal.

6. postfrontal.

7. squamosal.

8. quadrate.
I2. quadratojugal.

23. parietal.

24. frontal.

25. nasal. an, anterior nares; $o$, orbit; $p b$, postorbital bar; $s f$, supratemporal fossa; $t f$, lateral tem. poral fossa. 

two nasals form a narrow rod of bone that extends across the anterior nares, and, meeting a projection from the premaxillaries, divides the opening into right and left halves. In the crocodile the nasals project only a very little way into the nares; in the caiman (according to Reynolds) they do not extend into the nares at all, and in the gavial, whose much elongated snout is mainly due to the great length of the maxillaries, the nasals do not extend more than a third of the distance from the prefrontals to the anterior nares.

The maxilla (2) is a large bone that forms a large part of the upper jaw and that holds most of the teeth of that jaw. On the ventral side, as will be described later, it articulates with its fellow in the middle line, with the premaxilla, with the palatine, and with the transpalatine. Dorsally it articulates with the premaxilla in front; with the nasal and prefrontal on the medial side; and with the lachrymal and jugal behind.

The premaxilla (I) forms, with its fellow, the extreme tip of the upper jaw. Each bone forms the anterior and lateral borders of its half of the anterior nares. It articulates medially with its fellow and posteriorly with the nasal and maxilla. Ventrally, as will be noted later, it bears five teeth and articulates with its fellow medially and with the maxilla posteriorly. Between the premaxillæ on the ventral side is the large anterior palatine foramen. 
The lachrymal (3) is a fairly large bone that forms the anterior border of the orbit. It is bounded laterally by the jugal, anteriorly by the maxilla, and medially by the prefrontals. Its posteromedial border is pierced by a large lachrymal foramen that extends lengthwise through the bone and opens, at its anterior end, into the nasal chamber.

The supraorbital, missing in the skull figured, is a small bone lying in the eyelid close to the junction of the frontal and prefrontal. Being unattached it is usually absent from prepared skulls.

The jugal or malar (5) is an elongated bone that forms a part of the lateral border of the head, on the one hand, and most of the lateral border of the orbit on the other. Anteriorly it articulates with the maxilla; medially with the lachrymal and prefrontal; posteriorly with the quadratojugal, and ventrally with the transpalatine. With the transpalatine it sends, in a dorso-medial direction, a process that meets the process, described above in connection with the postfrontal, to form the postorbital bar.

The quadratojugal (I2) is a small bone, wedged in between the jugal in front and the quadrate behind.

The quadrate (8) is more irregular and has more complicated articulations than almost any bone in the skull. Its posterior end, which forms the articular surface for the lower jaw, is elongated laterally and slightly concave. Anteriorly the 



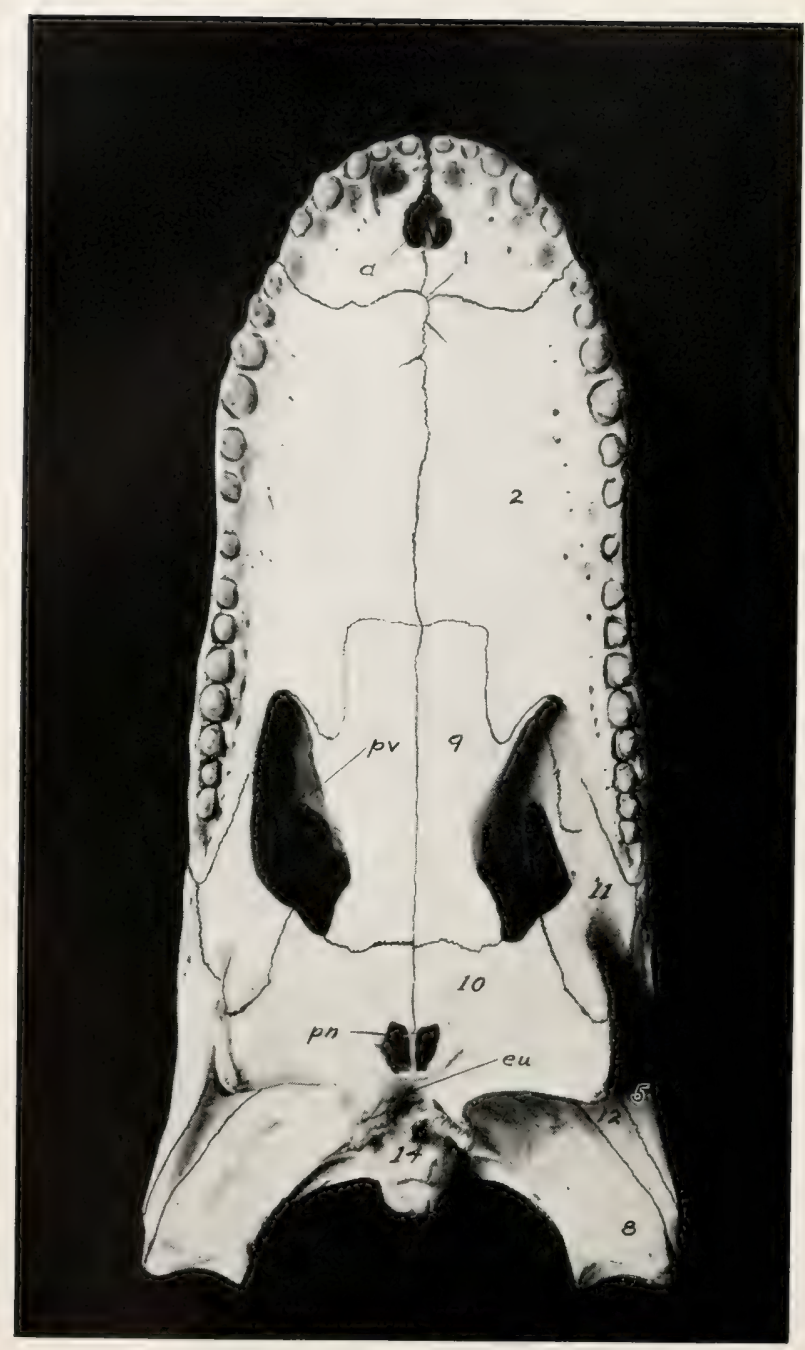

Fig, 20. Ventral View of the Skull of the Alligator (A. Mississippiensis).

2. maxilla.

5. jugal.

8. quadrate.

9. palatine.

I0. pterygoid.

II. transpalatine.

I2. quadratojugal.
14. basioccipital. $a$, anterior palatine vacuity; eu, opening of the median Eustachian canal: $p n$, posterior nares; $p v$, posterior palatine vacuity. 
quadrate articulates with the quadratojugal; medially with the basisphenoid and exoccipital; dorsally with the exoccipital, squamosal, postfrontal, and, possibly, with the pro-otic; ventrally with the pterygoid, alisphenoid, and probably with some of the otic bones. Its dorsal side forms most of the floor of the extcrnal auditory meatus which will be described later. While the basioccipital may be seen from the dorsal side, it is not really one of the dorsal bones of the skull and will be described later; the same is true of the pterygoids and palatines which may be seen through the empty orbits.

The Ventral Aspect (Fig. 20). The larger part of this side of the skull is made up of four pairs of bones: the premaxillæ, the maxillæ, the palatines, and the pterygoids, lying, from anterior to posterior, in the order named.

The premaxilla (I), as described in the dorsal view of the skull, is a triangular bone which, with its fellow, forms the anterior end of the snout. Each premaxilla bears five teeth, not only in the alligator but in the crocodile, the caiman, and in the gavial. Of these teeth the fourth from the front is the largest; the first two are small, and the third and fifth are of intermediate size. This arrangement as to size is also true, apparently, in the other groups of Crocodilia. The ventral surface of the premaxilla, which is more or less flat and horizontal, is pierced by a number of small foramina, in a row parallel to the curved outer margin 
of the bone. Between these foramina and the base of the teeth are four rounded depressions to receive the points of the first four teeth in the lower jaw; of these depressions the first and fourth are the deepest. The first pit often becomes so deep as to perforate the bone; this is true also with the crocodile and, according to Reynolds, with the caiman, but is not true of the gavial, whose interlocking teeth project outside of the jaws. It will be remembered that one of the chief distinctions, given early in this work, between the crocodile and the alligator is that in the former the fourth tooth in the lower jaw fits into a notch and not into a pit in the upper jaw.

The maxilla (2), which with its fellow forms most of the hard palate, has also been mentioned in connection with the dorsal aspect. Each maxilla is notched, posteriorly, to form the anterior border of the posterior palatine vacuity, and together they are notched to receive the rectangular anterior ends of the palatines. The postero-lateral extremity of the maxilla articulates with the transpalatine. Along the outer border of the bone are the teeth, of which there are fifteen or sixteen in the alligator, about the same number (perhaps one or two less) in the caiman and crocodile, and about twenty-four in the gavial. The first or anterior eight or ten teeth have individual sockets, the rest are placed in a groove. In the crocodile none of the teeth have individual sockets, and in the gavial 
they all have sockets. The premaxillary and more anterior of the maxillary teeth are slightly recurved and are sharper than the posterior maxillaries which besides being blunt have a constriction above the surface of the socket.

The crocodilian tooth consists of three layers (Fig. $20 \mathrm{~A}$ ).

The enamel (e) forms a fairly thick layer over the crown of the tooth; it exhibits a very clear striated structure, the striations being apparently due to stratification.

Some of the tubules of the dentine (d) continue into the enamel, where they may be distinguished by their remarkable fineness and their straight course.

The cement (c) covers the root of the tooth that projects into the alveolus of the jawbone; it is much more strongly developed than in the lizards and contains a very large number of bone corpuscles which are distinguished from the bone corpuscles proper by their greater circumference.

The fairly large pulp cavity (p) has, like the tooth itself, a conical form.

Parallel to the teeth is a row of small foramina, a continuation of those noted in the premaxilla; some or all of these foramina open into a longitudinal sinus along the alveolar border of the maxilla; this sinus opens posteriorly by one or more large apertures into the posterior palatine vacuity.

The palatines (9) form a broad bar of bone from 
the pterygoids behind to the maxillæ in front. They are united with each other by a straight median suture and form a considerable part of the floor as well as a part of the side walls and roof of the nasal passage. They form most of the median boundaries of the posterior palatine vacuities ( $\mathrm{pv}$ ). Dorsally they articulate with the pterygoids, prefrontals, and vomers.

The pterygoids (IO) are the very irregular bones that project ventrad and caudad from beneath the orbits. Their suture is continuous, caudad, with that between the palatines and at the posterior end of this suture is the posterior opening of the nasal chamber, the posterior nares (pn). This opening is divided by a vertical, longitudinal, bony septum, and the part of the chamber into which it immediately opens, which lies in the pterygoids, is divided by a number of transverse, vertical septa. Posterior and dorsal to the posterior nares the pterygoids are fused. Anteriorly the pterygoids articulate with the palatines; dorsally with the quadrates, basisphenoid, alisphenoids, and prefrontals, and dorso-laterally with the transpalatines. The lateral vertical border of the pterygoid is roughened and is, according to Reynolds, covered, during life, with a pad of cartilage against which the medial side of the mandible plays.

The transpalatine (II) is a T-shaped bone articulating ventrally with the pterygoid and dorsally with the maxilla, the jugal, and the postfrontal. 


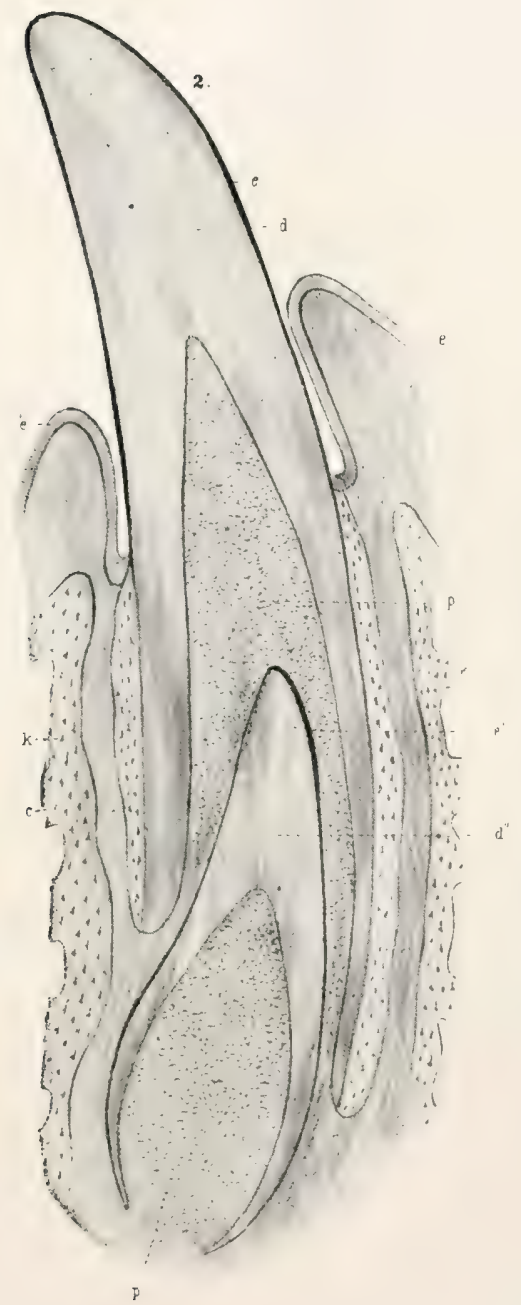

Fig. 20A. Longitudinal Section of the Jaw and Tooth of a Crocodile. (After Bronn.)

$c$, cement; $d$, dentine; $e$, enamel; $p$, pulp. of functional tooth; $c^{\prime}$, cement; $d^{\prime}$, dentine; $e^{\prime}$, enamel, of rudimentary tooth; $e^{\prime \prime}$, epidermis; $k$, bone of jaw. 

The brasioccipital (I 4 ) is seen projecting caudad as the single occipital condyle; it will be described in connection with the posterior aspect of the skull.

The jugal (5), quadratojugal (12), and quadrate (8) may all be seen from this view. The first two have been sufficiently described in connection with the dorsal aspect; the last will be further described in connection with the lateral aspect.

Just caudad to the posterior nares is a small opening, the unpaired Eustachian canal (eu).

The Lateral Aspect (Fig. 2 I). As will be seen by the figure, practically all of the bones visible in this view have already been described, except those of the mandible, which will be described separately. At the base of the skull are, however, two bones, the basi- and alisphenoid, that have not been described and that show as well in this as in any other view. The basisphenoid (just below $\mathrm{v}$ and hidden by the pterygoid) was mentioned in connection with the quadrate, with whose posterior margin it articulates. It is an unpaired bone of very irregular shape. Anteriorly it is flattened out to form the rostrum, a rectangular process that forms the posterior part of the interorbital septum; in fact it is the only part of the septum present in a prepared skull, since the rest is cartilaginous. Dorso-laterally the basisphenoid articulates with the alisphenoid; posteriorly with the basioccipital; ventrally with the pterygoid; and posteriorly with the exoccipital and basioccipital. On the dorsal 
surface of the basisphenoid is the pituitary fossa, not seen, of course, in this view of the skull.

The alisphenoids (crossed by the dotted line from $\mathrm{V}$ ) are a pair of very irregular bones that form most of the antero-lateral walls of the brain case. They articulate dorsally with the parietal, frontal, and postfrontal; ventrally with the basisphenoid and pterygoid; and posteriorly with the quadrate and some of the otic bones not visible in this view. Between it and the quadrate, plainly visible in this view, is a large opening, the foramen ovale (V), through which, according to Reynolds, the trigeminal nerve passes. In the middle line, directly under the frontal bone, is an opening between the anterior wings of the two alisphenoids, for the exit of the optic nerves. Ventrad and caudad to this opening, and sometimes continuous with it, is another large foramen, just dorsad to the rostrum, for the exit, according to Reynolds, of the oculomotor and abducens nerves. Projecting caudad is seen the rounded condylar part of the basioccipital (14) to be described later, and dorsocephalad to this is a part of the exoccipital (I3) in which four foramina may be seen; of the dorsal three the one nearest the condyle and foramen magnum is for the exit (Reynolds) of the hypoglossal nerve (XII); slightly dorso-cephalad to this is one for the vagus nerve $(\mathrm{X})$; between these two is a very small one for a vein; the largest and ventrally located foramen is for the entrance of the 
The Skeleton

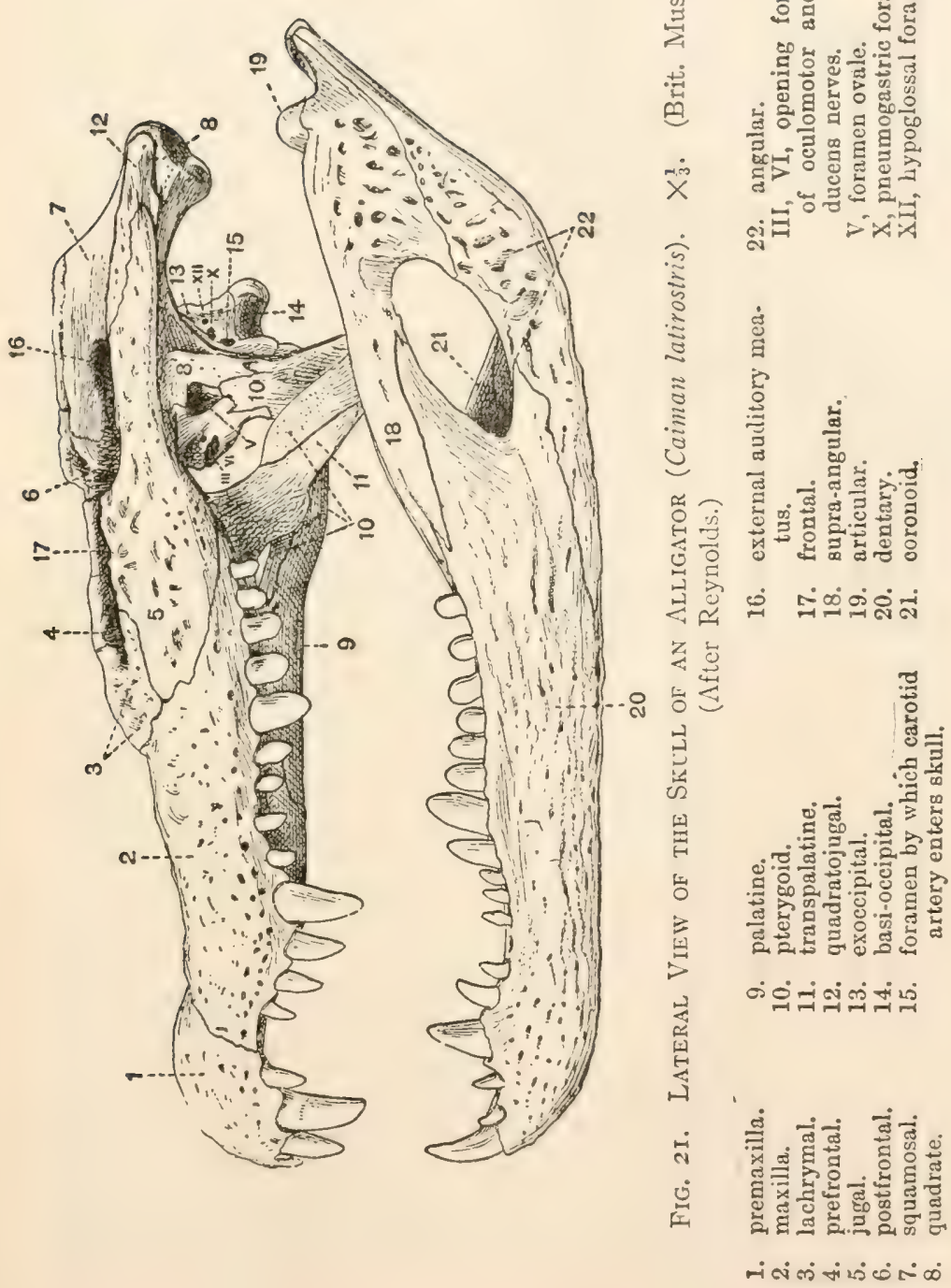


internal carotid (15). Another large foramen in the exoccipital bone will be seen and described in connection with the posterior view of the skull. Dorsal to the quadrate and largely bounded by it is the wide external auditory meatus (I6), which leads into the tympanic cavity. This cavity is complicated by a number of canals that lead from it in various directions. Overhanging the cavity and meatus is the squamosal bone, described in connection with the dorsal aspect of the skull.

The Posterior Aspect (Fig. 22). Most of the bones seen in this view have already been described. The ptcrygoids (IO) form the two prominent, ventrolateral projections, while dorsal to these is the large process formed by the quadrate (8) and quadratojugal (12). The dorsal margin is formed by the edges of the parietal (23) and the squamosals (7). Immediately below the parietal is the supraoccipital (26); it is a small, triangular bone, articulating above with the parietal and squamosals, below with the exoccipitals, and anteriorly with the epiotic. It takes no part in the formation of the foramen magnum.

The exoccipitals (I3) form the entire boundary of the foramen magnum except the narrow ventral portion formed by the basioccipital. Each exoccipital is a wing-shaped bone, articulating dorsally with the squamosal and supraoccipital, ventrally with the quadrate, basioccipital, and basisphenoid, and anteriorly with the opisthotic. It is pierced by 

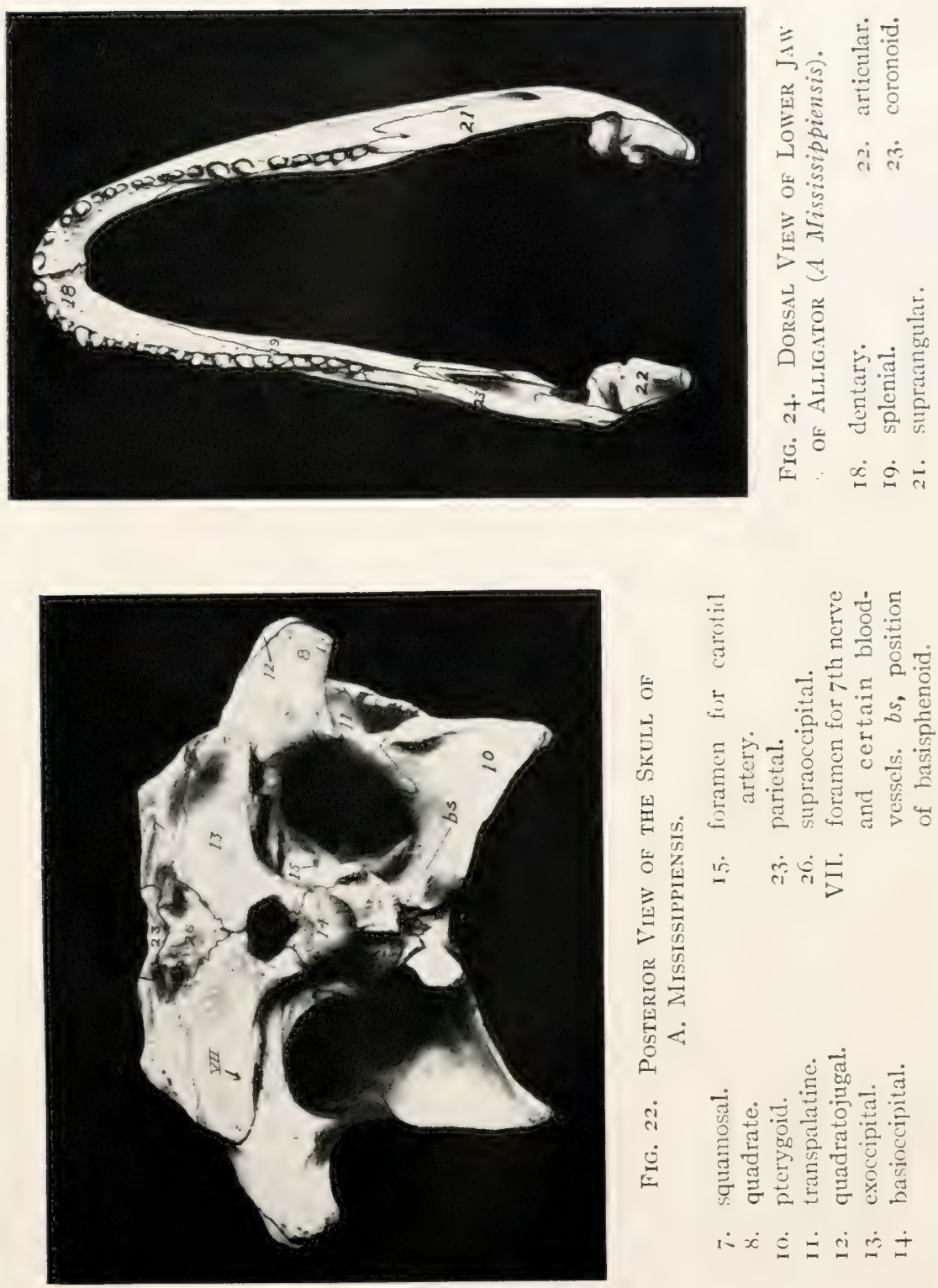


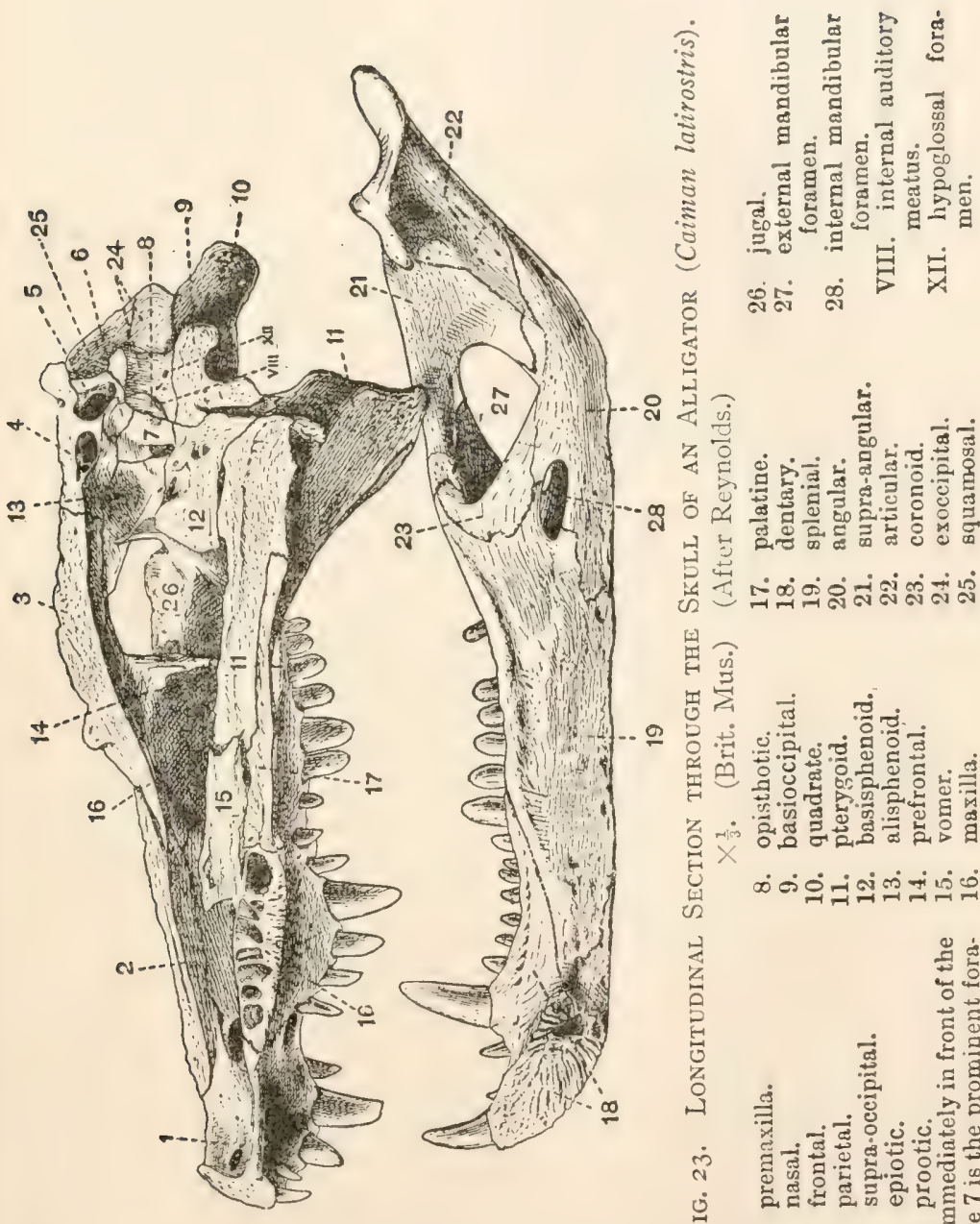

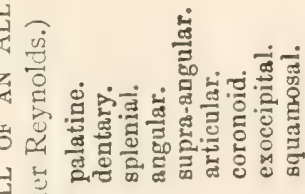

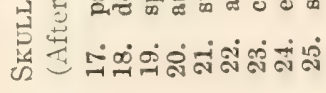

画 욜

落 焉

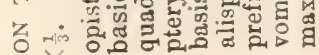

画

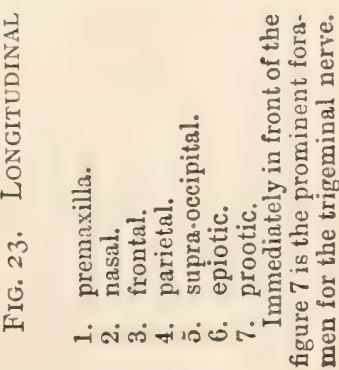


five foramina, four of which were described in connection with the lateral view. Some distance laterad and somewhat dorsad to the pair already described is the fifth and largest foramen (VII); it really lies between the exoccipital and quadrate, but the former bone forms almost its entire boundary; through it, according to Reynolds, pass the seventh nerve and certain blood-vessels.

The basioccipital (I 4 ) which, as has been said, forms a small part of the ventral wall of the foramen magnum, consists of a heavy dorsal portion, the ventrally curved condyle, and of a broader, irregular ventral portion, between which and the basisphenoid is the single opening of the Eustachian canals (eut). Dorsally and laterally the basioccipital articulates with the exoccipitals; ventrally, laterally, and anteriorly with the basisphenoid which was described in the lateral view.

The Sagittal Section (Fig. 23). The only bones shown in this figure (besides those of the mandible, to be described later) that have not already been described are the vomers and those of the auditory capsules.

The romers (15) are delicate bones articulating with the maxillæ, the palatines, the pterygoids, and with each other. They form a part of the septum and roof of the nasal passage.

The mesethmoid is not ossified.

Reynolds describes the bones of the auditory capsules as follows: 
"Three bones, the epiotic, opisthotic, and prootic, together form the auditory or periotic capstile of each side. They are wedged in between the latcral portions of the occipital and parietal segments and complete the cranial wall in this region. Their relations to the surrounding structures are very complicated, and many points can be made out only in sections of the skull passing right through the periotic capsulc. The relative position of the three bones is, however, well seen in a median longitudinal section. The opisthotic early becomes united with the exoccipital, while the cpiotic similarly becomes united with the supraoccipital, the pro-otic (Fig. 23, 7)-seen in longitudinal section to be pierced by the prominent trigeminal foramen - alone remaining distinct throughout life. The three bones together surround the essential organ of hearing which communicates laterally with the deep tympanic cavity by the fenestra ovalis.

"The tympanic carity, leading to the exterior by the cxternal auditory meatus (Fig. 2I, I6), is well seen in a side view of the skull; it is bounded on its inner side by the periotic bones, posteriorly in part by the exoccipital, and clsewhere mainly by the quadrate. A large number of canals and passages open into it. On its inner side opening ventro-anteriorly is the fencstra outis, opening ventro-posteriorly the internal auditory meatus (Fig. 23, VIII), while dorsally there is a wide open- 
ing which forms a communication through the roof of the brain case with the tympanic cavity of the other side. On its posterior wall is the prominent foramen through which the facial nerve passes on its way to its final exit from the skull through the exoccipital; this foramen is bounded by the quadrate, squamosal, and exoccipital. The opening of the fenestra ovalis is in the fresh skull occupied by the expanded end of the auditory ossicle, the columella, whose outer end articulates by a concave facet with a trifid cxtracolumellar cartilage which reaches the tympanic membrane. The lower process of this extracolumella passes into a cartilaginous rod which lies in a canal in the quadrateand is during life continuous with Meckel's cartilage within the articular bone of the mandible.

"The columella and extracolumella are together homologous with the chain of mammalian auditory ossicles."

The Lower Jaw (Figs. 21, 23, and 24). The mandible consists of two similar rami, rather closely united at the anterior-median symphysis with each other. Each ramus consists of six bones.

The dentary (Figs. 23 and 24, I8; Fig. 2I, 20) is a long bone that unites at the symphysis with its fellow to form the point of the jaw. It bears, along its dorsal edge, about twenty teeth; all but the posterior four or five of these teeth are in individual sockets; this may vary somewhat with age. The outer surface of the dentary, especially towards the 
symphysis, is covered with numerous, small, deep pits, while along its inner side, parallel to the row of teeth, is a row of somewhat larger pits like those noted in the maxilla and premaxilla. Articulating with the mesial side of the dentary along the greater part of its length is a flat bone, the splenial (Figs. 23 and 24, I9); between these two bones is a long cavity that makes the ramus hollow almost to the symphysis. A large foramen, not shown in any of the figures, leads through the splenial into this cavity.

Articulating with the caudal end of the splenial and forming the anterior border, as seen from the mesial side, of the large external mandibular foramen (Fig. 23, 27) is a small bone, the coronoid (Figs. 23 and 24, 23, Fig. 2I, 2I); it articulates with the splenial anteriorly, with the supra-angular dorsocaudally, and with the angular ventrally.

The supra-angular (Figs. 23 and 24, 2I, Fig. 2I, I 8 ) is an elongated bone that forms the dorsal border of the external mandibular foramen; it also forms the lateral cdge of the articular surface for the quadrate. It articulates anteriorly with the splenial, the dentary, and the coronoid; and posteriorly with the angular and articular.

The articular (Figs. 23 and 24, 22, Fig. 21, 19), which is scarcely visible in a lateral view, forms most of the surface for articulation with the quadrate, and sends back the large process so characteristic of the crocodilian skull. On the dorsal side 


\section{The Alligator and Its Allies}

of this process is a concavity that looks like another articular surfacc. Latcrally the articular articulates with the supra-angular; ventrally and posteriorly with the angular.

The ansular (Fig. 23, 20, Fig. 2I, 22) forms the ventro-posterior border of the jaw and of the external mandibular foramen. Its narrow, posterior end forms a part of the prominent process mentioned in connection with the articular. Between it and the posterior cdge of the splenial is the internal mandibular foramen, which is much smaller than the external (Fig. 23, 28). Anteriorly the angular articulates with the dentary, coronoid, and splenial; dorsally with the supra-angular and the articular.

The IIyoid (Fig. 25). The hyoid being mainly of cartilage is usually not seen in prepared skeletons. It is thus described by Reynolds:

"The hyoid of the Crocodile consists of a wide flattened plate of cartilage, the basilingual plate or body of the hyoid, and a pair of cormua.

"The basitingual plate (Fig. 25, I) is rounded anteriorly and marked by a deep notch posteriorly. The cormua (Fig. 25, 3), which are attached at a pair of notches near the middle of the outer border of the basilingual plate, are partly ossified, but their expanded ends are formed of cartilage. They pass at first backwards and then upwards and inwards. They are homologous with part of the first branchial arches of Selachians." 
III. The Ribs and Stermum.

The Cervical Ribs. As noted above, all of the cervical vertebre possess ribs. The first rib,
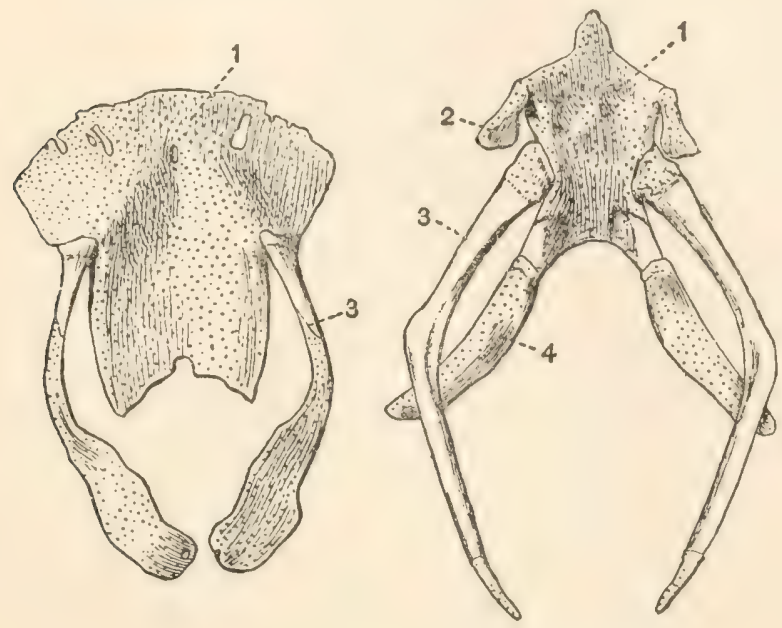

Fig, 25. Hyoids of AN Allrgator (Caiman latirosiris) (TO THE LEFT) AND OF A GREen Turtle (Chelone midas) (TO THE RIGHT). $\times_{\frac{5}{8}}$. (Brit. Mus.) (After Reynolds.)

The cartilaginous portions are dotted.

1. basilingual plate or body of the hyoid.

2. hyoid arch.
3. first branchial arch (anterior cornu).

4. second branchial arch (posterior cornu).

attached to the atlas, consists of a single, long blade projecting backward at an acute angle (Fig. I 7, 8) as far as the middle of the fourth vertebra. As described above it articulates with the atlas at but one place. All of the other cervical ribs have two articular surfaces, a tuberculum and a capitulum, 
with a well-marked vertebrarterial canal between them. The ventral surface or capitulum articulates with a short process on the centrum; the dorsal surface or tuberculum ( 7$)$ articulates with the transverse process. The third to seventh ribs are somewhat $\mathrm{T}$-shaped, the stem of the $\mathrm{T}$ being the tubercle and head, while the cross arm of the $T$ extends parallel to the axis of the neck (Fig. I7, 7). In the eighth rib the posterior arm of the $T$ is elongated and projects out at a wide angle from the body; and in the ninth or last cervical rib this arm extends laterally as far as the vertebral portion of the thoracic ribs and has a cartilaginous tip.

The Thoracic Ribs (Figs. I6 and 26). These are ten in number, the first eight pairs being connected with the sternum. The fourth may be taken as typical. It consists of a bony vertebral portion and partially ossified intermediate and stemal portions. The vertebral portion articulates with its corresponding transverse process by two surfaces, as described in connection with the thoracic vertebræ. In the first and second ribs only the tuberculum articulates with the transverse process, the head having a separate articular surface on the side of the centrum, as in the typical cervical rib. In the last thoracic rib the head and tubercle are not distinguishable from each other. Near the distal end of all the vertebral portions except the first and the last two ribs is a caudally projecting, partially ossified, uncinate process. The inter- 


\section{The Skeleton}

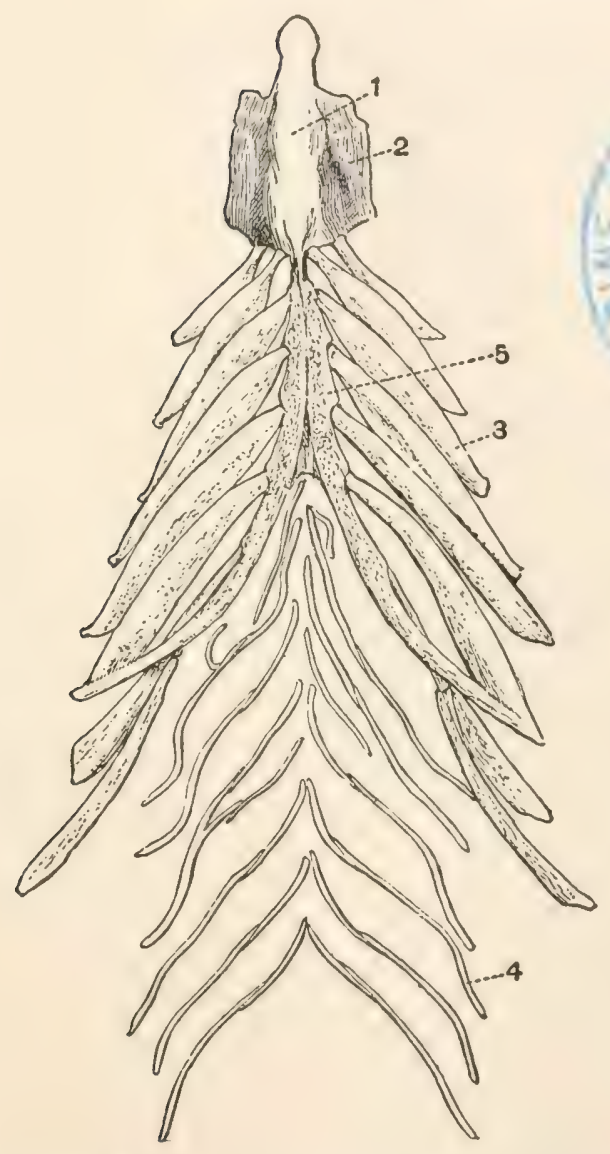

Fig. 26. Sternum and Associated Membrane Bones of a CroCODILE (C. palustris). $\times \frac{1}{3}$. (Brit. Mus.) (After Reynolds.)

The last pair of abdominal ribs which are united with the epipubes by a plate of cartilage have been omitted.

1. interclavicle.

2. sternum.

3. sternal rib.
4. abdominal splint rib.

5. xiphisternal horn. 
mediate portion is present in all but the tenth rib, and wherever present, except in the ninth rib, it articulates distally with the stcrnal portion. The sternal portions cxtend medio-cephalad in a direction atright angles to the intermediate portion; the first two articulate with the sternum, the next six with the xiphisternal horns, and the ninth and tenth are missing.

The Abdominal Ribs (Fig. 26, 4). While these ribs are membrane bones and are not homologous with the other ribs, they may as well be mentioned at this time. They consist of about seven $V$-shaped sets of slender bones, the point of each $V$ being directed cephalad. Each $V$ is made up of from two or five slender bones, the number and arrangement being subject to consicerable variation. The last $V$ of the series (not well shown in the figure) is considerably larger than the rest and is made up of four curved bones that extend around the anterior ends of the pubic bones and are united to them by a broad tough membrane. The first or most anterior $\mathrm{V}$ is united by a narrow membrane (not shown in the figure) with the membrane that extends between the xiphisternal horns. All of the V's are more or less connected with each other by fibrous membranes. Since these ribs lie superficial to the recti muscles of the ventral body wall they are sometimes missing in carelessly prepared skeletons.

The Stermum (Fig. 26). The sternum consists of 
the cartilaginous sternum proper (2), the xiphisternal horns (5), and the bony episternum or interclavicle (I). The latter is an elongated, flattened bone of somewhat spatulate outline, lying in the midventral line; it projects forwards to about the sixth cervical vertebra, while the anterior edge of the sternum is below the eighth cervical. Lying dorsal and lateral to the episternum is the flat, almost membranous sternum, to the posterior border of which the first two thoracic ribs are attached. The xiphisternum consists of two long, slender rods of cartilage; the anterior ends of these rods are in contact with each other and with the posterior border of the sternum; from this point they gradually diverge from each other as they extend caudad. A membrane extends between the horns as far back as the attachment of the last thoracic ribs.

\section{The Appendicular Skeleton.}

The Pectoral Girdle and Anterior Limb. The pectoral girdle (Fig. 27) is of a very simple type, consisting, unless the episternum (interclavicle) be counted, of but two bones, the scapula $(s)$ and coracoid $(c)$. The former consists of an upper, flat, paddle-shaped portion and a thicker lower portion which articulates anteriorly with the coracoid, and posteriorly forms about half of the notch-like glenoid cavity. The dorsal edge of the flattened portion is continued as a small, cartilaginous supra- 
scapula. The coracoid is a flattened bone, wide at cither end and narrow in the middle, so that in a dorsal view it is shaped like an hourglass. It is decidedly curved, with the convex side down.

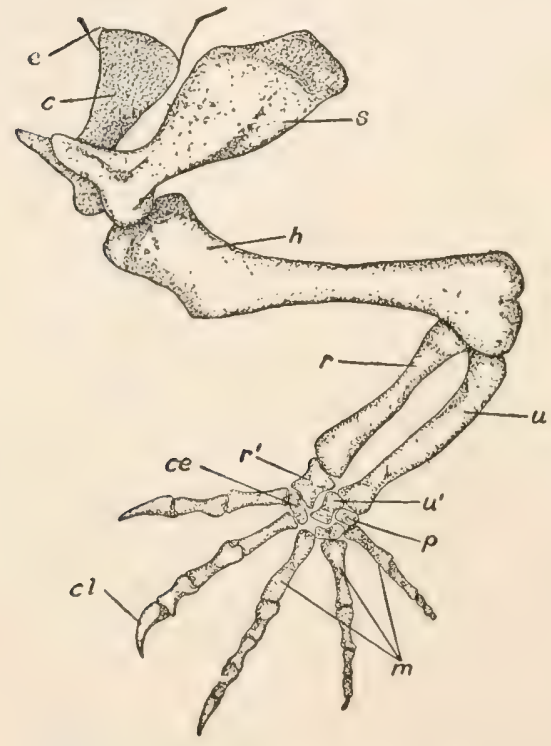

Fig. 27. Pectoral Girdle and ANTERIOR LIMB.

$c$, coracoid; $c e$, centrale; $c l$, claw; $e$, episternum;

$h$, humerus; $m$, metacarpals; $p$, pisiform; $r$,

radius; $r^{\prime}$, radiale; $s$, scapula; $u$, ulna;

$u^{\prime}$, ulnare.

There is no clavicle nor other coracoid elements.

The anterior limb consists of the usual parts,the upper arm, forearm, and manus. The $h u$ merus (Fig. 27, $h$ ) is rather thick in proportion to its length; it has an elongated articular surface at its proximal end for articulation with the glenoid 
cavity, and a larger, somewhat bilobed surface for articulation with the radius and ulna. On its ventral side, near the proximal end, is a very prominent protuberance, the deltoid ridge. The ulna (u) is slightly heavier and longer than the radius and forms the greater part of the elbow joint and about half of the wrist joint. Its proximal end is considerably larger than the distal, but has no olecranon process. Its distal end articulates with the ulnare and pisiform. The ulna as a whole is slightly curved, while the radius is quite straight.

The radius $(r)$ consists of a cylindrical shaft with enlargements of about equal size at the ends. The proximal end articulates with the side of the ulna and with the humerus; the distal end with the radiale.

The carpus consists of a proximal row of three distinct bones and a distal row of smaller and less fully ossified elements. Of the proximal row the radiale $\left(r^{\prime}\right)$ is much the largest bone. It is hourglass shaped, with the proximal end somewhat larger than the distal. Proximally it articulates mainly with the radius but also slightly with the ulna and ulnare. Distally it articulates with the centrale. The ulnare $\left(u^{\prime}\right)$, the second bone in size in the wrist, has about the same shape as the radiale but is much smaller. Proximally it articulates with the pisiform, radiale, and, apparently, with the ulna; distally it is in contact with the fused carpalia elements. The pisiform $(p)$ is a small, 


\section{4}

The Alligator and Its Allies

irregular bone, articulating with the ulna and the ulnare; it is apparently connected by a long ligament with the fifth metacarpal but does not actually articulate with it. The centrale (ce) is a flattened, partially ossified element between the radiale and the first and second metacarpals. The distal carpal bones are represented by two irregular, partially ossified elements between the ulnare and the third, fourth, and fifth metacarpals.

The manus proper consists of five digits. The metacarpals $(m)$ are of about the same shape, but vary in length and thickness; each consists of a cylindrical shaft with a slight enlargement at each end. The first digit or pollex has two phalanges, the second has three, the third has four, the fourth has four, and the fifth has three. The terminal phalanx of each of the first four digits is pointed, has a pair of lateral grooves, and is encased in a large, horny claw $(\mathrm{cl})$.

The Pelvic Girdle and Posterior Limb. The pelvic girdle is described differently by Wicdersheim and Reynolds; the bone called by the former the pubis, the latter calls the epipubis. The bone called by Wiedersheim the pubis takes no part in the formation of the acetabulum; the pubis of Reynolds helps form the acetabulum but is a very small, unossified structure. Gadow also calls the lower bone the epipubis. I shall follow Reynolds's interpretation.

The ilium (Fig. 28, I) is a heavy bone with 
a dorso-laterally projecting crest; medially it is firmly united to the sacral ribs (Fig. I 8,5 ) while its outer side forms the upper and greater part of the

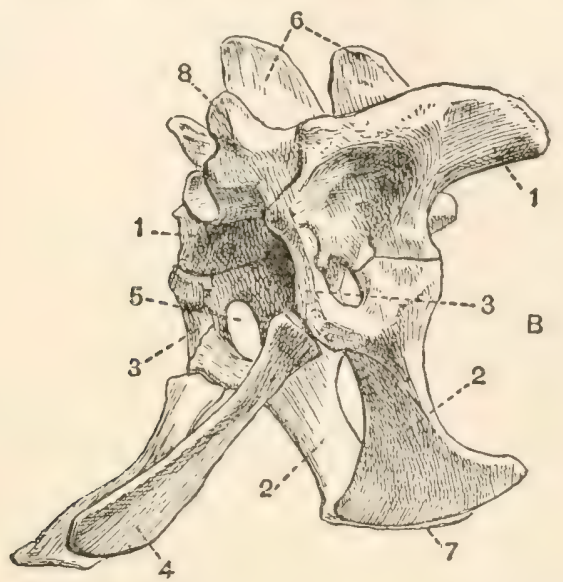

Fig. 28. Pelvis and Sacrum of an Alligator (Caiman latirostris). $\times \frac{1}{2} . \quad$ (Brit. Mus.) (After Reynolds.)

1. ilium.

2. ischium.

3. true pubis.

4. epipubis (so-called pubis).

5. acetabular foramen.
6. neural spines of sacral verte: brae.

7. symphysis ischii.

8. process bearing prezygapo. physis.

acetabulum. Its outer and lower border has two surfaces, the larger and more posterior articulating with the ischium, the other with the cartilaginous pubis.

The ischium (2) is a slightly arched bone, its ventral end a flattened blade articulating with its fellow, its dorsal end enlarged and thickened to articulate with the ilium, pubis, and epipubis. 
This dorsal end, which forms the ventral side of the acetabulum, is divided into two distinct articular surfaces by a deep, rounded notch; the posterior and larger surface articulates with the ilium, the anterior surface about equally with the pubis and epipubis.

The pubis (3), which is much the smallest element of the pelvis, is a small mass of cartilage lying between the ilium above and the ischium below. It forms a small part of the anterior wall of the acetabulum.

The epipubis (4) is a slightly arched bone, somewhat enlarged at its proximal end where it unites with the ischium, and flattened out into a fanshaped extremity, where it is united with its fellow and with the last pair of abdominal ribs by the broad, thin sheet of cartilage or fibrous tissue noted in connection with the abdominal ribs. As mentioned above, it is called by Wiedersheim and others the pubis. Near the center of the acetabulum there is a small foramen.

The posterior limb (Fig. 29) consists of the usual divisions-thigh, shin, and foot. The femur is a bone of the same general outline as the humerus, though slightly longer and heavier. The head, for articulation with the acetabulum, is rather hemielliptical than hemispherical in shape, the long axis of the ellipse being vertical. The distal enlargement is of at least as great, if not greater, bulk than the proximal and shows some indication 
of a division into two articular surfaces. The ventral side of the femur near the proximal end shows a fairly distinct trochantal ridge.

The shin or crus is made up of two well-developed bones, the tibia ( $t$ ) and fibula (fb), the former being somewhat longer and considerably thicker than the latter.

The tibia consists of a cylindrical shaft with enlargements of about equal size at the ends. The proximal end forms most of the knee joint, the distal end articulates with a tarsal element said by Reynolds to represent the fused astragalus and centrale, by Wiedersheim called the astragalus, and said to represent the united tibiale, intermedium, and centrale (tb,

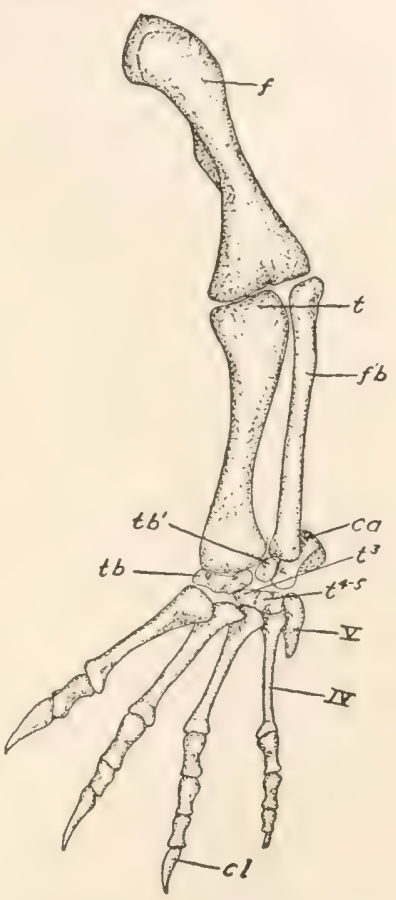

Fig. 29. Posterior Limb. $c a$, calcaneum or fibulare; $c l$, claw; $f$, femur; $f b$, fibula; $t$, tibia: $t^{3}, t 4-5$, tarsalia; $t b, t b^{\mathrm{x}}$, tibialecentrale; $1 V, V$, 4 th and 5 th metatarsals. $\left.t b^{\prime}\right)$. The fibula articulates by a small enlargement at its proximal end with the femur, and by an enlargement of about equal size, at its distal end, with the fibulare or calcaneum (ca), and with a small facet on the above-mentioned tibiale-centrale element. 
The tarsus is much modified and consists of four elements, in two rows; those of the proximal row are much larger than the two distal elements. Articulating with both tibia and fibula, as mentioned above, and with the first metatarsal and one of the distal tarsalia, is the large and irregular tibiale-centrale element of Reynolds ( $\mathrm{tb}, \mathrm{tb} \mathrm{b}^{\prime}$ ). In the tarsus here shown it consists of two elements. Post-axial in position is the calcaneum or fibulare (ca), articulating with the preceding tarsal element, with the fibula, with the rudimentary fifth metatarsal, and with the distal tarsal element said by Reynolds to represent the fourth and fifth tarsalia. The calcaneum is extended caudad into a prominent knob quite like the heel of the higher mammals.

The two distal tarsal bones are small; one is said by Reynolds to represent the first three tarsalia $\left(t^{3}\right)$, the other $\left(t^{4-5}\right)$ the fourth and fifth. Wiedersheim says one of these bones represents the first three tarsalia, the other the fourth. In the tarsus here shown these two elements are fused.

The foot has five digits, though the fifth is small and consists merely of a small, distally pointed metatarsal bone. According to Wiedersheim this fifth metatarsal is fused with the fifth tarsalia. The metatarsals of the first four digits are long and progressively more slender from the first to the fourth; each is distinctly enlarged at the ends. The first digit or hallux has two phalanges, the 
second has three, the third has four, and the fourth has four. According to Reynolds, the fourth toe has five phalanges; the figure here shown, which was drawn from nature, has only four on the fourth. toe; the latter is the number given by Bronn for the crocodiles. The terminal phalanges of the first three digits are large and pointed, with the same lateral grooves noted in connection with the fore foot; each is sheathed in a horny claw. The four fully developed digits of the pes are nearly twice as long as the corresponding digits of the manus, but they are not proportionately thicker. 


\section{CHAPTER III}

\section{THE MUSCLES}

7 HE description of the muscles here given is taken from Bronn (II), who, in turn, largely follows Gadow. The animal described is the crocodile, but while Bronn does not indicate the species, it is probable that the differences between the various members of the Crocodilia would be slight. The figures of the muscular system are mainly from the Florida alligator.

In his description Bronn gives for each muscle the various synonyms (often more than half a dozen) that are employed by different writers; in this work Bronn's nomenclature is given first and the synonyms follow in parentheses.

\section{The Chewing Muscles}

Temporalo-maxillaris (Temporalis) (Masseter, Temporal, Aeussere ober Heber or Schlafmuskel). Arises in the temporal fossa, passes under the zygoma, and inserts itself on the inner and outer sides of the lower jaw. 
Pterygo-maxillaris (Pterygoideus) (Pterygoidien, Aeusser Flügelmuskel, Pterygoideus externus, Pterygoideus internus). A large muscle which consists of two portions: the outer, weaker portion springs from the pterygoid process, the inner stronger part from the pterygoid fossa and pterygoid process; they run together around the angle of the lower jaw, where they form a large, bulging fold. They are the chief muscles of this part of the body since the masseter is lacking and the temporalis is weakly developed.

Occipito-maxillaris (Digastrucus maxillæ) (Niederzieher des Unterkiefers, Abaisseur ou l'analogue du digastrique, Senker des Unterkiefers, Aristotelis apertor oris, Digastricus, Aperator oris). Arises from the hinder border of the lateral occipital and is inserted at the hinder end of the lower jaw. Its course is from front to back. If the skull be stationary this muscle drops the lower jaw; if the jaw be fixed it raises the skull.

\section{Muscles of the Ventral Surface of the NECK}

Intermaxillaris and Sphincter Colli (Intermaxillaire, Mylo-hyoideus, Zwischenkiefermuskel, Latissimus colli). This muscle consists chiefly of transversely running fibers, and has in its middle third a small, median, longitudinal raphe or aponeurosis. In the posterior part of the neck it 
is very thin, but increases in thickness more and more as it passes cephalad. A short anterior and a long posterior portion may be distinguished. The former extends from the inner side of the right to that of the left half of the lower jaw, without a median aponeurosis. The hinder half of this muscle is united by a pair of aponeuroses to the lower jaw, on one hand (the smaller part), and to a fascia, on the other hand (the far larger part), that scparates several of the neck muscles. The smaller part begins immediately behind the pterygoid on the inner side of the halves of the lower jaw but ends on the outer side of the two halves of the jaw.

Latus Colli (Latissimus colli accessorius). Lies underneath the preceding. Its muscle bundles lie between the collo-capitis muscle and the bodies of the first three cervical vertebræ, and form a broad band that extends from the hyoid bone to the backwardly directed cervical ribs of the first and second pairs.

Coraco-ceratoideus (Omo-hyoideus, Coraco-hyoideus). A long, narrow, and moderately thick muscle which takes its origin from the upper border of the coracoid, where the latter touches the scapula. It extends forward near the œsophagus and attaches itself to about the middle of the backwardly turned border of the horn of the hyoid of that side. Episterno-ceratoideus (Niederzieher des Zungenbeins, or Brustbeinzungenbeinmuskel, Sterno-hyoideus). A flat and fairly broad muscle which 
springs from the ventral surface of the epistcrnum; behind, it is separated by a slight space from the corresponding muscle of the other side, with which it nearly covers the cervical part of the trachea. Towards its anterior end it divides into two heads; one of these inserts itself on the outer border and outer surface of the cornu of the hyoid; the other head, lying laterad to the former, is suddenly reduced to a short tendon by which it is attached to the following muscle.

Maxillo-coracoideus (Mylo-hyoideus anterior, Sterno-maxillare). This muscle arises from the upper border and inner surface of the caudal third of the lower jaw. In its further course it becomes tendinous and projects by a short tendon outwards from the hyoid cornu to unite with the head of the preceding muscle, as noted above; it then becomes fleshy again and is inserted on the medial part of the upper border of the coracoid.

Maxillo-hyoideus (Genio-ceratoidien, Hyomaxillaris, Hyoglossus, Hyomandibularis, Mylo-hyoideus posterior). This muscle arises, very thin, from the mandibular symphysis, goes thence immediately backward and inward to insert itself, by its broad end, on the whole anterior end of the horn of the hyoid and on the hyoid itself.

Cerato-hyoideus. Arises from the horn of the hyoid and inserts itself on the body of the hyoid.

Costo-coracoidcus. This muscle arises from the distal ends of the first and second ribs and is 


\section{The Alligator and Its Allies}

inscrted on the ventral surface of the coracoid at the boundary of the scapula.

Costo-scapularis (Collo-scapularis superficialis, Levator scapulæ superficialis). See shoulder muscles.

Costo-vertebralis Medialis (Scaleni). Fairly large, flat, and long-drawn-out three-cornered muscle. Attached by its base to the most anterior sternal rib, by its upper border to the fifth cervical rib, and by its point to the end of the second cervical rib.

Costo-vertebralis Lateralis (Longus colli). Originates thin and sharp on the body of the fifth thoracic vertebra, increases in thickness slowly but decidedly cephalad, then again becomes thinner and inserts itself on the inner side of the ribs of the most anterior two cervical vertebræ.

Collo-capitis (Rectus capitis anterior). Arises, as a rule, from the cervical centra, at times from the second thoracic vertebra (Gavialis). It extends forward and is inserted on the basi-occipital and the hinder border of the pterygoid. For a greater part of their length the two muscles lie close together, but forward they separate somewhat from each other.

\section{Dorsal Neck Muscles}

Occipito-cervicalis Medialis (Complexus cervicis, Biventer cervicis, Zweibäuchiger Strecker or Zwei- 
bäuchiger Nackenmuskel, Splenius capitis). It springs, by separate points, from the dorsal processes of the four anterior body vertebræ and the six posterior neck vertebræ; it is convex on its dorsal, weakly concave on its ventral surface; it leads cephalad as a short, strong tendon by which it is attached to the angle between the upper hinder border of the skull, i.e. to the superior and lateral occipital region.

Squamoso-ceriicalis Medialis (Kopfbäuchmuskel [Splenius] or durchflochtener Muskel [Complexus], Trachelo-mastoideus, Complexus). This muscle lies laterad and ventrad to the preceding and is at times partly covered by it in its posterior half. It arises from separate heads from the spinal processes of the two anterior and six posterior cervical vertebræ; beginning caudad, thin and sharp, it gradually becomes thicker as it passes cephalad until it becomes partially tendinous and inserts itself on the hinder border of the squamosal, laterad to the occipito-cervicalis medialis muscle.

Epistropheo-vertebralis (Splenius colli). This muscle springs from the spinous processes of the most anterior three body vertebræ and the last cervical vertebra; it receives fibers from the articular processes and intermediate parts of the six posterior cervical vertebræ and is inserted on the second cervical vertebra.

Collo-squamosus (Splenius capitis, Nackenwarzenmuskel, Trachelo-mastoideus). Springs from 
the upper transverse processes of the last three neck vertebrx, and, becoming tendinous, is inserted on the hinder border of the squamosal.

Collo-occipitis. Arises from the transverse processes of the posterior five cervical vertebræ, extends directly forwards on the ribs of the vertebræ, and is inserted under the articular surface of the lateral occipital.

Occipito-epistropheus (short, straight, hinder head-muscle, or extensor). This muscle springs from the lateral surface of the body of the second neck vertebra and inserts itself on the basi-exoccipital, under the preceding muscle.

Cervicalis Adscendens. Arises in great part from the angles under the most anterior ribs; a smaller part appears farther above where it is covered by the rhomboideus muscle. It is inserted on the upper side of the five posterior cervical ribs and on the distal ends of the long second cervical rib.

\section{The Muscles of the Scapula}

Capiti-stemalis (Sterno-mastoideus). This is a fairly large muscle, on the side of the neck, that extends from the skull to the breast and from the middle of the neck is divided into two portions: (a) an anterior part or atlanti-mastoideus (Plate I., Figs. I and 2, cst') (upper end of the "head nodder," sterno-mastoideus, anterior part of 
sterno-mastoideus, anterior part of atlanti-mastoideus); (b) a posterior part or sterno-atlanticus (Plate I., Figs. I and 2, cst ${ }^{2}$ ) (sterno-mastoideus, inner belly of the "head-nodder," posterior part of the sterno-atlanticus). The former part is a rather short but not weak muscle that arises from the squamosum and inserts itself on the rib of the atlas (alligator) or of the atlas and epistropheus (crocodile).

The latter part is fairly strong and exceeds the anterior part in length; it springs from the rib of the first cervical vertebra, opposite the insertion of the anterior part, and inserts itself on the anterior border of the outer surface near the episternum. At times superficial fibers pass into the pectoral fascia.

Dorso-scapularis (Cucullaris) (Plate I., Figs. I and $2, \mathrm{Cu}$ ) (Trapezius). A broad but thin muscle that begins as an aponeurosis from the dorsal fascia in the middle line of the hinder part of the neck and beginning of the back; with converging fibers it passes within to insert itself partly on the spine of the scapula and partly by superficial fibers in the fascia that cover the deltoides scapularis inferior muscle.

Collo-scapularis Superficialis (Plate I., Fig. I, cssp) (Levator scapulæ superficialis, Levator scapulæ, Heber des Schulterblatts, Acromio-trachélien, Teil des Serratus magnus, Levator anguli scapulæ). A considerable muscle on the side of the 
neck. It arises from the tips of the ribs of the first and second cervical vertebræ (where it is fused with the sterno-atlanticus muscle), and also from the transverse process of the third and fourth cervical vertebræ; it goes with diverging fibers to the entire anterior border of the scapula.

Thoraci-scapularis Superficialis (Serratus superficialis, Pectoralis minor, Hinterer Theil des inneren grösseren Rückwärtsziehers, Pars posterior m. serrati antici majoris, Theil des Grand dentelé, Serrati posteriores, Latissimus dorsi scapulocostalis). A strong muscle of three prongs that go directly, by superficial fibers, over into the oblique abdominal muscle and meet the ribs. The first and smallest prong arises from the under end of the rib of the ninth vertebra (last cervical); the second and medium-sized prong comes from the uncinate process of the tenth rib (first thoracic) and from beneath the uncinate process of the second thoracic rib; the third and strongest prong takes its origin from the uncinate processes of the second and third thoracic ribs. All three prongs unite to form a broad, homogeneous muscle which passes forward and above to the hinder border of the scapula, upon whose entire surface, except at the lower end, it is inserted.

Collo-thoraci-suprascapularis Profundus (Plate I., Fig. 3, cthspr) (Levator scapulæ et serratus profundus, Serrati anteriores, Serratus anticus major, Vorderer Theil des inneren grösseren Rückwärts- 
ziehers or vorderen grossen gezahnten Muskcls, Pars anterior $\mathrm{m}$. serrati antici majoris, Theil des Grand dentelé, Theil des Serratus magnus). This muscle arises in varying extent from the transverse process of the fifth cervical vertebra to the first (crocodile) or second (alligator) ribs. It is inserted on the inner surface of the suprascapula, except on its forward part, and is made up of two layers - a superficial and a deep one. The former layer (Fig. 3, cthspr $^{\mathrm{I}}$ ) is weakly developed and is composed of two or three thin, distinct bundles, that extend from the ribs of the eighth, ninth, and eleventh vertebræ (alligator) or from the transverse process of the seventh vertebra and the rib of the tenth. The deeper layer is considerably developed; its bundles come, in the alligator, from the fifth to tenth vertebræ; in the crocodile from the fifth to ninth.

Rhomboideus (Plate I., Fig. 3, rh) (Rautenmuskel, Angulaire de l'omoplate). This is a very small, independent muscle that springs, by two or three distinct bundles, from the fascia covering the longissimus dorsi muscle, in the region of the eighth and ninth vertebræ; after a short course it inserts itself on the antero-dorsal angle of the suprascapula.

Costo-coracoideus (Plate I., Fig. 3, cc) (Subclavius et Triangularis sterni and Levator secundæ superioris costæ, Petit dentelé, Pectoralis minor, Pectoralis). This is a broad muscle of considerable 
size on the ventral side of the breast; it consists of a lateral and of a medial portion, the former springing from the last cervical rib, the latter from the anterior border of the first sternocostal ridge. The two parts unite and are inserted on the whole posterior border of the coracoid.

Pectoralis minor (Pectoralis, Costo-coracoideus). A broad, considerable muscle on the under side of the breast, which is made up of two parts, of which the lateral springs from the anterior border of the last (ninth) cervical rib, and the medial from the anterior border of the first sternocostal ridge. Both parts unite into a homogeneous layer which is inserted broadly on the whole hinder border of the coracoid.

Pectoralis (Plate I., Figs. I and 2, p) (Pectoralis major, Grosser Brustmuskel). A broad muscle on the under side of the breast, bounded behind by the rectus abdominis and obliquus abdominis externus muscles, with which it is united. It arises from the whole episternum, from the whole sternum, except from the median line of its posterior part, from the sternal ends of the first six thoracic ribs, from all six sternocostal ridges, and, with a small prong, from the eighth rib. It is inserted on the distal part of the convex surface of the processus lateralis humeri.

Supracoracoideus (Plate I., Figs. I and 2, spc) (Supracoracoscapularis, Dcltoideus, Schlüsselbeinhälfte, Theil der Schulterblatthälfte des Hebers 
des Armes, Obergrätenmuskel, Hebemuskel des Oberarmes, Epicoraco-humeralis). A muscle of considerable size at the anterior region of the coracoid and the under region of the scapula, which is divided into two parts: (a) the coracoid (inferior) division is the stronger and arises from the whole anterior half of the coracoid, from its outer and inner surfaces; it is inserted, together with the second part, on the proximal, littledeveloped part of the processus lateralis humeri; (b) the scapularis (superior) division is the weaker of the two and is covered by the deltoides scapularis inferior muscle; it arises from the surface of the under third of the scapula, behind the spine; it unites with the preceding part to form a single muscle and inserts itself, as said above, on the proximal part of the processus lateralis humeri.

Coraco-brachialis (Brevis) (Plate I., Figs. 4, 5, and 6, cbb) (Theil des grossen Brustmuskels oder Hakenarmmuskel, Pectoralis II., Pectoralis minor). A fairly strong muscle. It arises from the outer surface of the coracoid, except the median edge and the anterior section, and runs to the flexor surface of the upper arm where it is inserted on the proximal third between the lateral and median processes.

Coraco-antebrachialis (Plate I., Figs. 2 and 5, $\mathrm{b}^{\mathrm{r}}$ ) (Biceps, Coracoideus, Langer Kopf des langen Beugers, Langer Kopf des Biceps, Biceps humeri, Biceps brachii, Coraco-radialis). A slender and 


\section{I02 \\ The Alligator and Its Allies}

rather weak muscle on the flexor side of the upper arm. It arises by a fairly broad but thin tendon from the outer surface of the coracoid immediately before the coraco-brachialis. As a weak bundle it passes between the lateral and median processes, lying medially near the brachialis inferior muscle, with which, at the end of the upper arm, it unites; after their union the two muscles continue as a broad tendon that splits into two parts, which are inserted on the proximal end of the radius and of the ulna.

Humero-antebrachialis Inferior (Plate I., Figs. 2 and 6, hai) (Brachialis inferior, Caput breve $\mathrm{m}$. bicipitis, Kurzer Kopf des Biceps, Brachial interne, Brachialis anticus, Erster vom Obcrarm ausgehender Beuger, Portion of Brachiæus). Springs from the lateral flexor side of the humerus, from the distal end of the lateral process to the distal end of the bone, except the epiphysis; at the end of the upper arm it unites with the biceps and with it is inserted, by two tendons, to the radius and ulna.

Dorso-lummeralis (Plate I., Fig. I, dh) (Latissimus dorsi, Breiter Rückenmuskel, Humero-dorsalis). It springs as an aponeurosis from the back at the level of the first four or five dorsal vertebræ, and passes, with converging fibers, cephalo-ventrad to unite with the teres major muscle; in common with the latter it extends along the extensor surface of the humerus to be inserted between the lateral and median processes. 
Dorsalis Scapulce (Plate I., Fig. I, dss) (Deltoides scapularis superior, Unterer Theil des äusseren Schulterblattmuskels, Untergrätenmuskel, Suprascapularis, Infraspinatus, Supraspinatus). Springs from the anterior half of the outer surface of the scapula, passes between the deltoides scapularis inferior and the caput scapulare laterale externum $\mathrm{m}$. anconæi, as a narrow band, to be inserted on the lateral side of the humerus.

Deltoides scapularis Inferior (Plate I., Figs. I and 2, dsi) (Deltoideus superior, Supra- and Infraspinatus, Theil der Schulterhälfte des Hebers des Armes, Theil der oberen [Schulterblatt-] Abtheilung des Deltoideus, Zweiter Hebemuskel des Oberarmes, Theil des Deltoides). A strong muscle on the side of the shoulder. It springs from the spine of the scapula, passes back with slightly converging fibers, and ends chiefly on the outer surface of the processus lateralis humeri, while a number of superficial fibers end in the humeroradialis muscle.

Scapulo-Inmeralis Profundus (Plate I., Fig. 4, shpr) (Teres minor, Erster Teres major, Scapulohumeralis). A small muscle that springs from the posterior border of the lower third of the scapula, and passes, with converging fibers, to its insertion on the humerus just distal to the medial process.

Teres Major (Grosser runder Muskel oder kleiner Rückwärtszieher des Oberarmbein, Zweiter teres 


\section{I04 The Alligator and Its Allies}

major). Springs from the posterior half of the upper region of the outer surface of the scapula. It passes down, with converging fibers, to unite with the latissimus dorsi muscle to form a strong tendon that is inserted on the extensor surface of the humerus.

Subscapularis (Unterschulterblattmuskel). Springs from the inner surface of the scapula, except from the suprascapula, goes with converging fibers directly over the capsule of the shoulder joint to be attached to the medial process of the humerus.

Anconaus. This strong muscle lies on the extensor side of the upper arm. It is made up of two layers: the superficial comes from the pectoral girdle in two heads: (a) the caput scapulare laterale externum and (b) caput coraco-scapulare; the decper layer originates on the humerus by three heads, (c) caput humerale laterale, (d) caput humerale posticum, and (e) caput humerale mediale. These five heads of the anconæus muscle with their synonyms will now be described.

(a) Caput Scapulare Laterale Extermum (Plate I., Figs. I and 4, as1) (Brevi proximum caput m. tricipitis, Gewöhnlicher [äusserer] langer Kopf des dreiköpfigen Streckers, Portion scapulaire externe du triceps-brachial, Erster langer Kopf des Triceps, [Zweiter] abducirender vom Schultergerüst entstehender Kopf des Streckmuskels des Vorderarmes, Triceps Nr. I, Triceps longus). 


\section{The Muscles}

This muscle springs as a tendon from the hinder border of the scapula directly beneath the articular cavity, and extends back, between the scapulohumeralis profundus and the dorsalis scapulæ muscles, into the muscle belly.

(b) Caput coraco-scapulare (Plate I., Figs. 2, 4, 5, 6, acs) (Externum caput $\mathrm{m}$. tricipitis, Innerer langer Kopf des dreiköpfigen Streckers, Portion scapulaire interne du triceps-brachial, Zweiter langer Kopf des Triceps, [Erster] abducirender vom Schultergerüst entstehender Kopf des Streckmuskels des Vorderarmes, Triceps Nr. 2, Triceps longus secundus). Arises by two distinct tendinous tips-the upper, weaker one from the hinder border of the scapula, the lower, broader one from the hinder border of the coracoid.

(c) Caput IIumeri Laterale (Plate I., Figs. I and 4, ahl) (Brevius caput m. brachiei interni, [Aeusserer] kurzer Kopf des dreiköpfigen Streckers, Portion huméral externe du triceps brachial, Aeusserer vom Humerus ausgehender Kopf des Streckmuskels des Vorderarmes, Theil des Triceps Nr. 3. Triceps externum). Springs from the lateral part of the extensor surface of the humerus dorsal to the lateral process and the origins of the humeroradialis and brachialis superior.

(d) Caput IItmerale Posticum (Plate I., Fig. 4, ahp) (Longissimum caput $\mathrm{m}$. brachiei internum, Theil des inneren [kurzen] Kopfes des dreiköpfigen Streckers, Theil des Triceps Nr. 3, Theil des 
Triceps internus, Theil der Portion humérale interne du triceps brachial, [Mittler] vom Humerus ausgehender Kopf des Streckmuskels des Vorderarmes). Springs from the middle of the extensor surface of the humerus between the lateral and medial heads.

(e) Caput Humerale Mediale (Longius caput m. brachiei interni, Theil des [inneren] kurzen Kopfes des dreiköpfigen Streckers, Theil der Portion humérale interne du triceps brachial, [Innerer] vom Humerus ausgehender Kopf des Streckmuskels des Vorderarmes, Theil des Triceps Nr. 3, Theil des Triceps internus). This head originates on the medial part of the extensor surface of the upper arm at the end of the medial process where it is united with the scapulo-humeralis profundus muscle.

The muscle mass formed by the union of all the above heads goes over, as a broad and somewhat thick tendon, to become inserted on the proximal part of the ulna.

IIumero-radialis (Plate I., Figs. I and 4, hr) (Caput longum m. bicipitis, Eigener kurzer Beuger, [Zweiter] vom Oberarm ausgehender Beuger, Brachialis externus, Portion a of Brachiæus). A fairly large muscle on the outer side of the upper arm, lying between the brachialis inferior and caput humerale laterale muscles, with both of which it is, at the beginning, united. It originates with its deeper and chief mass from the outer 
surface of the humerus, just distal to the lateral process; while its superficial layer, especially the upper fibers, come directly from the deltoides scapularis inferior and therefore have their origin on the scapula. In the middle of the upper arm it becomes a slender round tendon that extends, through a tendinous loop, to the radius, on whose outer side, at the end of the proximal third, it is inserted.

\section{Muscles of the Forearm}

In mero-radialis Intermus (Radialis internus, Lange Vorwärtswender, Pronateur, Pronator teres, Pronator quadratus, Oberflächlich gelegener, langer runder Einwärtsdreher). This muscle arises from the condylus internus (C. ulnaris s. medialis) and attaches itself to the radius throughout almost its entire length. It is a fairly strong muscle.

Ulno-radialis (Carré pronateur, Pronator teres, Pronator quadratus, Muskel welcher dem Pronator quadratus entsprect). A strongly developed muscle. It springs from the upper part of the flexor surface of the ulna and is inscrted on the lower part of the flexor surface of the radius.

Humero-radialis Longus (Plate II., Figs. I and 2, I) (Supinator longus, Long supinateur, Lange Rückwärtswender, Supinator radii longus). Among the Crocodilia this and the following muscle are well developed. This one springs from the con- 
dylus externus humeri and is inserted on the outer side of the entire length of the radius.

II mmero-radialis Breris (Plate II., Fig. 4, d) (Supinator brevis, Kurze Rückwärtswender, Extensor carpi-radialis brevis [?]). Arises near the preceding from the external condyle of the humerus and is inserted at the upper end of the radius.

IIumero-carpi-radialis (Plate II., Fig. 2, a) (Aeusserer oder langer Speichenmuskel, Musculus quem parti superiori extensoris digitorum communis respondere videbat, Extensor carpi-radialis longus, Abductor pollicis longus). Towards the ulna, near the supinator longus muscle. It springs from the external condyle of the humerus, covers the supinator brevis muscle, and is inserted on the proximal end of the carpi-radialis.

IIumero-carpi-ulnaris (Plate II., Fig. 2, c) (Extensor carpi-ulnaris, Ulnaris externus). Originates on the external condyle of the humerus, is inserted on the proximal end of the os carpi-ulnare.

IIumero-metacarpalis III., IV., V. (Plate II., Fig. 2, b) (Extensor digitorum longus, Aeusserer Speichenmuskel or Speichenstrecker der Hand, Extenseur commun, Extensor radialis longus, Extensor digitorum communis). This muscle lies between the humero-carpi-radialis and the humerocarpi-ulnaris muscles. It springs from the condylus externus humeri and divides, on reaching the carpus, into three thin, flat tendons, which in part fuse with the carpo-phalangei muscle, and in 
part are inserted on the carpal bones of the third, fourth, and fifth fingers.

Carpo-phulangei (Plate II., Fig. 2, d). (Extensor digitorum brevis, Extenseurs courts, Gemcinschaftlicher Strecker der Hand, Extensor digitorum communis brevis). Springs from the carpal and, in part, from the metacarpal bones and is inserted on the terminal phalanges of the five fingers.

Ulno-carpi-radiulis (Ein dem Strecker und Abzieher des Daumens analoger Muskel, Extensor pollicis longus, Extensor carpi-radialis brevior[?]). Springs from the under half of the ulna, and is inserted on the os carpi-radiale.

Carpo-phalangeus I (Extensor pollicis brevi:). This is a small, thick muscle that originates on the distal part of the os carpi-radiale and is inserted on the phalanx of the thumb.

Humero-radialis Lateralis (Plate II., Fig. I, 6) (Flexor carpi-ulnaris, Innerer Ellenbogenmuskel, Ulnaris internus). A fairly strongly developed muscle. It springs from the internal condyle of the humerus, cxtends along the ulna, and is inscrted on the proximal part of the os carpi-ulnare, and the nearby pisiform bone.

Humcro-radialis Mcdialis (Plate II., Fig. I, 2) (Flexor carpi-radialis, Radialis internus). A strongly developed muscle. It springs from the internal condyle of the humerus, receives fibers from almost the entire length of the radius, and is inserted on the proximal end of the os carpi- 
radiale and with a thin tendon to the metacarpal bone of the thumb. Rüdinger was not able to find this muscle in Alligator cynocephalus.

Carpo-phalangei (Plate II., Fig. I, 4) (Flexor digitorum communis brevis, Oberflächlicher gemeinschaftlicher Fingerbeuger, Fléchisseur sublime, Flexores sublimis a profundo perforati, Lange Flexoren der Finger, Flexor digitorum communis sublimis s. brevis, Flexor digitorum sublimis). A small thick muscle. It springs from the ligamentum carpi-volare proprium and from the ulnar border of the distal end of the os carpi-radiale and is divided into eight muscle-bellies which pass over to the proximal ends of the first phalanges as thin tendons that are penetrated by those of the humero-ulno-phalangei muscle.

Itmmero-ulno-phalangei (Plate II., Figs. I and 2,5 ) (Flexor digitorum communis profundus, Flćchisseur profond, Tiefer gemeinschaftlicher Fingerbeuger, Flexor digitorum profundus, Flexor profundus). Arises with three heads. The first head takes its origin from the internal condyle of the humerus, runs between the humero-radialis lateralis muscles, and passes as a tendon over to the carpus where it unites with the other two heads of this muscle. The second, deep head comes from almost the entire length of the ulna. These two heads may be called the long heads. The third, short head springs from the proximal ends of the two large carpal bones of the first row, 
and becomes united radially with the thick flat tendon ending the first two heads. The common terminal tendon splits into four points which pass among the tendons of the carpo-phalangei muscle and are inserted on the terminal phalanges. From the terminal tendons of this muscle spring the lumbricales muscles.

Carpo-phalangeus (Plate II., Fig. I, \&) (Abductor pollicis). Springs from the os carpi-radiale; is inserted on the first phalanx of the thumb.

Carpo-metacarpalis I. (Plate II., Fig. I, 9) (Opponens pollicis). Originates from the os carpiradiale and is inserted on the radial side of the entire first metacarpus.

Metacarpo-phalangeus $I$. Originates from the base of the metacarpus of digit III.; is inserted on the ulnar side of the first phalanx of the thumb.

Pisiformi-phalangeus primus digiti $V$. (Plate II., Fig. I, 7) (Abductor digiti minimi, Abducteur du petit doigt, Abductor digiti quinti). Springs from the pisiform bone, and is inserted on the medial border of the first phalanx of the fifth finger.

Carpo-metacarpalis $V$. (Opponens digiti minimi, Opponens primus). Springs from the carpi-ulnare bone and is inserted on the metacarpal bone of the fifth digit.

Carpo-phalangeus primus digiti V. (Plate II., Fig. I, 3) (Flexor digiti minimi brevis, Opponens secundus). Arises from the ulnar border of the proximal part of the carpi-radiale bone and is 
inserted on the proximal end of the first phalanx of the fifth finger.

Metacarpo-phalangeus $I$. digiti $V$. (Adductor digiti minimi). Springs from the metacarpal bones of the second and third fingers and is inserted on the radial side of the first phalanx of the fifth finger.

\section{The Abdominal Muscles}

Obliquns Abdominis Extermus (Grand oblique, Aeusserer schiefer Bauchmuskel, Obliquus externus, Obliquus externus + internus + Serrati, Oblique descendens). Springs, with a flat prong, from the uncinate processes of the true ribs, thence it extends as a tendinous aponeurosis, near the lateral boundary of the ileo-costalis muscle, caudalward to the region of the twenty-third (crocodile) vertebra. From this fairly straight line of origin the muscle takes a sharply distoventral course and is inserted, at least in part, on the outer surface of the sternal part of the ribs of the tenth to sixteenth vertebræ, but does not reach the mid-ventral line. Under this chief part of the outer layer of the abdominal muscle lies a second, more band-like muscle mass which is also strong but of considerably less extent. It takes its origin from the outer surface of the middle third of the ribs. In the region of the twenticth vertebra it fuses with the upper layer, but inwardly reaches nearer the median line than the upper layer. 


\section{The Muscles}

Obliquus Abdominis Internus (Petit oblique, ()1)liquus internus, Subcostalis). Arises as a flat muscle layer first with a strong tendinous portion from the anterior dorsal border of the os pubis and from the there-located cartilaginous inscriptio tendinea of the rectus; second, by a dorsal portion, with a short tendon, from the anteromedial surface of the pubo-iliac articulation from the pubis and ilium equally; third, from the dorsal anterior ends of the last named bones. It is inserted somewhat mediad to the lateral border of the rectus ventralis muscle that covers it on the outside.

Transversus Abdominis (Transverse, Oblique Bauchmuskel, Innerer Bauchmuskel, Transversus ventralis). This muscle springs by short, flat, indistinct forks from the inner surface of the proximal ends of the dorsal ribs but does not reach the centra of the vertebræ because of the long, broad transverse processes. Caudally the origin passes dorsalward to the lateral border of the quadratus lumborum muscle between which and the ilcocostalis muscle it is attached to the end of the transverse process.

Rectus Abdominis (Gerader Bauchmuskel + pyramidenförmiger Muskel, Pyramidalis, Rectus abdominis + pyramidalis). This muscle consists, in the Crocodilia, of several very distinct parts:

I. The rectus ventralis, the chief part, arises as a fleshy tendon from the sternum and from the 


\section{4 The Alligator and Its Allies}

ventral part of the last rib that reaches the sternum, and extends with direct longitudinal fiber-bundles of equal mass over the ventral third of the body back to the pelvis. It is inserted as a fleshy tendon on the anterior border of the pubis and more laterally is united, together with the obliquus internus muscle, chiefly to the last abdominal ribs which arise as an ossification of the last strongly developed inscriptio tendinea. This muscle-band, which unites with that of the opposite side to form the linea alba, is divided metamerically by seven distinct inscriptiones tendinea. These inscriptiones are the above described abdominal ribs which consist of bony connective-tissue without a trace of cartilage cells. These so-called abdominal ribs, then, are not true ribs but are ossifications of the tendinous structures.

II. From the anterior border of the os pubis and the last strong inscription, also, to some extent, as a process of the preceding part, begins a new fleshy layer which, extending in diminishing size backward, is inserted by a strong tendon on the distoventral end of the ischium somewhat laterad to the symphysis. It is the muscle that is called by different authors the pyramidalis.

III. Rectus lateralis. About in the region of the twentieth vertebra, or at the level of the fifth inscription, a fleshy band-like muscle separates itself from the edge of the rectus muscle and the obliquus internus muscle and passes over to fuse with the ischio-coccygeus muscle. 
IV. Rectus internus. On the inner surface of the rectus ventralis, from which it is separaterl by the intervening aponeurosis of the rectus muscle, appears a muscle lying on the outside of the diaphragmatic muscle. It extends as a broad band from the breast to the anterior border of the os pubis, with longitudinally directed fibers, to half the width of the rectus ventralis muscle.

Intercostales (Zwischenrippenmuskeln). The intercostal muscles in the Crocodilia are, in proportion to the strength of the ribs, of slight structure; they extend only from rib to rib and are, therefore, very short, though fairly thick. They, as usual, consist of the outer muscles with a direction like that of the external oblique, and of an inner muscle extending in the opposite direction, i.e., at right angles. The internal muscles are especially well developed in the breast region and pass over into the internal oblique muscle.

Quadratus Lumborum (Carré des lombes, Vicreckiger Lendenmuskel, Psoas major). A strong, thick muscle that springs from the inner surface of the transverse processes and bodies of the last six presacral and the first sacral vertebræ. The muscle diminishes as it passes in a caudoventral direction and is inserted with a strong tendinous band to the trochanter femoris.

The Diaphragm (Diaphragmaticus, Zwerchfell, Bauchfellmuskel). Closely inclosed between the skin and muscle of the abdomen, in the Crocodilia, 


\section{6 The Alligator and Its Allies}

is a pair of muscles; they are, as a whole, thin muscles that are widely separated and extend in an antcropostcrior direction. Each arises by two parts which, however, are united at the pelvis. One of these parts is small at its beginning, is fairly thick, and is attached by a short tendon, immediatcly over the pubis in front of the hip joint, to the ilium. The other part is not a very thick layer, and is attached, by a fairly long line, partly on the inner surface of the hindermost abdominal rib and partly on the outer border of the pubis. After the union of these two portions the muscle extends farther forwards and the fibers of the stronger portion spread out like a fan, becoming wider and thinner as they go forward and are at last attached partly to the pericardium, partly to the lobes of the liver of that side of the body. To be more exact, the fibers of the diaphragmaticus that lie nearest the middle line of the belly-wall extend forward as a fairly broad band to fuse with the pericardium. Most of the fibers of this muscle, however, are in close connection with a fibrous membrane which surrounds the liver parenchyma; this membrane is mostly very thin but it gradually becomes thicker towards the hinder border of the liver. Other muscle bands do not reach so far as the liver but are located near the middle line of the back; they are all, however, attached to an aponeurosis which passes over the upper, hinder border of the liver lobes to fuse with the fibrous capsule of the liver. 
To the sternum as to the ribs is only a small part of this muscle attached.

Between the two above described muscles is found a space which is filled, in great part, with a fibrous membrane that binds the two muscles together. This membrane begins very thin and without a marked boundary behind the kidneys; it runs forward directly under them and the dorsal wall of the body, becoming gradually thicker, though never very thick, and fuses, laterad to the kidneys, with the above-mentioned aponeurosis of the two diaphragmaticus muscles. Thence this aponeurosis goes to the upper, hinder side of the liver where it becomes fairly thick. One thus finds in front of the stomach a fibrous membrane, belonging to the diaphragmaticus, which is pierced by the osophagus and by a fairly large space that extends around the osophagus and between it and the liver. This membrane fastens the liver to the œsophagus.

The muscle of the right side is covered, on almost its entire inner surface (from its hinder end to the liver) by the belly-like skin, and is fairly closely united with it. The left muscle, on the other hand, is only covered by this skin from the hinder border of the stomach forwards; farther forward it lies immediately on the under and left side of the stomach and is united with it by loose connective-tissue. Outwardly both muscles are united by a thin layer of connective-tissue to the true abdominal muscles. 
II 8 The Alligator and Its Allies

So far as yet known this muscle is not present in other reptiles.

\section{Muscles of the Posterior Appendages}

Ambicns (Plate III., Figs. I and 2, amb, Plate IV., Figs. 2 and 4, amb, Plate V., Figs. 2 and 3, amb) (Part I., Rectus femoris and Sartorius partim, Vastus internus, Innere Streckmuskelmasse) (Part II., Gracilis, Rectus femoris, Sartorius). Arises by a short tendon from the anterior spine of the ilium, near its union with the pubis. The muscle swells quickly to a thick belly which, lying under the skin on the forward and inner side of the upper thigh, is again reduced to a small, flat tendon which extends abruptly over the anteromedial surface of the knee joint to its outer side; it then passes through the complex of tendons of the femoro-tibialis muscle, beneath which it unites with the tendon of origin for the peroneus posterior muscle.

To this muscle is the following strange muscle to be ascribed (Part II) : it springs, small in extent, from the inner surface of the os pubis near the acetabulum, extends thence forward around the pubis, and runs into a long, thin tendon which unites with the insertion tendon of the subcutaneous extensor ilio-tibialis muscle.

Extensor Ilio-tibialis (Plate III., Fig. 2, ex. il. tb.) (Part I., Rectus femoris, Adductor flexor, Glutæus maximus; M. du facia lata, Vastus externus, 
Tensor facix latx, Tensor femoris vaginx, Glutacus minimus, Tensor faciæ femoris). This muscle, in the Crocodilia, consists of two parts:

I. The chief part is long and broad, and springs as a tendon from more than the anterior half of the lateral border of the dorsal crest of the ilium, covering the origin of the ilio-fibularis muscle. Its insertion, by a broad, flat tendon, overlying the femoro-tibialis muscle, together with the tendon of this muscle, is on the anterior surface of the head of the tibia.

II. The second, significantly smaller and narrower, part arises outside of the quadratus lumborum by a short tendon from the most dorsal end of the ilium; it goes over, medially, along the nearer head of the ambiens muscle, then to the anteromedial side of the upper $1 \mathrm{eg}$, into the decperlying femoro-tibialis muscle.

Femoro-tibialis (Plate III., Fig. I, fm. tb., Plate IV., Fig. 2, fm. tb., Plate V., Figs. I and 3, fm. tb.) (Cruræus et Vasti, Cruralis). Arises by an anterior inner and a posterior outer head; both heads arise from the outer-anterior and inner surfaces of the femur, and unite with each other and with the extensor ilio-tibialis and ambiens muscles as a strong tendon, which extends over the knee and is inserted on the anterior border of the head of the tibia; this tendon incloses, like a sheath, the end-tendon of the ambiens muscle.

Ilio-fibularis (Plate III., Fig. 2, il. fib., Plate IV., 
Fig. 2, il. fib., Plate V., Fig. 3, il. fib.) (Biceps cruris, Semitendinosus + Semimembranosus, Glutæus maximus, Abductor fibularis, Flexor abductor cruris). This consists, in the Crocodilia, of two entirely separate small, band-like muscles. The first springs by a short tendon from the lateral surface of the middle ilium, very near the origin of the caudali-ilio-femoralis and extensor ilio-tibialis muscles. The chief part of the end-tendon is inserted at the end of the first sixth of the fibula, on its outer-forward corncr near the origin of the peroneus anterior muscle; a shorter tendon-branch goes to the tendon of the peroneus posterior muscle; and a third, still smaller branch goes to the caput femorale of the gastrocnemius muscle, by which it contributes to the structure of the lateral part of the tendo-communis externus.

The second part springs, by an equally short tendon, very near the first, from the hinder end of the dorsal crest of the ilium, goes directly over the preceding to the knee, where its tendon unites with that of the extensor ilio-tibialis muscle.

Ilio-femoralis (Plate III., Fig. 2, il. fm., Plate IV., Fig. 2, il. fm., Plate V., Fig. I, il. f.) (Glutæus, Quadratus femoris [?], Glutæus medius). This muscle is inwardly fused with the caudali-iliofemoralis, whose anterior part it forms.

Caudali-ilio-femoralis (Plate III., Fig. 2, cd. il. fm., Plate IV., Fig. I, cd. il., fm.) (Zweiter Auswärtsroller, Extensor femoris caudalis accessorius, 
Glutæus minimus). This forms a thick mass that springs directly from the lateral surface of the anterior and middle parts of the ilium, is covered outsicle by the ilio-fibularis muscic, and, pushing between the two heads of the femoro-tibialis muscle, is inserted on the whole outer surface of the middle third of the femur.

Caudi-femoralis (Plate III., Figs. I and 2, cd. fm., Plate IV., Fig. I, cd. fm.) (Pyriformis, Pyriformis + Subcaudalis, Femoro-peroneo-coccygeus, Extensor femoris caudalis). This muscle in the Crocodilia consists of two parts:

I. The chicf part extends from the first postsacral (the twelfth) vertebra caudad; it springs from the roots of the caudal ribs (transverse processes) and the whole lateral surface of the vertebral arches. Since the first postsacral vertebra has no ventral process, the muscles of the opposite sides fuse in the mid-line. Towards the caudal region it gradually increases in strength. Its fibers converge in a lateroventral direction to form a short, thick tendon which attaches itself to the inner surface of the femur mediad and somewhat below the trochanter. At right angles from this tendon extends a round, long tendon which, lying parallel to the hinder side of the thigh, pushes in between the chief parts of the ischiadicus and later between the origin-tendon of the gastrocnemius and peroneus posterior muscles, and is inserted on the posterior surface of the head of the fibula. 
II. This is a more anterior and inner muscle, small in size, which has a fleshy origin from the bodies and ribs (transverse processes) of the second sacral and first caudal vertebræ at a distance from the posteromedian border of the ischium. It extends caudad, lying near the hinder part of the pubi-ischio-femoralis externus, and is inserted on the trochanter.

Flexor Tibialis Extormus (Plate III., Figs. I, 2, 3, fl. tb. ext. or f. t. ext., Plate IV., Fig. 4, fl. tb. ext., Plate V., Figs. I and 3, fl. tb. ext. and f. t. ext.) (Triceps flexor cruris partim, Biceps). A strong, spindle-shaped muscle that arises, together with the ilio-fibularis, by a short tendon, from the side of the portio dorsalis of the ilium, and in the neighborhood of the bend of the knee is split into two tendons, of which the short one is inserted on the fibular side of the neck of the tibia, while the other, running along near the caput femoris of the gastrocnemius muscle, unites with the tendon of the caput tibix of the gastrocnemius muscle just beyond the ankle joint.

Flcxor Tibialis Intermus (Plate III., Figs. I, 2, 3, fl. tb. int., or f.t. int., Plate IV., Fig. 4, fl. tb. int., Plate V., Fig. I, fl. tb. int.) (Demi-nerveux + Demi-mombraneux, Triceps flexor cruris partim, Gracilis, Adductor flexor tibialis, Semimembranosus, Semitendinosus + Gracilis partim, Gracilis + Semimembranosus + Semitendinosus). A threeheaded muscle whose heads arise separately and 
first unite in the region of the lower $\operatorname{leg}$ as a short, strong tendon. Their origins are as follows: (I) As a band from the anterior margin of the ischium, pushing between the ischio-femoralis and the pubi-ischio-femoralis externus muscles; (2) From the posterior margin of the ischium as a narrow, tendinous band near the insertion of the ischio-caudalis muscle; (3) from the portio-dorsalis posterior of the ilium, ventralward, near the origin of the flexor tibialis externus muscle.

Ischio-femoralis (Plate III., Fig. I, is. f.) (Adductores, Adductor longus, Adductor primus). Springs directly (without tendon) from the entire anterior border of the ischium. It is band-like and, running over the tendon of the pubo-femoralis internus and externus muscle, is inserted as a broad, fleshy tendon on the middle third of the inner, posterior surface of the femur.

Pubi-ischio-femoralis Extermus (Plate III., Fig. I, p. is. f. int., Plate IV., Fig. I, p. is. f. int.) (as a whole: Quatuor pectinei [partim]; in parts: I. Marsupialis externus, Obturator externus; II. Quadratus femoris). This muscle arises in two parts. The anterior part is broad and comes from the entire ventral and inwardly turned outer surface of the pubis. Its insertion is on the femur in conjunction with the first part of the pubi-ischiofemoralis internus. The second part is shorter but thicker than the first and springs from almost all of the outer surface of the ischium that is not cov- 


\section{I24 The Alligator and Its Allies}

ered by the origins of the ischio-femoralis, pubiischio-tibialis, and flexor tibialis internus muscles. It is inserted, by a strong, short tendon, on the trochanter, somewhat caudad to the insertion of the pubi-ischio-femoralis internus.

Pubi-ischio-femoralis Intermus (Plate III., Fig. I, p. is. f. int., Plate IV., Figs. I and 2, p. is. f. int.) (as a whole: Iliacus internus +Quatuor pectinei [partim]; in parts: I. and II.: Kamm-Muskeln, Pectineus inferior [I.] +superior [II.], Marsupialis internus, Obturator internus; III., Iliacus [Darmbeinmuskel], Iliacus internus). This muscle arises by two or three parts: I. The anterior arises, without tendon, from the greater part of the inner and anteriorly directed surface of the pubis; median to this, in the alligator, is a small bundle, II., which unites with part I. These unite with the pubi-ischio-femoralis externus to form a strong tendon that is inserted on the trochanter.

III. This is a larger muscle that springs without tendon from the inner surface of the body and transverse processes of the twenty-fifth and twentysixth (in alligator) vertebra, from the part of the ilium that lies between these transverse processes and the ischium, and from a small part of the ischium. It is inserted on the whole inner surface of the proximal third of the femur.

Pubi-ischio-femoralis Posterior (Plate III., Fig. I, p. is. f. post., Plate IV., Figs. I and 4, p. is. f. 
post. and pb. is. f. m. post.) (Adductus [partim], Gemellus, Obturator internus). Springs without tendon from the whole caudally directed border of the ischium. It is inserted, by a short tendon, near and laterad to the tendon of the ischio-fenoralis muscle, on the hinder surface of the upper leg. Extensor Longus Digitorum (Plate V., Figs. 2 and 3, ext. 1. [long.] dig.) (Long extenseur commun, Gemeinschaftlicher Fussheber oder Beuger, Extcnsor communis digitorum). Springs, together with the tibialis anticus, from the external condyle of the femur, goes with this muscle under the ligamentum tibio-fibulare and after union with this divides into four short tendons. Three of these tendons are inserted on the fibular side of the bascs of the first three metatarsal bones; the fourth goes over into the muscle of the third toe.

Tibialis Anticus (Plate III., Fig. I, tib. ant., Plate IV., Fig. 4, tib. ant., Plate V., Figs. 2 and 3 , tib. ant.) (Jambier antéricur, Vorderer Schienbeinmuskel). Springs by a fleshy tendon from the anterior surface of the head and neck of the tibia and quickly unites with the following muscle.

Peroneus Anterior (Plate V., Figs. 2 and 3, peron. ant.) (Peroneus longus). In the alligator. Its origin: it extends from the insertion of the iliofibularis muscle distalwards by the whole outer surface of the fibula, under the skin and over the ligamentum tibio-fibulare, and gives off a broad, tendinous portion to help strengthen the tendon 


\section{I26 The Alligator and Its Allies}

Achilles, which portion may be followed to the rudiment of the fifth toe. On the outer side of this toe rudiment is attached a tendon from the tibial border of the muscle.

In the crocodile. This muscle is here divided into two parts, of which the one that springs from the anterior surface of the fibula is inserted on the toe rudiment, while the greater and outward part extends over the calcaneum bone and has the same distribution as in the alligator.

Peroneus Posterior (Plate IV., Figs. 3 and 4, peron. post., Plate V., Figs. 2 and 3, peron. post.) (Plantaris). Springs chiefly from the tendon of the ambicns muscle running over the knee and forms the direct continuation of this muscle. Besides this come tendinous fibers from the insertion tendons of the femoro-tibialis and extensor iliotibialis muscles; and finally supporting fibers from the outer, end-tendon of the ilio-fibularis muscle. The fibers of this muscle pass partly into the fibular portion of the caput femoralis of the gastrocnemius, while the chicf mass of the muscle is inserted on the posterior surface of the calcaneum.

Gastrocnemius (Plate III., Figs. I and 3, cap. int. gastr., Plate IV., Fig. 4, cap. int. gastr. and cap. ext. gastr., Plate V., Figs. 2 and 3, cap. ext. gastr. and cap. int. gastr.) (Solenmuskel, Outer head of gastrocnemius). This is the strongest superficial flexor muscle on the posterior surface of the lower leg; it consists of two heads: I. 
The caput femorale (externum) originates by a strong, short tendon from the lateral and posterior surface of the external condyle of the femur. This head has a double inscrtion: (I) from the outer, fibular border of the muscle separates off a tendon that spreads out in the first layer of the plantar tendon-muscle; (2) the chief part of caput I. becomes a broad, flat, subcutaneous tendon which is covered by the tendon Achilles and serves as the origin of the short flexors of the toes.

II. The caput tibiale (internum) springs without a tendon from the posterior surface of the head and the proximal third of the tibia. The broad and somewhat flat muscle has two insertions: (I) on the plantar and medial border of the first basis metatarsi; (2) the chicf insertion on the outer border of the rudimentary fifth toe, after forming, with the tendon of the flexor tibialis externus, the tendon Achilles.

Flexor Longus Digitorum (Plate IV., Fig. 4) (Langer durchbohrender gemeinschaftlicher Zehenbeuger). A many-headed muscle visible on the posterior side of the lower leg after removal of the preceding muscle. (a) Caput externum: a flat, fairly broad muscle which springs from the outer and posterior surface of the fibula. Arriving at the astragalo-scaphoid bone, it forms a very strong tendon which unites with the still stronger tendon of the other head and both together form the broad initial tendon of the flexor digitorum communis brevis 
muscle. (b) Caput internum: this springs without a tendon from the whole posterior surface of the upper half of the tibia, sometimes, as in crocodiles, uniting with the caput femoralis of the gastrocnemius muscle. The common tendon splits into three points for the first, second, and third toes.

Tibialis Posticus (Plate V., Fig. 2, tib. post.) (Jambier postérieur, Hinterer Schienbeinmuskel). Originates without tendon from the whole fibular side of the tibia, on the one hand, and from the whole inner and forward side of the fibula on the other hand, occupying the whole space between these two bones on the hinder side of the lower leg. At its proximal end it is united with the caput internum of the preceding muscle which completely covers it from behind. It narrows down to a very strong tendon which divides into two equally strong, round tendons; of these the one on the tibial side is inserted on the basis ossis of the first metacarpal, the one towards the fibula goes immediately to the second metacarpal.

Interosseus Cruris (Knichehlmuskel). A small muscle stretching between the distal ends of the fibula and tibia with almost transverse fibers; it is covered dorsally by the tibio-fibulare ligament and appears as a distal division of the tibialis posticus muscle.

Flexor Digitorum Brevis (Flexor longus accessorius, Flexor brevis perforatus). Springs from the bones of the foot and from the strong tendon of the 
flexor digitorum longus muscle. It divides into three bellies for the second, third and fourth toes. The first two are pierced by the above-mentioned tendon of the flexor digitorum longus and are inserted on the next to last phalanx of the second and third toes; the third, on the contrary, is inserted on the claw joint of the fourth toe and is not perforated; there is no tendon to the fourth toe from the flexor digitorum longus muscle.

Extensor IIallucis Proprius (Plate V., Fig. 3) (Kurzer gemeinschaftlicher Zehenstrecker, Extensor hallucis). This muscle springs by a short, flat, fairly strong tendon from the outer dorsal border of the distal half of the fibula. It is inserted: (I) on the proximal half of the first metatarsal bone, (2) a second much weaker part is united with the tendon of insertion of the tibialis anticus extensor longus digitorum to the first metatarsal bone.

\section{The Tail Muscles}

The muscles of the tail have, as shown by Gadow, the character of the primitive body muscles, with their primitive metameric division, fairly plainly preserved. This musculature is arranged in four rows of trumpet-shaped cones, one projecting into the other, by which arrangement each metamere exhibits a transverse zigzag line of four anteriorly and three posteriorly directed points. 
I30 The Alligator and Its Allies

Ilio-ischio-candalis (Plate III., Figs. I and 2, is. cd., Plate IV., Figs. I and 2, is. cd.) (Ischiococcygeus). The crocodile is the nearest to the typical condition in the musculature of the tail. The lateral and ventral part of the tail musculature forms a broad mass that extends to the end of the tail; it lies immediately under the skin and springs from the caudal ribs (transverse processes - Gadow) and from the spinous processes of all the caudal vertebræ. The entire side musculature of the tail ends cephalad in several portions; the most ventral and medial of these bound the cloaca as an at least slightly developed, morphological sphincter; the lateral portion is attached to the posteroventral border of the ischium; while the dorsal portion is inserted by two heads on the first caudal rib and on the posterior spine of the ilium. 


\section{.I $3 T / .39$}

"s; (.)

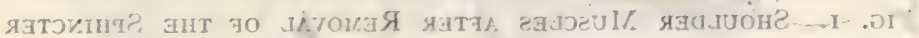

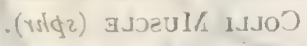

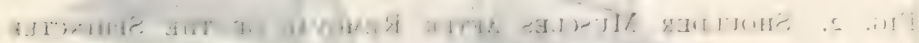
$13090,11 \%: 3.1 \% ?$

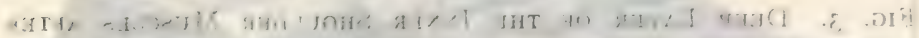

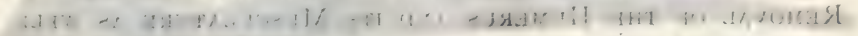

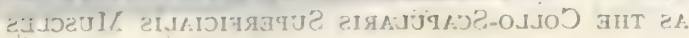

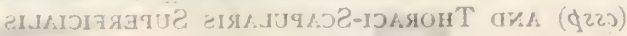

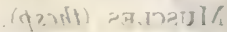

-1

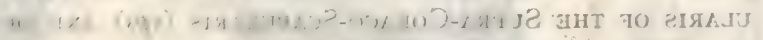

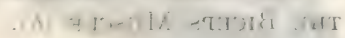

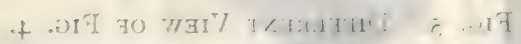

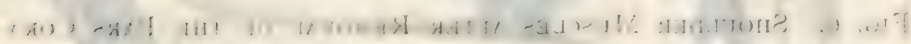

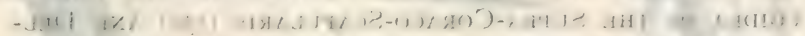

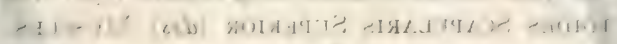

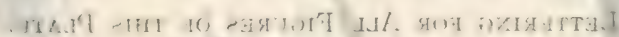

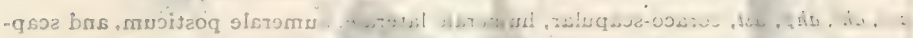

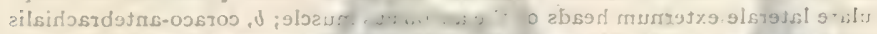

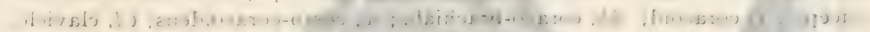

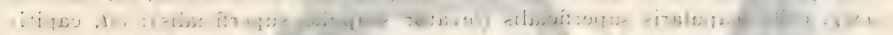

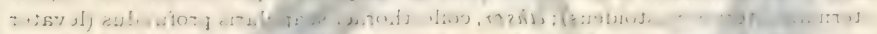

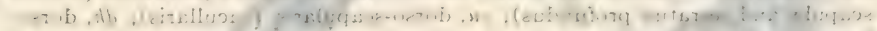

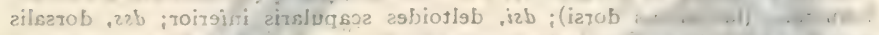

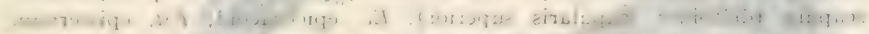

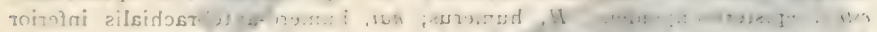

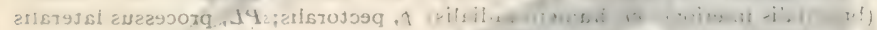

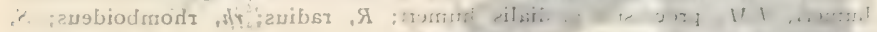

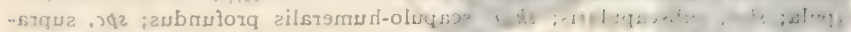

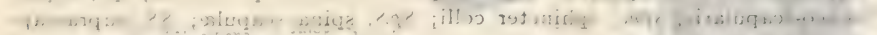

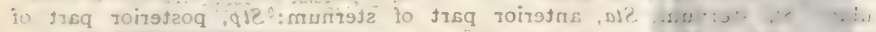

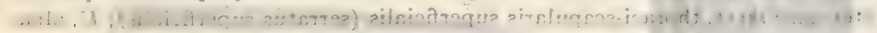
.

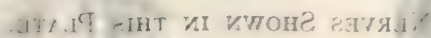

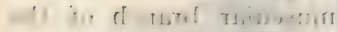
II? : : : : Aic

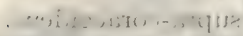

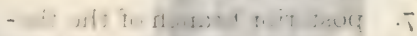

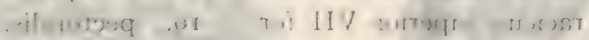

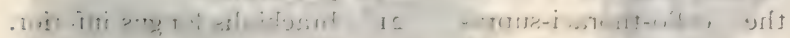

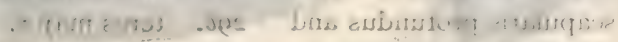

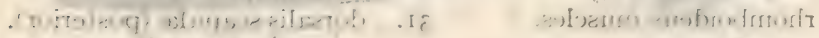

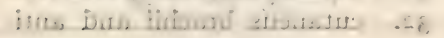
.2ilmofal zoingqua iinond

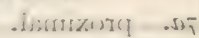
.eilsibgr-oromunt . .) bras ¿s) , Toirotri 29 biotlob . brs iidostd zmonstus , (st

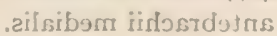

Toiroqua amonostorlf Igtaib . di .IIV

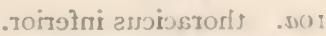
.5sobiojmoj-stqua .. $\mathrm{I}$

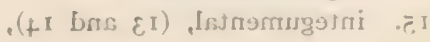


Plite I.

Shoulder Muscles of Crocodilus Acutus. (From Bronn after Fürbringer.)

Fig. $x$. Shoulder Muscles after Removal of the Sphincter Colli Muscle (sphr).

Fig. 2. Shoulder Muscles after Removal of the Sphincter Colli Muscle (sphc).

Fig. 3. Deep Layer of the Inner Shoulder Muscles after Rejoval of The Humerus and its MUSCUlature as Well as the Collo-Scapularis Superficialis Muscles (cssp) ANd ThORACI-Scapularis Superficialis Muscles (thcsp).

Fig. 4. Shoulder Muscles after Removal of the Pars ScapULARIS OF THE SUPRA-CORACO-SCAPUlARIS (sps) AND OF THE Biceps Muscle $(b)$.

Fig. 5. Different View OF Fig. 4.

Fig. 6. Shoulder Muscles after Removal of the Pars CoraCOIDEA OF THE Supra-Coraco-Scapularis $(s p c)$ and Deltoides Scapularis Superior (dss) Muscles.

Lettering for All Figures of this Plate.

$a c s, a h l, a h p, a s l$, coraco-scapular, humerale laterale, humerale posticum, and scapulare laterale externum heads of the anconæus muscle; $b$, coraco-antebrachialis (biceps); $c$, coracoid; $c b b$, coraco-brachialis; $c c$, costo-coracoideus; $\mathrm{Cl}$, clavicle; cssp, collo-scapularis superficialis (levator scapulæ superficialis): cst, capitisternalis (sterno-mastoideus); cthspr, collo-thoraci-scapularis profundus (levator scapulæ and serratus profundus); $c u$, dorso-scapularis (cucullaris); $d h$, dorsohumeralis (latissimus dorsi); $d s i$, deltoides scapularis inferior; $d s s$, dorsalis scapulæ (deltoides scapularis superior); $E_{c}$, epicoracoid; Est, episternum; esthy, episterno-hyoideus; $H$, humerus; hai, humero-antebrachialis inferior (brachialis inferior); $h r$, humero-radialis; $p$, pectoralis; $P L$, processus lateralis humeri; $P M$, processus medialis humeri; $R$, radius; $r h$, rhomboideus; $S$, scapula; $s b s c$, subscapularis; $s h p r$, scapulo-humeralis profundus; $s p c$, supracolaco-scapularis; sphc, sphincter colli; $S p S$, spina scapulæ; $S S$, suprascapulare; St, sternum; Sta, anterior part of sternum: Stp, posterior part of sternum: thssp, thoraci-scapularis superficialis (serratus superficialis); $U$, ulna: $V_{5}, V_{6}, 5$ th and 6 th vertebræ.

\section{Nerves Shown in this Plate.}

3a. thoracicus VII.

7. posterior branch of the thoracicus superior VII for the collo-thoraci-suprascapularis profundus and rhomboideus muscles.

7a. proximal.

$7 b$. distal thoracicus superior VII.

yoa. thoracicus inferior.

12. supra-coracoideus.

muscular branch of the supra-coracoideus.

19. pectoralis.

21. brachialis longus inferior.

29b. teres major.

31. dorsalis scapulæ (posterior).

32. cutaneus brachii and antibrachii superior lateralis.

32a. humero-radialis.

33. deltoides inferior, (25 and 42), cutaneus brachii and antebrachii medialis. 


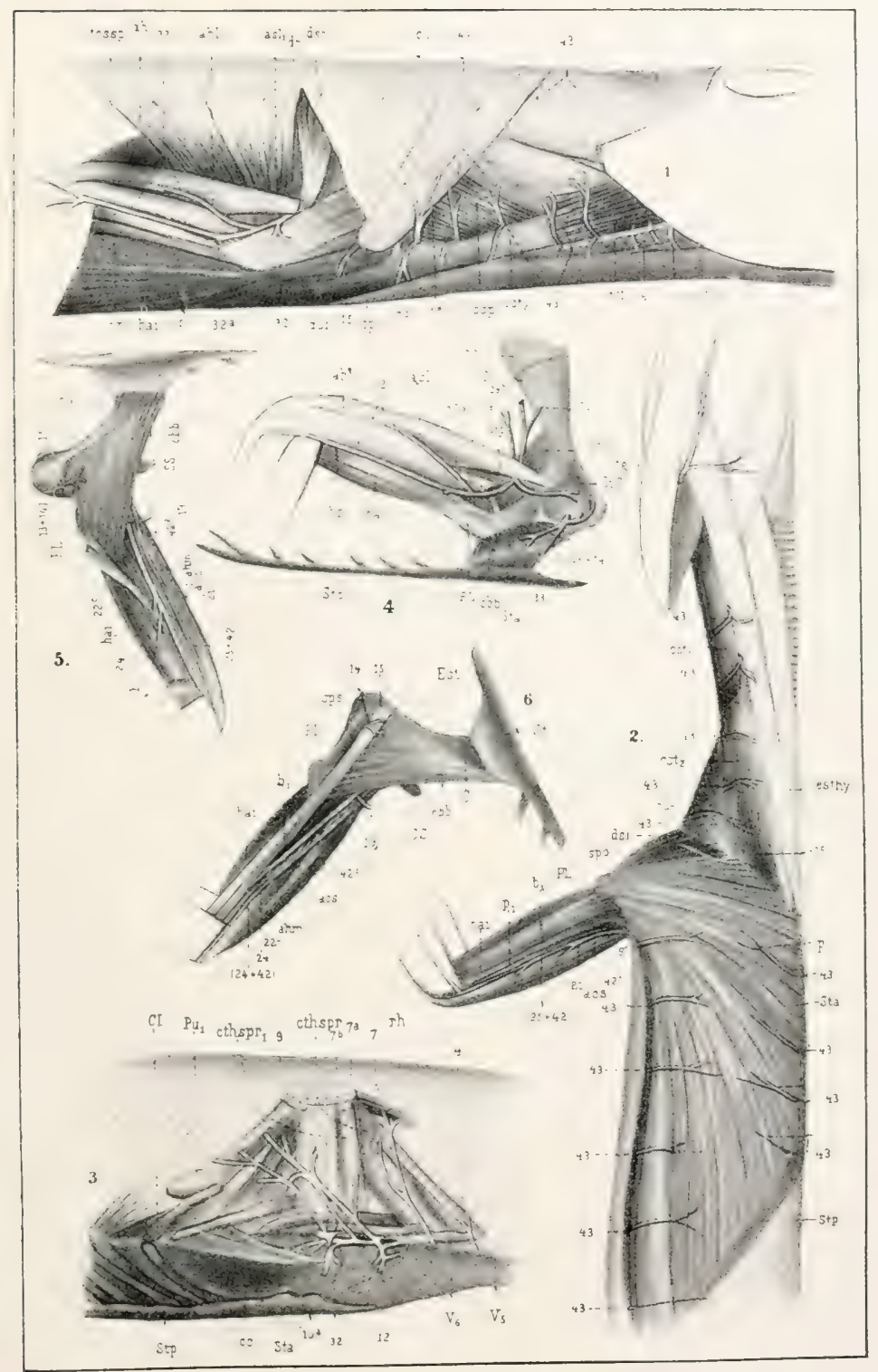





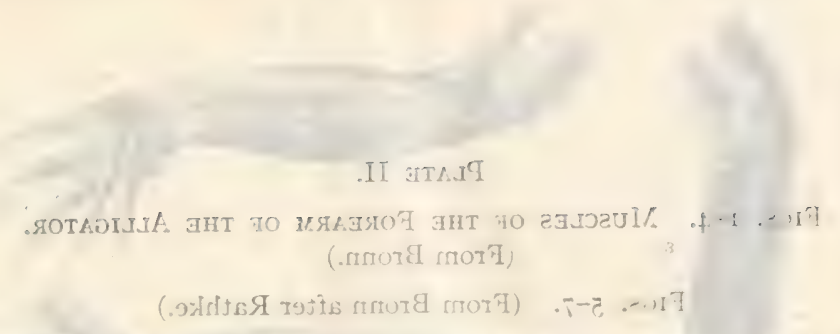

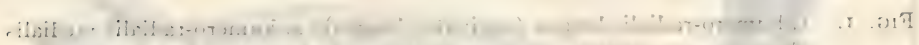

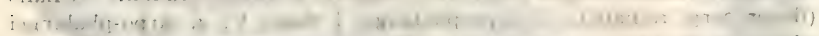

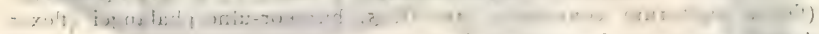

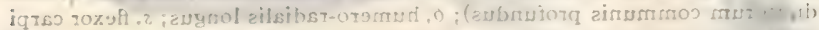

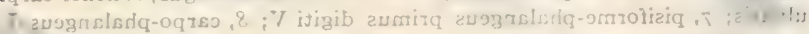

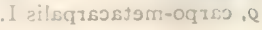

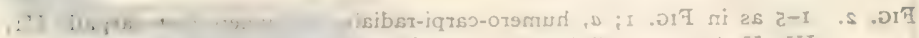

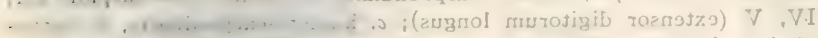

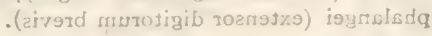

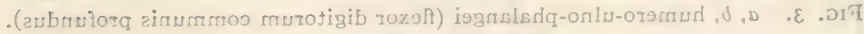

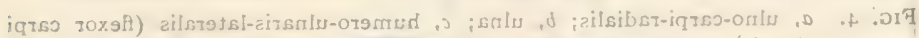

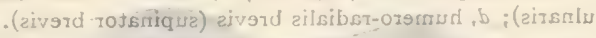

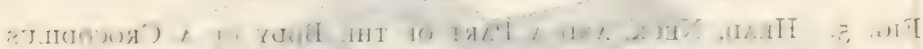

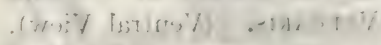

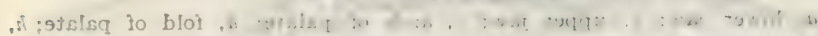

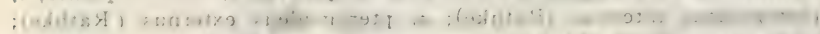

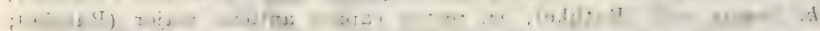

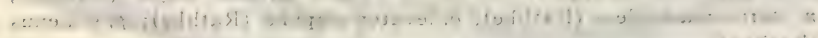

19.

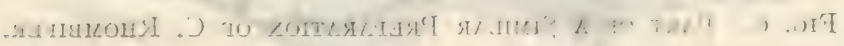
. : : :

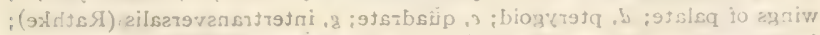

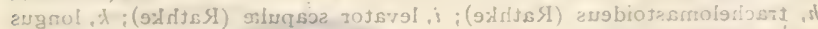

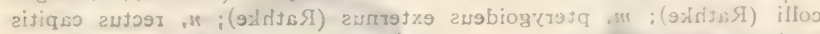

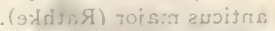

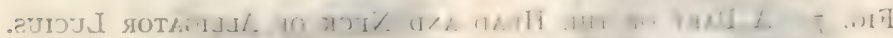

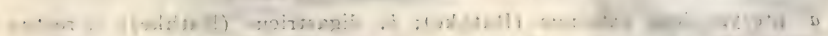

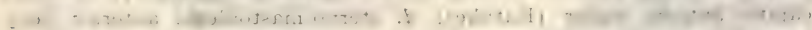

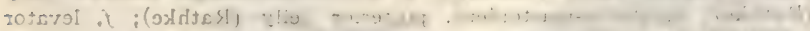

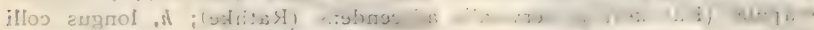

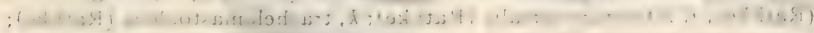

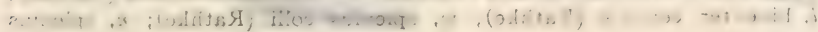

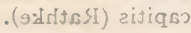




\section{Plate II.}

\section{Figs. I-4. Muscles of the Foreari of the Alligator. (From Bronn.)

\author{
Figs. 5-7. (From Bronn after Rathke.)
}

FIG. I. I, humero-radialis longus (supinator longus); 2 , humero-radialis medialis (flexor carpi radialis); 3, carpo-phalangei I digiti V; 4, carpo-phalangei (flexor digitorum communis brevis); 5, humeor-ulno-phalangei (flexor digitorum communis profundus); 6 , humero-radialis longus; s. flexor carpi ulnaris; 7 , pisiforme-phalangeus primus digiti $V ; 8$, carpo-phalangeus $I$; Q, carpo-metacarpalis I.

FIG. 2. I-5 as in FIG. I; $a$, humero-carpi-radialis; $b$, humero-metacarpalis III, IV, $\mathrm{V}$ (extensor digitorum longus); $c$, humero-carpi-ulnaris; $d$, carpophalangei (extensor digitorum brevis).

Fig. 3. $a, b$, humero-ulno-phalangei (flexor digitorum communis profundus).

FIG. 4. $a$, ulno-carpi-radialis; $b$, ulna; $c$, humero-ulnaris-lateralis (flexor carpi ulnaris); $d$, humero-radialis brevis (supinator brevis).

Fig. 5. Head, Neck, and a Part of the Body of a Crocodilus Vulgaris. (Ventral View).

$a$, lower jaw; $b$, upper jaw; $c$, arch of palate; $d$, fold of palate; $h$, pterygoideus internus (Rathke); $i$, pterygoideus externus (Rathke); $k$, longus colli (Rathke); $m$, rectus capitis anticus major (Rathke); $n$, sterno-mastoideus (Rathke); o, levator scapulæ (Rathke); $p$, scalenus (Rathke).

Fig. 6. Part of a Similar Preparation of C. Rhombifer.

$a$, the hindermost of the superior maxillary teeth; $b$, lower jaw; $c$, wings of palate; $d$, pterygoid; $\ell$, quadrate; $g$, intertransversalis (Rathke); $h$, trachelomastoideus (Rathke); $i$, levator scapulæ (Rathke); $k$, longus colli (Rathke); m, pterygoideus externus (Rathke); $n$, rectus capitis anticus major (Rathke).

Fig. 7. A Part of the Head and Neck of Alligator lucius. $a$, pterygoideus externus (Rathke); b, digastricus (Rathke); $c$, rectus capitis anticus major (Rathke); $d$, sterno-mastoideus, anterior belly (Rathke); e, sterno-mastoideus, posterior belly (Rathke); f, levator scapulæ (Rathke); $g$, cervicalis adscendens (Rathke); $h$, longus colli (Rathke); $i$, intertransversalis (Rathke); $k$, trachelomastoideus (Rathke); $l$, biventer cervicis (Rathke); $n$, splenius colli (Rathke); $n$, splenius capitis (Rathke). 


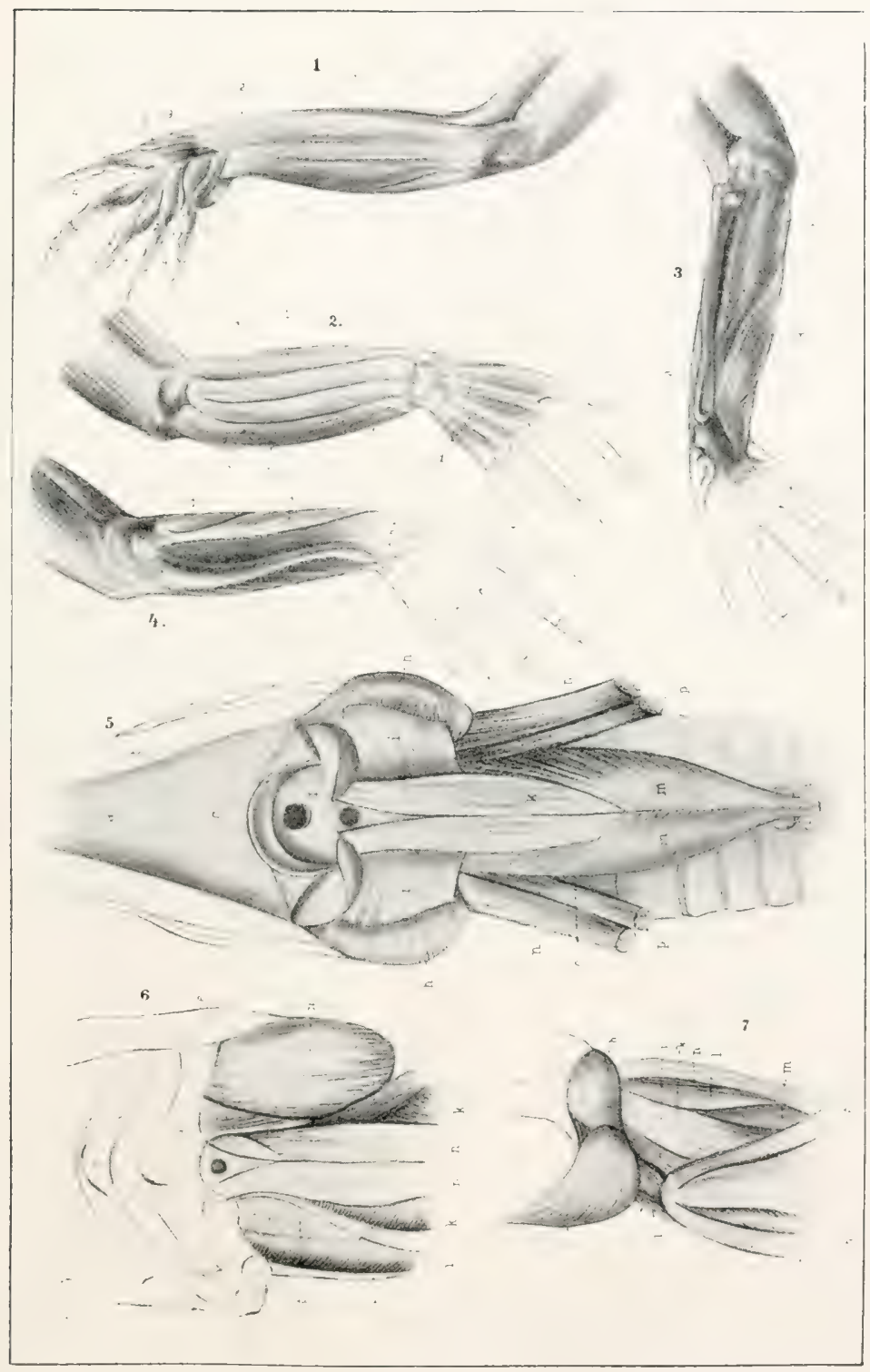





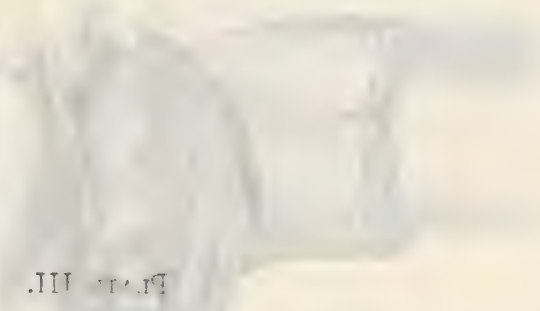

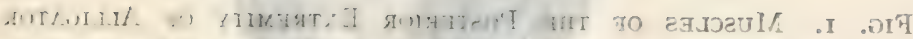

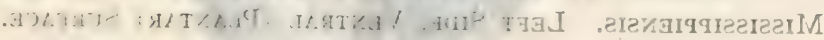

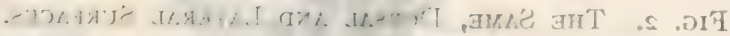

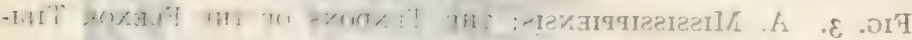

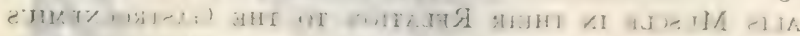

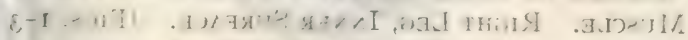

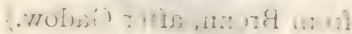

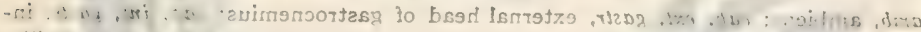

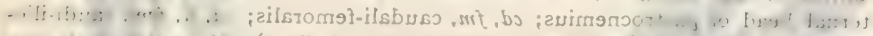

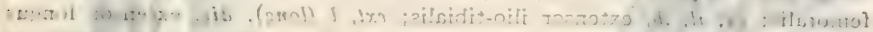

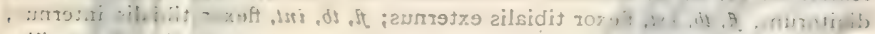

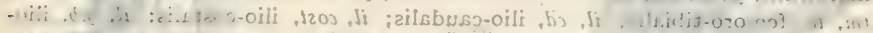

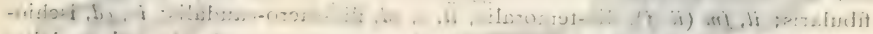

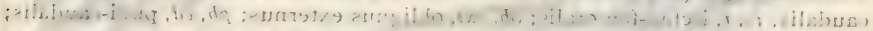

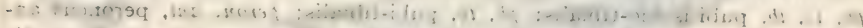

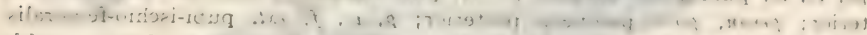

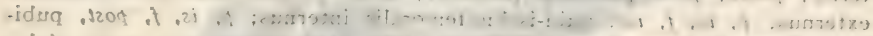

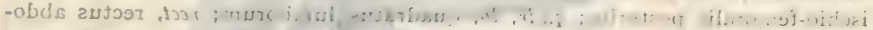

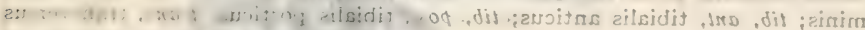

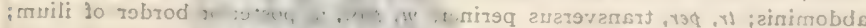

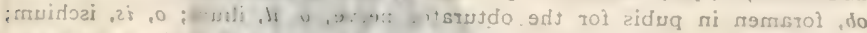

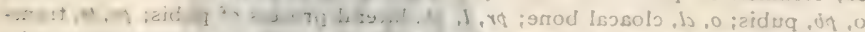

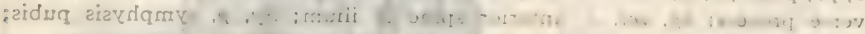

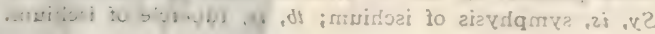




\title{
Plate III.
}

Fig. 1. Muscles of the Posterior Extremity of Alligator Mississippiensis. Left Side, Ventral (Plantar) Surface.

\author{
Fig. 2. The Same, Dorsal and Lateral Surfaces.
}

Fig. 3. A. Mississippiensis; the Tendons of the Flexor Tibialis Muscle in their Relation to the Gastrocnemius Muscle. Right Leg, InNer Surface. (Figs. I-3 from Bronn, after Gadow.)

$a m b$, ambiens; $c a p$, ext, gastr, external head of gastrocnemius; cap, int, gastr, internal head of gastrocnemius; $c d, f m$, caudali-femoralis; $c d, i l, f e m$, caudi-iliofemoralis; $e x, i l, t b$, extensor ilio-tibialis; $e x t, l$ (long), dig, extensor longus digitorum; $f, t b, e x t$, flexor tibialis externus; $f, t b$, $i n t$, flexor tibialis internus; $f m, t b$, femoro-tibialis; $i l, c d$, ilio-caudalis; $i l$, cost, ilio-costalis; $i l, f b$, iliofibularis; $i l, f m(i l, f)$, ilio-femoralis; $i l, s, c d$, ilio-sacro-caudalis; $i s, c d$, ischiocaudalis; is, $f$, ischio-femoralis; $o b$, ext, obliquus externus; $p b, c d$, pubi-caudalis; $p b, i s, t b$, pubi-ischio-tibialis; $p b, t b$, pubi-tibialis; peron, ant, peroneus anterior; peron, post, peroneus posterior; $p$, is, $f$, ext. pubi-ischio-femoralis externus; $p$, is, $f$, int, pubi-ischio-femoralis internus; $p$, is, $f$, post, pubiischio-femoralis posterior; $q u d r, l b$, quadratus lumborum; rect, rectus abdominis; $t i b, a n t$, tibialis anticus; $t i b$, post, tibialis posticus; trans, transversus abdominis; $t r$, per, transversus perinei; $m$, post, $i l$, posterior border of ilium; $o b$, foramen in pubis for the obturator nerve; $o$, il, ilium; $o$, is, ischium; $o, p b$, pubis; $o, c l$, cloacal bone; $p r, l$, pb, lateral process of pubis; $p r, t r$, transverse process; $s p$, ant, $i l$, anterior spine of ilium; $S y, p$, symphysis pubis; $S y$, is, symphysis of ischium; $t b, i s$, tubercle of ischium. 


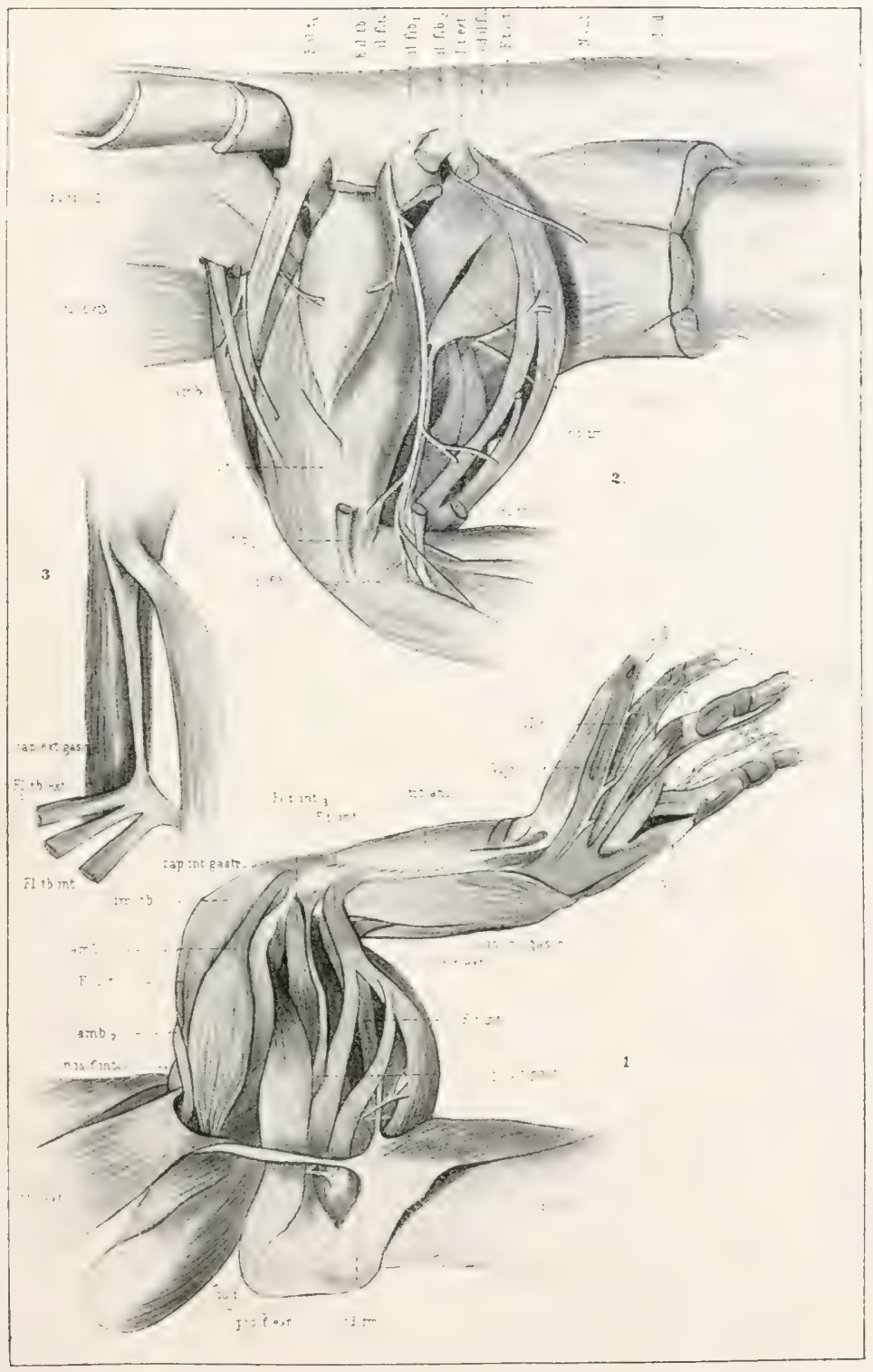





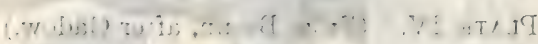

anr an Yol

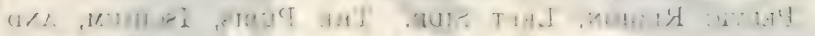

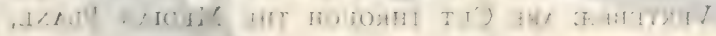

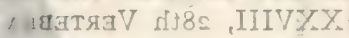

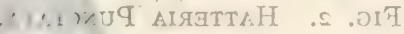

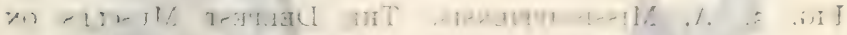

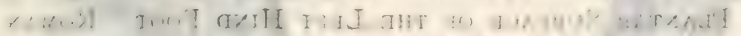

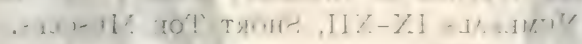

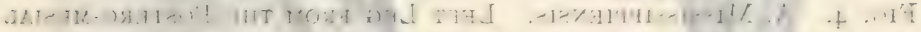

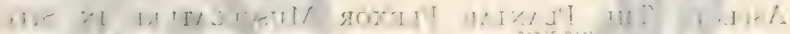

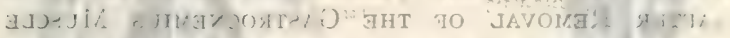

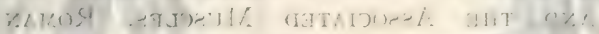

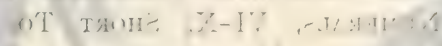
$-3.17-1 \%$

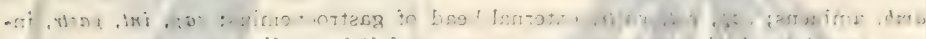

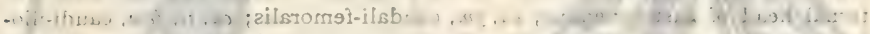
.

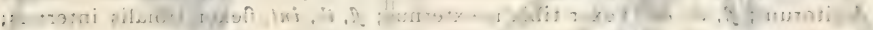

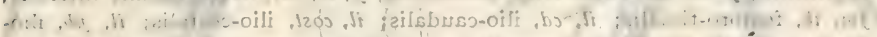

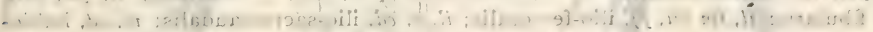

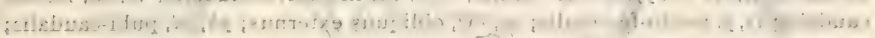

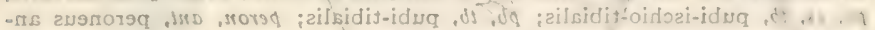

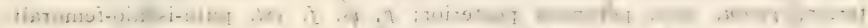

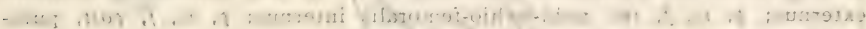

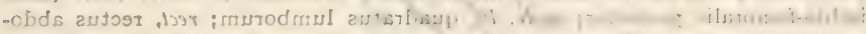

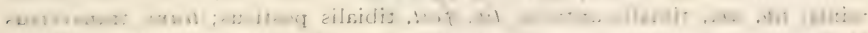

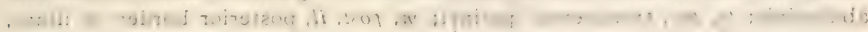

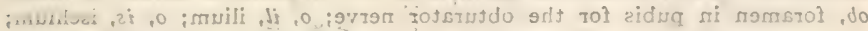

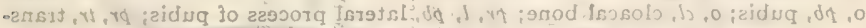

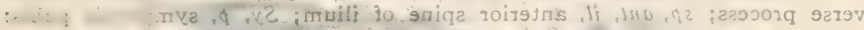

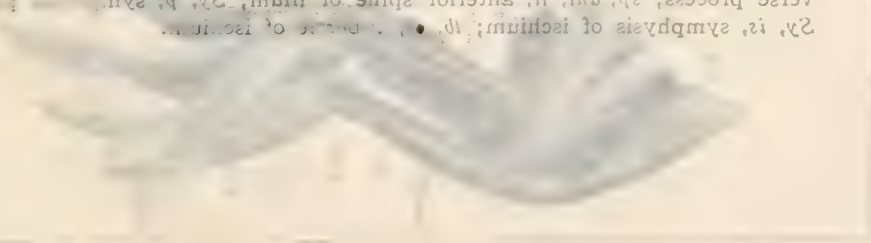


Plate IV. (From Bronn, after Gadow.)

Fig. I. Alligator Mississippiensis. Inner Surface of the Pelvic Region, Left Side. The Pubis, Ischium, And

Vertebre are Cut through the Median Plane, XXVIII, 28th VERTEBRA.

Fig. 2. Hatteria Punctata.

Fig. 3. A. Mississippiensis. The Deepest Muscles on the Plantar Surface of the Left Hind Foot. Roman Numerals IX-XiI, Short Toe Muscles.

Fig. 4. A. Mississippiensis. Left Leg from the Postero-mesial Aspect. The Plantar Flexor Musculature in Situ, after Removal of the Gastrocnemius Muscle and the Associated Muscles. Roman Numerals, VI-X, Short Toe Muscles.

$a m b$, ambiens; $c a p, e x t, g a s t r$, external head of gastrocnemius; cap, int, gastr, internal head of gastrocnemius; $c d, f m$, caudali-femoralis; $c d, i l$, fem, caudi-iliofemoralis; $e x, i l, t b$, extensor ilio-tibialis; ext, $l$ (long), dig, extensor longus digitorum; $f, t b, e x t$, flexor tibialis externus; $f, t b$, int, flexor tibialis internus; $f m, t b$, femoro-tibialis; $i l, c d$, ilio-caudalis; $i l$, cost, ilio-costalis; $i l, f i b$, iliofibularis; $\bar{i} l, f m(i l, f)$, ilio-femoralis; $i l, s, c d$, ilio-sacro-caudalis; is, $c d$, ischiocaudalis; $i s, f$, ischio-femoralis; $o b, e x t$, obliquus externus; $p b, c d$, pubi-caudalis; $p b, i s, t b$, pubi-ischio-tibialis; $p b, t b$, pubi-tibialis; peron, ant, peroneus anterior; peron, post, | peroneus posterior; $p$, is, $f$, ext. pubi-ischio-femoralis externus; $p, i s, f$, int, pubi-ischio-femoralis internus; $p$, is, $f$, post, pubiischio-femoralis posterior; $q u d r, l b$, quadratus Iumborum; rect, rectus abdominis; $t i b$, ant, tibialis anticus; $t i b$, post, tibialis posticus; trans, transversus abdominis; $i r$, per, transversus perinei; $m$, post, $i l$, posterior border of ilium; $o b$, foramen in pubis for the obturator nerve; $o$, il, ilium; $o$, is, ischium; $0, p b$, pubis; $o, c l$, cloacal bone; $p r, l, p b$, lateral process of pubis; $p r, t r$, transverse process; $s p, a n t, i l$, anterior spine of ilium; $S y, p$, symphysis pubis; $S y, i s$, symphysis of ischium; $t b$, is, tubercle of ischium. 


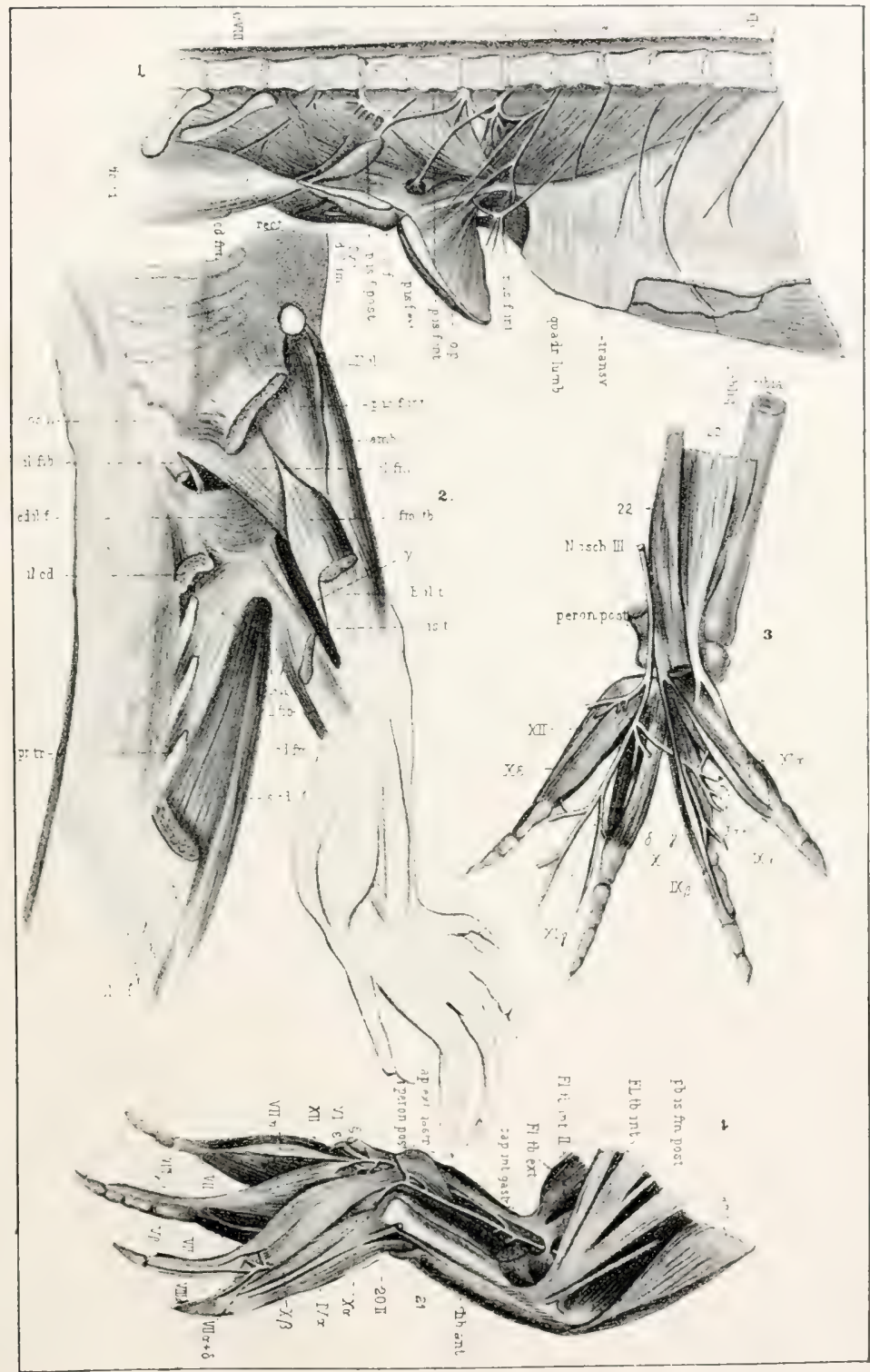





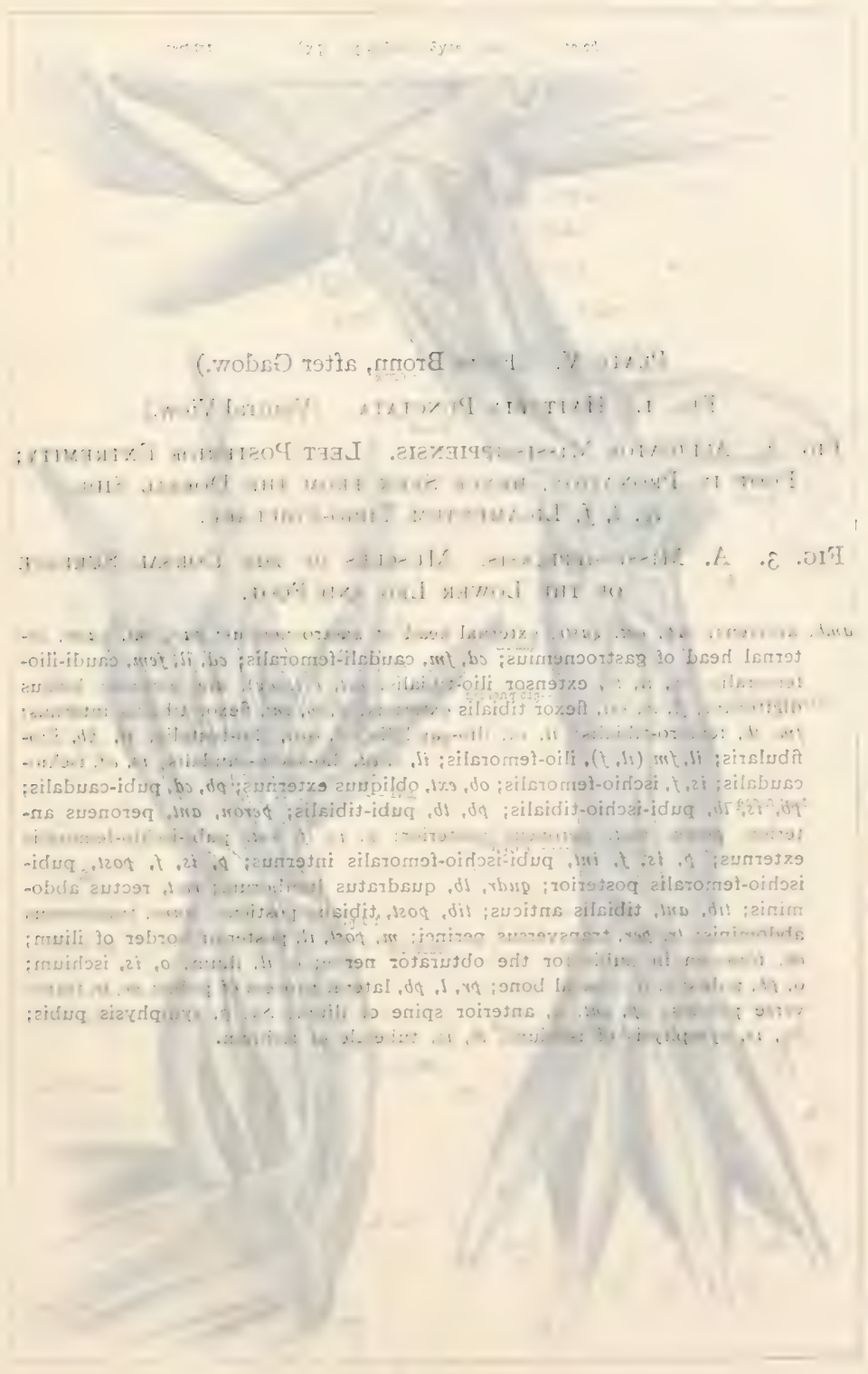




\section{Plate V. (From Bronn, after Gadow.)}

\section{Fig. I. Hatteria Punctata. (Ventral View.)}

Fig. 2. Alligator Mississippiensis. Left Posterior Extremity; Foot in Pronation, hence Seen from the Dorsal Side. $l g, t, f$, Ligamentum Tibio-Fibulare.

\section{Fig. 3. A. Mississippiensis. Muscles of the Dorsal Surface of the Lower Leg and Foot.}

$a m b$, ambiens; $c a p, e x t$, gastr, external head of gastrocnemius; cap, int, gastr, internal head of gastrocnemius; $c d, f m$, caudali-femoralis; $c d, i l, f e m$, caudi-iliofemoralis; $e x, i l, t b$, extensor ilio-tibialis; $e x t, l$ (long), dig, extensor longus digitorum; $f, t b, e x t$, flexor tibialis externus; $f, t b$, $i n t$, flexor tibialis internus; $f m, t b$, femoro-tibialis; $i l, c d$, ilio-caudalis; $i l, c o s t$, ilio-costalis; $i l, f i b$, iliofibularis; $i l, f m(l l, f)$, ilio-femoralis; $i l, s, c d$, ilio-sacro-caudalis; $i s, c d$, ischiocaudalis; $i s, f$, ischio-femoralis; $o b, e x t$, obliquus externus; $p b, c d$, pubi-caudalis; $p b, i s, t b$, pubi-ischio-tibialis; $p b, t b$, pubi-tibialis; peron, $a n t$, peroneus anterior; peron, post, peroneus posterior; $p, i s, f$, ext. pubi-ischio-femoralis externus; $p$, is, $f$, $i n t$, pubi-ischio-femoralis internus; $p$, is, $f$, post, pubiischio-femoralis posterior; $q u d r, l b$, quadratus lumborum; rect, rectus abdominis; $t i b$, ant, tibialis anticus; $t i b$, post, tibialis posticus; trans, transversus abdominis; $t r$, per, transversus perinei; $m$, post, il, posterior border of ilium; $o b$, foramen in pubis for the obturato- nerve; $o$, il, ilium; $o, i s$, ischium; $o, p b$, pubis; $o, c l$, cloacal bone; $p r, l, p b$, lateral process of pubis; $p r, t r$, transverse process; $s p, a n t, i l$, anterior spine of ilium; $S y, p$, symphysis pubis; $S y, i s$, symphysis of ischium; $t b, i s$, tubercle of ischium. 


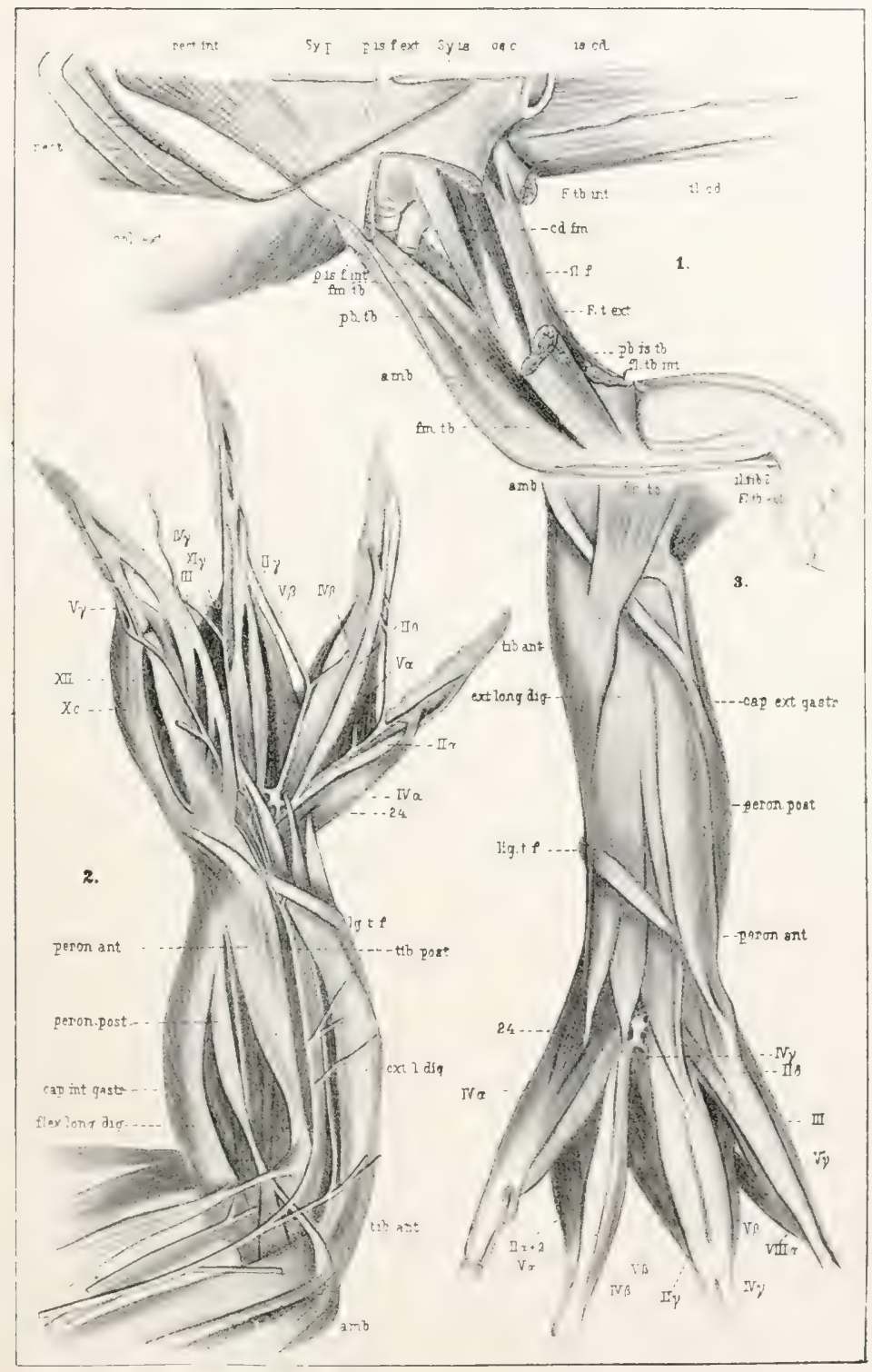





\section{CHAP'TER IV}

THE NERVOUS SYSTEM

\section{Spinal Cord}

THE spinal cord extends the whole length of the vertebral canal and ends near the end of the tail as a thin, round thread. It varies in thickness and shape in cross section, being nearly always elliptical, but at places approaching a circle. Large, spindle-formed thickenings of about equal diameter are present in the cervical and lumbar regions.

A cauda equina is absent in the alligator, the nerves of the large tail leaving the cord like the intercostals.

On its ventral surface the cord has a deep perpendicular fissure, the fissura ventralis, that extends almost to the center; it extends even along the reduced region in the tail. A vascular membrane extends into this fissure.

A shallow but distinct furrow extends along the dorsal side of the cord, parallel to which, on either side, is a fine, linear furrow.

The first two spinal nerves have no dorsal ronts. 


\section{BRAIN}

The cervical cord passes insensibly into the medulla, the dorsal furrow becoming wider and more shallow as it merges into the fourth ventricle.

A dorsal view of the brain is shown in Figure 30, A. The most prominent structures here seen are the cerebral hemispheres, VH, whose combined transverse diameter is greater than their longitudinal. The tapering, cephalic end of each hemisphere forms an olfactory tract, I, which extends cephalad to form the olfactory bulb, B. ol. Lying between the caudal ends of the hemispheres is a small conical body, G.p., called by Bronn and others the pineal body. The writer has found (62), however, that this body is the paraphysis rather than the epiphysis. Caudad to the ccrebrahemispheres and in contact with them are the optic lobes, MH; they have about the same shape and position as in the frog, but are much smaller in proportion to the size of the hemispheres. Immediately caudad to the optic lobes is the cerebellum, HH, somewhat elliptical in outline as seen from above.

Extending caudad from beneath the cere ellum is the medulla, NH, with its triangular fourth ventricle. The outlines of the medulla are somewhat obscured by the numerous roots of the eighth to eleventh cranial nerves, VIII-XI, which arise along its dorsal border. The medulla, as was 

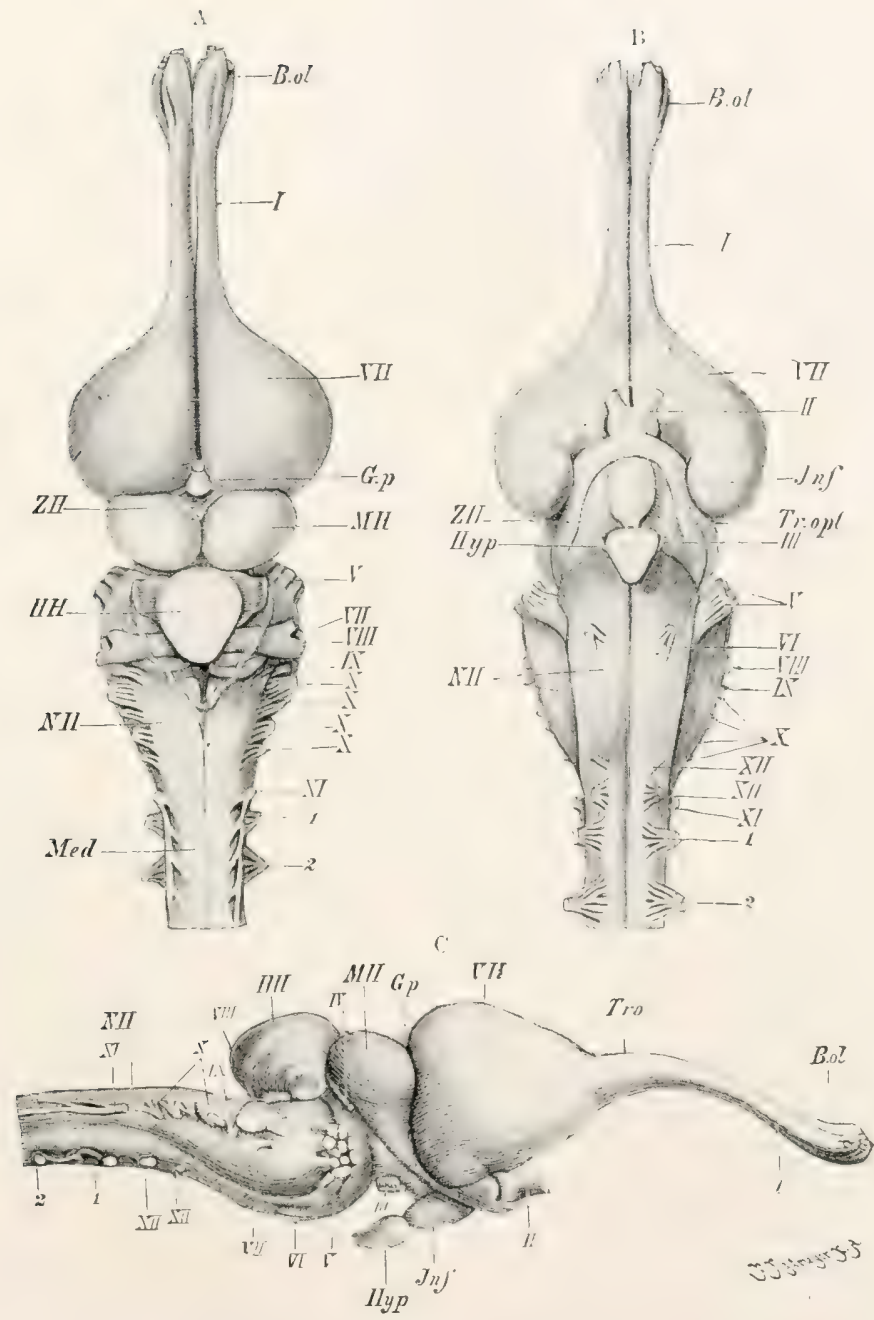

Fig. 30. Brain of Alligator. (A, dorsal; B, ventral; and C, lateral view.) (From Wiedersheim, slightly altered.)

$V I I$, cerebral hemispheres, each of which gives tise postero-laterally to a hippocampal lobe partially overlying the corresponding optic tract, Tr.opt; $Z H$, thalamencephalon; $M H$, optic lobes; $H H$, cerebellum; $N H$, medulla oblongata; $I-X I I$, cranial nerves; $I, 2$, first and second spinal nerves; B.ol, olfactory bulb; Tro, olfactory tract; G.p, paraphysis; Jnf, infundibulum; Hyp, hypophysis; Med, spinal cord. 

said above, passes, as is usually the case, without any line of demarcation into the spinal cord, the obex filling in the apex of the fourth ventricle at the anterior end of the median dorsal fissure.

A lateral view of the brain is shown in Figure 3o, C. The hemisphere, $\mathrm{VH}$, is conical in outline, with a small projection from the posteroventral region; its continuation forwards as the olfactory tract, Tro., and bulb, B. ol., is plain. Beneath it and extending forwards are the prominent optic nerve, II, and tract. Caudad to the latter and projecting ventrad and caudad are the infundibulum, Inf., and hypophysis, Hyp.

Caudad to the cerebrum are seen the end of the paraphysis, G.p., the optic lobes, MH, and the cerebellum, HH. From the cerebral peduncles (ventrad to the optic lobes) arises the oculomotor nerve, III, and dorsocaudad to this, between the optic lobe and the cerebellum, arises the trochlear nerve, IV. From the middle zone (in a dorsoventral direction) of the medulla, ventrad to the cerebellum, arises the very large trigeminal nerve, $\mathrm{V}$; while from its usual place, on the ventral surface of the medulla, the abducens nerve, VI, takes its origin by several roots. At some distance caudad from the trigeminal, from the dorsal surface of the medulla, as noted above, the very large acoustic nerve, VIII, arises; and immediately ventrad to this, on the side of the medulla, the facial nerve, VII, may be seen. Commencing just 


\section{I34 The Alligator and Its Allies}

caudad to the acoustic and extending along the upper border of the medulla and beginning of the spinal cord, are seen a dozen or more small nerve roots, which unite to form the glossopharyngeal, IX, vagus, $\mathrm{X}$, and spinal accessory, $\mathrm{XI}$, nerves. Ventral to the roots of the last, on the ventral surface of the medulla, arise the roots of the hypoglossal nerve, XII. A short distance caudad to this nerve are seen the first two spinal nerves, I and 2, which have, as noted above, no dorsal roots.

A ventral view of the brain is shown in Figure 30, B. The cerebral hemispheres, $\mathrm{VH}$, have the same outline, of course, as in the dorsal view, but the rounded projection from the caudal end of each is here seen on each side of the infundibulum, Inf. The infundibulum is in close contact with the chiasma anteriorly, and lies close between the converging optic tracts, Tr. opt. From the chiasma the optic nerves, II, extend, in an anterolateral direction, almost at right angles to each other. The appearance of the olfactory tracts, I, is the same as in the dorsal view. Caudad to the infundibulum, from the cerebral peduncles, $\mathrm{ZH}$, arise the rather small oculomotor nerves, IIT. Caudad to these, from near the ventral fissure, on the middle region of the medulla, arise the abducens nerves, VI, and from the ventral side of the posterior part of the medulla and of the anterior end of the cord arise the hypoglossal, XII, and the first two spinal nerves, I and 2. The ori- 
gins of the other cranial nerves were described in connection with the lateral view of the brain, where they show more clearly. On each side of the cercbral peduncles is seen the ventrolateral edge of the corresponding optic lobe. The pyramidal tracts are seen, extending caudad from the region of the peduncles, as a swelling on each side of the median ventral fissure.

\section{The Cranial Nerves (Crocodile)}

The origin of each of the cranial nerves was described in connection with the lateral and ventral views of the brain. A full description of the distribution of these nerves would require more space than the limits of this book will allow, but a brief account will now be given.

I and II. The olfactory and optic nerves. These two large nerves go immediately to their respective sense organs, so that no further discussion of them need be here given.

III. The oculomotor nerve. The single stem divides into three lranches: a median, going to the externus rectus muscle; a lateral, going to the inferior rectus muscle; and an intermedial, going to the inferior oblique muscle.

IV. The trochlear (pathetic) nerve leads to the superior oblique muscle.

V. The trigeminal nerve. The distribution of this nerve is very complicated. It has three 


\section{I36 The Alligator and Its Allies}

main divisions: (I) the ophthalmic branch, (2) the superior maxillary branch, and (3) the inferior maxillary branch. (I) The ophthalmic in turn divides into two branches: the smaller, frontal, going to the integument of the upper and lower eyelids; the larger, nasal, going chiefly to the nasal cavity but also sending some small branches to the upper and lower eyelids. (2) The superior maxillary branch separates into a number of divisions: (a) a branch that, in the neighborhood of the auditory capsule, fuses with the facial norve; (b) a twig to the integument of the forehead and to the upper and lower eyelids; (c) a branch to the Harderian gland and the conjunctiva; (d) a branch to the neighborhood of the cheek, to the angle of the mouth, and to the palatine branch of the facial nerve; (e) a branch to the palate; (f) a branch to the integument of the upper jaw; (g) a branch to the teeth of the upper jaw. (3) The inferior maxillary branch divides into four branches: (a) this division supplies the skin of the cheek region; (b) a branch to the chewing muscles; (c) a branch that divides into two nerves-the first going to the skin of the lower jaw, the second dividing again into two nerves, both of which lead to the integument of the lower jaw; (d) the fourth division of the inferior maxillary, known as the inferior alveolar, itself divides into two twigs - $\left(\mathrm{a}^{\prime}\right)$ the first twig divides into two parts, a larger and a smaller, both of which lead, 


\section{The Nervous System}

by different paths, to the inner skin of the mouth; (b') the second twig divides into four parts - two leading to the mylohyoid musclo and to the integument at the corner of the mouth, one to the integumental glands at the corner of the mouth, and one to the floor of the mouth cavity.

VI. The abducens nerve leads to the retractor oculi muscle and to the muscle for the nictitating membrane.

VII. The facial nerve gives off three main branches: (I) the first divides again into three twigs--(a) connecting with a branch of the trigeminal nerve, (b) and (c) connecting with the trigeminal and also leading to the palate; (2) the second branch divides into two twigs that connect with the glossopharyngeal nerve; (3) the third branch divides into two parts, a muscular twig, and the chorda tympani.

VIII. The auditory or acoustic nerve leads, of course, to the sensory regions of the ear.

IX. The glossopharyngeal nerve divides into four main branches, as follows: (I) to the larynx, (2) to the osophagus, (3) to the hyomaxillary and sterno-maxillary muscles, and $\left(\frac{1}{1}\right)$ to the tongue. There are also certain communicating twigs with the facial and vagus nerves.

$\mathrm{X}$. The vagus or pneumogastric nerve gives off four branches: (I) and (2) communicate with each other and supply the pharynx, larynx, œsoph- 
agus, and trachea; (3) goes to the œesophagus; (4) goes to the heart, lungs, and stomach.

XI. The spinal accessory nerve. There seems to be some doubt as to the exact identity and distribution of this nerve, but Bronn says that, according to Fischer, it gives twigs to the lower head-muscles and then divides into fine branches in the atlanti-mastoideus muscle.

XII. The hypoglossal nerve, going to the region of the tongue, divides into three branches: (I) the median and smallest goes to the sterno-maxillary muscle; (2) the inner and larger goes to the same muscle and also to the coraco-hyoid and sternohyoid muscles; (3) the outer and largest divides into three twigs of which the first two lead to the hyomaxillary and sterno-maxillary muscles respectively, while the third divides into two twigs that lead to the hyoglossal and genioglossal muscles respectively.

\section{The Spinal Nerves}

As was noted above, the dorsal roots of the first two spinal nerves are lacking.

I, II, and III. The ventral branches of these three nerves supply the smaller, ventral neck muscles.

IV. The ventral branch of this nerve innervates with its chief divisions the ventral muscles, the sphincter colli, and the integument of the neck, 


\section{The Nervous System}

and sends a small branch to the levator scapulix superficialis muscle.

V. The ventral branch of this nerve sends branches to the ventral muscles of the neck, to the levator scapulæ superficialis; a large branch goes to the sterno-mastoid; and the rest of the nerve distributes itself in the sphincter colli and the integument and ventral muscles of the neck.

VI. The sixth nerve distributes itself to the ventral musculature and to the integument of the neck, and sends a fairly strong branch to the levator scapulæ superficialis muscle and to the most anterior part of the collo-thoraci-suprascapularis profundus muscle.

VII. The seventh nerve is the first to enter, by a small branch, into the brachial plexus (Figure 3I). It also sends a branch to the ventral muscles and the integument of the neck, and three branches to various shoulder muscles.

VIII. The ventral branch of the eighth nerve (Figure 3I) is the second largest nerve of the brachial plexus. It gives some twigs to the ventral muscles and then gives one or two nerves to the collo-thoraci-suprascapularis profundus and the serratus superficialis muscles. The rest of the nerve divides into an inferior and a superior branch which unite with the ninth nerve.

IX. The ninth and tenth nerves are the largest of the brachial plexus. The former, after giving off some twigs to the ventral musculature and to 


\section{I40 The Alligator and Its Allies}

the serratus superficialis and the hinder regions of the collo-thoraci-suprascapularis profundus muscles, unites with the tenth nerve just after giving off the small thoracicus inferior nerve to the costo-coracoideus muscle. After uniting with the tenth nerve the ninth nerve immediately divides into two branches that form loops with branches of the eighth nerve, the whole making a very complicated plexus.

$\mathrm{X}$. The tenth nerve, as noted above, is one of the two largest nerves of the brachial plexus. After giving off a single nerve to the ventral musculature, this nerve unites with the eleventh nerve; it then gives a branch to the costo-coracoideus muscle and forms a loop with the ninth nerve. After giving off a couple of nerves it again divides into two equal branches which unite with similar branches of the eighth nerve.

XI. The eleventh nerve is next to the smallest of the plexus. Besides branches to the trunk musculature it gives a fine twig to the integument of the axilla and unites with the tenth nerve in the brachial plexus. This is the last nerve that enters into the brachial plexus.

The distribution of the nerves of the brachial plexus is as follows (Fig. 3I): (a) supracoracoideus to the muscle of that name and to the integument of the breast; (b) thoraci inferiores nerves (Ioa) a complex of nerves from the eighth, ninth, and tenth spinal stems-lead to the costo-coracoideus 


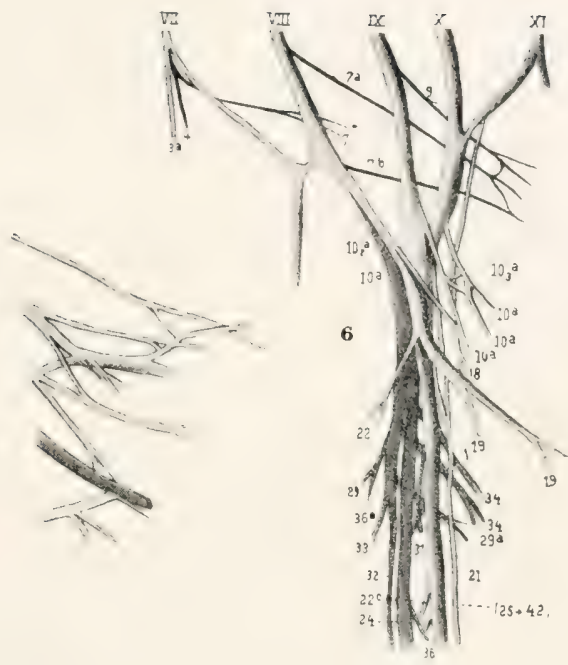

Fig. 31. Brachial Plexus of C. AcuTus. (From Bronn, after Fürbringer.)

VII-XI. ventral branches of seventh to eleventh s p i n a 1 nerves.

3a. thoracicus anterior VII.

4. thoracicus superior $\mathrm{V}$.

7. thoracicus superior VI.

7a. proximally1 ea $\mathrm{d}$ ing thoracicus superior.

7b. distally-leading thoracicus superior VIII.

9. thoracicus superior IX.

$\mathrm{IO} a, \mathrm{IO} a_{1}, \mathrm{IO} a_{2}, \mathrm{IO} a_{3}$. thoracicus inferior.

I8. cutaneuspectoralis.

I9. pectoralis.

2I. brachialis longus inferior.
22. coraco-brachialis.

22c. branch forthe distal belly of biceps muscle.

24. muscular branch for thehumeroantebrachialisinferior.

$(25+42)$. cutaneus brachii and antebrachii medialis.

29. subscapu laris.

3I. dorsalis scapulæ (posterior).

32. cutaneusbrachii superior lateralis.

33. deltoides inferior.

34. brachialis longus superior.

36. anconæus.

36a. scapulo-humeralis profundus. 



\section{The Nervous System}

muscles and to the anterior part of the transversus abdominis muscle; (c) the pectoralis (I9), a large nerve leading to the muscle of that name; (d) cutaneus pectoralis (Is), fine branches from the XIth spinal nerve to the integument of the axilla and the neighboring parts of the breast; (c) coracobrachialis (22) to the like named muscle; (f) cutaneus brachii et antebrachii medialis $(25+.12)$ to the medial side of the integument of the upper and fore arm; $(\mathrm{g})$ brachialis longus inforior (2I), a large nerve that supplies the biceps and humeroantebrachialis inferior muscles, and then divides into the medianus and ulnaris inferior nerves; (h) subscapularis (29) to the like named muscle; (i) scapulo-humeralis profundus (36a) to the like named muscle; (j) axillaris, a large stem that divides into two main twigs that lead to the skin of the lateral side of the upper arm, to the proximal part of the forearm, to the humero-radialis muscle, and to the deltoides coraco-sternalis muscle; (k) dorsalis scapulæ (posterior) (3I) to the deltoideus scapularis muscle; (1) teres major (29b), one (alligator) or two (crocodile) middle-sized nerves to the teres major muscle; (m) latissimi dorsi (29b) to the like named muscle; (n) brachialis longus superior (radialis) (not shown in Figure $3 \mathrm{I}$ ) to the extensor side of forearm and the hand.

Of the spinal nerves between the brachial and crural plexuses Bronn gives no description for the Crocodilia. The most posterior nerve of the 


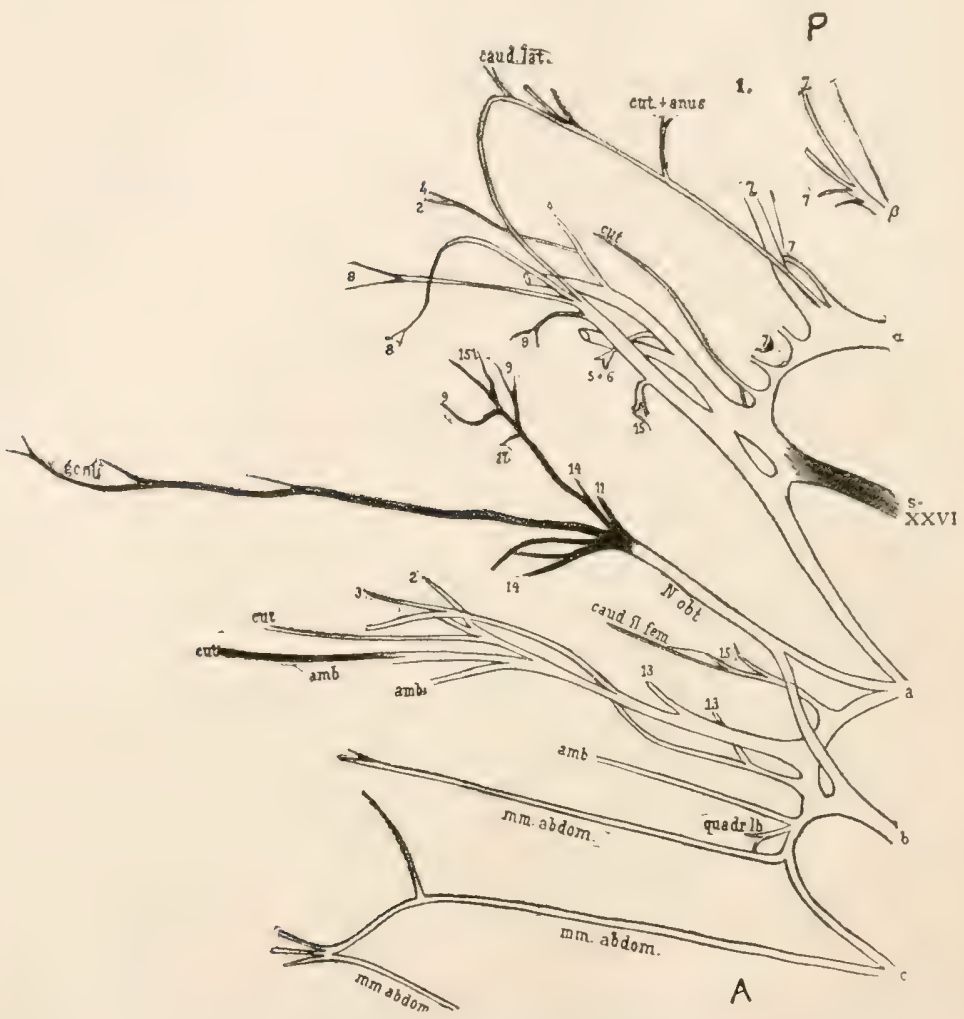

Fig. 32. Crural Plexus and Ischiadic Plexus of the Left Side of A. Mississippiensis. The Nerve Branches are Shown as far as their Entrance into the Muscles. The Crural Plexus is Made up of the Presacral Stems $a, b, c$. The Obturator Nerve is Built of Two Branches from Stems A \& is. (From Bronn, AFter GADOW.)

$a, b, c$. presacral nerves. $\alpha \& \beta$. postsacral nerves. $s=X X V I$. sacral nerve (26th spinal nerve).

2. to extensor ileo-tibialis muscle.

3. to femoro-tibialis muscle.

4. to ileo-fibularis muscle.

5. to ileo-femoralis muscle.

6. to caudi-ilco-femoralis muscle.

7. caudi-femoralis muscle.
8. to flexor tibialis externus muscle.

9. to flexor tibialis internus muscle.

II. to ischio-femoralis muscle.

I3. pubo-ischio-femoralis internus.

I4. pubo-ischio-femoralis externus muscle.

I5. to pubo-ischio-femoralis posterior muscle. 


\section{The Nervous System}

former plexus is the eleventh and the most anterior nerve to talie part in the latter is the twenty-third, so that there are eleven nerves that are doubtless distributed to the regions not supplied by the two plexuses.

The crural-ischial plexuses (Fig. 32) are made up of branches from five nerves, three presacral ( $a, b$, and $\mathrm{c}$ ), the sacral ( $\mathrm{s}=\mathrm{xxvi}$ ), and one postsacral $(\alpha)$; the second postsacral shown in the figure apparently does not enter into the plexus.

The first and second presacrals terminate chiefly in the abdominal and thigh muscles, though the second sends a large branch to fuse with a branch from the third to form the large obturator nerve (N. obt.) that leads to the muscles of the thigh and knee.

The third presacral sends a branch back to fuse with the large sacral $(s=x x v i)$, and these two, together with a branch from the first postsacral, form a complicated network that sends numerous branches to the muscles of the pelvic and femoral regions, to the skin, legs, and tail, as shown in Figure 32. The large muscles of the tail are innervated by the regular, metameric nerves of that region, and since there are usually thirty-nine caudal vertebræ, there are probably about that many pairs of caudal nerves, although the last few vertebræ and the muscles of that region are so small it may be that some of the nerves are lacking. 
I44 The Alligator and Its Allies

\section{Special Sense Organs}

It is not possible in a work of this size to give much space to the discussion of the anatomy of the special sense organs. A few of the main features will be given here, taken mainly from Bronn's Thierreich, but for details of structure the reader is referred to that larger work.

The Eye. As might be expected, the Crocodilia have the usual upper and lower eyelids and the nictitating membrane. Except along their thickened rims the lids are usually rather faintly pigmented, and near the thickened border numerous goblet cells are found.

The structure of the upper and lower lids is similar except that in the former a bony formation is present, as a support to that lid, even in very young animals. The arrangement of the muscles, which are of both smooth and striped fibers, and the histological structure cannot be described here.

The nictitating membrane is strongly developed in the Crocodilia. Its outer surface is marked by two fairly high folds that are conspicuously pigmented. The cartilage described in the nictitating membrane of Lacerta is wanting, according to Bronn, in the Crocodilia.

The glands of the eye are of three types: the lachrymal glands proper, the Harderian glands, and the conjunctival glands. The lachrymal gland is small in proportion to the size of the eye. It 


\section{The Nervous System}

is an elongated, almost band-like structure situated in the rool of the eye-socket, near its border; its long axis lies in an antero-posterior direction. It is so closely inclosed by and united with connective tissue that it is difficult to find.

The IIarderian glund is much larger than the lachrymal gland proper and is easily found. It lies in the forward part of the eye-socket and is of a somewhat three-cornered shape. From its outer and forward base it sends a short, delicate duct to open between the nictitating membrane and the eyeball.

The lachrymal canal is well developed in the Crocodilia. Near the forward angle of the eye, on the inner sicle of the lower lid, are found from three to eight tear dots, lying in a row from behind forward. Each of these dots opens into a small elongated sac. This sac opens downwards and forwards into a common canal, which canal, at first narrow but soon widening, extends for a time parallel to the free border of the eyelid and then enters the opening in the hinder side of the lachrymal bone. Rathke found none of these tear dots on the upper eyelid so concluded that the lachrymal fluid could cscape only through the lower lid. This canal, which might correspond to the lachrymal sac of higher forms, is rather narrow until it enters the lachrymal bone, then it becomes considerably wirler and forms a sort of reservoir that Rathke calls the "succus naso-luchrymu- 
lis." This reservoir is of irregular form and opens forwards into the base of the nasal cavity proper.

The third type of gland mentioned above, the conjunctival, is found on the lower eyelid where the conjunctiva passes from the lid to the eyeball. The gland is of a "scattered acinose" type.

The usual muscles of the eyeball are found in the Crocodilia. The four rectus and two oblique muscles have about the usual arrangement and are attached to the eyeball by very short aponeuroses. The retractor oculi muscle is only weakly developed. It consists of two separate bundles which, lying behind the optic nerve, arise from the forward bony wall of the socket and are inserted on the sclera very near the optic nerve.

The eyeball consists of the usual layers, including, as might be expected from the nocturnal habits of the Crocodilia, a typical tapetum hucidum.

In the sclera, instead of the bony ring common to the saurians, is found a well-developed cartilage covered with the fibrous layer of the sclera; the fibers of this layer are arranged into two more or less distinct layers.

While not worked out in detail the cornea consists of the usual five layers.

'In the iris the musculature is less developed than in the birds; Bronn thinks this may be compensated for by the greater development of the "vascular structures."

The pupil is a vertical slit. 


\section{The Nervous System}

The choroid is very closely united on the outside with the sclera; on the inside it is 1ess closely attached to the retina except at the ora serrata. It consists of an outer fibrous coat, an inner, unstratified pigmented epithelium derived embryologically from the pigmented layer of the retina, and the ground substance which is a network of irregular and very vascular cells.

As in probably all reptiles there is present in the Crocodilia a vascular pigmented fold of the choroid, the pecten, which projects into the middle of the cavity of the eyeball.

In the retina Bronn describes the following ten layers, which are those commonly given in other vertebrate retinas: (I) the inner limiting membrane, (2) optic fiber layer, (3) ganglion cell layer, (4) inner granular layer, (5) inner nuclear layer, (6) outer granular layer, (7) outer nuclear layer, (8) outer limiting membrane, (9) cone layer, (Io) pigmented layer. The Crocodilia differ from probably all other reptiles in having rods as well as cones in the retina. The rods are more numerous except in the neighborhood of the fovea centralis where the cones predominate; in the fovea itself only cones are found.

The lens does not show any characteristics unusual enough to warrant special description.

The Ear. The ear is of special interest here because it is in the Crocodilia that are first found the three distinct regions of the ear that are seen 
in the Aves and Mammalia: the external auditory meatus, the tympanic cavity, and the labyrinth. It is the presence of the meatus that lifts the Crocodilia above the other Reptilia.

Two strong folds of integument, one above and one below, completely cover the outer car and allow it to open as a mere slit on the lateral surface of the head a little back of the corner of the eye. By lifting the upper valve one may perceive the lower half of the meatus and the bottom of the tympanic membrane. The upper valve is the larger and is sickle shaped; the lower is smaller and more three cornered. Both spring from the outer surface of the squamosal bone, from its posterior obtuse angle to its anterior union with the postfrontal. The lower fold is raised highest behind the corner of the eye and is lost in the middle of the rima auditoria; by this Hasse indicates the position of the outer opening of the external auditory meatus. The form of the meatus may be compared to a wedge whose base is directed dorsomedio-caudad and whose edge points in a ventro1atero-cephalic direction; its side walls are either soft or bony; its outer end is covered by the folds; at its inner end is the tympanic membrane or drum.

The drum is a round, soft, elastic membrane in which a radial arrangement of its constituent fibers may be seen. It is funnel shaped from without and above, and the fibers radiate from the apex to which the columella is attached. The membrane 
is stretched tatt and while it does not, as in the higher vertebrates, lie in a bony groove, it possesses around its periphery a strong thickening of circular fibers, the ammulus tympanicus, by means of which it is closely united with the lining membrane of the outer ear passage. The drum is attached chicfly to the quadrate but in part to the squamosal bone.

The middle ear is divided into an outer part, the tympanic carity proper, and a part next to the labyrinth, the recessus cari tympani. Within the tympanic cavity, besides blood-vessels and nerves, is found the columella with its appendage (found in all Reptilia), the recessus scalce tympani. The tympanic cavity is formed mainly by the quadrate, though the exoccipital and squamosal bones take some part. In outline it might be compared to a truncated, four-sided pyramid, with its base below, its truncated apex above, and with an anterior, a posterior, a mesial, and a lateral side.

From the floor of each tympanic cavity a Eustachian tube leads towards the throat. These tubes unite and connect with the throat by a single small opening just behind the posterior nares, as shown in the figures of the skull.

The semicirculur canals with their ampullce lie in the usual positions as seen in other vertebrates: the anterior vertical, posterior vertical, and horizontal. The details in structure of the inner ear cannot be given here. The nervous epithelium is said to have the same characteristics as in other vertebrates. 


\section{CHAPTER V}

\section{THE DIGESTIVE SYSTEM}

\section{The Oral Cavity}

$7 \mathrm{HE}$ mouth in the Crocodilia is large, as is well known, and may be opened very wide. It is bounded anteriorly and laterally by the teeth of the two jaws; these teeth were described in connection with the skull. The mucous membrane of the roof of the mouth and of the dorsum of the tongue, especially the former, exhibits numerous small papillæ (see page I60), and among these, in the posterior region of the mouth, are the ducts of mucous glands.

The tongue extends from just back of the mandibular symphysis to the glottis. It is attached throughout its entire ventral side except for a short distance at its tip, so that it may be elevated and depressed but not protruded. Among the papilla on its dorsal surface are sense organs, said to be tactile and gustatory corpuscles (see page 165). The posterior margin of the tongue is elevated as a transverse fold that meets a corre- 



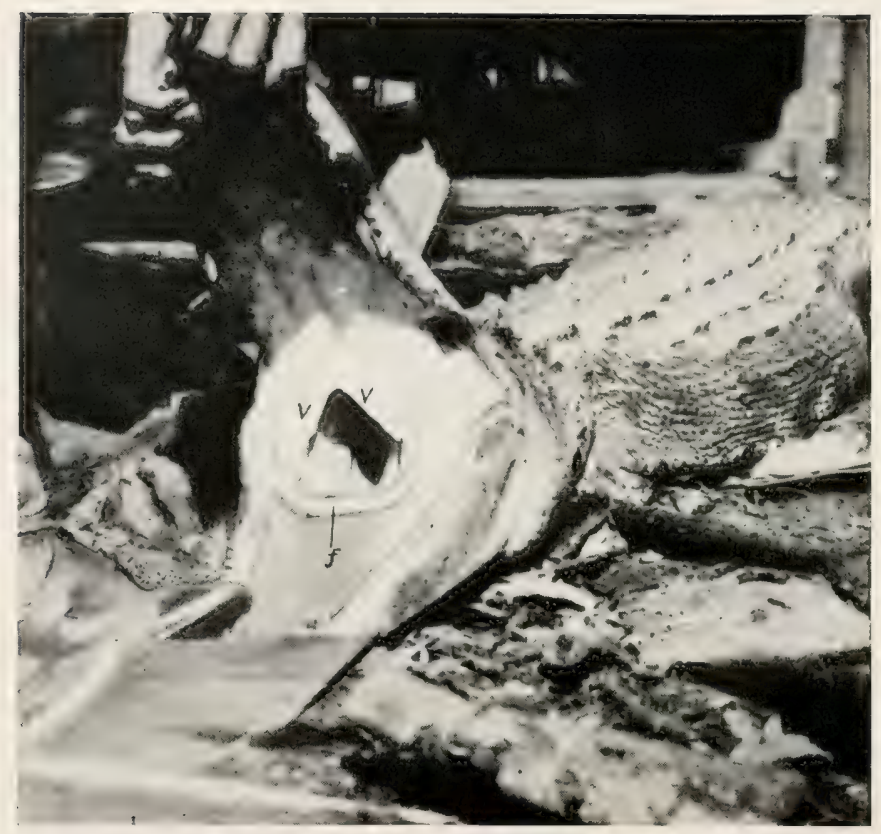

Fig. 33. Interior of the Mouth of A. Mississippiensis $f$, transverse fold at the base of the tongue; $z^{\prime}, v^{\prime}$, velum palatinum. 
sponding fold, the a'clum pulutinum, from the lower side of the palate and completely shuts off the mouth from the openings of the trachea and gullet (Fig. 33). Into this hinder chamber open the posterior nares, so that the animal can open its mouth under water without getting water into its trachea; or it may, while holding its prey in its mouth, come to the surface to breathe, without danger of letting water into its trachea. The nasal passages, leading from the nostrils to the posterior nares, are, of course, completely inclosed by bone, as described in connection with the sku1l. Ventral to the larynx and posterior part of the mouth is the large, shield-shaped hyoid apparatus, Fig. 25, h, also described in connection with the skull.

\section{The Esophagus}

The osophagus, Fig. $3+$, $e$, is long and of about the same diameter throughout except possibly for a slight enlargement of the anterior region where it leaves the pharynx. The two "olivary enlargements" mentioned by Chaffanjon (I5) are not always present, and when seen were found to contain either food or small stones or both.

The outside of the osophagus is smooth and muscular while the lining is thrown into numerous longitudinal folds that in the empty osophagus nearly obliterate the lumen; where distended by food or pebbles the longitudinal folds may be almost 
I52 The Alligator and Its Allies

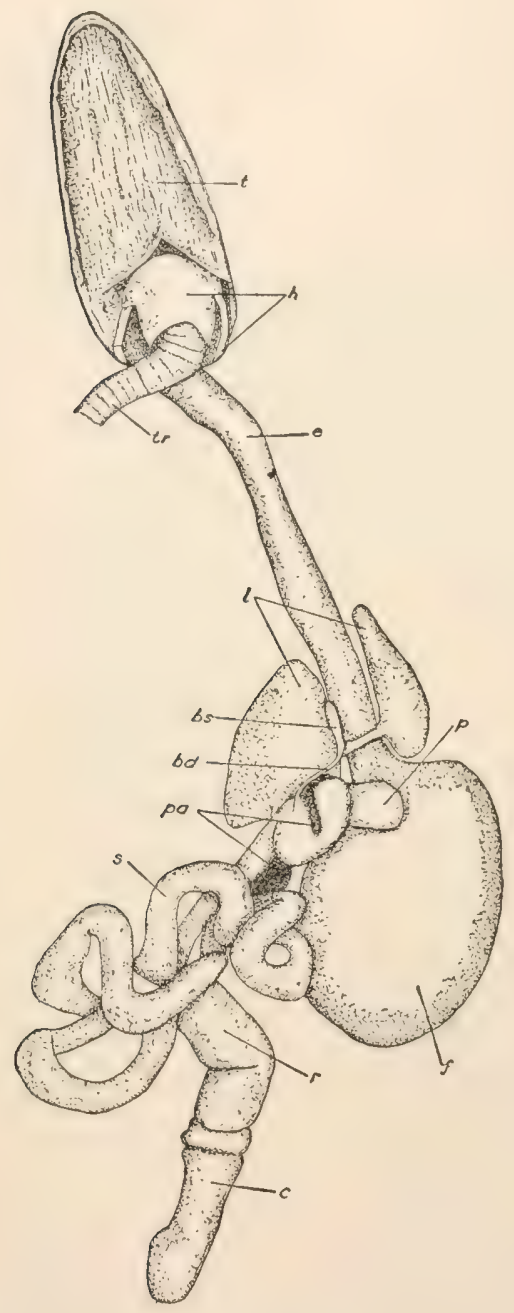

Fig. 34. Digestive System of A Mississippiensis.

$b d$, bile duct; $b s$, bile sac; $c$, cloaca; $e$, œsophagus; $f$, larger or fundic region of stomach; $h$, hyoid apparatus; $l$, liver; $p$. smaller or pyloric region of the stomach; $p a$, pancicas; $r$, rectum; $s$, small intestine; $t$, tongue; $t r$, trachea. obliterated. In a thirty-inch animal the œesophagus is about six inches long, and opens suddenly, but without any apparent valve, into the large chamber of the stomach. The histology of the œesophagus and the other regions of the digestive tract will be described later.

\section{The Stomach}

The stomach, as is well known, is made up of two distinct parts; that on the animal's left, into which the œesophagus opens, is many times larger than the part from which the small intestine leads. The larger or fundic region, Fig. 34, $f$, has, as will be described, very heavy muscular 
walls. When empty the lining of this part of the stomach is thrown into a few comparatively large folds, but when greatly distended with food, as it sometimes is, the internal folds are completely obliterated and the muscular layers are stretched until they have scarcely an eighth of their original thickness. In Figure 34 the stomach is considerably distended.

The large region of the stomach frequently contains a number of stones, and for that reason, probably, is sometimes spoken of as the gizzard. In one thirty-inch alligator fourteen pebbles of irregular shape, varying in largest diameter from four to seventeen $\mathrm{mm}$. and aggregating six grams in weight, were found. Voeltzkow (78) says that gastroliths of two to three $\mathrm{cm}$. diameter are found in the stomach of the adult Madagascar crocodile.

Neither the transverse fold nor the smooth, lateral disks (or shields) described by Chaffanjon could be seen in either the empty or in the distended stomach.

The smaller part of the stomach, Fig. 34 , p, lies to the right and somewhat ventrad to the anterior region of the larger part, near the entrance to the osophagus. It connects by a fairly large opening with the larger part of the stomach, and by a smaller opening with the duodenum. The former opening apparently has no valve, unless it be a slight sphincter muscle; the latter is guarded by 
I54 The Alligator and Its Allies

a pair of thickened lips, called by Chaffanjon "semilunar valves."

The walls of the smaller part of the stomach are, as might be expected, much thinner than those of the larger region, but they are proportionately fairly thick and are internally thrown into numerous folds.

\section{The Intestine}

In the intestine three regions may be distinguished: a long, considerably coiled small intestine; a wide, nearly straight rectum; and a short, wide cloaca.

The small intestine, Fig. 3t, s, is of moderate and rather uniform diameter, though somewhat thicker near the stomach, and is not coiled so extensively as figured by Chaffanjon. Near the stomach it receives the ducts of the liver and pancreas. The bile duct, Fig. $34, b d$, is a continuation of an elongated bile sac, $b s$, which lies between the large right and smaller left lobes of the liver, $l$. The two main lobes of the liver, which appear smaller than in reality because of foreshortening in drawing, are connected, across the base of the œesophagus, by a narrow transverse band.

The pancreas, $p a$, which is of fair size, lies partly dorsal to and partly in a narrow loop of the intestine, so that it is not very evident in a ventral view of the animal. 


\section{The Digestive System}

The small intestine has heavy muscular walls whose histological structure will be described elsewhere. It opens abruptly, without any indication of a cæcum, into the large intestine or rectum.

The rectum, $r$, is of about twice the diameter of the small intestine, though this, of course, varies with the amount of fecal matter it contains; it is nearly straight and possesses much thinner walls than the small intestine, though this, again, varies with the state of collapse or distention.

At the posterior end of the rectum is a heavy sphincter valve separating that part of the intestine from the cloaca.

The cloaca, $c$, is widest anteriorly where it is about as wide as the rectum; it gradually diminishes in diameter caudad, and appears flattened laterally. Its wall has the same general structure as the rectum, as will be described below. The mucous membrane posterior to the openings of the genital ducts is thrown into a more or less complete, ring-like transverse fold (Fig. 55 G.). In some species there may be a second, half-ring-like fold in the dorsal wall caudad to the more complete ring. The cloaca is divided by this fold into a larger anterior portion, g, and a shorter posterior portion, $h$; in the former the mucous membrane is thrown into a large number of small folds that in places form a network; in the latter the mucous membrane has a hard, thick epithelium, with a smooth surface and only a few longitudinal folds. 
I56 The Alligator and Its Allies

The ureters open, Fig. $55, d, e$, at a moderate distance from each other, into the anterior region of the cloaca (about where the dorsal and lateral walls of this region come together). The genital ducts (oviducts or vasa deferentia), $c, f$, on the other hand, open close together through the ventral wall of the posterior half of the cloaca, just in front of the copulatory organ.

Into the cloaca, very near the anus, open two glands of fairly large size that Rathke called musk glands. These glands lie outside of the pelvis between the side walls of the cloaca and a large muscle that surrounds this part of the body. They have an oval form and open usually from their anterior end, sometimes just caudad to this, by a short, fairly wide, slit-like opening which has an anteroposterior direction. The walls of the glands are made up of three closely associated layers of connective tissue, the inner one being thrown into folds. Since these layers contain no muscle fibers the secretion of the gland is probably squeezed out by contraction of the circular muscles of the cloaca. Usually the cloacal glands are stretched full by a thick, yellowish mass that smells strongly of musk.

The part of the cloaca caudad to the pelvic opening has a differently arranged musculature from the more anterior region. It consists of two separate pairs of striped muscles that surround the musk glands on the outer side. The first 


\section{The Digestive System}

pair form a fairly broad, moderately thick ring muscle next to the anus that is attached anteriorly to the pubis and posteriorly to the second hremal process. When these muscles draw together they narrow or completely close the anal slit. 'The muscles of the other pair are broader but thinner, and extend in a general dorso-ventral direction. Anteriorly, above the cloaca, they are united with each other, but posteriorly they separate and, with the above ring muscle, are inserted on the second hæmal arch. Judging from their attachment they widen the anal opening laterally.

\section{The Histology of the Enteron of the Florida Alligator}

It has long been known that the sea lamprey, Petromyzon marimus, during the spawning season, when the body is distended with eggs, takes no food, and that the digestive tract during this period shrivels up until it is reduced to a mere thread. This condition dotibtless obtains in other forms as well, though it has not been actually observed by the writer elsewhere.

A number of small alligators that were kept alive in the laboratory for a year or more caused the writer to wonder whether any very marked change had taken place in their digestive tracts during the months they took no food.

In captivity, especially if the water in their tank 


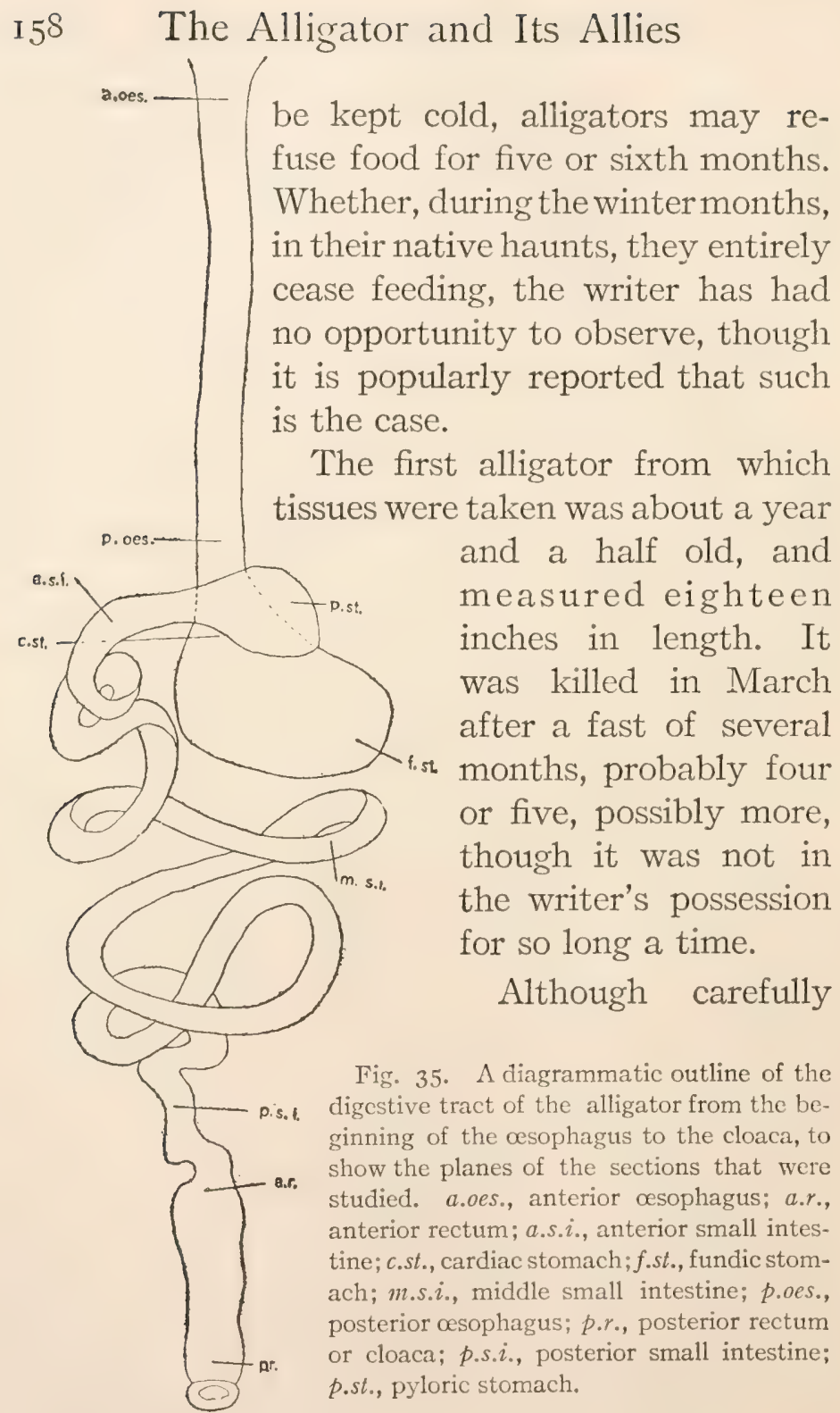

Fig. 35. OUtline of

Digestive Tract 


\section{The Digestive System}

fixed in the usual fluids, the epithelial structures from this animal were not as clcarly defined in most cases as could be desired; this rather unsatisfactory fixation may have been due to some physiological condition characteristic of the period of hibernation. That this was the case seems likely from the better fixation obtained by the same methods in the case of animals killed during the feeding season.

The other animals from which tissues were taken were considerably smaller than the one mentioned above. They were killed early in the fall, after having been fed regularly for about five months upon bits of meat, both raw and cooked.

The Tongue. The covering of the tongue was studied in two regions, near the free end, and towards the base.

A section of the former region, drawn under high power, is shown in Figure 36. It consists of a dense mass of fibrous tissue, $a$, and small scattered cells, overlaid by a stratified epithelium of eight or ten layers. Only a small part of the fibrous base, just beneath the epithelium, is here shown. It is a dense areolar tissue with the elastic fibers apparently predominating.

The epithelium, $e$, consists, as has just been said, of about eight or ten layers of cells, those at the base being generally cuboidal in shape, while towards the surface the cells become more and more flattened until at the surface they form 
a thick horny layer, $h$, in which no nuclei can be secn. The cells of the horny layer are flattened into mere fibers, which, at places, are seen projecting from the sur-

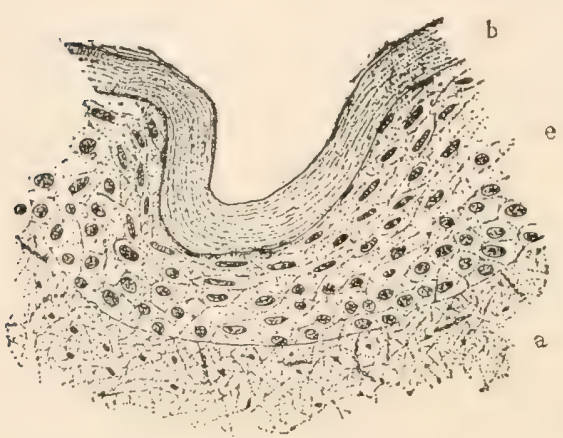

FIG. 36. The covering of the anterior region of the tongue of the hibernating animal, under fairly high magnification; the plane of this section is not shown in Figure 35; $a$, areolar tissue; $e$, epithelium; $h$, horny layer of epithelium.

face. The boundary between the horny cells and those beneath is quite distinct, though perhaps not quite so sharp as shown in the figure under discussion.

In a previous paper, the writer noted that the dorsum of the tongue is covered with small, evenly distributed papillæ, easily seen by aid of a hand lens. These so-called papillæ are here seen to be hardly papillæ at all, but small folds or wrinkles, although the epithelium is somewhat thickened at intervals. No glands are to be seen in this region of the tongue.

The only difference between the anterior region of the tongue during hibernation and during the feeding scason seems to be in the scaly layer of the epithelium. Instead of the compact, sharply differentiated layer of scaly cells seen in Figure 36 , 
the anterior regrion of the tongue during feeding is covered with a layer of rather loose, scaly cells, in most of which the nuclei may be seen. No difference in the amount of sloughing off can be noticed as is the case with the epithelium of the roof of the mouth.

Figure 37 represents a section, under very low magnification, of the covering of the base of the tongue. The areolar tissue, $a$, is about the same as in the preceding

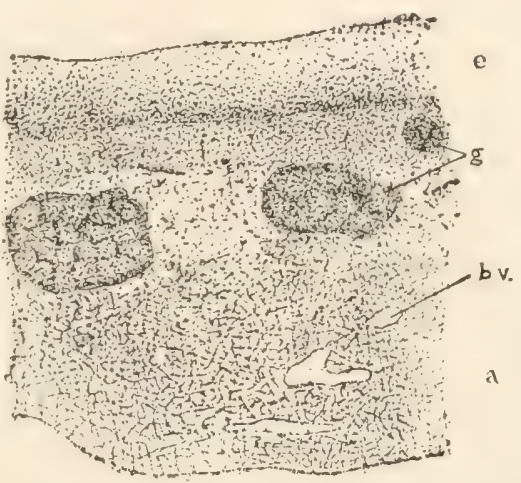

FIG. 37. Covering of the posterior region of the tongue of the hibernating animal showing glands, under low magnification; $a$, areolar tissue; $b v$, blood-vessels; $g$, glands; $e$, epithelium. section, except that it is more compact just under the epithelium than it is in its deeper regions. It secms also more vascular than in the preceding section.

The epithelium, $e$, is of the stratified squamous variety, but consists of many more layers of cells than in the preceding section and is hence several times as thick. While its cells are flattened towards the surface, after the manner of this kind of epithelium, they do not form the definite horny layer described above. 
The most marked difference between the two regions of the tongue is the presence, in the posterior or basal region, of numerous glands, $g$, probably mucous- or slime-secreting. They are thickly

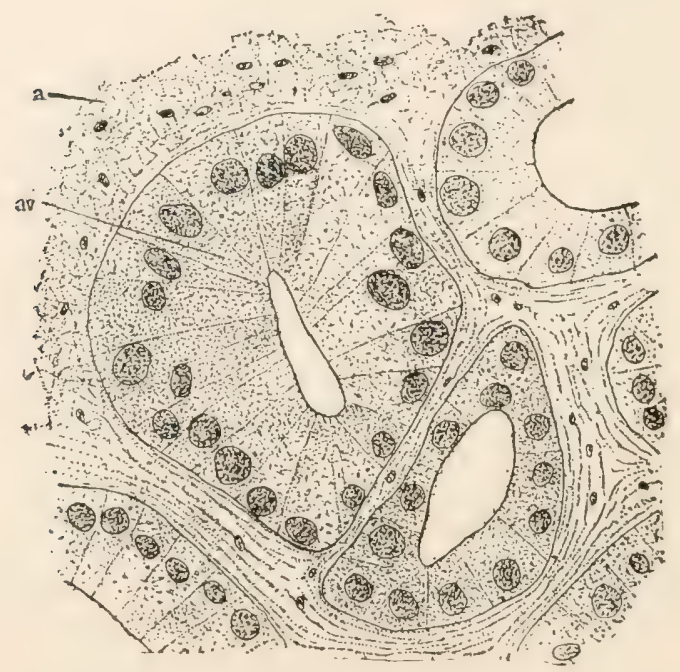

FIG. 38. One of the glands from the posterior region of the tongue of the hibernating animal, under high magnification; $a$, areolar tissue; $a v$, alveolus.

scattered through the areolar base, close beneath the epithelium. Two large glands and one small one are shown in the figure under discussion. Each gland opens to the surface by an apparently wide duct, but since no good section of such a duct was obtained it is not shown in the figure. A1though the rest of the tissue was well preserved 
and showed cell structure clearly, it was with difficulty that the details of the glands could be determined.

A high-power drawing of a portion of one of the glands is shown in Figure 38 . The large alveolus, $a v$, to the left, is from the peripheral region of the gland and is surrounded, on its free side, by the areolar tissue described above. The inter-alvcolar spaces, which are somewhat exaggerated in the figure, are filled with fibers which are arranged more or less in layers and hence appears different from the surrounding areolar tissue. The alveoli are circular or elongated in section, and have fairly wide lumina. They are lined with a single layer of columnar or cuboidal cells which are very granular, so that their walls are difficult to determine. Each cell contains, near its base, a very large, usually spherical nucleus. These nuclei stain darkly and give the dark appearance to the glands as seen under low magnification, especially in rather thick sections.

During feeding the epithelium of this region of the tongue consists of fewer layers of cclls than during hibernation but is otherwise unchanged from what is described above. The glands consist, at least in all of the material examined, of much fewer alveoli than are shown in Figure 37. One of these glands is shown in Figure 39.

Although no more care was used in fixation than in the corresponding tissue of the hibernating 


\section{I64 The Alligator and Its Allies}

animal the glands here show their cell details far more clearly than in the former tissue; this may have been partly due to the latter sections being thinner. The glands are of a compound, tubulo-alveolar

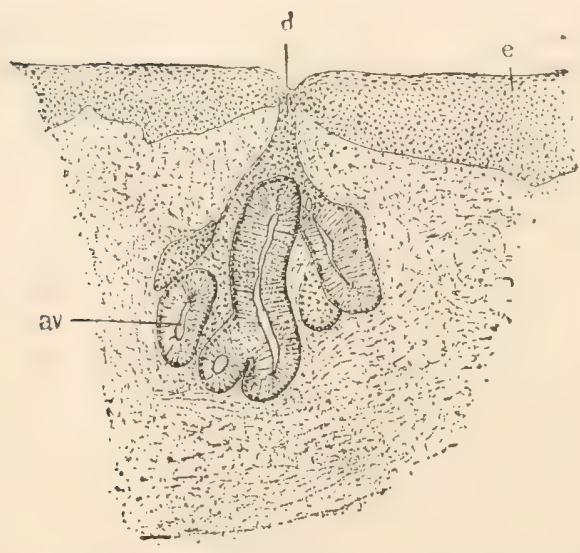

FIG. 39. One of the glands from the posterior region of the tongue of the feeding animal, under somewhat higher magnification than used in Figure 37; a ${ }^{\prime}$, alvcolus; $d$, duct of gland; $e$, stratified epithelium. type; although numerous sections through ducts were obtained (as in Fig. 39), no details of these ducts could be seen.

As noted above, and as may be seen by comparing Figures 37 and 39 , the gland during hibernation, at least in the animals studied, consists of many more alveoli than during the feeding season; this, of course, might not prove to be always the case if larger numbers of animals were studied; the difference in the ages of the animals might have caused this difference in the glands. In the material studied the largest glands from the hibernating animals consist of more than twice as many alveoli as the glands in the feeding animals. As seen 


\section{The Digestive System}

under higrh magnification there is no noticeable difference in the glands at the two seasons.

Rathlie has given the name of "Gescmackwärzchen" to the conical projections found on the dorsum of the crocodilian tongue; they are distinguished by their softness and thinner epithelial covering from the cones that, in many of these animals, bear the openings of the mucous glands.

These taste papillæ generally have the form of a truncated cone and often are surrounded by a shallow circular pit, outsicle of which, in turn, is sometimes a small low wall. They are distributed over the entire dorsum of the tongue, usually at considerable distance from each other in comparison to the size of the tonguc, and are not so numerous as the taste papillæ of the Mammalia. Rathie found their absolute number greatest in $A$. lucius.

Rathke mentions other larger and harder projections on the tongue of certain Crocodilia which, though not perforated by a mucous duct, he thinls are of questionable relation to the sense papillæ. They usually have more the form of a flattened than of a truncated cone, and are very numerous in some species.

The Roof of the Mouth. In the paper mentioned above the author notes that the papille on the roof of the mouth are evenly distributed and are more distinct than those of the dorsum of the tongue. 
One of these papillæ as seen under fairly high magnification is shown in Figure 40.

The areolar tissue, $a$, forming the base of the section is of about the same character as seen in

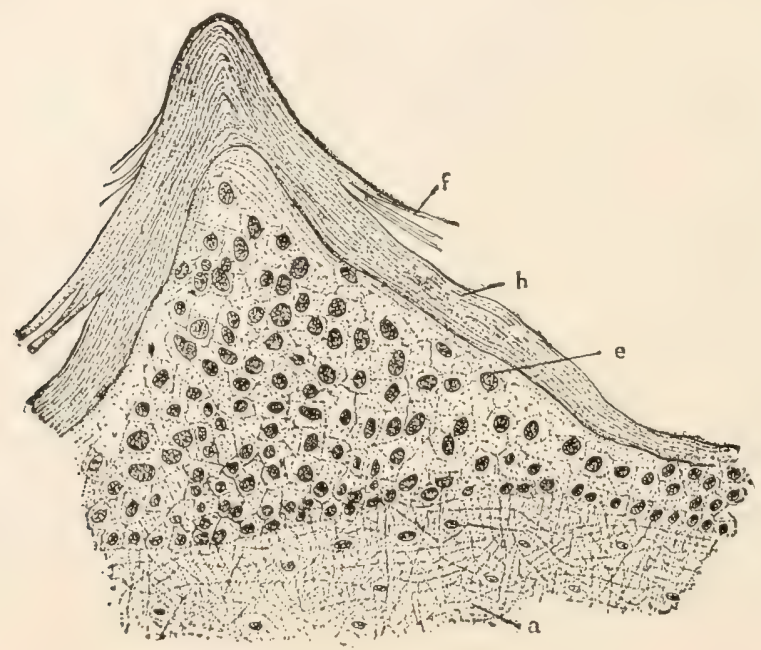

FIG. 40. The covering of the roof of the mouth of the hibernating animal, under fairly high magnification; $a$, areolar tissue; $e$, epithelium; $h$, horny layer; $f$, fibers of horny layer.

the section of the tongue. Less than one tenth of the thickness of the entire areolar base is shown in this section.

The epithelium, $e$, where not thrown into papillæ, has also about the same character as that of the anterior region of the tongue - the same number of cell layers and the same distinct horny layer. At intervals the thickness of the cellular part of 


\section{The Digestive System}

the epithelium is greatly increased, and at the same time the horny layer is also thickened, to form distinct papillæ like the one shown in the figure. These, as has been said, are comparatively small and have the shape of a blunt cone. The center of the cone is, of course, made up of the cellular epithelium, while the outside is covered with the thickened horny layer from which fibers, $f$, are often scen projecting. Near the apex of the cone the nuclei are larger and more widely scattered than those at the base.

No glands were seen in the roof of the mouth of the hibernating animal, but since the entire roof was not sectioned it is probable that they may exist in some regions; in fact, as noted below, sections through the posterior region of the roof of the mouth of the feeding animal do show numerous glands.

As might be expected there is comparatively little difference between this region of the enteron during hibernation and during the feeding season. The only noticeable difference is in the stratified epithelium; that of the feeding animal not only has less sharp papillæ but has also a much thinner scaly layer of cells. As is seen in the figure of the roof of the mouth during hibernation the scaly cells make up, except on the papillæ, nearly or quite half of the thickness of the epithelium, while in the feeding animal they make up not more than one fourth or one third of the entire epithelium. Very 
few cells are scen sloughing off as in Figure to; possibly the act of feeding keeps the superficial scaly cells rubbed off smooth.

In the extreme posterior region of the roof of the mouth the epithelium consists of a greater number of layers (though the number is very variable) than in the region shown in Figure 40. In this posterior region, as noted above, glands are found. These glands have the same structure as those described in connection with the posterior region of the tongue.

The Esophagus. Sections of the osophagus were made from two regions, an anterior, half-inch caudad to the pharnyx, and a posterior region, half-inch cephalad to the opening of the œsophagus into the stomach (Fig. 35).

The general structure of the wall of the osophagus, as seen under a low magnification, will first be described, after which the minute structure of the epithelium, as seen under high magnification, will be discussed.

In the anterior region the usual layers of the vertebrate enteron are present, except, possibly, the muscularis mucosa.

The epithelium, to be described later, is, together with the submucosa, thrown into complicated folds; its closely arranged and darkly stained nuclei cause it to stand out in strong contrast to the other tissues of the section (Fig. 4I,e).

The submucosa, $s m$, is of considerable thickness. 
It is composed of a fairly dense mass of connective tissue, mainly elastic fibers, through which are scattered small blood-vessels, $b v$, and small dark areas, $m b$, that are apparently longitudinal bundles of involuntary muscle fibers. These few and scattered fibers probably represent the muscularis mucosa that is so well developed in the posterior region of the œsophagus.

Outside of the mucosa is a thick circular layer of involuntary muscle fibers, $\mathrm{cm}$, the fibers being collected into irregular bundles, between which are narrow spaces filled with connective tissue that contains a few small bloodvessels.

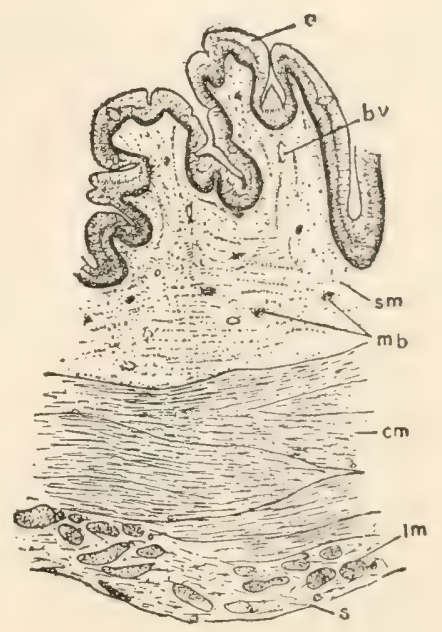

FIG. 4I. A transsection through the anterior region of the cesophagus of the hibernating animal under low magnification $b v$, blood-vessels; $m b$, muscle bundles; other letters as in Figure $\psi^{2}$.

\section{Surrounding the circu-}

lar layer is a thinner and less clearly defined layer of longitudinal muscle fibers, $l m$. The muscle bundles are more definite than in the circular layer and are separated from each other by a considerable amount of connective tissue with a few small blood-vessels. 
The serosa, $s$, is here quite indistinct. It con-

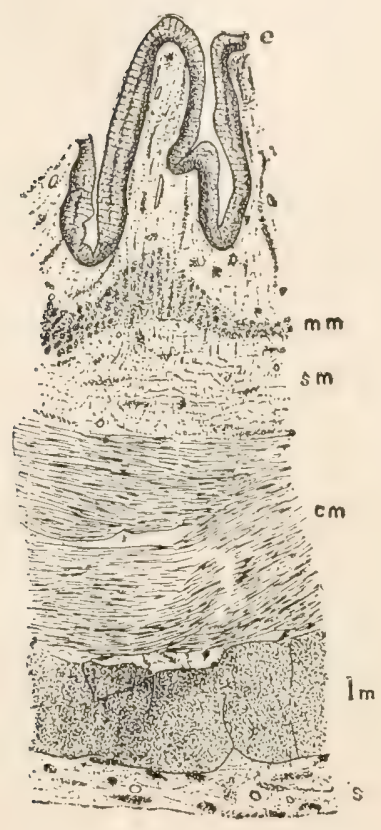

FIG. 42. A transsection through the posterior region of the oesophagus of the hibernating animal, under low magnification; $e$, epithelium; $c m$, circular muscles; $l m$, longitudinal muscles; $m m$, muscularis mucosa; $s m$, submucosa; $s$, serosa. sists of a slightly vascular connective tissue which cannot be distinctiy differentiated from the connective tissue of the longitudinal layer.

In the posterior region of the œsophagus, as may be seen by comparison of figures $4 \mathrm{I}$ and 42 , the wall as a whole is about one third thicker than in the anterior region just described, though how much of this difference is due to different degrees of distension or contraction it is hard to say.

The epithelium, $e$, is in the tissue studied thrown into less complicated folds than in the anterior region, and is not so thick.

The submucosa, $s m$, if the entirelayer may be so called, has about the same thickness and structure as in the more anterior region; but instead of the small and widely scattered bundles of longitudinal muscle fibers there is a distinct layer of muscle 


\section{The Digestive System}

which may be called the muscularis mucosa, $m$, lying about midway between the epithclium and the circular muscle layer.

The muscularis mucosa is somewhat variable in thickness and is thrown into folds that correspond to the larger folds of the epithelium and the submucosa; one of these folds is shown in Figure 42. The fibers of the muscularis mucosa are apparently all longitudinal in position.

Outside of the submucosa is a layer of circular muscle fibers, $\mathrm{cm}$; it is here somewhat wider and more dense than in the anterior region.

The longitudinal muscle layer (Fig. $42, \mathrm{~lm}$ ) is much wider and more compact than in the anterior region. The fibers are indistinctly divided into large irregular masses as shown in the figure.

The serosa (Fig. 42,s) is a varying but fairly thick layer that is quite distinct from the longitudinal muscle layer. It consists of the usual connective tissue groundwork with scattered bloodvessels.

The epithelium, as was said above, is thicker and somewhat more folded in the anterior than in the posterior region, and in the former region is partially ciliated while in the latter cilia are entirely wanting. With these exceptions the epithelium is practically the same in the two regions.

Figure 43 represents the epithelium from the anterior region as seen under high magnification. The outlines of all the cells could not be determined 


\section{2 The Alligator and Its Allies}

but if each nucleus represents a cell there are twenty-five or thirty layers of cells. The nuclei are arranged in two dense,

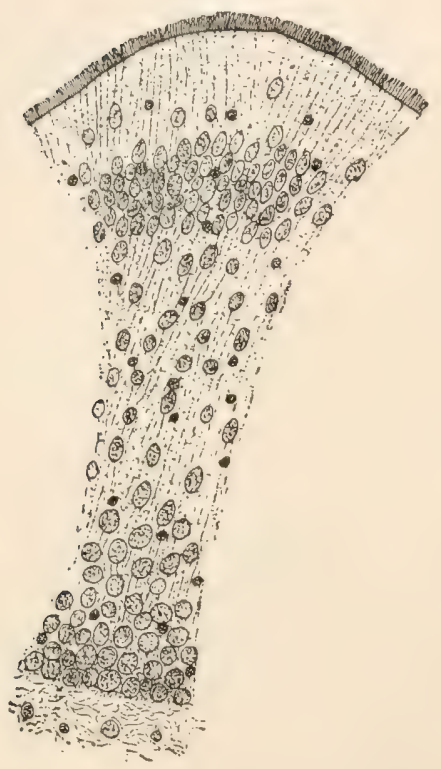

FIG. 43. The epithelium of the anterior region of the œsophagus of the hibernating animal, under high magnification. irregular groups, one along the base of the epithelium, the other about two thirds of the distance from the base to the free border. The basal nuclei are perhaps slightly larger and more rounded than those of the distal group. Between these two groups are numerous more scattered nuclei; while scattered through the epithelium, except near the free border, are smaller, round nuclei that stain somewhat darker than the rest; these, from their size and appearance, seem possibly to belong to an invisible network of connective tissue that has penetrated the epithelium from the surrounding mucosa.

The free border of the epithelium consists of long, ciliated, columnar cells in which the cell walls may be easily seen. The cilia are of average length and 
even in this anterior region are not everywhere present; possibly they are arranged in bands, but the material at hand was not sufficient to determine this. As was noted above, cilia are wanting in the posterior region.

The only differences noted in the anterior region of the œesophagus between the feeding and the hibernating conditions are in the muscularis mucosa and the epithelium. As was noted above, the muscularis mucosa is practically absent in the hibernating stage, being represented only by a few small, scattered bundles of longitudinal muscle fibers; while in the feeding stage there is a narrow but fairly distinct layer to represent the muscularis mucosa.

The difference in the appearance of the epithelium is not striking. The nuclei are somewhat larger in the feeding stage and, instead of being crowded into a basal and a

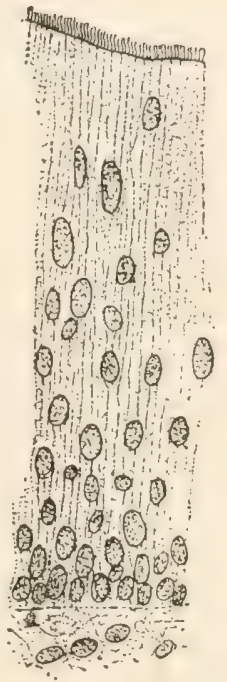

FIG. 44. The epithelium of the anterior region of the osophagus of the fceding a nimal, under high magnification. median zone, as noted in the hibernating conditions, they form a dense basal zone, but show no indication of medial zone. From the dense basal zone the nuclei become more scattered towards the free surface and are rarcly found closer to the surface than is shown in Figure 4. 


\section{I74 The Alligator and Its Allies}

The smaller nuclei scattered among the larger ones, noted in connection with the hibernating stage, are not here seen.

As in the hibernating stage cilia are present on some but not all cells of this region.

The only noticeable difference betwcen the feeding and hibernating conditions of the posterior region of the œesophagus is in the epithelium, which, as in the feeding condition of the anterior œsophagus, exhibits but one zone of closely set nuclei, that at the base of the epithelium.

The Stomach. The stomach was sectioned in three regions, as shown in Figure 35: (I) in the cardiac region very near the opening of the œesophagus; (2) in the middle or fundic region; and (3) in the region near the opening of the pylorus. The first two sections are in the first or large region of the stomach; the third section is in the second or small region of the stomach (Fig. 35).

The wall as a whole is thickest in the fundus, being there practically twice as thick as in the pyloric and half again as thick as in the cardiac region. This great thickening is due mainly to a thickening of the middle or oblique layer of muscle, which is here remarkably developed. The mucosa is of nearly uniform thickness in the different regions and will be described later.

Since there is no striking difference beside that of thickness in the general structure of the wall of the 


\section{The Digestive System}

different regions, the pyloric region, as seen under low magnification, will now be described (Fig. 45).

The mucosa, $m$, consists of fairly long glands underlaid by a well-marked muscularis mucosa, $\mathrm{mm}$, the latter exhibiting a compact circular layer over a wider but more scattered layer of longitudinal fibers. A considerable amount of fibrous connective tissue lies among the muscle fibers. The circular layer of the muscularis mucosa sends towards the surface numerous strands or septa between the glands; six or eight of these are seen in the figure. These strands are not nearly so numerous in the large region of the stomach. As was said, the outer or longitudinal layer of the muscularis mucosa is wider but less compact than the circular and its bundles of fibers are seen in the figure as a layer of large, scattered dots just beneath the circular layer.

The submucosa, sm, is of average thickness and density. In the fundic and cardiac regions it seems to extend between the circular and oblique layers; at any rate, there is a considerable layer of connective tissue between these two muscular layers.

The circular muscular layer, $\mathrm{cm}$, is of only moderate thickness and is of rather a loose character. In the pyloric region it is not very distinct from the underlying oblique layer, but in the other regions, as has just been said, it is separated from 
the oblique layer by a considerable layer of connective tissue like that of the submucosa.

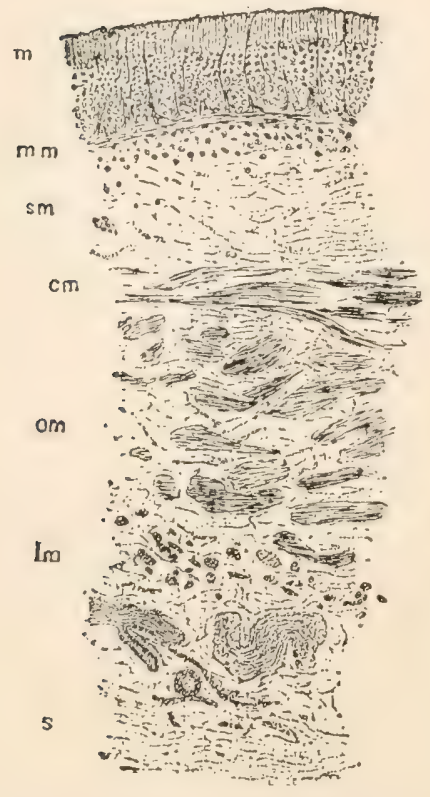

FIG. 45. A transsection through the wall of the pyloric region of the stomach of the feeding animal, under low magnification; $m$, mucosa; $o m$, oblique muscles; other letters as in Figure 42 .
The oblique layer, om, even in this section of the pyloric region is the thickest of the three muscle layers; while in the cardiac, and especially in the fundic, regions it is of great thickness, as was noted above, and is made up of larger bundles with less intervening connective tissue.

The outer or longitudinal muscle layer, $l m$, is comparatively little developed and consists of small rather scattered bundles of muscles with a correspondingly large amount of connective tissue. This connective tissue passes insensibly into that of the surrounding serosa, $s$, a loose, vascular layer of varying thickness and density, shown very thick in Figure 45 , but often much thinner.

So far as could be determined, the mucous mem- 
brane has the same structure in both anterior and middle regrions of the stomach. That of the pyloric or small region, although fixed, stained, et cetera, just as carefully as the rest, did not show cell details suffi-

ciently well to draw; the ducts of the glands in this regionarefairly distinct but thedeeper parts of the glands have the appearance of series of alveoli or large adipose cells. What the significance of this condition may be the writer is not able to say, but since the structure of this region of the gastric mucous
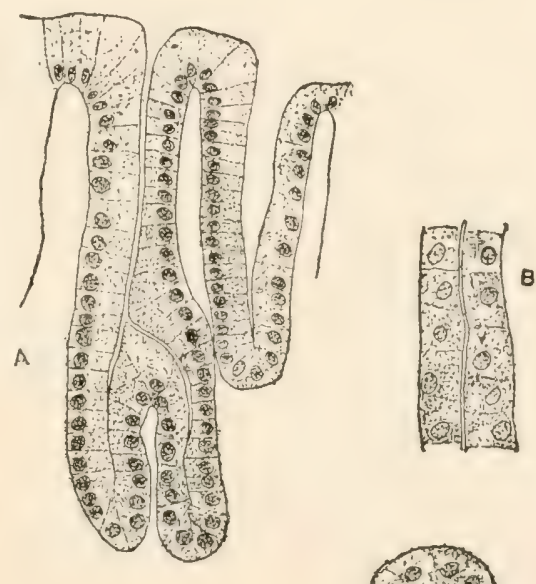
membrane is not Fig. 46. The glands of the middle or fundic region of the stomach of the hibernating animal, under high magnification; $A$, through duct; $B$, through body of gland; $C$, through fundus of gland.

clear no attempt

will be made to describe its appearance under higher magnification than was employed in the figure above. However, as will be noted below, there is probably no great difference between the pyloric mucosa and that of the other regions of the stomach.

Figure 46 shows portions of typical glands 
from the mucosa of the middle region of the stomach, the postcrior border of the large stomach cavity; $A$ is a longitudinal section through two ducts where they open to the surface; $B$ is a similar section through the body of a gland below the region of the duct; $C$ is a transsection through the bottom or fundus of a gland; all are drawn with a camera under the same magnification.

As is seen in Figure 45, under low magnification, the duct is about one third of the entire length of the gland. The lumen of the duct is fairly wide, that of the body of the gland is reduced to a mere slit, while that of the fundus is quite wide.

One, two, or possibly more, glands may open to the surface through one duct, as is shown in Figure 46. There is nothing peculiar about the epithelium of these glands. Near the opening of the duct the cells are of a typical columnar character with finely granular cytoplasm, each with a nucleus at its basal end.

In the deeper parts of the duct the cells become shorter until in the body of the gland (Fig. 46, B) they are cuboidal in outline.

The bodies of the glands are so closely packed together that it is difficult to pick out an individual tube that will show details clearly enough to draw with a camera lucida. So far as could be observed all of the cells of this region of the gland are alike.

The bottom or fundus of the gland, as seen in Figure $46, C$, is somewhat enlarged and has a wide 


\section{The Digestive System}

lumen. The cells are of the same general character as in the more distal parts of the gland except that they are somewhat more columnar or pyramidal than in the body of the gland. The nuclei of the body and fundus are usually somewhat larger and more nearly spherical than in the columnar cells of the duct.

The fecding animals from which tissues were taken were considerably smaller than the hibernating specimen, so that the stomach walls were proportionately thinner; but, so far as could be discovered, there was no difference in structure.

The relative thickness of the entire wall in each of the three regions sectioned was about the same as described above.

As has been said, the mucosa or the pyloric or small region of the stomach from the hibernating animal was so poorly fixed that its structure could not be made out. In the feeding stage the mucosa of this region was as well fixed as any of the other tissues and showed that its structure is essentially like that shown in Figure 46, except that the glands are proportionately not quite so long as in the fundic and cardiac regions, and are somewhat more open - that is, they have wider lumina; their lining cells are all of one kind and are unchanged from what was seen in the hibernating condition.

The Small Intestine. Three regions of the small intestine will be described: (I) an anterior, just 
caudad to the stomach; (2) a middle; and (3) a posterior, one half inch cephalad to the rectum or large intestine (Fig. 35).

As might be expected, the general structure of the wall of the intestine is essentially the same in all three regions, the slight differences noticeable bcing due mainly to variations in the thickness of the various layers.

The middle and posterior regions have about the same diameter, while the diameter of the anterior region is considerably greater, due partly to the greater diameter of the lumen but mainly to the greater thickness of the constitucnt layers, especially the mucosa. The mucosa is also thrown into more numerous and complicated folds in the anterior than in the middle and posterior regions; the complexity of the mucosa seems to diminish as the intestine is followed caudad. In the anterior region the mucosa may form at least one half of the entire thickness of the wall, while in the posterior region it may form less than one third of the thicliness of the intestinal wall. The minute structure of the intestinal epithelium will be described below.

The chief peculiarity of the intestinal wall is the apparent total absence of a submucosa (Fig. 47). As will be described later, the mucosal epithelium is laid upon the usual bed of fibrous and lymphatic tissue, the tunica propria (Fig. $47, t p)$. 
At the outer border of the tunica propria, and with no tissue corresponding to a submucosa between it and the circular muscular layer, is a thin and indistinct layer that has the appearance

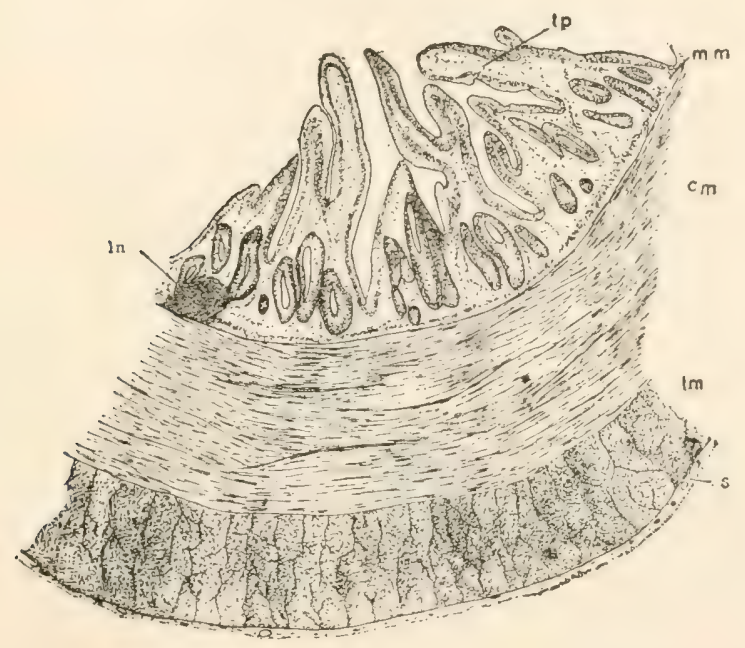

FIG. 47. A transsection of the wall of the anterior region of the small intestine of the hibernating animal, under low magnification; $l n, l y m p h$ node; $t p$, tunica propria; other letters as in Figure 42.

of a longitudinal layer of muscle fibers; this should correspond to the muscularis mucosa (Figs. 47,48 , 49 , and $5 \mathrm{I}, \mathrm{mm})$.

The circular, $\mathrm{cm}$, and longitudinal, $m$, muscle layers are compact, and are distinct from the other layers of the wall; the former is approximately twice the thickness of the latter. The relative thickness of all the layers in the three 
regions of the intestine may be seen by comparing Figures 47,48 , and 49 .

The serosa, $s$, which is of about the same character in the three regions under discussion, is a distinct

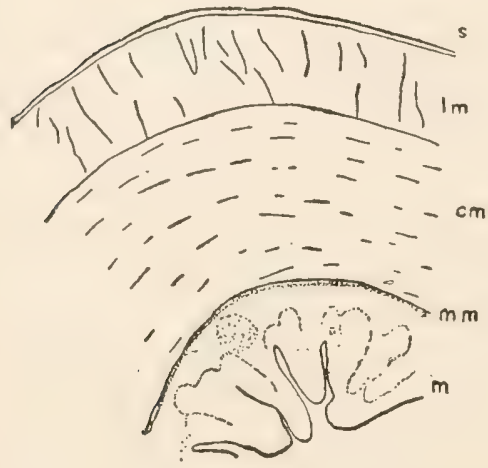

Fig. 48. An outline of a transsection of the wall of the middle region of the small intestine of the hibernating animal, under low magnification; lettering as in Figure 42. and fairly dense layer of connective tissue with numerous bloodvessels.

The general appearance of the mucous membrane as a whole is sufficiently clear in the low-power drawing described above, so that all that need be shown under a higher magnification is the epithelium (Fig. 50). The upper part of this figure represents the lower end of one of the intestinal glands cut longitudinally, below which is the end of another gland in transverse section. Between the two sections is the compact tunica propria of lymphatic tissue.

The section from which this particular figure was drawn was in the anterior region, but the corresponding part of a section in either of the other regions would have practically the same appearance. 
The epithelium is of the stratified columnar type. The superficial cells are very tall and narrow, with the nuclei generally at or near the bases, though an occasional nucleus may be seen near the free end of a cell. Below the tall columnar cells are four or five rows of nuclei which represent smaller, irregular cells, though the cell walls could not always be determined between the closely packed nuclei. No goblet cells are to be seen at any place.

The relative diameters of the three regions of the small intestine in the feeding condition are about the same as noted for the hibernating stage;

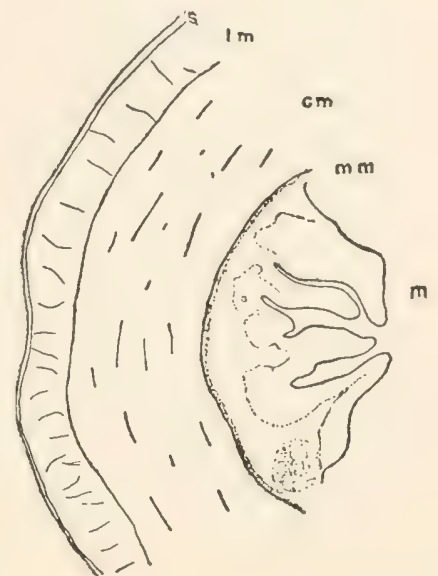

Fig. 49. An outline of a transsection through the wall of the posterior region of the small intestine of the hibernating animal, under low magnification; lettering as in Figure 42. that is, the anterior region has the greatest diameter and the other regions are smaller and have about the same average diameter.

The most marked difference between the intestine during hibernation and feeding is in the relative thickness of the mucosa and muscular layers. As described for the hibernating stage, so in the feed- 


\section{I84 The Alligator and Its Allies}

ing stage, the mucosa is relatively the thickest in the anterior regions and diminishes in thickness

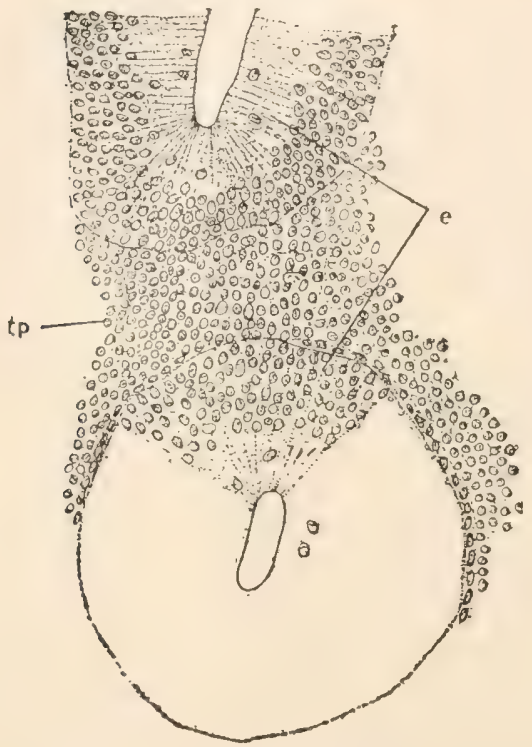

FIG. 50. Part of the mucous membrane of the anterior region of the small intestine of the hibernating animal, under high magnification. The upper part of the figure shows a part of a gland cut longitudinally, the lower part of the figure shows another gland cut transversely; $c$, epithelium; $t p$, tunica propria. caudad; but while, in the hibernating stage, it forms, in the anterior region, as much as half of the entire thickness of the wall, in the feeding condition it forms, in the same region, at least two thirds of the entire wall and in the middle and posterior regions more than half of the wall.

The feeding animals being the smaller, the diameter of the intestine was considerably 1 ess than in the hibernating stage; but the actual thickness of the mucosa was practically the same, so that the difference in diameter was due to the difference in the thickness of the muscular and fibrous layers. It is therefore probable that the differences noted above are due rather to the differences in the size 
of the animals from which the tissues were taken than to the different conditions of hibernation and feeding. The point to be noticed is that the increase in the diameter of the intestine is due almost if not entirely to an increase in thickness of the connective tissue and muscle layers.

No difference in the complexity of the folds of the mucosa of the two stages can be noticed.

The thickness of the fibromuscular part of the wall of the intestine varies considerably on different sides of the same region, but it consists of the same layers in about the same relative amounts.

Figure $5 \mathrm{I}$ represents in outline the wall of the middle region of the small intes-

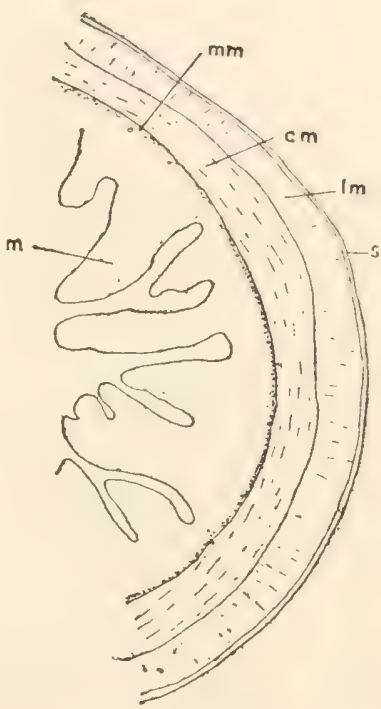

FIG. 51. An outline of a transsection of the wall of the middle region of the small intestine of the feeding animal, under low magnification; $m$, mucosa; other letters as in Figure 42. tine during feeding.

The epithelium is of the same thickness in the two stages, and the only difference in its character that can be seen under a high magnification is that, in the middle region at least, the nuclei are not crowded so close together at the basal ends of 
the cells as in the hibernating stage but are scattered more towards their free ends.

Altogether, the differences in microscopic struc-

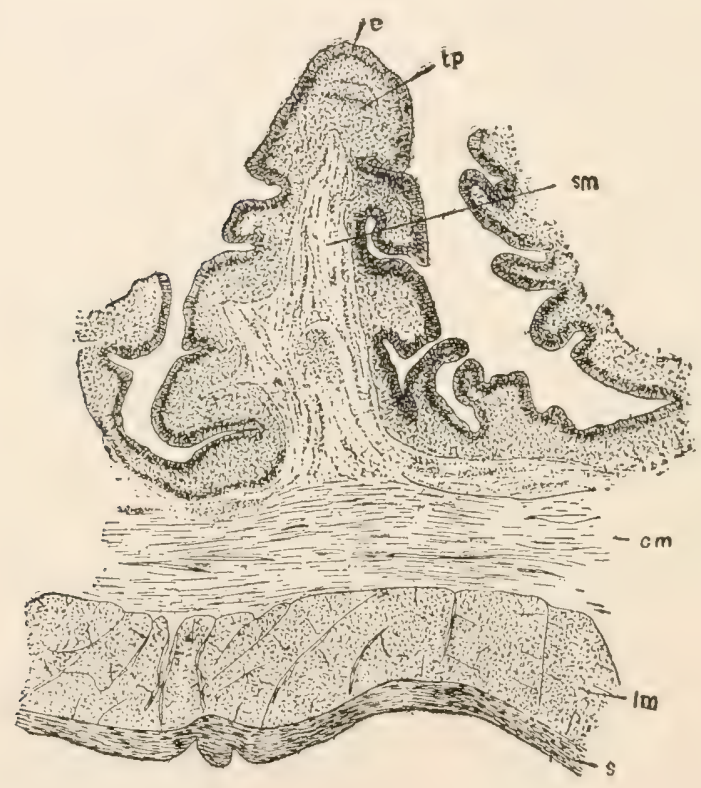

FIG. 52. A transsection of the wall of the anterior region of the rectum or large intestine of the hibernating animal, under low magnification; $t p$, tunica propria; other letters as in Figure 42.

ture between the small intestine of an alligator at the end of the hibernating period and at the end of a period of regular feeding are very slight.

The Large Intestine. The planes of the two sections studied are shown in Figure 35; a low- 


\section{The Digestive System}

power drawing of the postcrior region is shown in Figure 52. The anterior and posterior regions of the large intestine do not differ from each other sufficiently to make it worth while to represent both by drawings. Had an entire section through either region been drawn it would be seen that the wall is of very different thickness in different places, as was noted in connection with the small intestine; the posterior section was drawn where the wall was thin.

It might be supposed that in the feeding season the fecal matter in the posterior region of the rectum would stretch the walls sufficiently to obliterate largely the prominent folds seen in Figure 52 , but such does not

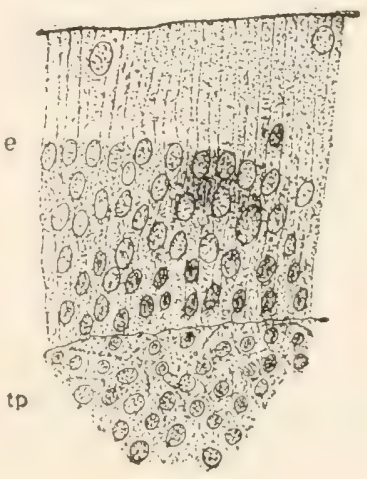

FIG. 53. The epithelium of the anterior region of the rectum of the hibernating animal, under high magnification; $e$, epithelium; $t p$, tunica propria. seem to be the case. The usual layers of the vertebrate intestine are present.

The epithelium, shown under high magnification in Figure 53, is of the same character and thickness throughout, except that as the anal aperture is approached the columnar epithelium changes into the stratified variety. It consists of very tall and narrow columnar cells apparently in one layer, though it is difficult to be sure of this. With an 
occasional exception, near the top, all of the nuclei are arranged in a fairly wide zone below the middle of the epithelium. The nuclei are oval in shape and lie so close together that it is difficult, as has been said, to be sure that the cell to which each belongs extends throughout the entire thickness of the epithelium.

Beneath the epithelium (Fig. 52,e) is a dense tunica propria, tp, underlaid, in turn, by the muscularis mucosa, mm, and a submucosa, sm, of the usual character, which is thrown into marked folds. The circular, $\mathrm{cm}$, and longitudinal, $\mathrm{lm}$, layers are of the usual character except that they vary more in thickness, as noted above, and in density than is usually the case.

The serosa, $s$, is comparatively thin and compact in both regions, and varies somewhat in thickness at different places.

The large intestine of the feeding animal was sectioned in the same regions as in the hibernating. As has been said, the feeding animals used were much smaller than the hibernating, so that, as might be expected, the diameter of the large intestine was much less in the former than in the latter. Except for this difference in diameter there was no noticeable difference between the two stages. In the case of the small intestine, it will be remembered, the greater diameter of the intestine of the larger animal was mainly due to the greater thickness of the muscular and connective- 


\section{The Digestive System}

tissue layers and not to any increase in thickness of the mucous membrane. In the large intestine the mucosa varies in thickness in the animals of different size as do the other layers of the wall.

The glandular character of the lining of the large intestine seems to indicate that his region of the intestine must have some digestive or absorptive function and that it does not act merely as a receptacle for fecal matter; this makes it all the more strange that there should not be some change produced in its structure by five or six months of feeding or of fasting.

Summary. The matcrial used in this investigation was taken from young animals at the end of a feeding period of about five months, and towards the end of the hibernating period after fasting for four or five months.

The regions of the enteron that were studied were as follows: the tip and base of the tongue; the anterior and posterior regions of the roof of the mouth; the anterior and posterior regions of the œsophagus; the cardiac, fundic, and pyloric regions of the stomach; the anterior, middle, and posterior regions of the small intestine; the anterior and posterior regions of the large intestine. Since the work was started at the end of the hibernating period, the tissues of that period were studied and drawn first.

The only difference between the structure of the tip of the tongue during hibernation and during 
the feeding season is that the scaly epithelium with which it is covered is somewhat thicker and more compact in the former than in the latter condition, though even this difference may have been due to differences in the ages of the animals used. The base of the tongue differs from the tip in having a thicker epithelium and in having compound tubulo-alveolar glands. These glands in the hibernating animal have many more alveoli than in the feeding animal, though this, again, may have been due to the difference in age.

The lining of the roof of the mouth is essentially the same as that of the tongue. The glands are found only in the postcrior region. The slight differences in tho papillæ here found may easily be due to the difference in age.

The oesophagus shows the usual layers for that region. Its epithelium is partly ciliated in the anterior part. The muscularis mucosa is very scant in the anterior region. The only difference between the two stages is that in the feeding the muscularis mucosa in the anterior region is much more strongly developed than in the hibernating stage; and in the former the nuclei of the epithelium are not arranged in two zones as in the latter.

The stomach has the usual layers, and has essentially the same structure in the three regions studied, except that the wall in the fundic region is much the thickest, due mainly to the great 
thickness of the middle muscle layer. Only one kind of cell is found in the gastric glands. No difference is to be noted between the hibernating and feeding conditions.

The chief peculiarity of the small intestine is the apparent entire absence of the submucosa. Gol)let cells are also wanting. The greater diameter of the anterior region is due both to the greater diameter of the lumen and to the greater thickness of the walls. The middle and posterior regions have about the same diameter, though the mucosa becomes thinner and less complicated caudad. There is practically no difference between the hibernating and feeding stages.

The anterior and posterior regions of the large intestine have essentially the same structure. No difference can be seen between the hibernating and feeding conditions. 


\section{CHAPTER VI}

\section{THE UROGENITAL ORGANS}

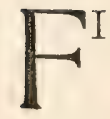

IGURE 54 represents the urogenital apparatus of a thirty-inch female specimen of Alligator mississippiensis. Figure 55 shows the corresponding organs of a male $A$ lucius; reproduced from Bronn.

The urogenital organs in the young animal are so similar in the two sexes that one might easily be mistaken for the other; of course in sexually mature animals, especially during the breeding season, this is not the case.

The kidneys, Fig. 54, k, Fig. 55, a, are flattened, lobulated organs lying against the dorsal body wall. The large anterior lobe of each kidney is pointed at its anterior end and lies at some little distance from its fellow; it is partially divided into secondary lobes and is traversed on its ventral surface by branching bloodvessels. Its antero-medial border is sometimes partially concealed, in a ventral view, by the elongated gonad of that side. Caudad to the main lobe of the kidney is a smaller, usually distinct, lobe in contact mesially with its fellow of the opposite side. 
A fairly wide ureter, Fig. 54, u, Fig. 55, d, extends from the posterior end of each kidney to open (Fig. 54, ư ${ }^{\mathrm{T}}$, Fig. 55, e) into the anterior region of the cloaca, as described in connection with the digestive system.

The ovary, Fig. 54, o, as noted above and as seen in Figs. 54 and 55, in the young animal is of practically the same shapeas the testis. The ova at this stage are of microscopic size and are hence not visible to the naked eye. The ovary, even at this stage, is more or less distinctly marked off into lobules by a series of small grooves.

The oviduct, Fig. 54, f, which at this stage is, of course, of small diameter, extends across the ventral surface of its corresponding kidney and opens, $\mathrm{f}^{\mathrm{r}}$, into the posterior part of

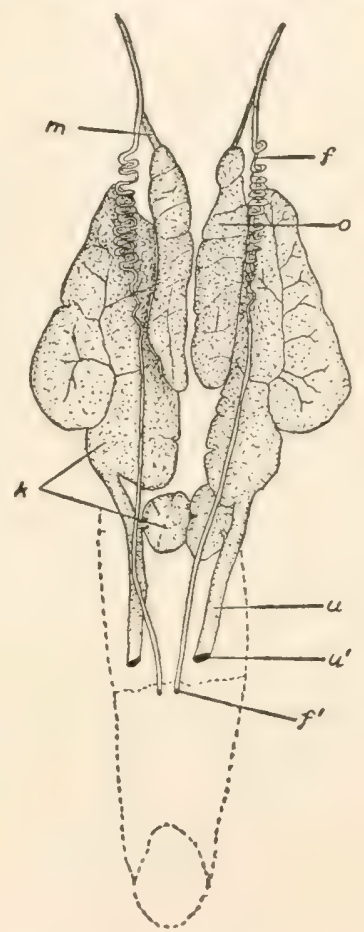

Fig. 54. Female UrogenITAL SYSTEM.

$f$, oviduct; $f^{\mathrm{T}}$, opening of oviduct; $k$, kidney; $m$, mesentery ; $o$, ovary; $u$, ureter; $u^{x}$, openof ureter. the cloaca as has already been described. Its peritoneal opening is some distance cephalad to the head of the ovary. Its course from this opening is straight until about the anterior end of the ovary; it then becomes somewhat con- 


\section{I94 The Alligator and Its Allies}

voluted for a short distance, but gradually straightens out, to pass to its posterior end as a nearly straight duct. The anterior straight portion of the oviduct is connected with the head of the ovary by a narrow band of mesentery.

Each testis, Fig. 55, b, like the ovary, lies along the ventro-mesial border of its corresponding kidney and is connected with the posterior region of the cloaca by a slender vas deferens, Fig. 55, c, f.

According to Rathke (in C. acutus) a small, slender epididymis lies along the outer side of the posterior half of each testis.

The Copulatory Organs. The penis, Fig. 56, usually lies completely hidden in the cloaca; with its glans projecting backwards it is strongly arched; along the convex side of the arch, which is directed towards the upper wall of the cloaca, runs a groove, which serves as a penial urethra to conduct the semen.

According to Rathke there may be recognized in connection with the penis two fibrous strands (resembling the corpora cavernosa of mammals), a corpus cavernosus urethrea, and a covering derived from the mucous membrane of the cloaca. The two fibrous strands arise from the pubis as two thick plates that soon completely fuse together by their adjacent sides to form the shaft, c, of the penis. These fused strands taper gradually towards the glans, in which they end in a point. From their mode of fusion there is left between 

1.

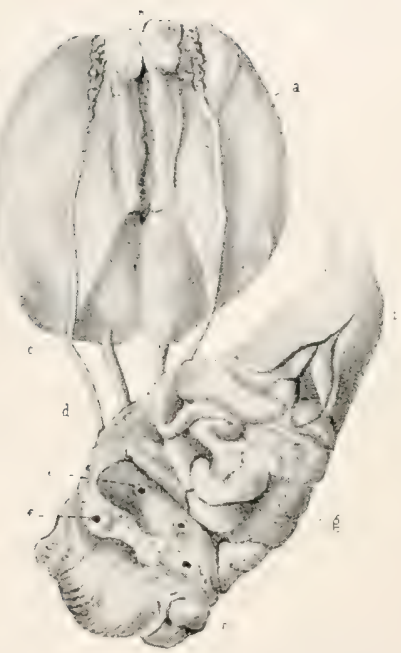

Fig. 55. MALE Urogenital Apparatus of Alligator Lucius. (After Bronn.)

$a$, kidney; $b$, testis; $c$, vas deferens; $d$, ureter; $e$, opening of the ureter into the cloaca; $f$, opening of the vas deferens into the cloaca; $g$. upper region of the cloaca; $h$. hinder region of the cloaca; $i$, rectum. s.

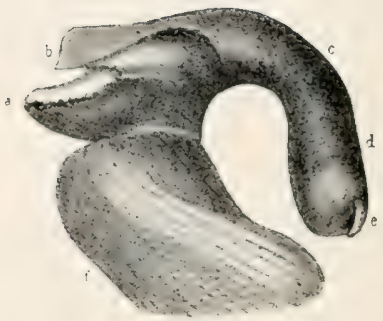

Fig. 56. Male Organ of Alligator Lucius, XI. (From Bronn, after Rathke.)

$a$, the right crus penis; $b$, the $\mathrm{mucous}$ membrane of the cloaca that covers the organ; $c$, shaft of the penis; $d$, base of glans; $e$, point of glans; $f$, part of the ring muscle of the cloaca. 
them, on the side towards the upper wall of the cloaca, a fairly deep furrow that extends to the tip. According to Rathke these shafts are not of cavernous tissue, but the tube is lined by a layer of this tissue.

The glans, e, consists of two parts between which, where they leave the shaft of the penis, is a funnel-shaped hole, wider towards the free end of the penis and divided into similar lateral halves by a fold of skin. The glans is much shorter than the shaft of the penis. The covering of the penis is much thinner than the mucous membrane of the cloaca and is thinnest along the groove; it extends from the shaft over the glans without forming a foreskin.

The base of the penis is attached to the pubis near its symphysis. With this base the most anterior part of the strong ring-muscle of the cloaca is closely attached by a fairly large mass of fibrous tissue. Rathke fails to find any muscles that are concerned alone with the copulatory organs.

In the copulation of the crocodile, according to Rathke, the penis is erected, though how this is caused is difficult to say since the corpora cavernosa consist only of fibrous tissue and the cavernous tissue lining the groove is very thin. The penis can, therefore, project only a short distance from the cloaca. The cavernous tissue is capable of causing only a slight elongation of the shaft, but 
I96 The Alligator and Its Allies

the glans is considerably elongated by the strong influx of blood into that structure. According to Voeltzkow (78) the penis in the Madagascar crocodile is $20 \mathrm{~cm}$. in length.

The clitoris of the sexually mature female crocodile is very much smaller than the penis of a male of the same size, but, according to Rathke, it varies greatly in size in different species. It is built on exactly the same plan as the penis.

According to Bronn the clitoris as well as the penis projects from the cloaca, out through the anus, in the embryo of the crocodilc; this was not observed by the present writer in the embryo of the Florida alligator, A. mississippiensis. 


\section{CHAPTER VII}

\section{THE RESPIRATORY ORGANS}

The Larynx and Trachea. In the Crocodilia the framework of the larynx consists of three cartilages, of which two represent the arytenoids of the Mammalia; the third represents the thyroid and cricoid of mammals. The last is considerably larger than the first and is a broad closed ring, differing in form in the different species. In spite of the fact that some of them have a voice, the vocal cords, according to Bronn, are wanting in the Crocodilia. According to Henle the vocal apparatus is produced by the projection into the laryngeal cavity of the inner border of the small arytenoid cartilages and by the infolding, under these cartilages, of the mucous membrane of the larynx; this forms the thick but fairly free folds that, when the glottis is narrowed, are well adapted to produce the harsh tone of the animal.

The epiglottis is absent in the Crocodilia.

In many Crocodilia ( $C$. anlgaris, for example) the trachea, Fig. 57, tr, forms a loop which begins in some species before hatching, in other species not 
until long after hatching. In the genus Alligator

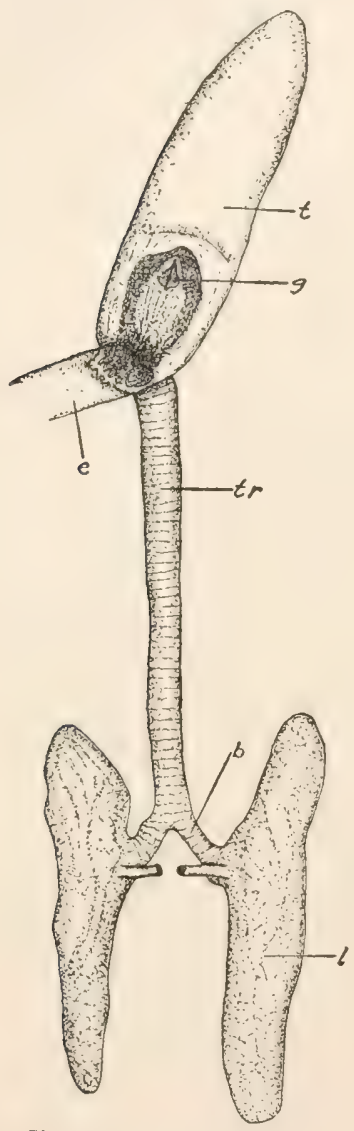

Fig. 57. Respiratory ORGANS.

$b$, bronchus: $e$, cesophagus; $g$, the trachea is straight.

More universal than this looped structure there is found another peculiar structure in the crocodilian trachea. It is a short vertical partition in the stem just before its division into the two branches. This partition is partly membranous and possesses one or more stiffening cartilaginous strands which are outgrowths of so many cartilaginous rings of the trachea. The number of the stiffening fibers varies in the different species.

The number of the tracheal rings varies not only in the different species but also in different individuals of the same species. There are between fifty and sixty in $A$. mississippiensis. According to Rathke the number of rings in the individual animal almost certainly does not inglottis; $l$, lung; $l$, tongue; $t r$. trachea.

crease with age. The number of rings is smallest in the gavials and greatest in the crocodiles (genus Crocodilus). The number of rings in the two 
divisions of the trachea does not increase with age except, pcrhaps, in C. acutus and biporcatus. The lateral bend that the tracheal stem of so many Crocodilia exhibits is not due to the greater number of rings because in some species (gavials) where the bend is present the number of rings is smaller than in the Crocodilia where the bend is absent. According to Rathke and others most of the tracheal rings are closed, but a varying, though at most small, number are open on the dorsal side. These openings become wider as the larynx is approached. The transverse muscle fibers which are found in the most anterior and largest of these brealis in the tracheal rings were found, says Rathke, in embryos after the middle period of incubation.

The cartilaginous rings of the bronchi, $b$, are also apparently open for a time after their formation, but soon close. Not infrequently in embryos and in young animals are found rings that are split like a fork, with one or both branches fused with neighboring branches.

The Lungs. The lungs, Fig. 57, 1, are more highly developed among the Crocodilia than among any other Saurian or Hydrosaurian group. The histological groundwork of the whole lung tissue is a connective tissue of finc elastic fibers. In the lungs, on the canal that appears as the elongation of the bronchus, cartilage appcars, according to Rathke, as bands lying one behind the other; some of these 
bands form complete, others partial rings; some of the latter are forked. The hindermost appear to be the broadest and most irregular. Their number is different in different species and varies in different individuals of the same species. They range in number, according to Rathke, from nine, in $A$. lucius, to twenty-five, in $C$. acutus. ${ }^{\mathrm{I}}$

The arterial branch, carrying venous blood to the lungs, develops a capillary network close to the alveolar walls, which leads away over the low alveolar septa, while over the tops of the higher septa and on the inner surface of the tube-like bronchial processes it forms a wide-meshed network of capillaries that are apparently chiefly nutrient.

All the respiratory capillaries are attached by only one side to the alveolar wall; the free side that projects into the air space of the alveolus is covered by a continuous pavement epithelium.

While the respiratory surfaces are covered with an alveolar epithelium of large polygonal cells, the free borders of all high septa and ridges, as well as the inner surfaces of the bronchial processes, are covered with ciliated cylindrical cells.

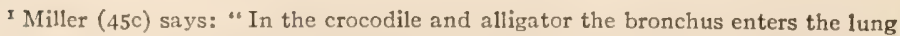
near its center, and passes somewhat obliquely into the lung until it reaches the junction of the lower middle third; here it breaks up into eight to fifteen tubular passages. These tubular passages are studded with a great many air-sacs. In these animals the lung for the first time gives the structure as it is found in mammals. There are many air-sacs which communicate with a common cavity. or atrium, all of which in turn communicate with a single terminal bronchus. A single lobule of the mammalian lung is simply enlarged to form the lung of the crocodile; the lung of the former is only a conglomerate of that of the latter."
} 


\section{CHAPTER VIII}

\section{THE VASCULAR SYSTEM}

$\mathrm{HE}$ account given by Bronn in his Thicreict
is apparently the only published description
of the circulatory organs in the Crocodilia. This account, even when translated, is not very satisfactory, especially because it contains no diagrams of the circulation. It was, therefore, deemed worth while to work out the circulation in the Florida alligator in order that we might have not only a written description, but also a scries of more or less accurate diagrams of the veins and arterics.

A number of departures from the description of Bronn were found, some of which are noted below.

Most of the work was done upon animals of about thirty inches length, which were obtained alive from the Arkansas Alligator Farm at Hot Springs, Ark.

The arteries were injected with a colored starch mass by inserting a two-way cannula into the dorsal aorta. With the blood thus forced into them from the arteries, the veins could, in most cases, be traced without difficulty. 
In the diagrams the outlines of the more important organs are accurately shown by dotted lines, and the relative diameters of the blood-vessels are shown as accurately as possible by the solid black lines.

\section{The HEART}

In the Crocodilia, as is well known, the heart is four-chambered and has about the same general shape as in the higher vertebrates, Fig. 58.

The venous blood is emptied into a thin-walled sinus venosus on the dorsal side of the heart by three large vessels and one small one. The largest of these, the postcava, empties into the posterior side of the sinus venosus and brings blood from the posterior regions of the body; it is quite wide, but is exposed for a very short distance between the liver and the heart. Two large hepatic veins empty into the postcava so near the sinus venosus that they practically have openings into the sinus, as is shown in a somewhat exaggerated way in Fig. 59. Near the postcaval and hepatic openings is the distinct coronary vein, lying in a slight depression between the right and left ventricles.

From the anterior regions of the body the blood is brought back through two fairly wide but very thin-walled precaval veins which pass across the dorsal surface of the heart to enter the sinus venosus. The arterial blood is brought from the lungs by 


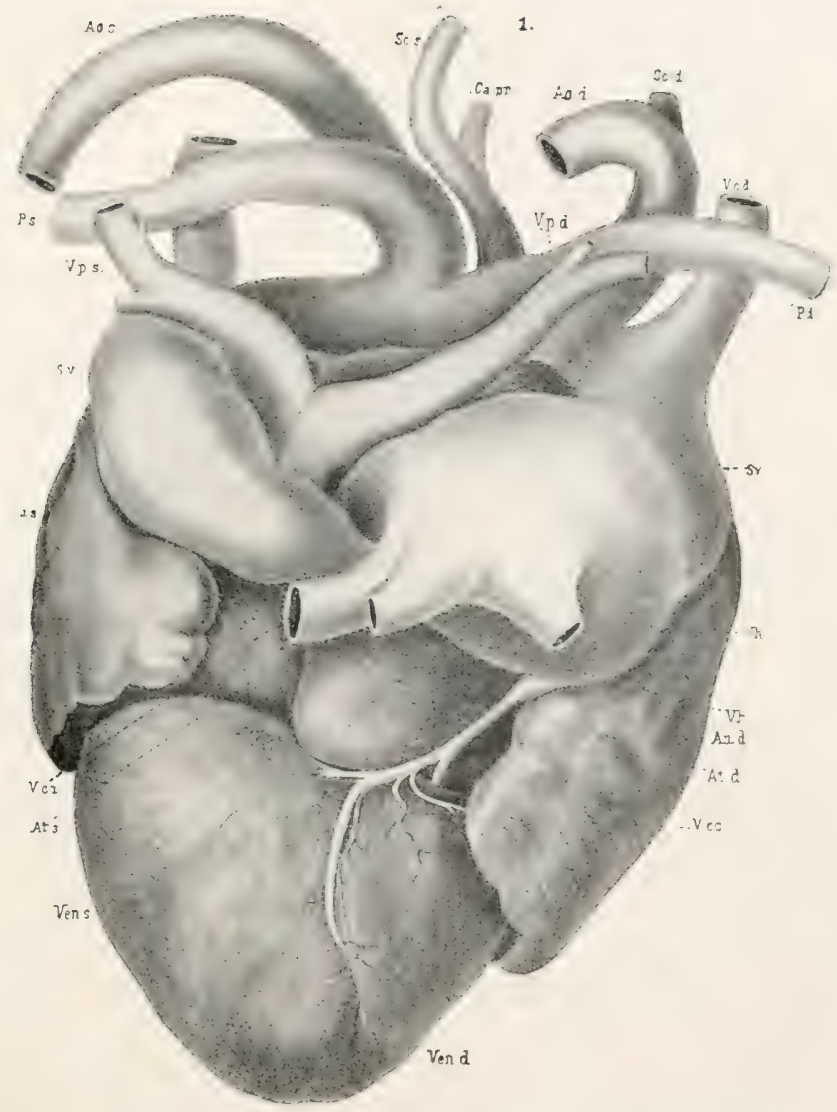

Fig. 58. Heart of A. Lucius. (Dorsal View.) (From Bronn, after Fritsch.)

$A \circ, d, A o, s$, right and left aortx; $A t, d, A t, s$, right and left atria; $A u, d$, $A u, s$, right and left auricles; $C a, p r$, primary carotid; $P, d, P$, s, right and left pulmonary arterie;; $S c, d, S c, s$, right and left subclavians; $S v$, sinus venosus; $V, c c$, coronary vein; $V, c, d, V, c, i$, right precava, and inferior cava; $\boldsymbol{V} e n, d, \boldsymbol{V} e n, s$, right and left ventricles; $V, h$, hepatic vein; $l, p, d, V, p, s$, right and left pulmonary veins. 

two wide, thin-walled pulmonary veins, Fig. 58 , V.p.s., V.p.d. They leave the lungs somewhat caudad to their middle region, near the point of cntrance of the bronchii and the pulmonary arteries, pass mediad in a direction almost at right angles to the long axis of the body, and enter the left auricle at the same point.

Blood leaves the heart through five large vessels: (I) the pulmonary artery, (2) the two aortic arches, (3) the right subclavian, (4) the primary carotid.

The pulmonary leaves the small right ventricle as a single stem, which soon branches into two arteries that pass cephalad and laterad to the lungs, along with and close to the main bronchi. The other arteries that carry blood into the systemic circulation are fused at their base to form a sort of conus arteriosus which may be distended in injected specimens until it is larger than the two ventricles together. When opened this conus is found to contain two chambers that lead into the left ventricle; the larger chamber gives origin to the right systemic arch, the right subclavian, and the primary carotid; the smaller chamber is the basal part of the left systemic arch.

The two systemic vessels, Fig. 58, Ao.s, Ao.d, pass, in the usual manner, as two arches to the dorsal region, just posterior to the ventricles, where they form the dorsal aorta in the manner to be described in connection with the arterial system.

The further course of the primary carotid and 
204 The Alligator and Its Allies

of the right subclavian will also be described in connection with the arterial system.

The auricles are very large in proportion to the
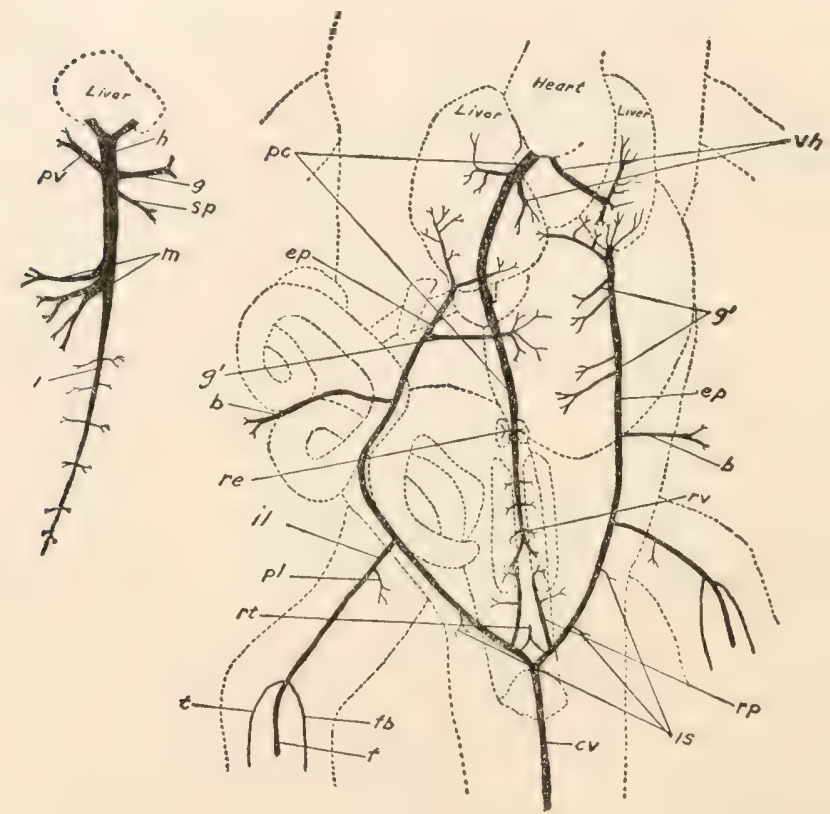

FIG. 59. The veins of the postcrior region of the Florida alligator. The postcaval system and its associated veins are shown in the main figure; the hepatic portal system is shown in the smaller figure to the left.-For lettering, see pages 224-25.

ventricles, though their relative sizes will, of course, vary with the amount of contained blood.

\section{The Venous System}

The Posterior Vena Cava and its Branches. The postcura, Fig. 59, pc, as noted above, is a wide, 


\section{The Vascular System}

thin-walled vessel seen extending across the short space between the anterior face of the right lobe of the liver and the sinus venosus. As was also noted above, the hepatic veins, vh, - at any rate that from the left lobe of the liver,--enter the postcava so close to the heart that they may be considered to have one or more distinct openings into the sinus venosus. Followed caudad, the postcava may be traced through the large right lobe of the liver, from which it receives several branches. Emerging from the posterior border of the liver, it is seen to extend caudad, in the median line, as a rather inconspicuous vessel that receives blood from the reproductive organs and the kidneys that lie close on either side of it.

The hepatic portal vein, $h$, has the usual distribution for that vessel. Entering the liver in the neighborhood of the bile duct, it receives first (i.e., nearest the liver) a small branch from the pancreas, pv; near the pancreatic are one or two branches from the stomach, g, and a branch from the spleen, sp. A short distance caudad to these vessels are two or three mesenteric veins, $m$, lcading from the mesentery and small intestine. Caudad to the mesenterics, the portal system may be seen as a vein of diminished caliber, i, leading from the posterior part of the small intestine and from the large intestine.

The connection mentioned by Bronn between the rectal branch of the portal vein and the caudal 
vein could not be demonstrated. After entering the liver, the portal, of course, breaks up into capillaries, and the blood thus distributed is re-collected by the capillaries of the hepatic veins above mentioned.

The internal epigastric veins, ep, are, perhaps, the most conspicuous vessels of the postcaval system. When the ventral abdominal wall of the animal is removed, they may be seen extending forward from the pelvic region, on each side of the body, to enter the posterior edge of the liver. The epigastric of the right side enters the large or right lobe of the liver, where it breaks up into capillaries; the left epigastric sends its main branch into the left lobe of the liver, but also sends a branch over to enter the right lobe.

Following the epigastrics caudad, they are seen to receive vesscls from nearly all parts of the posterior region of the body. The left epigastric, which extends across the ventral side of the stomach, receives from that organ four or five branches, $\mathrm{g}^{\mathrm{I}}$; while the farther removed right epigastric reccives only one or two branches from the stomach. Posterior to these gastric veins the epigastrics receive one or more veins, $b$, from the body wall and skin. Posterior, again, to the lastnamed veins, each epigastric receives, in the pelvic region, a large vein, the iliac, il, which receives, in turn, a vein from the pelvis, $\mathrm{pl}$, and continues down the thigh and lower leg to the foot as the femoral, 


\section{The Vascular System}

$\mathrm{f}$, the chief vein of the posterior appendage. After receiving small branches from the muscles of the thigh, the femoral receives near the knee a small branch from the posterior surface of the lower leg, $\mathrm{fb}$, and a larger one, t, that leads from the anterior surface of the lower leg and foot.

The veins of the pes were so small, in the comparatively small animals it was necessary to use, that their distribution could not be determined with certainty, though they seemed to parallel very closely their corresponding arteries to be described below.

A short distance candad to the iliac veins, each epigastric receives one or two fairly large branches from the pelvic region, called by Bronn the ischiadic veins, is. Caudad to the ischiadics and dorsal to the cloaca, each epigastric is united with a short but wide renal portal or renal advehente vein, rp, leading to the posterior border of its respective kidney and receiving, on the way, a short branch from the pelvic region, shown just cephalad to the reference lines rt and rp.

Very close to its junction with the renal portals each epigastric gives off a small branch which unites with its fellow of the opposite side to form a median vein, rt, the rectal leading from the posterior part of the large intestine. A very short distance caudal to these last veins, in the region just dorsal to the anal opening, the epigastrics are formed by the division of the caudal vein, $\mathrm{cv}$, which, of course, brings blood from the tail and is, 
on account of the large size of that organ, of considerable caliber.

The Anterior Vence Cavce and their Branches. The entrance of the precaval veins into the heart was mentioned above; their branches, in order from the heart cephalad, will now be described. Since the two precavæ are alike, it will be necessary to describe the branches of only one side of the body. After leaving the heart, the precava may be traced forward, for a short distance, at the side of the trachea and œsophagus, as a wide, thin-walled trunk, Fig. 60, vca. The first tributaries that it receives are the internal mammary and vertebral veins, which join it at the base of the neck at almost the same place.

The internal mammary, Fig. 6o, $\mathrm{im}$, is a rather small vein, bringing blood from the ventral wall of the thorax. It may be followed along the inner surface of the ribs, near the sternum, in company with its corresponding artery.

The rertebral vein, Fig. $60, \mathrm{v}$, is also of small diameter and extends to the dorsal body wall near the spinal column, from which region it returns blood to the anterior vena cava; it is drawn too large in the figure.

Just cephalad to the vertebral and internal mammary, the internal jugular, $\mathrm{j}$, enters the precava. The internal jugular may be followed directly forward, close to the side of the trachea and oesophagus, from which it receives numerous 


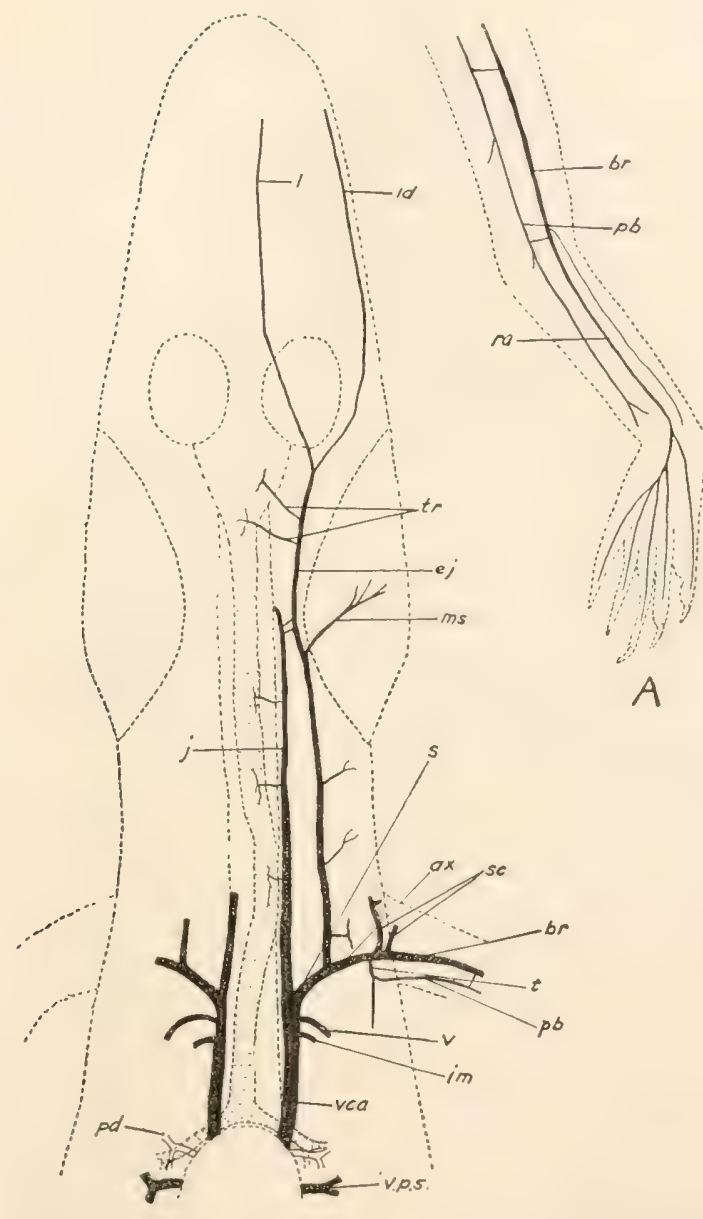

FIG. 60. The veins of the anterior region of the Florida alligator. The veins of the left foreleg are shown at A.-For lettering, see pages 224-25.

branches. Near its point of entrance to, or rather exit from, the skull, it anastomoses, by two or 
three short branches, with the external jugular, ej, to be described later. Its distribution in the cranial cavity could not be detcrmined in the available material. At the point of entry of the internal jugular the precava passes laterad for a short distance and then divides into two more or less equal branches, the above-mentioned external jugular, ej, and the subclavian, s, of which the latter will first be described.

The sublavian, s, of course, returns blood from the regions of the shoulder and arm. On reaching the body wall, where it might be called the axillary, ax, it receives, on its posterior side, a large thoracic vein, $t$, which returns blood from the thorax, shoulder, and skin. The thoracic receives a branch from the posterior surface of the arm, which might be called the postbrachial, pb; this postbrachial may be traced, as a rather small vessel, to the hand; at the elbow it is connected, by one or more small branches, with the brachial.

Just distal to the thoracic the axillary vein receives two fairly large vessels, the subscapulars, sc, that return blood from the shoulder and upper arm. After receiving the subscapulars, the axillary may be followed into the upper arm as the brachial, br. As has been said, the brachial and postbrachial anastomose near the elbow, and in this region the former receives a small vessel that extends parallel to it from the manus. 


\section{The Vascular System}

In the forearm the brachial may be called the radial, Fig. 6o, A, ra; on the back of the manus the radial receives branches from the various digits and from a rather complex plexus of vessels in the carpal region.

The externul jugulur, Fig. 60, ej, after separating from the subclarian, may be traced cephalad, close beneath the skin, to the base of the skull, where it is connected with the internal jugular by short branches, as has already been noted. It receives several small branches from the slin and muscles of the neck and shoulder regions. At the region of its anastomosis with the internal jugular it receives a large branch, the muscular, ms, from the massive muscle at the angle of the jaw and from the skin of that region.

A short distance cephalad to the muscular the external jugular receives, on its mesial side, two or three branches from the trachea, larynx, and œsophagus, tr. Anterior to these ressels the external jugular is formed by the union of two chicf veins, the lingual, 1, from the ventro-lateral surface of the tongue, and the inferior dental, id, from the mesial : urface of the lower jaw. The connection of the superior dentul (extending along the bases of the maxillary tceth) with the jugular could not be determined with certainty, hence that vessel is not shown in the figure. The same is true of the small veins in the region of the cranium. 


\section{The Arterial System}

The Abdominal Aorta and its Branches. The right and left aortic arches, Fig. 6I, Aod, Aos, arising from the heart in the manner already described, form a rather long loop and approach each other in the middorsal line. Here they are united by a short, wide connective in such a way that the left arch seems continued into the cœliac artery and the right into the dorsal aorta proper. Each arch, anterior to the connective, gives off two fairly large branches, oe, to the posterior region of the œesophagus.

The coliac artery, Fig. 6I, c, is the largest branch of the abdominal aortic system. After giving off a couple of small branches, oe, to the posterior region of the oesophagus, it gives off a large spleno-intestinal artery, si, to the spleen and small intestine.

The coliac then breaks up into three arterics of about the same size: the gastro-hepatico-intestinal, ghi, carrying blood to the stomach, liver, and small intestine; the pancreo-intestinal, pi, leading to the pancreas and small intestine; and the gastric, $g a$, to the greater part of the stomach.

From the dorsal aorta proper, da, which, as has been said, seems to be the direct continuation of the right aortic arch, several arteries are given off; these will be described as they occur in an antero-posterior direction.

At about the point of union of the two aortic 
arches arises the most anterior of seren or cight pairs of lumbar arteries, lu I-7; this first lumbar artery is continued cephalad for some distance as a longitudinal trunk that gives off severallateral branches to the walls of the thoracic region. The other six or seven lumbars are distributed to the dorsal body wall, and arise, at more or less regular intervals, as far caudad as the sacrum, or even back of that point.

The first large branch of the aorta is the un-

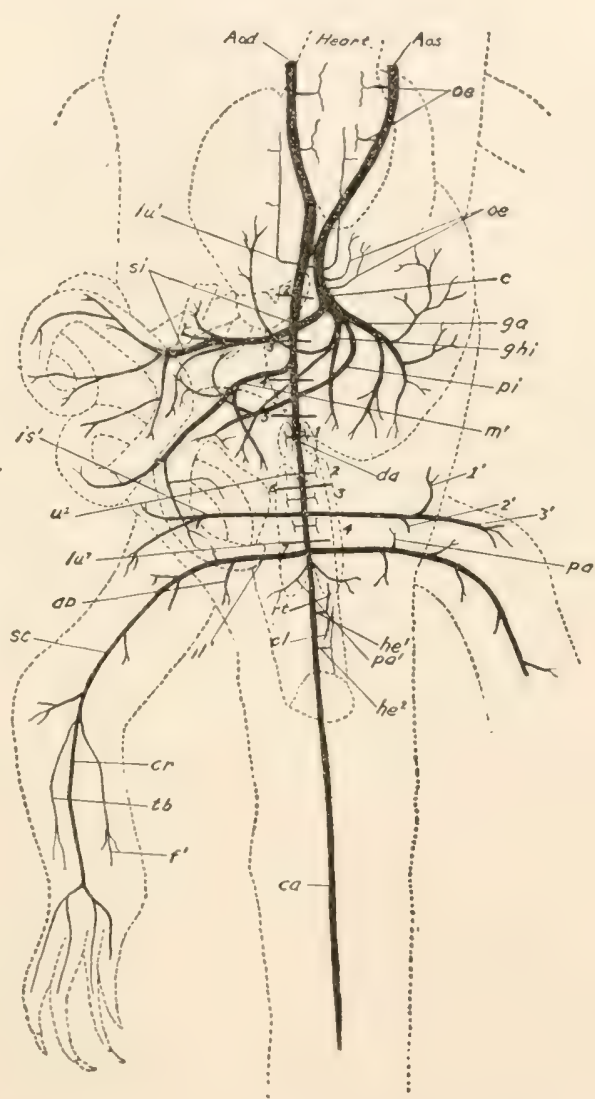

FIG. 6I. The arteries of the posterior region of the Fluricia alligator.-For lettering, see pages $224^{-25}$. paired mesenteric artery, $\mathrm{m}^{\mathrm{I}}$, which is given off in about the region of the fourth pair of lumbars; it 
carries blood throwgh the mesentery to the greater part of the small intestine and also sends a small branch to the large intestine.

Posterior to the mesenteric, the aorta gives off four or five pairs of short arteries, the urogenitals, $u \mathrm{I}-4$, that lead to the nearby reproductive organs and kidneys.

About the middle region of the kidneys, a short distance anterior to the sacrum, is given off a pair of rather large arteries, called by Bronn the $i s c h i$ adice, is ${ }^{\mathrm{x}}$; each ischiadica, after giving off a couple of small branches to the back, passes laterad and divides into three main branches: ( $\mathrm{I}^{\mathrm{I}}$ ) to the ventral body wall, ( $3^{\mathrm{I}}$ ) to the anterior border and deeper region of the thigh, and $\left(2^{*}\right)$ to the pelvis.

In the region of the sacrum is given off a pair of iliac arterics, il ${ }^{1}$. Each iliac is of about the same diameter as the ischiadica and gives off, soon after leaving the aorta, an artery, ab, that apparently leads chiefly to the abdominal muscles. Distal to the origin of the abdominal, the iliac gives off a small peliic artery, pa, which leads, as the name would indicate, to the pelvis. The iliac then passes into the thigh, where it gives off several large branches and may be called the sciatic, sc. At the knee the sciatic gives off two rather small branches: one, the fibular artery, $\mathrm{f}^{ }$, extends down along the posterior side of the lower leg; the other is parallel to the first and may be called the tibial artery, tb, since it extends along the anterior or 


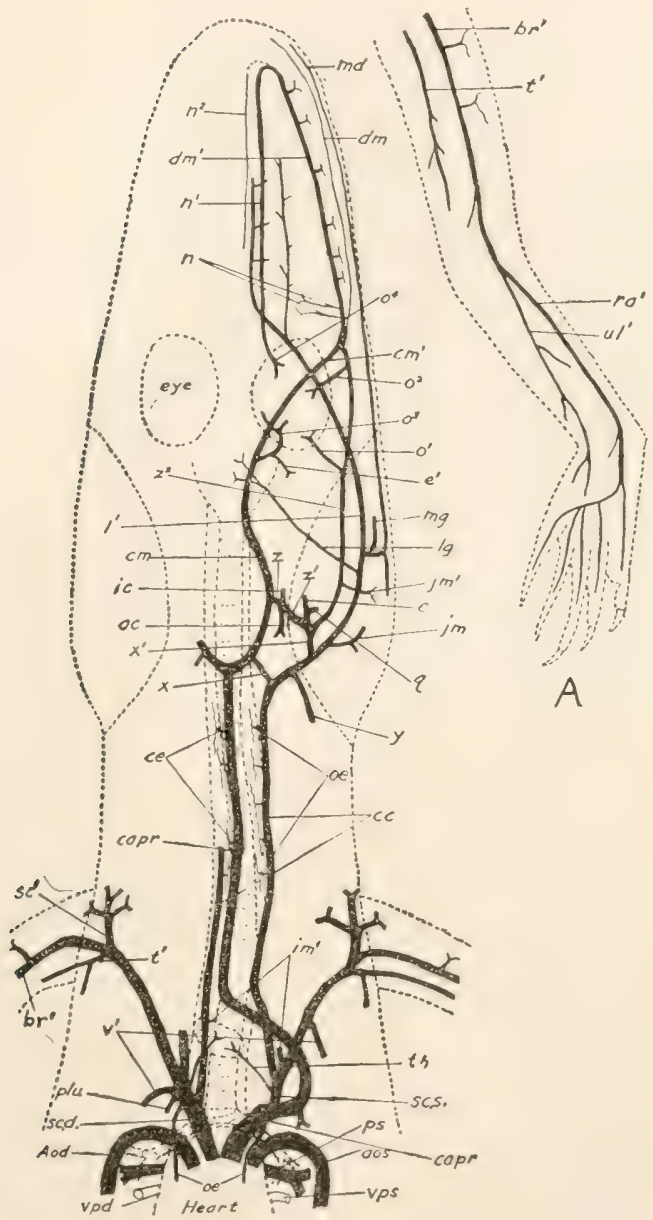

FIG. 62. The arteries of the anterior region of the Florida alligator. The arteries of the left foreleg shown at A.-For lettering, see pages $224^{-25}$.

tibial side of the shank. These two arteries give off numerous branches to the muscles of the lower 
2i6 The Alligator and Its Allies

leg. After giving off the fibular and tibial arteries, the sciatic passes, as a large vessel, through the lower leg, to which it gives but few branches, and may here be called the crural artery, cr. At the tarsus it divides rather suddenly and, perhaps, variably, into four chief branches, leading to the toes.

A short distance caudad to the origin of the iliacs the dorsal aorta gives off a pair of small pelvic arteries, $\mathrm{pa}^{\mathrm{r}}$, going to the muscles of that region. Caudal to these pelvic arteries is given off the unpaired first hamorrhoidal artery, he ${ }^{\mathrm{r}}$, which divides into a rectal, $\mathrm{rt}^{\mathrm{I}}$, and a cloacal, cl, branch.

Caudal to the first hæmorrhoidal arises the sccond hcemorrhoidal, he ${ }^{2}$; also unpaired, leading to the cloaca.

Posterior to the second hæmorrhoidal, the aorta continues into the tail as the large caudal artery, ca.

The Anterior Arteries. The origin of the great arterial trunks - the pulmonary, aortic arches, primary carotid, and right subclavian has already been given and the distribution of the pulmonary arteries and aortic arches has been described, so that it now remains to describe the distribution of the right subclavian, Fig. 62, sc.d., and the primary carotid, capr.

The right subclavian, sc.d., since it has an independent origin from the heart, instead of arising as a branch of the primary carotid, will be described first. After leaving the heart it passes cephalad and laterad and gives off the following branches in order, beginning at the heart: an 
a'sophageal artery, oe, a small, caudally directed vessel carrying blood to the posterior region of the osophagus. Close to the oesophageal arises another small, caudally directed vessel, the pleural artery, plu, extending to the pleura and possibly to the pericardium. From the same region as the preceding two arteries, but extending cephalad along the trachea and oesophagus, arises the much larger branch of the right subclavian, the right collateralis colli, cc, whose course and distribution will be described later.

Close to the distal side of the collateralis colli arises the very small thyroid artery, th, leading to the oval thyroid gland that lies against the ventral surface of the trachea a short distance anterior to the heart.

A short distance distal to the thyroid artery the subclavian gives off a fairly large artery, the internal mammary, im (shown too large in the figure), that passes to the inner surface of the ribs near the sternum and lies parallel to the vein of the same name, described above.

A short distance distal to the internal mammary arises an artery of about the same diameter, the rertebral, $\mathrm{V}^{\mathrm{r}}$; it passes dorsad and caudad to the region of the thoracic vertebræ.

After giving off the five vessels just described, the subclavian artery passes into the shoulder where it divides into three main branches: (a) the subscapular, $\mathrm{sc}^{\mathrm{x}}$, going to the skin and muscles 
of the shoulder; (b) the thoracic, $t^{x}$, carrying blood to the posterior muscles of the shoulder and to the posterior region of the upper arm; (c) the brachial, $\mathrm{br}^{\mathrm{r}}$, which is really the continuation of the subclavian and is the chief artery of the anterior appendage.

After sending several branches to the upper arm the brachial divides, in the region of the elbow, into two main vessels, the radial, $\mathrm{ra}^{\mathrm{x}}$, and unar, $\mathrm{ul}^{\mathrm{I}}$, arteries, Fig. 62, A. The radial artery, in the carpal region, divides in a complicated way into five main vessels that extend into the digits. The ulnar artery gives off several branches to the forearm, but apparently does not connect directly with the branches to the digits.

The primary carotid, capr. After leaving the heart, this very large vessel passes cephalad and laterad for some distance on the left side of the body and then gives off, from its anterior side, the large left subclavian artery, sc.s., to be described later. After giving off the subclavian artery, it makes a short loop, still farther to the left, and then turns sharply mediad to pass to the head in the median plane directly dorsal to the œesophagus. Its distribution in the cervical and cephalic region will be described later. The mate to the œsophageal branch, oe (near heart), of the right subclavian which was mentioned above is apparently sometimes given off from the primary carotid near its base (as shown in Fig. 62) and sometimes as a branch of the left pleural artery. 


\section{The Vascular System}

The left subclarian artery, sc.s., although it has a different origin, has the same branches as described in connection with the right subclavian. The exact order in which the first of these (the thyroid, th; the internal mammary, $\mathrm{im}^{\mathrm{I}}$; the collateralis colli, cc; the pleural, plu; and the vertebral, $\mathrm{v}^{\mathrm{r}}$ ) are given off is, as might be expected, subject to some variation.

The collateralis colli, cc (foilowing Bronn's nomenclature), whose origin was noted above, will now be discussed; since the two are alike only one need be described. After leaving the subclavian, it passes cephalad, at the side of the trachea and oesophagus, in company with the internal jugular vein, so that in this part of its course it would seem to be the internal carotid artery. It gives numerous small twigs to the trachea and œsophagus, oe. In the region of the posterior part of the huge jaw muscle it is connected directly, $x$, with the adjacent branch, cm (called by Bronn the common carotid) of the primary carotid, and indirectly, $\mathrm{x}^{\mathrm{I}}$, with a complicated group of branches from the common carotid. Cephalad to the connective $\mathrm{x}^{\mathrm{r}}$, which extends dorsad and is hence foreshortened in the figure, the collateralis colli gives off a small vessel, y (too large in Fig. 62), to the shoulder and skin; it then sends a fairly large branch, jm, into the large jaw muscle, close to which it now lies. Next a small branch, $1 \mathrm{~g}$, is sent to the larynx. Continuing cephalad and laterad 
(in Fig. 62 it is drawn farther to the side than it actually lies) for a short distance farther, it divides into three branches: (I) a short twig, mg, that goes to the musk gland on the side of the mandible and to the skin of that region; (2) a large branch, the mandibular, md, that enters the large foramen on the mesial side of the mandible and extends in the cavity of that bone throughout its entire length; (3) the lingual artery, $1^{\mathrm{I}}$, which in turn divides, some distance cephalad, into two branches, one extending along the lateral region, the other nearer the micl-ventral surface of the tongue. It is seen, then, that the collateralis colli arteries supply directly the lower side of the head-tongue, mandible, etc.--though they may also send blood through the above-mentioned connectives to the brain and dorsal regions of the skull.

The primary carotid, capr, as was noted above, makes a curve to the left after leaving the heart and then passes back to the median plane, where it may be seen lying against the ventral side of the neck muscles and dorsal to the osophagus; in this place it gives off a series of unpaired cerrical arteries, Fig. 62, ce, each of which almost immediately divides into an anterior and a posterior branch, that carry blood to the cervical vertebræ. At the base of the skull, in the region where it is united by the first connective, $\mathrm{x}$, with the collateralis colli, as described above, the primary carotid divides into two similar branches, called by Bronn 


\section{The Vascular System}

the common curotids, $\mathrm{cm}$. The distribution of these two vesscls is symmetrical, so that only one need be described. While the collateralis colli, as has been said, carry blood chiefly to the tongue and lower jaw, the common carotids supply the cranium and upper jaw.

Soon after its formation by the division of the primary carotid, the common carotid is joined, as noted above, with the collateralis colli of that side by the connective, $\mathrm{x}$; since the common carotid and its branches all lic dorsal to the collateralis colli and its branches, the connectives $\mathrm{x}$ and $\mathrm{x}^{\mathrm{I}}$ extend in a more or less dorso-ventral direction. The two common carotids, almost completely surrounded by bone, in passing cephalad sweep first laterad, then mediad, so that they together form almost a complete ellipse, as seen in Fig. 62; there is, however, no apparent connection between them at the anterior region where they lie so close together.

A short distance cephalad to the connective $\mathrm{x}$ the common carotid is connected laterally, $z$, with a rather complicated plexus of vessels lying at the base of the sliull; it is through this plexus that the common carotid is connected with the collateralis colli by the second connective, $\mathrm{x}^{\mathrm{I}}$.

The short branch $z$ quickly divides into three parts: (I) a small anteriorly directed vessel which may be called the internal carotid, ic, since it enters the skull through the most ventral of the three foramina in the exoccipital, and probably supplies 
the brain, though its further course could not be followed; (2) a somewhat larger posteriorly directed artery, oc, going to the muscles at the occipital region of the skull; (3) a short laterally directed stem, $z^{1}$. The last-named branch, $z^{1}$, in turn, leads in three directions: (a) to the collateralis colli artery through the connective $\mathrm{x}^{\mathrm{I}}$; (b) a short anteriorly directed vessel, e, that passes into the skull, possibly to the ear, through the large foramen that lies between the exoccipital and quadrate bones; it gives off a small twig, q, to the muscles in the region of the jaw articulation (quadrate); (c) the main stem of the branch $z$ continues laterad and cephalad as one of the chief arteries, $z^{2}$, to the anterior region of the sku1l, giving off a fairly wide branch, $\mathrm{jm}^{\mathrm{I}}$, to the large jaw muscle, and then two branches, $\mathrm{O}^{\mathrm{I}}$ and $\mathrm{O}^{2}$, to the lateral surface of the eyeball and socket; it then anastomoses, just cephalad and laterad to the eye, with the forward continuation, $\mathrm{cm}^{x}$, of the corresponding main stem, $\mathrm{cm}$, of the common carotid, already mentioned. The vessel $\mathrm{cm}^{\mathrm{I}}$, after almost meeting its fellow in the middle line, passes cephalad and laterad across the ventral surface of the eye to the union, above mentioned, with the lateral branch, $\mathrm{z}^{2}$; at the posterior-mesial border of the eye it gives off a branch that divides into two twigs, one, $\mathrm{O}^{3}$, for the posterior eye muscles, and one, $\mathrm{e}^{3}$, to the region of the ear and the top of the skull. 


\section{The Vascular System}

At the point of union of the branches $\mathrm{cm}^{\mathrm{I}}$ and $\mathrm{z}^{2}$ a sort of simple plexus may be formed from which two vessels, n, pass to the posterior nasal region, and two vessels pass forward along the side of the upper jaw. Of the latter two vessels one, which may be called the inferior dental of the maxilla, dm, is very small and extends along the maxilla to its very tip, at the base of the teeth and ventral to the palatine bone; the other, which is larger and may be called the superior dental of the maxilla, $\mathrm{dm}^{\mathrm{I}}$, extends cephalad along the mesial side of the maxilla, dorsal to the palatine bone; it sends numerous twigs into the maxillary bone among the roots of the teeth. After passing nearly to the end of the snout, the superior dental, $\mathrm{dm}^{\mathrm{r}}{ }^{\mathrm{r}}$, suddenly forms a loop towards the median line and passes as a straight branch, $\mathrm{n}^{\mathrm{I}}$, directly caudad, near and parallel to the median plane. The branch $n^{\mathrm{I}}$ extends along the floor of the nasal cavity and, after giving off twigs to this chamber, ends in a network of vessels, $\mathrm{O}^{4}$, on the anterior surface of the eyeball and socket.

A pair of very small arteries, $n^{2}$, may be seen in the nasal chamber between and parallel to the branches, $\mathrm{n}^{\mathrm{x}}$; they lie close to each side of the nasal septum and supply the anterior nasal region. They apparently arise, as shown by the broken lines, from the loop of the superior dental artery, $d \mathrm{~m}^{\mathrm{I}}$, though this could not be definitely determined. 


\section{LetTering FOR Figures 59-62}

Aos., Aod., left and right aortic arches.

ab, abdominal artery.

ax, axillary vein.

$b$, veins from body wall.

$\mathrm{br}$, brachial vein.

$\mathrm{br}^{\mathrm{I}}$, brachial artery.

c, cœliac artery.

ca, caudal artery.

capr, primary carotid.

cc, collateralis colli artery.

ce, cervical artery.

$\mathrm{cl}$, cloacal artery.

$\mathrm{cm}, \mathrm{cm}^{\mathrm{I}}$, common carotid artery.

cr, crural artery.

$\mathrm{cv}$, caudal vein.

da, dorsal aorta.

$\mathrm{dm}$, inferior dental artery of maxilla.

$\mathrm{dm}^{\mathrm{I}}$, superior dental artery of maxilla.

e, $\mathrm{e}^{\mathrm{x}}$, artery into skull, perhaps to ear.

ej, external jugular vein.

$\mathrm{ep}$, internal epigastric vein.

$f$, femoral vein.

$\mathrm{f}^{\mathrm{x}}$, fibular artery.

$\mathrm{fb}$, fibular vein.

$\mathrm{g}$, gastric vein of portal.

$\mathrm{g}^{\mathrm{I}}$, gastric vein of epigastric.

ga, gastric artery.

ghi, gastro-hepatico-intestinal artery.

$h$, hepatic portal vein.

he ${ }^{x}, h^{2}$, hxmorrhoidal arteries.

$i$, intestinal vein.

ic, internal carotid artery.

id, inferior dental vein.

il, iliac vein.

il $^{\mathrm{x}}$, iliac artery.

im, internal mammary vein.

$i^{\mathrm{x}}$, internal mammary artery. is, ischiadic vein.

is $^{x}$, ischiadic artery.

$\mathrm{j}$, internal jugular vein.

$\mathrm{jm}, \mathrm{jm}^{\mathrm{I}}$, artery to jaw muscle.

1 , lingual vein.

1 r, lingual artery.

lg, laryngeal artery.

lu, I-7, lumber arteries (numbers on left side of figure).

$\mathrm{m}$, mescnteric vein.

$\mathrm{m}^{\mathrm{x}}$, mesenteric artery.

md, mandibular artery.

$\mathrm{mg}$, artery to musk gland.

$\mathrm{ms}$, muscular vein.

$\mathrm{n}$, artery to posterior nasal region.

$\mathrm{n}^{\mathrm{I}}$, artery to anterior and midnasal region.

$\mathrm{n}^{2}$, artery to anterior nasal region.

$\mathrm{O}^{\mathrm{I}}-\mathrm{O}^{4}$, arteries to eye.

oc, artery to muscles at base of skull.

oe, œsophageal arteries.

pa, pelvic artery.

$\mathrm{pa}^{\mathrm{x}}$, second pelvic artery.

$\mathrm{pb}$, post brachial vein.

pc, post cava.

pd, right pulmonary artery.

pi, pancreo-intestinal artery.

$\mathrm{pl}, \mathrm{pl}^{\mathrm{I}}$, pelvic vein.

plu, pleural artery.

$\mathrm{ps}$, left pulmonary artery.

$q$, artery to muscle at angle of jaw.

ra, radial vein.

$\mathrm{ra}^{\mathrm{I}}$, radial artery.

re, reproductive vein or artery.

$\mathrm{rp}$, renal portal vein.

$\mathrm{rt}$, rectal vein.

$\mathrm{rt}^{\mathrm{I}}$, rectal artery.

rv, renal vein.

$\mathrm{s}$, subclavian vein.

sc, sciatic artery (Fig. 6I). 


\section{The Vascular System}

sc, subscapular vein (Fig. 60).

$\mathrm{Sc}^{\mathrm{x}}$, subscapular artery.

v, vertebral vein.

sc.d., sc.s., right and left subclavian

$\mathrm{V}^{\mathrm{I}}$, vertebral artery. arteries.

si, spleno-intestinal artery.

sp, splenic vein.

vea, anterior vena cava.

vh, hepatic vein.

s.v., sinus venosus.

vpd, vps, right and left pulmonary veins,

$t$, thoracic vein.

$t^{x}$, thoracic artery.

$\mathrm{x}, \mathrm{x}^{\mathrm{I}}$, connectives between collateralis colli and carotid.

tb, tibial artery.

th, thryoid artery.

$\mathrm{tr}$, tracheal vein.

$\mathrm{u}, \mathrm{I}-4$, urogenital arteries (numbers on right side of figure). ul $^{\mathrm{z}}$, ulnar artery.

$y$, artery to shoulder and skin.

$z, z^{I} z^{2}$, branches of common carotid.

$I^{I}, 2^{I}, 3^{I}$, branches of ischiadic artery. 


\section{CHAPTER IX}

THE DEVELOPMENT OF THE ALLIGATOR

(A. mississippiensis)

\section{INTRODUCTION}

$W^{\text {IT }}$

TH the exception of S. F. Clarke's wellknown paper, to which frequent reference will be made, practically no work has been done upon the development of the American alligator. This is probably due to the great difficulties experienced in obtaining the necessary embryological material. Clarke, some twenty years ago, made three trips to the swamps of Florida in quest of the desired material. The writer has also spent parts of three summers in the Southern swamps-once in the Everglades, once among the smaller swamps and lakes of central Florida, and once in the Okefinokee Swamp. For the first of these expeditions he is indebted to the Elizabeth Thompson Science Fund; but for the more successful trip, when most of the material for this work was collected, he is indebted to the Smithsonian Institution, from 


\section{The Development of the Alligator}

which a liberal grant of money to defray the expenses of the expedition was received.

The writer also desires to express his appreciation of the numcrous courtesies that he has received from Dr. Samuel F. Clarke, especially for the loan of several excellent series of sections, from which a number of the earlier stages were drawn.

In preparing the material several kinds of fixation were employed, but the ordinary corrosive sublimate-acetic mixture gave about the most satisfactory results. Ten per cent. formalin, Parker's mixture of formalin and alcohol, etc., were also used. In all cases the embryos were stained in toto with borax carmine, and in most cases the sections were also stained on the slide with Lyon's blue. This double stain gave excellent results. Transverse, sagittal, and horizontal series of sections were made, the youngest embryos being cut into sections five microns thick, the older stages ten microns or more in thickness.

\section{The EGG}

Figures I, i $a$ (Plate VI.)

The egg (Fig. I) is a perfect ellipse, the relative lengths of whose axes vary considerably in the eggs of different nests and slightly in the eggs of the same nest. Of more than four hundred eggs measured, the longest was $85 \mathrm{~mm}$; the shortest $65 \mathrm{~mm}$. Of the same eggs, the greatest short 
diameter was $50 \mathrm{~mm}$; the least short diameter was $38 \mathrm{~mm}$. The average long diameter of these four hundred eggs was $73.74 \mathrm{~mm}$. ; the average short diameter was $42.59 \mathrm{~mm}$. The average variation in the long axis of the eggs of any one nest was Ir.32 mm., more than twice the average variation in the short axis, which was $5.14 \mathrm{~mm}$. No relation was noticed between the size and the number of eggs in any one nest. Ten eggs of average size weighed 8I 2 grams-about 8I grams each.

Voeltzkow (78) states that the form of the egg of the Madagascar crocodile is very variable. No two eggs in the same nest are exactly alike, some being elliptical, some "egg-shaped," and some "cylindrical with rounded ends." The average size is $68 \mathrm{~mm}$. by $47 \mathrm{~mm}$., shorter and thicker than the average alligator egg.

When first laid, the eggs are pure white, and are quite slimy for a few hours, but they generally become stained after a time by the damp and decaying vegetation composing the nest in which they are closely packed.

The shell is thicker and of a coarser texture than that of the hen's egg. Being of a calcareous nature, it is easily dissolved in dilute acids.

The shell membrane is in two not very distinct layers, the fibers of which, according to S. F. Clarke, are spirally wound around the egg at right angles to each other. Noair-chamber, such as is found in the hen's egg, is found in any stage in the development. 
The Development of the Alligator 229

In most-probahly all normal-cgrgs a white band appears around the lesser circumference a short time after being laid. This chalky band, which is shown at about its maximum development in Fig. $\mathbf{I} a$, is found, on removal of the shell, to be caused, not by a change in the shell, but by the appearance of an area of chalky substance in the shell membranes. Clarke thinks this change in the membrane is to aid in the passage of gases to and from the developing embryo. Generally this chalky area forms a distinct band entirely around the shorter circumference of the egg, but sometimes extends only partly around it. It varies in width from about I $5 \mathrm{~mm}$. to $35 \mathrm{~mm}$., being narrowest at its first appearance. Sometimes its borders are quite sharp and even (Fig. I $l$ ); in other cases they are very irregular. If the embryo dies the chalky band is likely to become spotted with dark areas.

The shell and shell membrane of the egg of the Madagascar crocodile are essentially the same as those just described, except that the shell is sometimes pierced by small pores that pass entirely through it. The same chalky band surrounds the median zone of the egg (78).

The white of the egg is chiefly remarkable for its unusual density, being so stiff that the entire egg may be emptied from the shell into the hand and passed from one hand to the other without danger of rupturing either the mass of albumen or the enclosed yolk. The albumen, especially in the 
immediate neighborhood of the yolk, seems to consist of a number of very thin concentric layers. It varies in color, in different eggs, from a pale yellowish white, its usual color, to a very decided green.

As might be expected, no chalazæ are present.

The yolk is a spherical mass, of a pale yellow color, lying in the center of the white. Its diameter is so great that it lies very close to the shell around the lesser circumference of the egg, so that it is there covered by only a thin layer of white, and care must be taken in removing the shell from this region in order not to rupture the yolk. The yolk substance is quite fluid and is contained in a rather delicate vitelline membrane.

The albumen and yolk of the crocodile's egg, as described by Voeltzkow, differ from those of the alligator only in the color of the albumen, which in the crocodile is nomally light green (78).

As pointed out by Clarke, the position of the embryo upon the yolk is subject to some variation. During the earliest stages it may occur at the pole of the yolk nearest the side of the egg; later it may generally be found toward the end of the egg; and still later it shifts its position to the side of the egg. It is probable, as Clarke says, that the position at the end of the egg secures better protection by the greater amount of white, at that point, between the yolk and the shell; while the later removal to the side of the egg, when the vascu- 


\section{The Development of the Alligator 23I}

lar area and the allantois begin to function, secures a better aëration of the blood of the embryo.

Around the embryo, during the stages that precede the formation of the vascular area, is seen an irregular area of a lighter color and a mottled appearance. This area is bounded by a distinct, narrow, white line, and varies in size from perhaps a square centimeter to one third the surface of the yolk.

During the earliest stages of development the embryo is very transparent; so that, as there is no fixed place upon the yolk at which it may be expected to occur, it is often very difficult to find. Owing to this transparency, to the extreme delicacy of the embryo, and to the character of the white, the removal of an early embryo from the egg of the alligator is a difficult operation and is accomplished only after some practice.

\section{The Development of the Embryo}

As the writer has pointed out elsewhere (59), the embryo of the alligator is often of considerable size when the egg is laid. This makes the obtaining of the earliest stages of development a difficult matter; so that the writer, as has already been said, like S. F. Clarke ( 7 ), made three trips to the South in quest of the desired material. Voeltzkow (78) experienced the same difficulty in his work on the crocodile, and made several trips to Africa 


\section{The Alligator and Its Allies}

before he succeeded in obtaining all the desired stages of development.

To obtain the earliest stages, I watched the newly made nests until the eggs were laid, and in this way a number of eggs were obtained within a very few hours after they had been deposited, and all of these eggs contained embryos of a more or less advanced stage of development. Gravid females were then killed, and the eggs removed from the oviducts. These eggs, although removed from a "cold-blooded" animal, generally contained embryos of some size, and only one lot of eggs thus obtained contained undeveloped embryos, which embryos refused to develop further in spite of the most careful treatment. Voeltzkow (78) found, in the same way, that the earlier stages of the crocodile were extremely difficult to handle; so that, in order to obtain the earlier stages, he was reduced to the rather cruel expedient of tying a gravid female and periodically removing the eggs from the oviducts through a slit cut in the body wall.

The older embryos are hardy and bear transportation well, so that it is comparatively easy to obtain the later stages of development.

For the stages up to the formation of the first four or five somites, I am indebted, as I have already said, to Professor Clarke, and, since I have had opportunity to examine only the sections and not the surface views of these stages, I shall 


\section{The Development of the Alligator 233}

quote directly Clarke's paper in the Joumal of Morphology $(\mathbf{I} \tau)$ in description of these surface views.

\section{STAGE I}

Figures 2-2f (Plates VI., VII.)

The youngest embryo that we have for description is shown in Figures 2 and $2 a$. Of Figure 2 Clarke says:

"The limiting line between the opaque and pellucid areas is clearly marked, and within the latter is a shield-shaped area connected by the narrower region of the primitive streak with the area opaca. The blastopore is already formed near the posterior end of the shield.

"A ventral view of another embryo of the same age (Fig. 2a), seen from the ventral side, shows that the blastopore extends quite through the blastoderm, in an oblique direction downwards and forwards, from the dorsal to the ventral side. The thickened arca of the primitive streak is here very prominent. There is, too, the beginning of a curved depression at the anterior end of the shield, the first formation of the head-fold."

Transverse sections of this stage are shown in Figures $2 b-2 f$.

Figure $2 b$, through the anterior region of the blastoderm, shows a sharply defined ectoderm (ec) which is composed of three or four layers of cclls 


\section{The Alligator and Its Allies}

in the median region, while it gradually thins out laterally. Closely underlying this ectoderm is a thin sheet of irregular cells, the entoderm $(\mathrm{en})$.

Figure $2 c$ is about one fifth of the length of the blastoderm posterior to the preceding and represents approximately the same conditions, except that there is an irregular thickening of the entoderm in the median region $(\mathrm{cn})$. This thickening apparently marks the anterior limit of the mesoderm, to be discussed shortly.

Figure $2 d$ represents the condition of the blastoderm throughout about one third of its length, posterior to the preceding section. The somewhat regular folds in the ectoderm (ec) are probably not medullary folds, but are such artificial folds as might easily be produced in handling the delicate blastoderm. The thickening of the entoderm, noticed in the preceding figure, is here more sharply defined, and as we pass toward the blastopore becomes separated somewhat from the entoderm proper as a middle layer or mesoderm (Fig. $2 e$, mes). It would thus scem, from a study of these sections, that most of the mesoderm is derived from the entoderm. In fact, all of the mesoderm in front of the blastopore seems to have this origin, for it is not until the anterior edge of the blastopore is reached that there is any connection between the ectoderm and entoderm (Fig. 2e).

Figure $2 c$ is a section through the region just 


\section{The Development of the Alligator 235}

mentioned, where, medially, the ectoderm, mesoderm, and entoderm form a continuous mass of cells. Laterally the mesoderm (mes) is a distinct layer of cells of a fairly characteristic mesodermal type. The notochord is not yet discernible, though a slight condensation of cells in the middle line may indicate its position.

Figure $2 f$ is one of the four sections that were cut through the blastopore $(b l p)$, which is a hole of considerable size that opens, as the figure shows, entirely through the blastoderm. Along the walls of the blastopore the ectoderm and entoderm are, of course, continuous with each other and form a sharply defined boundary to the opening. As we pass laterally from the blastopore the cells become less compact, and are continued on each side as the mesodermal layer (mes). In this series the sections posterior to the blastopore were somewhat torn, and so were not drawn; but they probably did not differ materially from those of the corresponding region of the immediately following stages, which are shown in Figures $3 m$ and $6 i$ and will be described in their proper order.

STAGE II

Figures $3^{-} 3^{\circ}$ (Plate VII., VIII., IX.)

The next stage to be described is shown in surface views in Figures 3 and $3 a$. Of this stage Clarke says: 


\section{The Alligator and Its Allies}

"The head-fold rapidly increases in depth and prominence, as shown in Figure 3, which is a ventral view a fow hours later [than the preceding stage]. The time cannot be given exactly, as it is found that eggs of the same nest are not equally advanced when laid, and differ in their rate of devclopment. The lighter curve in front of the head-fold is the beginning of the anterior fold of the amnion. The notochord has been rapidly forming, and now shows very distinctly on the ventral side, when viewed by transmitted light. A dorsal view of the same embryo (Fig. $3^{a}$ ) shows that the medullary or neural groove is appearing, and that it ends abruptly anteriorly'near the large transverse headfold. Posteriorly it terminates at the thickened area in front of the blastopore, which still remains open."

Figures $3 b-m$ are drawn from transsections of an embryo of about this stage of development. For a short distance in front of the beginning of the headfold, there is a mass of cells of considerable thickness between the ectoderm and entoderm. In Figure $3 b$ these cells appear as an irregular thickening of the entoderm, while in Figure $3 c$ they form a continuous mass, uniting the upper and lower germ layers. This condition is seen, though in a much less striking degree, in the following stage of development. As to its significance the writer is not prepared to decide.

Figure $3 d$ passes through the head-fold, which 
in this embryo was probably not so far developed as it was in the embryo shown in Figures 3 and $3 *$. Not having seen the embryo, however, before it was sectioned, the writer cannot be certain of this point. The ectoderm and entoderm are here of nearly the same thickness.

Figure $3 e$ is a short distance posterior to the preceding. It shows a marked thickening of the ectoderm in the medial region (cc), which is continuous posteriorly with the anterior cnds of the medullary folds that are just beginning to differentiate (Figs. $3 f-h$ ).

Figure $3 g$ passes through the anterior end of the medullary plate or folds ( $m f$ ), whichever they may be called. The ectoderm of the folds is thickened and is considerably elevated above the rest of the blastoderm. There is scarcely any sign, in this region, of a medullary groove. The entoderm ( $c n$ ) is considerably thickened in the medial region, this thickening being continuous posteriorly, as in the preceding stage, with the mesoderm.

In Figure $3 h$, cut in a plane at some distance posterior to the preceding, the medullary groove $(\mathrm{mg})$ is well marked; its bordering folds gradually thin out laterally to the thickness of the ordinary ectoderm. The medial thickening of the entoderm is very marked, but it has not in this region separated into a distinct mesoblastic layer.

Immediately under the medullary groove is a 
dense mass of cells ( $n t$ ), apparently the anterior end of the notochord in process of formation.

Figure $3 i$, still farther toward the blastopore, shows the medullary groove wider and shallower than in the more anterior sections. The mesoderm (mes) is here a layer laterally distinct from the entoderm. In the middle line it is still continuous with the entoderm, and at this place it is the more dense mass of cells that may be recognized as the notochord $(n t)$. It is evidently difficult to decide whether this group of cells $(n t)$, which will later become a distinct body, the notochord, is derived directly from the entoderm or from the mesoderm, which is itself a derivative of the entoderm. There is here absolutely no line of demarcation between the cells of the notochord and those of the mesoderm and entoderm.

In Figure $3 j$ the ectoderm $(e c)$ is nearly flat, scarcely a sign of the medullary groove appearing. The mesoderm (mes) is here a distinct layer, entirely separate from both notochord $(n t)$ and entoderm $(\mathrm{en})$. The notochord is a clearly defined mass of cells, distinct, as has been said, from the mesoderm, but still closely united with the underlying entoderm, which is much thinner than the ectoderm. This condition of the notochord, which is found throughout about one third of the length of the embryo, would give the impression that the notochord is of a distinctly entodermal origin. 
The Development of the Alligator 239

In Figure $3 k$ there is no sign of the medullary groove, though the ectoderm (cc) is still much thickened in the middle line. The section passes, posterior to the notochord, through the anterior edge of the ventral opening of the blastopore (blp). The mesoderm (mes) is here again continuous with the entoderm, around the edge of the blastopore, but is distinct from the ectoderm.

Figure $3 l$ represents the third section posterior to the preceding. The blastopore, which passes upward and backward through the blastoderm, is seen as an enclosed slit (blp). It is surrounded by a distinct layer of compactly arranged cells continuous with the thickened ectoderm (ec) above, with the thin entoderm ( $\mathrm{cn}$ ) below, and laterally with the gradually thinning and scattering mesoderm (mes).

Figure $3 m$ is the next section posterior to the one just described. It passes through the dorsal opening of the blastopore $(b l p)$, which appears as a deep, narrow cleft with thick ectodermal borders. The three germ layers are still continuous with each other, though the connection of the entoderm with the other two is slight. The sections posterior to this one will be described in the next stage, where they have essentially the same structure and are better preserved.

Figures $3^{n}$ and $3^{o}$ are sagittal sections of an embryo of about the stage under discussion. In both figures the head-fold is seen as a deep loop 
of cctoderm and entoderm, while the head-fold of the amnion is seen at $a$.

The beginning of the foregut is seen in Figure $3 n$ $(f g)$, which is the more nearly median of the two sections, Figure 30 being a short distance to the side of the middle line.

In Figure 30 the thin entoderm (en) is separated from the much thicker ectoderm (ec) by a considerable layer of rather loose mesoderm (mes). In Figure $3 n$, which is almost exactly median in position, there is, of course, no mesoderm to be seen in front of the blastopore, and the entoderm shows a considerable increase in thickness, due to the formation of the notochord $(n t)$. The blastopore $(b l p)$ is the most striking feature of the figure, and is remarkable for its great width in an anteroposterior direction. Its anterior and posterior borders are outlined by sharply defined layers of ectoderm and entoderm. Posterior to the blastopore the lower side of the ectoderm is continuous with a considerable mass of cells, the primitive streak $(p s)$.

\section{STAGE III}

Figures $4,4 a, 5,5 a$, And $6-6 i$ (Plates X., XI.)

"Figures 4 and $4 a$ are of an embryo removed, on June $\mathrm{I} 8 \mathrm{th}$, from an egg which had been taken out of an alligator two days before. Figure 4, a dorsal view, is of special interest in that it shows a second- 
ary fold taling place in the head-fold. 'This grows posteriorly along the median dorsal line, forming a $V$-shaped process with the apex pointing backward toward the blastopore. There is quite a deep groove between the arms of the $\mathrm{V}$. The headfold on the ventral side, as seen in Figure $4^{a}$, made from the same embryo as Figure 4, grows most rapidly on the mid-line, and also becomes thicker at that place. The medullary folds now begin to form on either side of the medullary groove, ending posteriorly on either side of the blastopore and anteriorly on either side of the point of the $\mathrm{V}$ shaped process in the middle of the head-fold. This is seen in Figure 5, which is a dorsal view of an embryo from an egg three days after it was taken out of an alligator. A ventral view of the same embryo (Fig. $5^{a}$ ) represents the thickened process on the mid-line at its greatest development. For some reason the notochord did not show in this embryo, possibly owing to particles of the yolk material adhering about the mid-line.

"In an embryo a day or two older, the V-shaped fold of the head-fold is seen to have broken through at the apex, and each of the arms thus separated from one another unites with the medullary fold of its respective side. This can be seen in Figure 6 , which is a dorsal view of part of an embryo a day or two older than the one represented by Figures 5 and $5 a$.

"This is so unexpected a method of formation r6 
for the antcrior part of the medullary folds that I have made use of both Figures 4 and 5. They were made from very perfect specimens, and the sections of both of them, and of the specimen from which Figure 6 was drawn, proves that the structure is what it is indicated to be in surface appearance. That is, the transverse sections posterior to the $V$, in the embryos shown in Figures 4 and 5 , show the medullary groove and the medullary folds; the several sections passing through the apex of the $\mathrm{V}$ show neither groove nor folds, but only a median thickening; and in front of the point or apex of the $V$ the successive sections discover a gradually widening groove between the arms, which is also much deeper than the shallow groove found posterior to the $V$. While I have not seen, and from the nature of the conditions one cannot see, the change actually proceeding from the form of Figure 5 to that of Figure 6 , still the explanation given appears to be the only one possible" (I 7 ).

A somewhat extended serics of transverse sections of an embryo of about this age is represented in figures $6 a-i$.

Figure $6 a$ is a section through the head-fold; it passes through the extreme anterior end of the secondary folds $(s f)$ that were described, in surface view, above (Figs. 5 and 6 ). The section was not quite at right angles to the long axis of the embryo, so that the fold on the right was cut farther toward its anterior end than was the fold on the left. 
The Development of the Alligator 243

The pushing under of the head causes a forward projection of the secondary folds, so that the fold to the right appears as a rounded mass of cells with a small cavity near its center. On the left the plane of the section passes through the posterior limit of the head-fold, and shows the cells of the secondary fold continuous with the dorsal side of the ectoderm (ec). As pointed out above by Clarke, the secondary folds are here some distance apart, and gradually approach each other as we procecd toward the posterior. The entoderm ( $\mathrm{cll}$ ) is here flat and takes no part in the secondary folds.

In Figure $6 b$, a short distance back of the one just described, the secondary folds $(s f)$ are much larger and are closer together. On the right the section passes through the extreme limit of the head-fold, so that the secondary fold of that side is still a closed circle, with a few scattered cells enclosed. On the left the section is posterior to the head-fold; on this side the secondary fold is seen as a high arch of ectoderm, with a thick mass of entoderm beneath it.

Figure $6 c$ represents a section which passes back of the head-fold on both sides. The secondary folds $(s f)$ are seen as a pair of ectodermal arches continuous with each other in the middle line of the embryo. The ectoderm of the folds is much thickened and gradually becomes thinner distally. On the right the entoderm shows the same thickening (en) that was shown on the left side of the 


\section{The Alligator and Its Allies}

preceding figure. This thickened appearance of the entoderm is due to the fact that the section passes through the anterior limit of a tall fold of that layer, which underlies the similar fold of the ectoderm that has already been described. This secondary fold of the entoderm is seen on the left side of the section. It may be traced through several sections, but soon flattens out posteriorly.

Figure $6 d$ is a short distance posterior to tne preceding. The secondary folds are here much less pronouncedly arched and the deep groove between them is reduced to a line (l). The entoderm (en) is no longer markedly arched and is closely adherent, along the median plane, to the ectoderm, where there is seen the thickening ( $t h$ ) that has been mentioned by Clarke (see above). Springing from the entoderm on each side of this thickening is a small mass of mesoderm (mes).

The section immediately posterior to the one just described is represented in Figure $6 e$. The line (l) which separated the two secondary folds in the preceding section is no longer present, so that the ectoderm $(e c)$ is continuous from side to side, with only a shallow depression $(m g)$, which may be considered as the extreme anterior end of the medullary groove. The median thickening $(t h)$ is cut near its posterior limit and still shows a close fusion of the germ layers. There is no line of demarcation between the gradually flattening 
secondary folds of the anterior end of the embryo and the just forming medullary folds of the posterior end, so that it is impossible to say whether the thickenin of ectoblast in this figure should be called secondary folds or medullary folds. As a matter of fact, the secondary folds become, of course, the anterior ends of the medullary folds. The mesoblast (mes) is here of considerable extent, and its entodermal origin is beyond doubt, though not well shown in the figure.

Figure $6 f$ is about one sixth of the length of the embryo posterior to the preceding. The medullary thickening of the ectoderm (ec)is still marked and the shallow medullary groove $(\mathrm{mg})$ is fairly distinct. The entoderm (en) is medially continuous with both mesoderm (mes) and notochord $(n t)$, though these two tissues are otherwise distinct from each other.

Figure $6 g$ is nearly one third the length of the embryo posterior to the preceding and passes through the posterior third of the embryo. The medullary thickening of the ectoderm $(e c)$ is marked, but shows no sign of a medullary groove; in fact, the median line is the most elevated region of the ectoderm. The notochord $(n t)$ is larger in cross-section than in the more anterior regions. It is still continuous with the entoderm $(c h)$ and is fairly closely attached to, though apparently not continuous with, the mesoderm (mes) on each side. 
246 The Alligator and Its Allies

Figure $6 h$ passes through the blastopore $(b l p)$. The appearance of the section is almost identical with that of Figure $2 f$, already described.

Figure $6 i$ is five sections posteric" to the preceding and has about the same structure as the corresponding sections in the preceding two stages, where this region of the embryo was injured, and hence not drawn. Continuous with the posterior border of the blastopore (seen in the preceding figure) is the dcep furrow, the primitive groove $(p g)$. The ectoblast $(e c)$ bordering this groove is much thickened and may be called the primitive streak. The lower side of this primitive streak is continuous with the mesoblast (mes), while the entoderm (cn) is here entirely distinct from the mesoderm. It is evident that the mesoderm posterior to the blastopore is proliferated from the lower side of the ectoblast and not from the upper side of the entoblast, as is the case anterior to the blastopore. The primitive groove gradually becomes more and more shallow, as it is followed toward the posterior, until it is no longer discernible; back of this point the primitive streak may be traced for a considerable distance, becoming thinner and thinner until it too disappears, and there remains only the slightly thickened ectoblast underlaid by the thin and irregular layers of mesoblast and entoblast. The primitive streak may be traced for a distance equal to about one third the distance between the head-fold and the blastopore. 


\title{
The Development of the Alligator 247
}

\author{
STAGE IV
}

\section{Figures $7 a-7 h$ (Plates XI., XII.)}

No surface view of this stage was seen by the writer, and hence is not figured. The figures were drawn from one of the scries of sections obtained through the courtesy of Prof. S. F. Clarke. This series was marked "3 Urwirbeln," so that the embryo was apparently slightly younger than the youngest stage obtained by myself and represented in Figures 8 and $8 a$.

Figure $7^{a}$ represents a section that passed through the head-fold of the amnion (u) just in front of the head-fold of the embryo; the amniotic cavity here appears as a large empty space.

Figure $7^{b}$ is several sections posterior to the preceding; it passes through the head-fold of the embryo, but is just back of the head-fold of the amnion. The deep depression of the ectoderm (ec) and entoderm (enl) caused by the hoad-fold is plainly seen. In this depression lie the ends of the medullary folds, distinct from each other both dorsally and ventrally. Each medullary fold is made up of two parts - a medial, more dense nervous layer $(n l)$, and a distal, less dense cpidermal layer $(e p)$. The section corresponding to this one will be more fully described in connection with the following stage.

Figure $7 c$ is some distance posterior to the preceding, though the exact distance could not be 
determined because of a break in the series at this point. The section passes through the posterior limit of the head-fold. The medullary groove $(m g)$ is very deep and comparatively wide; around its sides the germ layers are so closely associated that they may scarcely be distinguished. Ventral to the medullary groove the foregut $(f g)$ is secn as a crescentic slit.

Figure $7 d$ is about a dozen sections posterior to the one just described and is about one seventh the length of the embryo from the anterior end. The embryo is much more compressed, in a dorsoventral direction, and the medullary groove $(\mathrm{mg})$ is correspondingly more shallow. Where the ectoderm (ec) curves over to form the medullary folds it becomes much more compact and somewhat thicker. The notochord $(n t)$ is large and distinct, but is still fused with the entoderm (cnl). The mesoderm (mes) forms a well-defined layer, entirely distinct from both the notochord and the entoderm. From this region, as we pass caudad, the size of the embryo in cross-section gradually decreases and the medullary groove becomes more shallow.

Figure $7 e$ is about one third of the length of the embryo from the posterior end, and is only a few sections from the caudal end of the medullary groove. The ectoderm $(e c)$ is much thinner than in the preceding figure and the medullary groove $(m g)$ is much more shallow. The notochord $(n t)$ 
is of about the same diameter as before, but is here quite distinct from the entoderm (en) as well as from the mesoderm (mes).

Figure $7 f$ is seven sections posterior to Figure 7c. The medullary groove has disappeared and the medullary folds have flattened to form what might be called a medullary plate (at the end of the reference line $c c$ ), which continues to the anterior border of the blastopore. The notochord ( $n t)$ is larger in cross-section than in the more anterior regions; it is still distinct from the entoderm.

Figure $7 \mathrm{~g}$ passes through the blastopore and shows essentially the same structure as was described in connection with the corresponding section of Stage I (Fig. $2 f$ ).

Figure 7 th represents the region of the primitive groove $(p g)$ and primitive streak $(p s)$. The section shows the typical structure for this region-a thick mass of cells is proliferating from the ventral side of the ectoderm $(e c)$ and is spreading laterally to form a distinct mesoderm (mes). The entoderm $(e n)$ is entirely distinct from the other layers.

\section{STAGE V}

Figures 8-8j (Plates XII., XIII., XIV.)

On opening the egg this embryo (Figs. 8 and $8 a$ ) was found to lie on the end of the yolk, near the center of the irregular, lighter area which was mentioned in connection with the description of 
the egg. The length of the embryo proper is $3 \mathrm{~mm}$. This was the youngest stage found in 1905 , and approximates quite closely the condition of the chick embryo after 24 hours' incubation. The dorsal aspect of this embryo, viewed by transmitted light, is shown in Figure 8. The medullary folds $(m f)$ have bent over until they are in contact, though apparently not fused for a short distance near their anterior ends. As will be described in connection with the sections of this stage, the medullary folds are actually fused for a short distance at this time, though in surface views they appear to be separated from each other. In the Madagascar crocodile ( 78 ) the first point of fusion of the medullary folds is in the middle region of the embryo, or perhaps even nearer the posterior than the anterior end of the medullary groove. Throughout the greater part of their length the medullary folds are still widely separated; posteriorly they are merged with the sides of the very distinct primitive streak ( $p s)$, which seems, owing to its opacity, to extend as a sharp point toward the head. Extending for the greater part of the length of the primitive streak is the primitive groove $(p g)$, which, when the embryo is viewed by transmitted light, is a very striking feature at this stage of development and resembles, in a marked way, the same structure in the embryo chick. Clarke (I7) figures the blastopore at this stage as a small opening in front of the primitive 


\section{The Development of the Alligator 25I}

streak, but does not mention any such condition as above described at any stage of development. Five pairs of somites $(s)$ have been formed and may be seen, though but faintly outlined, in both dorsal and rentral views of the embryo; they lie about half-way between the extreme ends of the embryo. The head-fold ( $h$, Fig. $8 a$ ) shows plainly in a ventral view as a darker, more opaque anterior region, extending for about one fourth the length of the embryo. The still unfused region of the medullary folds may be seen also in the ventral view at $m g$. The head-fold of the amnion $(a)$ forms a very thin, transparent hood over the extreme anterior end of the embryo. The tail fold of the amnion has not made its appearance, and in fact is not apparent at any stage in the development. This is true also of the Madagascar crocodile. The notochord (nt) may be seen in a ventral view as a faint, linear opacity extending along the middle line from the head-fold to the primitive streak.

Two sagittal sections of this stage are shown in Figures $8 b$ and $8 c$. The embryo from which the sections were made was apparently somewhat crooked, so that it was not possible to get perfect longitudinal sections. For example, in Figure $s b$ the plane of the section is almost exactly median in the extreme posterior and middle regions, but is on one side of the middle line elsewhere. This explains the enormous thickening of the ectoblast 
in the region of the head, where the section passes through one of the medullary folds $(m f)$ at its thickest part; and also explains the fact that the ectoblast is thinner in the middle region (ec), where the section passes through the medullary groove, than it is farther toward the blastopore where the section cuts the edge of the medullary folds. The outlines of the middle and extreme posterior regions of the ectoblast are much more irregular and ragged than is shown in the figure. The plane of the section passes through the notochord $(n t)$ in the posterior region, but not in the anterior end of the embryo, where a layer of mesoblast (mes) is seen. The great size of the blastopore (blp) is well shown, as is the beginning of the foregut $(f g)$. Comparison of this figure with the more anterior transverse sections and with the dorsal surface view of this stage will make the rather unusual conditions comprehensible.

Figure $8 c$ is cut to one side of the median plane, distal to the medullary folds. Being outside of the medullary folds, the ectoderm $(e c)$ is thinner and less dense than in Figure $8 b$; anteriorly it is pushed down and back as the head-fold, and posteriorly it becomes thin where it forms the dorsal boundary of the primitive streak ( $p s)$.

The foregut $(f g)$, as would be expected, is not so deep as in the median section ( $(8 b)$. The most striking feature of the section is the presence of five mesoblastic somites $(s)$. Each somite, espe- 


\section{The Development of the Alligator 253}

cially the second, third, and fourth, is made up of a mass of mesoblast whose cells are compactly arranged peripherally, but are scattered in the center, where a small myocœl may be seen.

A series of transverse sections of the embryo shown in Figures 8 and $8 a$ is represented in Figures $8 d-j$.

Figure $8 d$ is through the anterior end of the embryo; the posterior cdge of the amnion is cut only on one side (a). The medullary folds $(m f)$ are shown as two distinct masses of tissue, separated by a considerable space from each other, both dorsally and ventrally; they are underlaid by the ectoderm of the head-fold, through which the section passes. A mass of yolk $(y)$ is shown at one side of the section.

Figure $8 c$ represents a section a short distance posterior to the one just described, and passes through the short region where the dorsal edges of the medullary folds have fused with each other. The ventral side of the medu1lary groove $(m g)$ is, as in the preceding section, still unclosed. An epidermal layer of ectoblast $(c p)$ is now distinct from the nervous layer $(n l)$.

Figure $8 f$ is through a region still farther toward the posterior end. Here the medullary groove is again open above, and is still open below. A well-marked space is seen between the epidermal $\left(e^{\prime} p\right)$ and nervous ( $\left.\mathrm{nl}\right)$ layers of the ectoderm, but no mesoblast is yet to be seen. 


\section{The Alligator and Its Allies}

Figure $8 g$ passes through the middle part of the head-fold, and shows that the medullary folds in this region are fused below, but are widely separated above, where their margins are markedly bent away from the mid-line. Between the epidermal and nervous layers of the ectoderm a considerable mass of mesoderm cells (mes) is seen. The curious appearance of the preceding four figures, as well as the first three figures of the next stage, was at first quite puzzling, until a model of the embryo was made from a series of sections. It was then plain, as would have been the case before, except for the unusual depth dorso-ventrally of the head of the embryo, why the medullary canal should at the extreme anterior end be open both dorsally and ventrally, while a few sections caudad it is open only ventrally, and still farther toward the tail it is again open both above and below. These conditions are produccd by the bending under of the anterior region of the medullary folds, probably by the formation of the head-fold. It is apparently a process distinct from the ordinary cranial flexure, which occurs later. The fusion of the medullary folds to form a canal begins, as has been already mentioned, near the anterior end, whence it extends both forward and backward. Hence, if the antcrior ends of the medullary folds be bent downward and backward, their unfused dorsal edges will come to face ventrally instead of dorsally and sections through the anterior part of this bent-under region 


\section{The Development of the Alligator 255}

will show the medullary canal open both above and below, as in Figure $8 d$, while sections farther caudad pass through the short region where the folds are fused, and we have the appearance represented in Figure $8 e$. In Figure $8 f$ is shown a section passing posterior to the short, fused region of the folds, and we again have the medullary canal open both above and below. Figure $8 g$ represents a section through the tip of the bent-under region of the medullary folds, which are here fused below and open above.

Figure $8 h$ passes through the posterior part of the head-fold, between the limits of the fold of the ectoderm and that of the entoderm. The medullary groove $(\mathrm{mg})$ is here very wide and comparatively shallow; its walls are continued laterally as the gradually thinning ectoderm $(e c)$. The enteron $(e n t)$ is completely enclosed, and forms a large, somewhat compressed, thick-walled cavity. Between the dorsal wall of the enteron and the lower side of the medullary canal lies the notochord $(n t)$, a small, cylindrical rod of closely packed cells derived, in this region at least, from the entoderm. In the posterior region of the embryo it is not possible to determine with certainty the origin of the notochord, owing to the close fusion of all three germ layers. Between the wall of the enteron and the lower side of the ectoderm is a considerable mass of mesoderm (mes), which here consists of more scattered and angular cells than in the preceding section. 
256 The Alligator and Its Allies

Figure $8 i$ shows the appearance of a section through the mesoblastic somites, in one of which a small myocol (myc) is seen. As is seen by the size of the figure, which is drawn under the same magnification as were all the sections of the series, the embryo in this region is much smaller in section than it is toward either end, especially toward the anterior end. The medullary groove $(\mathrm{mg})$ is still more shallow than in the more anterior sections, and the ectoderm (ec), with which its folds are continuous laterally, is here nearly horizontal. The mesoblast (mes) is of a more compact nature than in the preceding section and shows little or no sign of cleavage, although a distinct myocol may be seen and cleavage is well marked in sections between this one and the preceding.

The notochord $(n t)$ has about the same appearance as in the preceding section, but is more distinctly separated from the surrounding cells.

Figure $8 j$ is through the posterior end of the embryo; it shows the relation of parts in the region of the primitive streak. Although not visible in surface views, and hence not represented in Figure 8 , the medullary groove is continued without any line of demarcation into the primitive groove, and the medullary folds into the edges o the primitive streak, so that it is impossible to set any definite boundaries between these structures unless the dorsal opening of the blastopore be taken as the point of division. The medullary groove $(\mathrm{mg})$, if 


\section{The Development of the Alligator 257}

it be here so called, is proportionately more shallow than in the preceding figure and is actually much wider. The section passes behind the posterior end of the notochord, so that structure is not seen. Though not so well indicated as might be desired in the figure, the three germ layers are here indistinguishable in the middle line, and in the center of this mass of cells the blastopore (blp) or neurenteric canal may be seen as a small vertical slit. As will be more fully described in the following stage, this canal opens dorsally a few sections posterior to the one under discussion and ventrally a few sections farther toward the head.

In all the sections of this stage the ectoderm and entoderm are fairly thick in the region of the embryo proper, but become thinner until reduced to a mere membrane as we pass to more distal regions. Both layers are composed of loosely arranged cells, with scattered nuclei. Where the ectoderm becomes thickened to form the medullary folds, the cells are much more compactly arranged; hence this region stands out in strong contrast to the rest of the ectoderm.

\section{STAGE VI}

Figures 9a-9m (Plates XIV., XV.)

The embryo represented by this series of transverse sections is intermediate in development between those represented in surface views by 


\section{The Alligator and Its Allies}

Figures 8 and ro. The amnion and head-fold are nearly the same as in Figure 8 ; the medullary folds are intermediate in development, the anterior end not showing so marked an enlargement as shown in Figure Io, $v^{\prime}$. There are six or seven faintly distinguishable somites.

Figure $9 a$ represents a section through the anterior part of the head-fold; it shows one unusual condition: the head lies entirely beneath the surface of the yolk. This condition is quite confusing when the section is studied for the first time. The pushing of the head under the yolk is shown at its commencement in Figure II. The process continues until nearly the entire anterior half of the embryo is covered; but when the embryo attains a considerable size it is seen to lie entirely above the yolk, as in the chick. According to Voeltzkow's figures (78) this same condition is found in the crocodile, and Balfour also mentions it in connection with the lizard. The fusion of the medullary folds has made considerable progress, so that the entire anterior end of the canal is enclosed, except in the region where the folds are bent down and back, as in the preceding stage; here the folds are still distinct from each other, leaving the medullary canal open on the ventral side, as shown in Figures 9 and $9 b$. In the section under discussion the ectoderm $(e c)$ is a very thin membrane on top of a considerable mass of yolk, while no entoderm can be distinguished. The amnion ( $($ ) completely sur- 


\section{The Development of the Alligator 259}

rounds the cmbryo as an irregular membrane of some thickness in which no arrangement into layers can be seen. The epidermal ectoderm (cp) is composed of the usual loosely arranged cells, so that it is clearly distinguishable from the compactly arranged cells of the nervous layer ( $n l)$, from which it is separated by only a line.

In Figure $9^{b}$, which shows a section a short distance posterior to the preceding, the medullary canal (mc) is somewhat deeper and is still open ventrally. There is a distinct space between the nervous $(n l)$ and epidermal $(e p)$ layers of the ectoderm, in which space a few mesoblast cells (mes) may be seen. The section is cut just posterior to the edge of the amnion, so that there is now neither amnion nor yolk above the embryo.

Figure $9 c$ is about ten sections posterior to Figure 96. The scction passes through the anterior wall of the bent-under part of the medullary canal $\left(m c^{\prime}\right)$, so that the actual canal is shown only on the dorsal side $(m c)$, where it is completely closed and begins to assume the shape of the typical embryonic spinal cord. The space between the superficial $(e p)$ and nervous $(n l)$ layers of the ectoderm is quite extensive and is largely filled by a fairly compact mass of mesoderm (mes).

Figure $9 d$, although only five sections posterior to the preceding, shows a marled change in structure. The medullary canal (mc) is here of the typical outline for embryos of this age. A large, 
compact mass of cells $(c n t)$ appears at first glance to be the same that was noted in the preceding stage at the tip end of the turned-under medullary canal; it is, however, the extreme anterior wall of the enteron, which is in close contact with the abovementioned tip of the medullary canal. Between this anterior wall of the enteron, of which wall it is really a part, and the medullary canal is the notochord $(n t)$. The space surrounding the notochord and enteron is filled with a fairly compact mass of typical, stellate mesoblast cells. The depression of the ectoderm (cc) and entoderm ( $\mathrm{cn}$ ) of the blastoderm caused by the formation of the headfold is here less marked, and the dorsal side of the embryo in this region is slightly elevated above the level of the blastoderm.

Figure $9 e$ represents a section passing through the posterior edge of the head-fold. The epidermal ectoderm is here continuous with the thin layer of superficial ectoderm (ec) of the blastoderm, while the entoderm $(e n)$ of the blastoderm is still continuous beneath the embryo. The thick ectoderm of the embryo is sharply differentiated from the thin layer of ectoderm that extends laterally over the yolk. The pharynx (ent) is a large cavity whose wall is thick except at the dorsal side, where it is thin and somewhat depressed, apparently to make room between it and the medullary canal for the notochord $(n t)$.

Figure $9 f$ is about twenty sections posterior to 
The Development of the Alligator 26I

the preceding section, and passes through the point of separation of the folds of the entoderm (en). From this point the entoderm gradually flattens out, leaving the enteron unenclosed. The medullary canal ( $m c$ ) and notochord $(n t)$ are about as in the preceding section, but the ectoderm ( $c p$ ) is somewhat thinner and more flattened. The mesoderm (mes) on the right side exhibits a distinct cleavage, the resulting body cavity $(b c)$ being a large, triangular space.

Figure $9 g$, the twenty-fifth section posterior to that represented in Figure of, shows a marlied change in the form of the embryo. While of about the same lateral dimensions, the dorsoventral diameter of the embryo in this region is less than one half what it was in the head region. The epidermal ectoderm $(e p)$ is now nearly horizontal in position and is not so abruptly separated laterally from the thin lateral sheets of ectoblast. The medullary groove $(\mathrm{mg})$ is here a very narrow vertical slit. At this stage the fusion of the medullary folds has taken place over the anterior third of the embryo. For a short distance, represented in about thirty-five sections, the canal is open as in the figure under discussion; for the next one hundred sections (about one third the length of the embryo) in the region of the mesoblastic somites the canal is again closed, while throughout the last one third of its length the canal is widely open dorsally. The enteron is here entirely open ventrally, 
the entoderm being almost flat and horizontal. The notochord $(n t)$ is distinctly outlined and is somewhat flattened in a dorso-ventral direction. The body cavity (bc) is well marlied, but is separated by a considerable mass of uncleft mesoblast from the notochord and the walls of the medullary groove.

A space of about one hundred sections, or one third the length of the embryo, intervenes between Figures $9 g$ and $9 i$. This is the region of the mesoblastic somites, and in this region, as has been above stated, the medullary canal is completely enclosed. It is evident then that the entire anterior two thirds of the medullary canal is enclosed except for the short region represented in Figure $8 g$. Whether or not this short open region between the two longer enclosed regions is a normal condition the material at hand does not show.

Figure $9 / 2$ represents a typical section in the region of the mesoblastic somites just described. It shows the enclosed medullary canal $(m c)$, the body cavity $(b c)$ on the right, and a mesoblastic somite with its small cavity $(m y c)$ on the left. The entire section is smaller than the sections anterior or posterior to this region, and secms to be compressed in a dorso-ventral direction, this compression being especially marked in the case of the notochord.

Figure $9 i$ is through a region nearly one hundred sections posterior to the preceding, and cuts the 


\section{The Development of the Alligator 263}

embryo, therefore, through the posterior one fourth of its length. The chief difference between this and the preceding section is in the medullary canal, which is here open and is in the form of a wide groove with an irregular, rounded bottom and vertical sides. The size of the section is considerably greater than in the preceding, the increase being especially noticeable in the notochord $(n t)$, which is cut near its posterior end. There is little or no sign of mesoblastic cleavage.

Figure $9 j$ is about twenty sections posterior to Figure $9 i$. The medullary groove $(m g)$ is considcrably larger than in the more anterior regions, and its folds are somewhat inclined toward each other, though still wide apart. The notochord and entoderm are fused to form a large, compact mass of tissue close under the ventral wall of the medullary groove. On the ventral side of this mass of cells a groove (blp) marks the anterior and ventral opening of the blastopore shown in the next figure. The mesoblast shows no sign of cleavage.

Figure $9 k$ shows the medullary groove $(m g)$ in about the same position as in the preceding section. The blastopore $(b l p)$ is here seen as a small cavity in the center of the large mass of cells that was noted in the last figure. The entoderm $(e n)$ is continuous from side to side, but is not so sharply differentiated from the other germ layers as is represented in the figure.

Figure $9 l$ is four sections back of the preceding; 
264 The Alligator and Its Allies

the wide, dorsal opening ( $b l p)$ of the blastopore or neurenteric canal into the medullary groove $(\mathrm{mg})$ is shown. The blastopore or neurenteric canal, then, is still at this stage a passage that leads entirely through the embryo, the medullary canal being in this region unenclosed above. Ventrally it is seen as a narrow opening through the entoderm; it then passes upward and backward, behind the end of the notochord, as a small but very distinct canal, which may be traced through about ten sections. The enclosed portion of the canal lies, as has been stated (Figure $9 k, b l p$ ), in the center of the mass of cells that is fused with or is a part of the floor of the medullary groove.

The above-described neurenteric canal is essentially like that described by Balfour in the Lacertilia . He does not say, however, and it is not possible to tell from his figures, whether there is a long, gradually diminishing groove posterior to the dorsal opening of the canal, as in the alligator. He says that the medullary folds fuse posteriorly until the medullary canal is enclosed over the opening of the neurenteric canal; also that "the neurenteric canal persists but a very short time after the complete closure of the medullary canal."

In Figure $9 m$, for about thirty sections (one tenth the entire length of the embryo), behind the section represented in the last figure, there is a very gradual change in the embryo, converting the deep 


\section{The Development of the Alligator 265}

groove, $m g$ in Figure $9 l$, into the shallow slit, $p g$, Figure $9 \mathrm{~m}$.

There is no line of demarcation between the typical medullary groove region of Figure $9 l$ and the equally typical primitive groove region represented in Figure $9 \mathrm{~m}$. As was noted in the preceding stage, the medullary folds are quite continuous with the folds of the primitive streak, and the medullary groove with the primitive groove; so that, unless we take the dorsal opening of the neurenteric canal as the point of separation, there is no line of division between these structures. The entoderm $(\mathrm{en})$ and the lateral regions of the cctoderm $(e c)$ and mesoderm (mes) in Figure $9 m$ are about as they were in Figure $9 l$, but in the middle line is scen a compact mass of cells forming the primitive streak $(p s)$, with the shallow primitive groove $(p g)$ on the dorsal side. The cells on each side of the primitive groove and for a short distance below it are compact, as is shown in the figure, but as we pass ventrally and laterally they become looser and more angular to form the lateral sheets of mesoblast (mes), very much as is the case in the chick and other forms. For a few sections posterior to the one shown in Figure $9 m$ the primitive streak may be seen, then it disappears, and only the ectoderm and entoderm remain as thin shects of tissue above the yolk. 


\section{STAGE VII}

Figures io and ioa (Plates XV., XVI.)

Although of practically the same size as the preceding, this stage has advanced sufficiently in development to warrant a description.

The medullary folds are apparently still slightly open for the greater part of their length, though they are evidently fused together in the head region, except at the extreme end. Transverse sections, however, of Figure I2, in which the medullary folds, from the dorsal aspect, seemed open $(m g)$ as in Figure Io, have shown that these folds are fused throughout their length.

The first cerebral vesicle $\left(\imath^{\prime}\right)$ is clearly indicated as an enlargement of the anterior end of the nervous system, and a slight enlargement $\left(v^{\prime \prime}\right)$ posterior to the first probably represents the second cerebral vesicle.

There are now eight pairs of somites $(s)$.

The head-fold $(h)$ now shows in both dorsal and ventral views, appearing in the former, when vicwed by transmitted light, as a lighter, circular area on cither side of the body, just posterior to the hinder edge of the amnion.

The head-fold of the amnion (a) has extended about twice as far backward as it did in the preceding stage.

Owing to the opacity caused by the medullary folds being in contact along the middle line, the notochord is no longer visible in surface views. 


\section{The Development of the Allisator 267}

The head at this stage hegins to push down into the yolk in a strange way that will be described later.

\section{STAGE VIII}

Figures II-IIk (Plates XVI., XVII., XVIII.)

This stage is about one fourth longer than the preceding. The medullary canal is enclosed throughout its entire length, though it appears in surface view (Fig. I I) to be open in the posterior half (mc) of the embryo. An enlargement of this apparently open region at the extreme posterior end $(p g)$ is probably caused by the remains of the primitive groove or the neurenteric canal, and a slight opacity at the same point may be caused by the primitive streak. The anterior end of the neural tube is bent in a ventral direction (i'), as in the preceding stage. The somites $(s)$ now number fifteen pairs; they are somewhat irregular in size and shape.

The head-fold is not so striling a feature as in the preceding stage. The head-fold of the amnion (a) now covers nearly two thirds of the embryo. The heart $(h t)$ is seen as a dark, rounded object projecting to the right side of the neural canal, just anterior to the first somite. The vitelline bloodvessels are just beginning to form, but are not shown in the figure.

The depression of the anterior region that was 
noted in the preceding stage has advanced so far that a considerable part of the embryo now projects forward under the blastoderm. In some cases it is almost concealed in a dorsal view; in other cases it may casily be seen through the transparent membranes, especially after clearing.

In opening eggs of this stage one is at first apt to underestimate the size of the embryos, since the anterior part of the embryos cannot be seen until after they are removed from the yolk and are viewed from the ventral side.

The embryo from which the series of transverse sections of this stage was made, while of the same state of development as that shown in Figure II, was more fully covered by the blastoderm than is shown in the surface view in question.

Figure I I $a$ passes through the tip of the head. Dorsal to the embryo is the ectoderm and a thick mass of yolk $(y)$. The amnion $(a)$ is seen as an irregular membrane which entirely surrounds the head. The medullary canal ( $m c$ ) is entirely closed except at the extreme anterior end, which is bent downward so that the opening is on the ventral side. The nervous $(n l)$ and epidermal $(e p)$ layers of the ectoderm are in contact throughout, but are clearly distinguishable because of the difference in the compactness of their cells.

In Figure $\mathrm{I} b$ is represented a section, behind the preceding, which passes through the posterior tip of the turned-under anterior end $\left(m c^{\prime}\right)$. Here the 


\section{The Development of the Alligator 269}

medullary canal is closed both above (mc) and below $\left(m c^{\prime}\right)$. The amnion ( $($ ) has about the same appearance as in the more anterior section, but there is here a considerable space, filled with mesoblast (mes), between the nervous ( $\mathrm{nl}$ ) and epidermal $(e p)$ layers of ectoderm.

Figure II $C$ is twenty sections, about one tenth the length of the embryo, posterior to the one last described. The large mass of overhanging yolk $(y)$ is still present, as is also the amnion ( $a)$, though the latter no longer passes entirely around the embryo; only the truc amnion could be made out. The thickened walls of the medullary canal have reduced that cavity to a narrow, Y-shaped slit $(m c)$. The notochord $(n t)$ is very slender in this region, compared to its diameter farther toward the posterior end. The enteron (ent) is a large cavity, whose wall is made up of loosely arranged cells except around a median, ventral depression where the cells are more compact. This depression may be traced through ten or fifteen sections and may represent the beginning of the thyroid gland, though this point was not worked out with certainty. Surrounding the notochord and enteron is a loose mass of typical, stellate mesoblast cells (mes), which are cleft on either side to form the anterior limit of the body cavity (bc). Between the body cavity below and the enteron above, on each side, is a small blood-vessel $\left(b i^{\prime}\right)$ which when followed caudad 
is found to open ventrally and medially into the anterior end of the heart.

Figure I $\mathrm{I} d$ is about a dozen sections posterior to the preceding. The appearance of the overhanging yolk $(y)$, of the amnion $(a)$, and of the notochord $(n t)$ is about as in the more anterior section. The medullary canal $(m c)$ is a straight, vertical slit, and the depression in the floor of the pharynx (ent) is much more shallow. The body cavity $(b c)$ is much larger and extends across the mid-ventral line beneath the heart ( $h t$ ), which is cut through its middle region. The heart may be traced through about twenty sections (one tenth the length of the embryo); its mesoblastic wall (mes') is thin and irregular, and is lined by a distinct endothelium $\left(\mathrm{en}^{\prime}\right)$ whose exact origin has not yet been worked out.

Figure I $e$ is just back of the heart, and shows in its place the two vitelline veins $(i n)$. The depression in the floor of the enteron (ent) is entirely distinct from the one that has been mentioned above, and is simply the posterior limit of the head-fold of the entoderm; the fifth section posterior to this shows where this depression opens ventrally to the yolk sac. The other structures shown in the figure are not markedly different from what was seen in Figure II $d$.

Figure I $f$ is about one tenth the length of the embryo posterior to Figure i $c$. The chief differences here noticed are in the enteric and colomic 
The Development of the Alligator 27

cavities. The former is no longer enclosed, a dorsal fold in the entoderm being all that remains of the cavity that was seen in the more anterior figures, while the latter is here reduced to a narrow cleft between the somatic and splanchnic mesoblast. A thickening of the mesoblast on either side of the notochord, especially on the left, represents a mesoblastic somite. The medullary canal (mc) is more open than in the more anterior sections.

For about one third of the length of the embryo posterior to Figure I I $f$ there is a gradual flattening, in a dorso-ventral direction, with loss of the amnion, until the condition represented in Figure II $g$ is reached. The most striking feature of this region is the great thickness of the ectoderm (ec), which is still made up of scattered, irregular cells. In the middle line, directly over the medullary canal (here a nearly cylindrical tube), is a sort of break in the ectoderm, as though there had not been a complete fusion of the epidermal layer when the nervous layer came together on the closure of the medullary groove. This break in the ectoderm may be followed back to the region of the primitive streak, and will be mentioned again. As has been noted, the medullary canal $(m c)$ is nearly circular in crosssection, and is closely underlaid by the notochord $(n t)$, which is several times the diameter that it was in more anterior sections. The mesoblast (mes) is a comparatively thin layer, intermediate 
in thickness between the ectoderm and entoderm. It shows laterally a slight separation to form the body cavity.

Figure $I I h$ is about ten sections posterior to Figure II $g$, and differs from it chiefly in that the notochord $(n t)$ is continuous with the lower side of the medullary canal $(m c)$, though still distinct from the underlying entoderm (en).

Figure I $i$, four sections farther from the head, shows the same greatly thickened ectoderm (ec) with the same break $\left(e c^{\prime}\right)$ in the middle line. The section is pesterior to the notochord and passes through the anterior edge of the blastopore or, as it may now perhaps better be called, the neurenteric canal. The cells of the medullary wall are continuous with those of the entoderm. The mesoderm (mes) is still distinct from the other germ layers.

Figure I $j$ is the next section posterior to the one just described and differs from it only in showing the actual opening of the neurenteric canal (nc) into the medullary canal (mc). The medullary canal extends, with gradually diminishing caliber, for about fifteen sections posterior to the point at which the neurenteric canal empties into it. The mesoblast (mes) is so closely attached to the lower wall of the neurenteric canal that it seems to be actually continuous with it.

For a considerable distance posterior to the end of the medullary canal we find the structure 


\section{The Development of the Alligator 273}

similar to that shown in Figure I $k$, which is about the twentieth section posterior to Figure IIj. The break $\left(e c^{\prime}\right)$ in the ectoderm is here seen as a compact group of cells which at first glance seem to be continuous with a rounded mass of cells below (ps). Examination under greater magnification, however, shows that the two groups of cells are distinct. As the sections are followed back of this region, the upper mass of cells $\left(e c^{\prime}\right)$ gradually disappears, and after its disappearance the lower mass $(p s)$, which is already continuous with the mesoderm (mes) on either side, becomes continuous with the under side of the ectoderm. The mass of cells $(p s)$ is apparently the primitive streak, though it is distinct from the ectoderm for a considerable distance posterior to the neurenteric canal. Just what may be the meaning of the thickened ridge of ectoderm $(e c)$ it is difficult to determine.

\section{STAGE IX}

Figures I2-I2g (Plates XVIII., XIX.)

The entire length of the embryo proper is 6.5 $\mathrm{mm}$. from the extreme posterior end to the region of the midbrain $\left(v^{2}\right)$, which now, on account of the cranial flexure, forms the most anterior part of the body. Besides being slightly longer than the preceding stage, the embryo has increased in thickness, especially in the anterior region, where the enlargement of the cerebral cavity is considerable. 


\section{The Alligator and Its Allies}

Body torsion has begun (Fig. I2), so that the anterior third of the embryo now lies on its right side, while the rest of the body is still dorsal side up. The direction of body torsion does not scem to be as definite as it is in the chick, some alligator embryos turning to the right side, others to the left. Clarke has illustrated this fact in his alligator figures. He says (I 7 ) that embryos lie "more frequently on the left, but often on the right side."

The head is distinctly retort-shaped, and at the side of the forebrain $\left(i^{\prime}\right)$ a small crescentic thickening is the optic vesicle $(c)$. The auditory vesicle, though of considerable size, does not show in this surface view. The head-fold $(h)$ extends for about one third the length of the entire embryo, though its exact limit is difficult to determine in surface view. There is no sign of a tail-fold.

About seventeen pairs of somites are present.

The amnion extends over the anterior two thirds of the embryo.

The above-mentioned increase in the diameter of this embryo over that of the preceding is evident when the first two transverse sections of this stage are compared with the corresponding sections of the earlier stage; in the middle and posterior regions there is not very much difference in size.

Figure I $2 a$ passes through the region of the forebrain. This end of the embryo lies on its side, as was noted above and as may be recognized from the relative positions of the head and the overlying 


\section{The Development of the Alligator 275}

yolk $(y)$. The great size of this and the following figure is due partly to the increase in size mentioned above and partly to the fact that the sections pass through the region of cranial flexure. The present figure (I2a) represents the brain cavity as large and dumbbell-shaped, with comparatively thick walls of compactly arranged cells. The ventral cnd of this cavity $(f b)$ is cut anterior to the region of the optic vesicles, while the dorsal end $(m b)$ may perhaps be called the midbrain. In the sections that follow this one the two cavities are distinct from each other. The medullary canal, as was stated above, is now completely enclosed, except for the ventral opening of the neurenteric canal, to be presently noticed. Surrounding the brain is a considerable mass of mesoblast (mes). It is composed of the typical stellate cells. The ectoderm $(c c)$ is made up of the same irregularly and loosely arranged cells that have been seen in earlier stages; it is of unequal thickness in different regions, the thicker parts being at the sides. The amnion ( $a$ ) has the usual appearance, and in this region of course completely surrounds the embryo.

Figure $12 b$ is ten sections posterior to the section just described. The width of the embryo is greater in this region, but the dorso-ventral diameter is about the same as in the more anterior section.

The overlying yolk and blastoderm are not 
shown in any figure of the series except the first. In this figure the forebrain $(f b)$ and midbrain $(m b)$ are widely separated instead of being connected, as in the preceding figure, where the section passed through the actual bend of the cranial flexure. The anterior and ventral part of the cranial cavity, the forebrain $(f b)$, is nearly circular in outline. It cxhibits on one side a well-marked optic vesicle (oi), which is sufficiently advanced in development to show a rudimentary optic stalk. The outer wall of the optic vesicle is in close contact with the superficial cctoderm, which shows as yet no sign of the formation of a lens vesicle. The plane of the section being probably not quite at right angles to the long axis of the embryo, the optic vesicle of one side only was cut. The wall of this part of the forebrain is of about the same thickness and appearance as in the preceding stage. The other cerebral cavity $(m b)$ of this section is probably the hinder part of the midbrain, though it may be the anterior part of the hindbrain; there is no sharp line of demarcation between these regions of the brain. This cavity $(m b)$ is much smaller in section than the forebrain; its walls are of about the same thickness.

Ventral to the midbrain is the anterior end of the notochord ( $n t)$, surrounded by the mesoblast. At various places throughout the mesoblast irregular open spaces may be seen; these are bloodvessels. The ectoderm (ec) and amnion ( $a$ ) have 
The Development of the Mlligator 277

about the same appearance as in the preceding figure, though the former seems somewhat thinner.

Figure $12 c$ is just back of the bent-under forebrain represented in the preceding figure and in front of the main body of the heart. The plane of the section not being at right angles to the long axis of the body (as was mentioned above), the figure is not bilaterally symmetrical. The neural canal, since the section passes through the auditory vesicles, may here be called the hindbrain $(h b)$. It has an almond-shaped cavity, surrounded by a wall of medium thickness. In close contact with the wall of the hindbrain, on each side, is the inner side of the auditory vesicle $(o)$, which is scen as a deep, wide-mouthed pit in the superficial ectoderm. On the right side of the section the auditory pit is cut through its middle region; it is simply a thickened and condensed area of the ectoderm which has been invaginated in the usual way. Directly beneath the hindbrain is the notochord $(n t)$, on each side of which, in the mesoblast, is the dorsal aorta $(a o)$, or rather the continuation of the aorta into the head. Beneath these structures and extending from one side of the section to the other is the pharynx $(p h)$; its lining wall is fused on each side with the ectoderm, but there is no actual opening to the exterior. These points of contact $(g)$ betwcen entoderm and cctoderm are of course the gill clefts; they are not yet visible from the outside. The roof of the pharynx is flat and 
comparatively thin, while the floor is thickened and depressed to form a deep, wide pit, traceable through six or eight sections. This pit may be the thyroid gland already noticed in the preceding stage. Below the main cavity of the pharynx and close to each side of the thyroid rudiment just mentioned is a large blood-vessel $(t r)$. These two vessels when traced posteriorly are found to be continuous with the anterior end of the heart, and hence may be called the truncus. They were noticed in Figure $I I c, b i$. The ectoderm surrounding the lower side of the embryo was so thin and indistinct that it could scarcely be distinguished from the mesoderm of that region. The amnion $(a)$ is still a continuous envelope entirely surrounding the embryo.

Figure I2d, about twenty sections posterior to Figure I2c, is in the posterior heart region. The spinal cord $(s c)$, as might be expected, is smaller than in the more anterior region, but is otherwise not markedly different from what was there seen. The notochord (nt) also has the same appearance as before. The enteron (ent) shows of course in this region no gill clefts; it is a small, irregular cavity with thicker walls than in the figure just described. The ventro-lateral depression is entirely distinct from the depression that was called the thyroid rudiment in the preceding figure. Dorsal to the enteron are the two dorsal aortæ (ao), now smaller and more ventral to the notochord 


\section{The Development of the Alligator 279}

than in the preceding figure. Ventral to the enteron is the large heart $(h t)$, projecting below the body cavity, which is no longer enclosed. The mesodermic wall (mes') of the heart is still comparatively thin and is separated by a considerable space from the membranous endocardium $\left(\mathrm{cn}^{\prime}\right)$. The extent and shape of the heart are shown in the surface view of this stage. On the right side of the section the body cavity extends to a point nearly opposite the middle of the spinal cord, considerably dorsal to the notochord, while on the left side the dorsal limit of the body cavity is scarcely level with the lower side of the notochord. Between the dorsal end of the body cavity and the side of the spinal cord, on the left, is a dense mass of mesoblast $(s)$, one of the mesoblastic somites. A few sections either anterior or posterior to the one under discussion will show the condition of the two sides reversed - that is, the body cavity will extend to the greater distance on the left and will be interrupted by a mesoblastic somite on the right. It is evident, then, that the upper angle of the body cavity is extended dorsally as a series of narrow pouches between the somites. The mesoblast that lines the body cavity, the splanchnopleure $(\mathrm{sm})$ and somatopleure $(\mathrm{so})$, is somewhat denser than the general mass of mesoblast, so that these layers are quite distinct, the former $(\mathrm{sm})$ extending around the enteron (ent) and heart (ht), and the latter (so) being carried dorsalward as the 
mesoblastic part of the amnion $(a)$. The amnion may be traced through about I 30 of the 200 sections into which this embryo was cut.

Figure I $2 e$ is nearly one fourth the length of the embryo posterior to Figure I $2 d$; it is approximately in the middle region. The diameter of the embryo has been gradually decreasing until now it is very much less than in the head region. The section being behind the head-fold the entoderm (en) is nearly flat and the enteron is quite unenclosed. The canal of the spinal cord $(s c)$ is smaller in proportion to the thickness of its walls, and the notochord $(n t)$ is somewhat larger than in the preceding sections. In proportion to its extent, the ectoderm is very thick. Under the notochord the dorsal aortæ ( $(10)$ are seen as two large, round openings in the mesoblast. On the left side the section passes through the center of a somite and shows a small, round myoccel (myc). The mesoblastic layer of the amnion (so) is distinct throughout from the ectoblastic layer $(a)$.

The most important structures to be here noted are the first rudiments of the Wolffian ducts (wd). They are seen in the present section as lateral ridges of mesoblast projecting outward and upward toward the ectoblast, which suddenly becomes thin as it passes over them. These ridges or cords of mesoblast are as yet quite solid. They arise suddenly at about the eighticth section of the scries of two hundred and may be traced through 


\section{The Development of the Alligator $28 \mathrm{I}$}

about forty sections, or one fifth of the length of the embryo. Their exact length is difficult to determine because, while their anterior ends are blunt and sharply defined, they taper so gradually posteriorly that it is hard to tell just where they end. They apparently originate anteriorly and gradually extend toward the tail. In a slightly younger embryo the rudimentary Wolffian duct could be seen as a still smaller rod of cells cxtending posteriorly for a few sections, from the seventyfifth section of a series of about two hundred. In the particular series under discussion the left rudimentary Wolffian duct was about one fifth longer than the right one.

Figure I $2 f$ is just posterior to the head-fold of the amnion, passing, in fact, on the left side through the cxtreme edge of its lateral fold, which is shown as a upward bend in the ectoblast and somatopleure.

The ectoblast $(e c)$ shows the same remarkable thickening that was noted in the corresponding region of the preceding stage. The spinal cord $(s c)$, notochord $(n t)$, aortæ ( $(10)$, and entoderm ( $\mathrm{ch})$ need no special mention. The mesoderm seems to be separated by unusually wide spaces from both ectoderm and entoderm, and is made up of rather closely packed cells except around the aortæ, where there secms scarcely enough tissue to hold these vessels in place. The body cavity $(b c)$ is large, and a small myocoel $(m y c)$ is seen on the left. 
Figure I $2 g$ is through the neurenteric canal $(n c)$, a distinct opening through the floor of the spinal canal. The section is of course just back of the posterior end of the notochord. The entoderm (cn) along the margin of the neurenteric canal is naturally continuous with the wall of the spinal cord $(s c)$. The ectoderm (ec) is thicker than ever, except in the median plane, where it passes over the spinal cord. The mesoblast is more abundant than in the preceding figure, and shows on the left what appears to be a distinct myocol (myc), though in surface view the mesoblastic somites do not extend this far toward the tail.

\section{STAGE $\mathrm{X}$}

Figures 13-I $3 g$ (Plates XIX., XX., XXI.)

This embryo (Fig. I3) is about $5 \mathrm{~mm}$. in length, and hence is slightly smaller than the preceding stage, though somewhat more advanced in development. The medullary canal is still apparently unclosed for a short distance at the extreme posterior end; this appearance is probably due to the neurenteric canal (nc) and to the thinness of the roof of the medullary canal rather than to any lack of fusion of the medullary folds. The optic vesicle is more distinct than in the preceding stage; a somewhat similar, though smaller, opacity (o) marks the position of the ear. There are now about twenty pairs of somites, though it is difficult 


\section{The Development of the Alligator $28_{3}$}

to determine their exact ntumber on account of the torsion of the body. The amnion is at about the same stage of development as in Stage IX. The heart $(h t)$ is a large double mass, whose outlines may be dimly seen when the embryo is viewed hy transmitted light. The vitelline vessels ( $i^{\prime \prime}$ ) are still but faintly outlined in the vascular area; the veins and arteries cannot yet be distinguished from each other. The gill clefts, though not visible externally in the embryo drawn, may be seen in sections of this stage as evaginations of the wall of the pharynx.

The transverse sections of this stage are slightly more advanced in development than was the embryo that has just been described in surface view. Only those sections have been figured which. show a decided advance in the development of some special structures over their condition in the preceding stage. The sections of the preceding stages were drawn under a magnification of cightyseven diameters; those of this and the following stage were drawn under a magnification of only forty-one diameters. All of the figures have been reduced one half in reproduction.

Figure $\mathrm{I} z a$ is the most anterior section of this series to be described. On account of the cranial flexure, which causes the long axis of the forebrain to lie at right angles to that of the spinal cord, this section cuts the head region longitudinally. The ectoderm $(c c)$ is of varying thickness, the 


\section{4}

The Alligator and Its Allies

thickest areas being on each side of the forebrain; it is more compact than in the earlier stages, and, owing to the low magnification under which it is drawn, it is represented here by a single heavy line. Under this magnification only the nuclei of the mesoderm cells (mes) can be seen, so that this tissue is best represented by dots, more closely set in some places than in others. The forebrain is an elongated cavity $(f b)$ with thick, dense walls. Attached to each side of the forebrain is an optic vesicle $\left(o \pi^{\prime}\right)$, which is considerably larger than in the preceding stage. The connection between the cavity of the forebrain and that of the optic vesicle is not seen in this section; it is a wide passage that may be seen in several sections posterior to the one under discussion. The beginning of the invagination of the optic vesicle to form the optic cup may be seen on both sides, but more plainly on the right. On the right side aiso is noticed a marked thickening of the ectoderm, which is invaginated to form a small pit, the lens vesicle $(l v)$; on the left side the section is just behind the lens vesicle. Above the optic stalk on each side, in the angle between the optic vesicle and the side of the forebrain, is a small bloodvessel $\left(b_{i^{\prime}}\right)$. Several other blood-vessels may be seen at various places in the mesoblast, four of them near the pharynx being especially noticeable. The hindbrain $(h b)$ is wider than, but not so deep as, the forebrain; its walls are very thick laterally, but 
The Development of the Alligator $28_{5}$

are thin on the dorsal and ventral sides. The dorsal wall is reduced to a mere membrane, which, with the overlying ectoderm, has been pushed into the brain cavity, as is generally the case with such embryos. Close to the ventral wall of the hindbrain the notochord $(n t)$ is seen. The character of the notochord has already begun to change; the cells are becoming rounded and vacuolated, with but few visible nuclei except around the periphery of the notochord. Near the center of the section, close to the ventral end of the forebrain, is the pharynx $(p h)$, cut near its anterior limit; it is here a small, irregularly rectangular cavity with a comparatively thin wall. On the left side of the pharynx the first gill cleft $(g)$ is indicated as a narrow diverticulum reaching toward the ectoderm. A few sections posterior to this one the first gill cleft is widely open to the exterior. As has becn said, in the surface view of this stage above described none of the gill clefts showed; so that in this respect at least the sectioned cmbryo was more nearly of the state of development of the embryo represented in Figure It, to be described later.

Figure $13 b$, about forty sections posterior to Figure $\mathrm{I} 3 a$, passes through the hindbrain in the region of the ears. Being back of the region affected by cranial flexure, this section is of course of much less area than the preceding. The ectoderm shows no unusual features; it is of uniform thickness except where it becomes continuous with the 
entoderm around the mandibular folds $(m d)$; there it is somewhat thickened. The most striking feature of the section is the presence of two large auditory vesicles (o). The section being not quite at right angles to this part of the embryo, the vesicles are not cut in exactly the same plane; the one on the left is cut through its opening to the extcrior, while the one on the right appears as a completely enclosed cavity. In a section a short distance posterior to this one the appearance of the vesicles would be the reverse of what it is here. As may be seen in the figure, the vesicles are large, thick-walled cavities lying close to the lateral walls of the hindbrain. The hindbrain itself has the usual triangular cross-section, with thick lateral walls and a thin, wrinkled dorsal wall. Close to the ventral side of the hindbrain lies the notochord $(n t)$, on each side of which, in the angle between the brain and the auditory vesicles, is a small blood-vessel ( $\left.b c^{\prime}\right)$. Ventral to these structures and close to the dorsal wall of the pharynx $(p h)$ are the two large dorsal aortæ (ao). The ventral side of the section passes through the open anterior end of the pharynx $(p h)$. On the left is seen the widely open hyomandibular cleft $\left(g^{\prime}\right)$, between the main body of the section and the mandibular arch $(m d)$. On the right side the plane of the section was such that the hyomandibular cleft was not cut through its external opening. In each mandibular fold a large aortic arch $(a r)$ is 
seen, and also a slight condensation of mesoblast, the latter probably being the forerunner of cartilage.

Figure I $3 c$ passes through the anterior part of the heart about seventy-five sections posterior to Figure $13 b$. The embryo in this region is narrow but deep (dorso-ventrally), the depth being largely due to the size of the heart. The ectoderm (cc) is considerably thickened on each side of the pharynx $(p h)$; this thickened area may be traced for some distance both anteriorly and posteriorly from this point; its significance could not be determined. The spinal cord (sc) and notochord (nt) need no special description; the former is smaller and the latter larger than in the more anterior sections. The two large blood-vessels (ac) near the spinal cord and notochord are probably the anterior cardinal vcins. The aortæ are cut by the plane of this section just anterior to their point of fusion into a single vessel. A few blood corpuscles are seen in the right aorta. The enteron $(\mathrm{cht})$, cut posterior to the region of the gill clefts, is a large elliptical cavity, with its long axis in a transverse position. Its entodermal wall is comparatively thin and smooth, with the cell nuclei arranged chiefly on the outer side, $i$. $e$., away from the cavity of the enteron. The body cavity $(b c)$ is here still unenclosed, and its walls, the somatic stalk, are cut off close to the body of the cmbryo. The heart $(h t)$, the most conspicuous feature of 
this section, is nearly as large in cross-section as all the rest of the embryo. As seen in such a section it is entirely detached from the body of the embryo, and in this particular case has about the shape of the human stomach. The mesoblastic portion of its wall (mes') is of very irregular thickness; it forms a dense layer entirely around the outside, except for the pointed dorsal region, and is especially thick along the ventral margin, where it is thrown into well marked folds, the heavy muscle columns. Lining the cavity of the heart is the membranous endothelium $\left(e n^{\prime}\right)$, and between this and the dense outer wall just described is a loose reticular tissue with but few nuclei.

As the series is followed toward the tail the sections diminish in size until, at a point about one third the embryo length from the posterior end, they are of scarcely one fourth the area of the sections through the region of the hindbrain.

Figure $\mathrm{I} 3 d$ is about one hundred and twentyfive sections posterior to Figure I $3 c$. Although not so small as the sections that follow it, this section is considerably smaller in area than the one last described. The amnion (a), which was not represented in the last three figures, is very evident here. The spinal cord (sc) is considerably smaller here than in the preceding figure, while the notochord $(n t)$ is not only relatively but actually larger than in the more anterior regions. Beneath the notochord is the aorta (ao), now a single large 


\section{The Development of the Alligator 289}

vessel. The mesoblast on each side of the body is here differentiated into a distinct muscle plate $(m p)$. These muscle plates have very much the appearance of the thickened ectoderm seen in the younger stages of development. At about its middle region (i.c., at the end of the reference line ec) each muscle plate is separated from the overlying ectoderm by an empty space; this space is still more marked in some other series. Ventral to the aorta, and supported by a well marked though still thick mesentery ( $m s$ ), is the intestine. It is a small, nearly cylindrical tube with thick walls; the splanchnic mesoblast which surrounds it is more dense than the general mass of mesoblast; it was somewhat torn in the section and is so represented in the figure. The urinary organs have made considerable progress since the last stage. In the figure under discussion they are seen as a group of tubules on either side of the aorta. The tubule most distant from the middle line, on each side, is the Wolffian duct (wd). It extends through the posterior two thirds of the embryo and varies in diameter at different points; it is usually lined with a single layer of cubical cells which contain large nuclei. The Wolffian bodies (wt) are a mass of slightly convoluted tubules that may be traced throughout the greater part of the region through which the Wolffian duct extends. These tubules also vary somewhat in diameter, but they are usually of greater caliber than the duct. No 


\section{The Alligator and Its Allies}

actual nephrostomes are to be seen, though the occasional fusion of a tubule with the peritoneal epithelium, as is seen on the left side of the present figure, may represent such an opening.

Figure I $3 e$ is about one hundred and forty sections posterior to the section just described. The embryo is here very slender, so that the contrast between this and the first figure ( $13 a$ ) of this stage is remarkable. Except in size, this section does not differ greatly from the preceding. The spinal cord, notochord, etc., are smaller than before, but are of about the same relative size. The mesentery (ms) in the section drawn was torn across, so that the intestine is not represented. Medial to the Wolffian duct is a tubule (wt), which seems to be the same as those which were called Wolffian tubules in the preceding stage, but which may be the beginning of the ureter.

Figure I $3 f$, about two hundred and fifty sections posterior to the last, passes through the extreme posterior end of the embryo. The section is nearly circular in outline and is somewhat larger than the preceding. The amnion (a) completely encircles the embryo. The ectoderm $(e c)$ is of fairly even thickness, and the mesoblast which it encloses is of the usual character. The spinal cord (sc) is nearly circular in outline, as is its central canal. The digestive tract (cnt) is larger in section than it was in more anterior regions; it is nearly circular in cross-section and its walls are made up of 


\section{The Development of the Alligator 29I}

several layers of cells, so that it resembles to a considerable degree the spinal cord of the same region. In the narrow space between the spinal cord and the hindgut is seen the notochord $(n t)$, somewhat flattened and relatively and aciually smaller than in the preceding figure. A few scattered blood-vessels may be seen in the mesoblast at various places.

A sagittal section of an embryo of this stage, drawn under the same magnification as were the transverse sections, is shown in Figure $13 \mathrm{~g}$. The cmbryo being bent laterally could not be cut by any one plane throughout its entire length, so that only the anterior end is represented in the figure. The amnion (a) may be clearly seen except at certain places where it is closely adherent to the superficial ectoderm. Under the low magnification used the superficial ectoderm cannot be distinguished from the ectoderm of the nervous system. The plane of the section being in the anterior end almost exactly median, this part of the central nervous system is seen as the usual retort-shased cavity, while in the region back of the brain, where the neural canal is narrow, the section passes through the wall of the spinal cord (sc) and does not show the neural canal at all. The wall of the forebrain $(f b)$ is quite thick, especially at the extreme anterior end; the wall of the midbrain $(m b)$, where the marked cranial flexure takes place, is somewhat thinner, and it gradually 
becomes still thinner as it is followed posteriorly over the hindbrain $(h b)$. Between the floors of the fore- and hindbrains, in the acute angle caused by the cranial flexure, is the anterior end of the notochord $(n t)$, the only part of that structure that lies in the plane of the section. Ventral and posterior to the notochord is a large cavity, the pharynx $(p h)$, whose entoblastic lining can scarcely be distinguished under this magnification from the surrounding tissues. The stomodeal opening being as yet unformed, the pharynx is closed anteriorly; posteriorly also, owing to the plane of the section, the pharynx appears to be closed, since its connection with the yolk stalk is not shown. In the floor of the pharynx, almost under the reference line $p h$, a slight depression marks the position of the first gill cleft. In the mesoblast ventral to the pharynx and near the gill cleft just mentioned, a couple of irregular openings represent the anterior end of the bulbus arteriosus, posterior and ventral to which is the heart $(h t)$, a large, irregular cavity. The dorsal aorta (ao) may be seen as an elongated opening in the mesoblast, extending in this section from the middle region of the pharynx to the posterior end of the figure where it is somewhat torn. Two of the eighteen or twenty pairs of mesoblastic somites possessed by this embryo are shown at the posterior end of the figure $(s)$, where the plane of the section was far enough from the median line to cut them. 


\title{
The Development of the Alligator 293
}

\author{
STAGE XI
}

Figure I4 (Plate XXI.)

Only the anterior region of this embryo is shown in the figure, which is a ventro-lateral view. While there is some change in the general shape and in parts of the head, the reason for figuring this stage is to show the first gill cleft $\left(g^{\prime}\right)$, which lies at an acute angle to the long axis of the neck behind the eye $(e)$. The cleft is narrow but sharp and distinct in outline; it shows neither in this nor in the following stages the branched, Y-shaped outline mentioned by Clarke.

\section{STAGE XII}

Figures i5 ${ }^{-1} 5 f$ (Plates XXI., XXII.)

In this stage, also, only the anterior region of the embryo is figured in surface view. The shape of the head is about the same as in the preceding stage, but it is drawn in exact profile. Three gill clefts $\left(g^{\mathrm{r}^{-3}}\right)$ are now present, and are wide and distinct. The first cleft, as in the preceding stage, lies at an acute angle to the long axis of the pharynx and nearly at right angles to the second cleft. The third cleft sends a wide branch $\left(g^{4}\right)$ toward the posterior, as has been described by Clarlie, from which, or in connection with which according to Clarke, the fourth cleft will develop. All three clefts may be distinctly seen to open entircly 
through the pharyngeal wall. The outlines of the visceral folds, especially of the mandibular, begin to be apparent. The nasal pit (n) now shows as a round depression in front of the more definitely outlined cye $(c)$. The auditory vesicle $(o)$ is so deep beneath the surface that it may be seen only by transmitted light.

Figures $15(-) e$ represent transverse sections of an embryo of about this general state of development, except that the gill clefts are not so definitely open as in the surface view.

Figure $15 a$, the most anterior section of the series, passes through the forebrain $(f b)$ in the region of the eyes, and through the hindbrain $(h b)$ anterior to the auditory vesicles. The forebrain is here a large cavity with a dense wall of a comparatively even thickness. Owing probably to the section not being exactly in the transverse plane, the eyes are cut in different regions, that on the left $\left(o r^{\prime}\right)$ being cut through its stalk, while that on the right $(o c)$ is cut near its middle region and hence does not show any connection with the forebrain. The almost complete obliteration of the cavity of the optic vesicle to form the optic cup by the invagination of the outer wall of the vesicle is shown on the right side of the section $(o c)$. The lens vesicle (li) is completely cut off from the superficial ectoderm $(e c)$, which is comparatively thin. The hindbrain $(h b)$ has the usual shape for that structure. Its ventral wall is dense and thick, while its 


\section{The Development of the Nlligator 295}

roof is reduced to the usual thin, wrinkled membrane. Close to the floor of the hindbrain lies the notochord $(n t)$, which is large and is distinctly vacuolated. To the right of the hindbrain a large mass of darkly stained cells $(\mathrm{c} n)$ is one of the cranial nerves, which is connected with the hindbrain a few sections anterior to the one under consideration. The pharynx (ph), which is cut near its cxtreme anterior end, is represented by three irregular cavities near the base of the forebrain. Scattered throughout the mesoblast, which makes up the greater part of the section, are numerous blood-vessels (bv).

Figure $5^{b}$ is twenty sections posterior to Figure I $5^{a}$ and passes through the tip of the bent-under forebrain $(f b)$. On the left the section is anterior to the optic vesicle and barely touches the side of the optic stalk, which is seen as a small lump on the ventro-lateral wall of the brain. On the right the connection of the optic vesicle $\left(o \sigma^{\prime}\right)$ with the forebrain is shown. Dorsal to the optic vesicle just mentioned is a markedly thickened and slightly invaginated region of the cetoderm (n); this is the nasal pit; on the left side of the figure the thickening is shown, but the section did not pass through the invagination. The hindbrain $(h b)$ is somewhat narrower than in the preceding figure, but is otherwise about the same; the origin of a cranial nerve is seen on its left side $(\mathrm{c} n)$. The notochord $(n t)$ has the same appearance as in the preceding section. 
A number of blood-vessels may be seen, the pair lying nearest the notochord being the aortæ (ao), while the two other pairs, on either side of the fore- and hindbrains, are the anterior cardinals ( $a c$ ). The first aortic arches are shown at ar. On the left the section passes through the exterior opening of the first gill cleft $\left(g^{\prime}\right)$, so that the mandibular fold $(m d)$ on that side is a distinct circular structure, made of a dense mass of mesoderm surrounded by a rather thick ectoderm. The mesoderm of this fold is especially dense near the center, probably the beginning of the visceral bar. Near the center is also seen the aortic arch that has already been mentioned. On the right the section does not pass through the external opening of the first gill cleft $\left(g^{\prime}\right)$ so that the tissue of the mandibular fold is continuous with the rest of the head. It is of course the slight obliquity of the section that causes the pharynx $(p h)$ to be completely enclosed on the right, while on the left it is open to the exterior both through the gill cleft and between the mandibular fold and the tip of the head. The superficial ectoderm shown here as a heavy black line varies considerably in thickness, being thickest in the region of the nasal pit already mentioned and thinnest over the roof of the hindbrain. The amnion $(a)$ in this, as in the other sections of the series, has the appearance of a thin, very irregular line.

Figure ${ }^{5}{ }^{c}$ is posterior to the region affected by 
cranial flexure and so shows only one region of the embryo, that of the hindbrain $(h b)$, which is here of essentially the same structure as above described. On each side of the hindbrain is a large auditory vesicle $(0)$; that on the left is cut through its center and shows the beginning of differentiation, its lower end being thick-walled and rounded, while its upper end is more pointed and has a thin, somewhat wrinkled wall. The notochord $(n t)$ is slightly larger than in the more anterior sections. Numerous blood-vessels $\left(b^{\prime}, a r\right)$ are seen in the mesoblast. The pharynx $(p h)$ is here open ventrally and also through the gill cleft of the left side; on the right side the plane of the section did not pass through the external opening of the cleft. The mesoblast of the visceral folds is much more dense than that of the dorsal region of the section.

Figure $15 d$, as is evident, is a section through the region of the heart, which appears as three irregular cavities $(h t)$ with fairly thick mesoblastic walls $\left(m e s^{\prime}\right)$ lined with endothelium $\left(e n^{\prime}\right)$. The body wall, though consisting of but little besides the ectoderm (ec), completely surrounds the heart, and the pericardial or body cavity thus formed extends dorsally as a narrow space on either side of the foregut, giving the appearance of a rudimentary mesentery, though no especial development of such a structure would naturally be expected in this region of the embryo. The foregut (ent) is a moderately large cavity lined with a very distinct 
entoderm of even thickness. Dorsal to the foregut are three large blood-vessels, a median, and now single, dorsal aorta ( $(10)$, and a pair of cardinal veins $\left(c i^{\prime}\right)$. The notochord $(n t)$ is small and is flattened against the ventral side of the spinal cord $(s c)$, which latter structure needs no special mention. The muscle plates $(m p)$ are considerably elongated, so that they now extend ventrally to a point slightly below the upper angles of the body cavity.

Figure I $5 e^{e}$ is through the middle region of the embryo, and, owing to the curvature of the body, is not an exact dorso-ventral section; this accounts, in part at least, for the unusual diameter in a dorso-ventral direction of the aorta ( $a$ o), which is very large in proportion to the other structures. The posterior cardinal vein is shown on the left, but not on the right. The relative sizes of the spinal cord (sc) and notochord $(n t)$ are very different from what was seen in the preceding figure. In this section the spinal cord is considerably smaller than in the preceding, while the notochord is very much larger; in fact the notochord here seems abnormally large when compared to corresponding sections of other series. It is true, however, that while the spinal cord has been diminishing in diameter the notochord has been increasing. The spinal cord, notochord, and dorsal aorta are all so large that they are flattened against each other, the pushing in of the ventral side of the spinal cord being even more 


\section{The Development of the Alligator 299}

marked than is shown in the figure. On either side of the spinal cord a large spinal ganglion $(\mathrm{sg})$ is seen, closely wedged in between the spinal cord and the adjacent muscle plate $(m p)$. As in the preceding stage, there is a marked space between the muscle plate and the adjacent ectoderm (ec). The somatic mesoblast at the upper angle of the unenclosed body cavity is thickened on each side and somewhat bulged out by the IVolffian body to form what might be termed a Wolffian ridge (iur). In the mid-ventral line is the considerably developed mesentery ( $m s$ ), from which the intestine has been torn. The Wolffian bodies now consist, on cach side, of a group of five or six tubules (wt) of various sizes, near which in a more ventro-lateral position, close to the upper angle of the body cavity, is the more distinct Wolffian duct (ivd). The allantois is fairly large by this time, and may be seen in the most posterior sections as an irregular, thick-walled outgrowth from the hindgut.

A horizontal section through the anterior end of an embryo of this age is shown in Figure $I_{5} f$. While enclosed of course in the same membranous amnion (a), the pharyngeal region of the section is separated by a consideralle space from the more anterior region where the section passes through the forebrain $(f b)$ and eyes. The spinal cord $(s c)$, notochord $(n t)$, muscle plates $(m p)$, aortæ $(a 0)$, and anterior cardinal veins (ac) need no special description. The appearance of the pharynx 
$(p h)$, with its gill clefts and folds, is quite similar to that of the corresponding structures in the chick. None of the four clefts $\left(g^{1-4}\right)$ show, in the plane at which the section was cut, any connection with the exterior; in fact the fourth cleft $\left(g^{4}\right)$ would scarcely be recognized as a cleft if seen in this section alone. One or two of the more anterior clefts are open to the exterior. Three pairs of aortic arches are seen, and each visceral fold has a central condensation of mesoblast.

\section{STAGE XIII}

Figures i6-i6g (Plates XXII., XXIII.)

The embryo (Fig. I6) now lies on one side, body torsion being complete. The curvature of the body is so marked that the exact length is difficult to determine. The eye (e) and ear (o) have about the same superficial appearance as in the preceding stage. The nose is not shown in this figure. About thirty somites are present; the exact number cannot be determined in surface view. The amnion is complete, though not shown in the figure, and the tail $(t)$ is well formed. The umbilical stalk was torn in the removal of the embryo, so that it is not shown in the figure. The dim outline of the now convoluted heart may be seen if the "cleared" embryo be viewed by transmitted light; it is not shown in the figure. The allantois $(a l)$ is a rounded sac of considerable size just 


\section{The Development of the Alligator 301}

anterior to the tail. Four gill clefts $\left(\mathrm{g}^{\mathrm{I}-4}\right)$ are now present; the most posterior one is more faint than is represented in the figure, and it could not be definitely determined from a surface view whether or not it opened to the exterior. The mandibular fold ( $m d$ ) is now fairly well outlined, but there is as yet no sign of the maxillary process.

Figure $I 6 a$ is the most anterior of a series of transverse sections made of an embryo of the approximate age of the surface view just described; it passes through the tip of the forebrain $(f b)$ and shows the nasal pit $(n)$ of the right side. The great thickening of ectoderm in the region of the nasal invagination is represented by a solid line. Owing to the obliquity of the section, the left nasal pit was not cut. The mesoblast is quite dense and contains two or three small blood-vessels near the roof of the brain. The plane of this section, owing to the cranial and body flexure, cut the embryo also in the region of the pharynx; this part of the section was, as a matter of convenience, omitted from the drawing.

Figure $\mathrm{I} 6 \mathrm{~b}$ is in reality more anterior in position, considering the entire embryo, than the preceding; but the region of the embryo represented is more posterior, so that it is described at this point. The greatly elongated outline of the brain is due to its being cut through the region of flexure, so that the forebrain $(f b)$, or, perhaps, midbrain, is shown at one end, and the hindbrain $(h b)$ at the 
other. The walls of these cavities are somewhat wrinkled and irregular and their constituent cells are beginning to show slight differentiation, though this is not shown in the figure. On the left side are seen a couple of darkly stained masses; one is the origin of a cranial nerve $(\mathrm{cm})$; and the other is one of the auditory vesicles (o), which is still more irregular in outline than it was in the preceding stage. The only blood-vessels to be seen are a few very small ones that lie close to the wall of the brain. The ectoderm is quite thin at all points.

Figure $16 c$, the largest section of this series, passes through the forebrain in the region of the cyes and through the gill clefts. The forebrain $(f b)$ exhibits on the left a marked thickening of its wall $(\mathrm{ch})$, the edge of the cerebral hemisphere of that side, which is just beginning to develop; on its right side the lower part of the forebrain is connected by a well marked optic stalk (os) with the optic cup $(o c)$, in whose opening lics the lens vesicle $\left(l \varepsilon^{\prime}\right)$, now reduced to a crescentic slit by the thicliening of its posterior wall. The mesoblast is more dense in those parts of the section adjacent to the pharynx than in the more distant regions, and the ectoderm thickens in a marked way as it approaches the borders of the pharynx and gill clefts. Only a few small blood-vessels $(b i)$ are to be seen in the region of the forebrain.

Parts of three pairs of clefts $(\mathrm{g})$ are shown in the 


\section{The Development of the Alligator 303}

figure: one pair opens widely on either side, so that there is a large area of the section that is distinct from the two still larger portions and contains a small, thick-walled cavity (g) on the right side; this cavity is a gill cleft that is cut through neither its outer nor its pharyngeal opening.

No structures other than this small portion of a gill cleft and a few blood-vessels are to be seen in this middle region of the section. In the more posterior part of the section, in which the notochord $(n t)$ is located, a pair of curved clefts may be seen, opening entirely through the wall on the left, but closed on the right $(\mathrm{g})$. One distinct pair of aortic arches is shown $(a r)$, and also the dorsal aortæ $(u o)$, which are of very unequal size. The spinal cord (sc) and muscle plates need no special description.

Figure $I \sigma d$ is in the region of the heart (ht) and lungs $\left(l_{u}\right)$. The former is an irregular cavity whose walls, especially on the ventral side (mes'), are becoming very thick and much folded. Although thin, the body wall completcly surrounds the heart, as would be expected, since this was true of the preceding stage. The lung rudiments ( $/ u$ ) and the foregut from which they have arisen have the same appearance as in the chick; they consist of three small, thick-walled tubes so arranged as to form a nearly equilateral triangle. They are surrounded by a swollen, rounded mass of mesol)last which almost completely fills the surrounding portion of the 
304 The Alligator and Its Allies

body cavity $(b c)$. The pleural sides of these crescentic portions of the body (or pleural) cavity - that is, the boundary of the mass of mesoblast just mentioned - are lined with a thickened layer of cells, shown by the solid black lines in the figure. The lung rudiments may be traced through about fifty sections of this series, or about one twelfth of the entire series. At the dorsal angle of the part of the body cavity $(b c)$ just described, near the dorsal aorta (ao), are two dark, granular masses (ge), which, under a higher magnification than is here used, are seen to consist of a small group of bloodvessels filled with corpuscles; although several sections in front of the anterior limits of the kidneys these are evidently glomeruli. They may be traced, though diminishing in size, far toward the tail, in close connection with the Wolffian bodies. At intervals they are connected by narrow channels with the dorsal aorta; no such connection was present in the section drawn. The notochord $(n t)$, spinal cord $(s c)$, muscle plates $(m p)$, and spinal ganglia $(\mathrm{sg})$ need no special mention. The mesoblast is beginning to condense in the neighborhood of the notochord, and the ectoderm is slightly thickened laterally and dorsally.

Figure r6e is in the region of the liver and the Wolffian bodies; it also shows the tip of the ventricular end of the heart. The liver (li) is a large irregular mass, of a blotchy appearance under this magnification, lying between the heart $(\mathrm{m} m)$ and 


\section{The Development of the Alligator 305}

the intestine (i). Under greater magnification it is seen to be made up of indefinite strings of cells; and its still wide opening into the intestine may be. scen in more posterior sections. The intestine (i), which in this section might be called the stomach, is a fairly large carity with the usual thick entodermic walls; it is supported by a comparatively narrow mesentery. The body cavity on the side next this mesentery has the same thick lining that was noted in the region of the lungs. The convolutions of the thick peritoneal lining may easily be mistaken in places for parts of the enteron. The Wolffian bodies may be seen as two groups of tubules (wt) in their usual location. The heart is cut through the ventricle $\left(i^{\prime} h\right)$, as has been said. The section being at right angles to the long axes of the villi-like growths of the myocardium, the depressions between these mesoblastic cords are seen as a number of small irregular areas, each one lined with its endocardium. The incompleteness of the body wall below the heart is appareutly due to an artificial break and not to a lack of fusion. The only point that need be mentioned in connection with the structures of the dorsal part of the section is that the distinctness of the myocœl $(m y c)$ on the right side is somewhat exaggerated.

Figure I $6 f$ is in the middle region of the embryo where both splanchnopleure and somatopleure are unfused. Owing chiefly to the unclosed condition of the midgut $(i)$ and to the increase in length of 


\section{The Alligator and Its Allies}

the mesentery ( $m s)$, the section is quite deep dorsoventrally. The continuation of the amnion (a) with the somatopleure is of course here evident.

The most striking feature of the section is the marked projection of the Wolffian ridges, though no local enlargements of these ridges indicate the rudiments of the limbs. A large mass of Wolffian tubules (wt) is seen projecting into the upper part of the body cavity on each side; close to each of these masses is the posterior cardinal vein $(p c)$, and between them is the large aorta (ao). The other structures are about as in the preceding section.

Figure $I 6 g$ represents a sagittal section of the anterior half of the body of an embryo of this or possibly a slightly younger stage of development. The three regions of the brain are clearly indicated, as well as the cavity of the spinal cord (sc). The roof of the hindbrain has been made too thick in the figure; it should be represented by a mere line. A little mesoblast is to be seen at places between the roof of the brain and the superficial ectoderm. A slight invagination of the epithelium $(p)$, between the floor of the brain and the anterior end of the notochord, probably represents the beginning of the hypophysis. No indication of the paraphysis is yet to be seen. Extending from the region of the hypophysis to the posterior end of the section is the notochord $(n t)$; it is much vacuolated and gradually increases in thickness toward the posterior, though its outline is quite 
The Devclopment of the Alligator 307

irregular; except at the extreme anterior end and at one or two other places, it lies in close contact with the floor of the neural tube. Directly under the notochord lies, in the posterior half of the figure, the large dorsal aorta (ao). The pharynx ( $p h)$, opening between the end of the forebrain and the thick mandibular fold (across which opening the amnion, $a$, of course extends), is a funncl-shaped space which passes out of the plane of the section toward the posterior end of the figure. Its thick endodermal lining extends to the mandibular fold on the ventral side, while on the dorsal side it gradually thins out and becomes continuous with the thin ectoderm that extends over the forebrain. Just back of the mandibular fold is the bulbus (b), and back of that is the edge of the ventricle ( $i n)$. Posterior and dorsal to the ventricle the liver (li) is seen as an irregular mass of cells, and dorsal to the liver one of the Wolffian bodies ( $w t$ ) is cut through its extreme edge.

\section{STAGE XIV}

Figures I 7 -I $7 g$ (Plates XXIII., XXIV.)

Body flexure has increased until now the forebrain and tail are almost in contact (Fig. I7). The eye has developed somewhat; the ear vesicle, which is not shown in the figure, is small and scems to lie nearer the ventral side; the nasal pit is much larger and is crescentic in shape. The hyomandib- 


\section{8 \\ The Alligator and Its Allies}

ular cleft $\left(g^{\prime}\right)$ still persists as a small crescentic slit, while the next three clefts are now represented merely by superficial grooves separated by distinct ridges, the visceral folds. No indication of a fifth cleft is seen. The maxillary process $(m x)$ grows ventralward under the forebrain and is already longer than the mandibular arch $(m d)$.

The chief advance in development over the preceding stage, besides the formation of the maxillary process, is in the appearance of the appendages ( $a$ a and $p a$ ); they have the characteristic shape of the rudimentary vertebrate appendage, though the anterior pair seem to point in an unusual direction at this stage and to be slightly more developed than the posterior. The curious, anteriorly directed heart $(h t)$ is, perhaps, somewhat abnormal. The umbilical stalk $(u)$ is comparatively narrow and, like the allantois, was cut off close to the body.

Transverse sections of an embryo of this stage are represented in Figures $I 7 a-g$, drawn under a lower magnification than were any of the preceding figures.

Figure I $z a$ is in the region of the pharynx, and passes through the forebrain $(f b)$ and posterior part of the hindbrain $(h b)$. In the thick walls of both of these structures histological differentiation has begun, so that even under low power an inner granular and an outer clear zone may be distinguished. Under greater magnification the pres- 
The Development of the Alligator 309

ence of short fibers may be made out among the cells. The cerebral hemispheres $(c h)$ are wellmarked structures, their asymmetry being of course due to the oflliquity of the section. Only one eye is cut by the plane of the section, and this one shows no connection with the forebrain. The outer wall of the optic cup (oc) is so thin that under this magnification it can scarcely be seen as a dark line surrounding the retinal wall. The lens $(l n)$ is now a solid mass, of the usual type for vertebrate embryos, its front or outer wall being a scarcely discernible line. The hindbrain $(h b)$ has the usual form for that region and does not differ particularly from what was noted in earlier stages except in the histological differentiation that has already been mentioned. As with the eye, it is only on the right side that the auditory vesicle $(o)$ is shown. It shows some differentiation, but not so much as would be seen were it cut in another region. In the center of the section the pharynx $(p h)$ forms an irregular cavity connected with the exterior on the left by a gill cleft $(g)$ and by another slit which is simply the anterior margin of the stomodæum. On the right neither of these openings is in the plane of the figure, though the gill cleft (hyomandibular), which lies close to the auditory vesicle, is almost an open passage. A few small blood-vessels are scattered through the section; one of these $\left(b_{r}\right)$, lying between the notochord $(n t)$ and the floor of the brain, is noticeable 
from its being very closely packed with corpuscles, so that at first glance, under low magnification, it looks more like a nerve than a blood-vessel.

Figure $I 7 b$ is also through the pharyngeal region, a short distance behind the preceding section. The growth of the cerebral hemispheres $(c h)$ is better shown than in the preceding figure, as is also the general form of the optic cup (oc). On the left the nasal cavity $(n)$ is seen as an elongated slit with thick walls; it is cut near, but not through, its opening to the exterior. The same gill cleft $(g)$ that was seen in the preceding figure is seen here as a narrow, transverse cleft, open at both ends. Between the notochord ( $n t)$ and the spinal cord (sc) is the same, though now double, bloodfilled vessel $\left(b{ }^{\prime}\right)$ that was seen in the preceding section. The other blood-vessels are larger here than in the more anterior region. There is a faint condensation of mesoblast in the neighborhood of the notochord, and a more marked condensation $(m p)$ farther toward each side is the curiously shaped muscle plate.

Figure $I 7 c$ is through the heart region, and that organ is cut through the opening from the lower or ventricular into the upper or auricular chamber. The thickening of the wall of the ventricle, which was noticed in the preceding stage, has increased to such an extent that there is now a marked difference in the thickness of the ventricular and auricular walls. As in the preceding stage, the body 


\section{The Development of the Alligator 3iI}

wall is torn, probably in handling, so that it appears to be incomplete around the ventral side of the heart. Dorsal to the heart two small circular holes (ent) with thick walls are the ocsophagus and trachea, cut anterior to the point of bifurcation of the latter into the bronchial or lung rudiments. On either side of these structures is an elongated blood-vessel $(a c)$, the anterior cardinal vein, its elongation being due to the fact that it is cut at the place where it turns downward to empty into the heart. Dorsal to the osophagus are the aorta $(a o)$, which are here cut just at the point where the two vessels unite to form one; the next section, posterior to the one under discussion, shows an unpaired aorta. The notochord $(n t)$ and spinal cord (sc) need no description, except to note that the latter shows active histological differentiation, numerous mitotic figures being seen under higher magnification, especially in the cells that line the spinal canal. On the right of the cord the edge of a spinal ganglion $(s g)$ is seen, in connection with which in other sections are secn the clearly defined nerve roots. The condensation of mesoblast around the notochord is quite evident, and in close contact with this medial condensation are two very characteristic, S-shaped muscle plates $(m p)$, which extend from the level of the dorsal side of the spinal cord to the upper limits of the cardinal veins. In some sections the muscle plates even yet show slight remains of the myocol at the dorsal end. 
Figure $17 d$ is in the region of the posterior end of the heart $(h t)$, which is cut through the tip of the ventricle, and the anterior end of the liver (li), which has the appearance of a mass of darkly stained cords or strands of cells surrounding a large blood-vessel (mi). This blood-vessel may be called the meatus ienosus, though it is not separated by any line of demarcation from the auricle. A few sections anterior to this region the meutus zenosus opens dorsally into a large vessel on each side $(d c)$, which at first glance seems a part of the body cavity, but which is in reality the ductus Cuileri, formed by the union of the anterior and posterior cardinal veins. An irregular, crescentic cleft $(b c)$, lying medial and parallel to each of the Cuvierian vessels, is the body carity. In the upper angle of this cavity is a granular mass, the glcmerulus, that of the left side being accompanied by the extreme anterior end of the Wolffian duct. In the rounded mass of mesoblast, between the cleftlike regions of the body cavity, the lung rudiments $(l i t)$, and the osophagus $(o c)$ are seen as three small, circular openings; that of the oesophagus is somewhat smaller than the other two. The notochord $(n t)$, spinal cord $(s c)$, and muscle plates $(m p)$ have almost the same appearance as in the preceding section. A spinal ganglion $(s g)$ is seen on each side of the spinal cord; the one on the left shows a well-defined spinal nerve $(s n)$, which may be traced ventrally as far as the end of the muscle 
The Development of the Alligator 313

plate, along whose medial side it courses. The ventral nerve root is plainly seen; the dorsal root, in this section, less plainly. The amnion $(a)$ and abdominal wall are, as in the preceding figure, torn in the region of the ventricle.

Figure $17 c$ is a short distance posterior to the figure just described. The liver is cut through its middle region and forms a large, darkly staining, reticular mass on the left side of the figure. The digestive tract is seen at two places to the right of the liver; the smaller and more ventral of these openings ( $i)$ may be called the intestine, while the larger is evidently the stomach $\left(i^{\prime}\right)$. The body wall is here unfused and becomes suddenly thinner as it passes upward into the amnion $(a)$. The Wolffian tubules ( $w t$ ) form a very conspicuous mass on either side of the mesentery, in close connection with the posterior cardinal veins $(p c)$. In the mesoblast between the dorsal aorta (ao) and the notochord are two small, irregular, darkly stained masses $(s y)$. These are shown in the preceding two figures, but were not mentioned in the description. They may be traced through a great part of the length of the embryo back of the head region; at intervals corresponding in length to the distance between the spinal ganglia they are enlarged, while between these enlargements they are very small in cross-section. At certain points a small blood-vessel is given off by the dorsal aorta to the immediate neighborhood 


\section{The Alligator and Its Allies}

of each of these small areas. Although they show no connection with the central nervous system, these structures appear to be the rudiments of the sympathetic nerves.

Figure i $f$ is in the region just in front of the hind legs. The abdominal walls are here unfused, and into the unenclosed body cavity projects the intestine (i), supported by a narrow mesentery and surrounded by a comparatively thick mass of mesoblast. The Wolffian body and duct form a mass of considerable size on each side of the mesentery. The Wolffian body is cut near its posterior end and consists of smaller tubules than in the more anterior regions. The Wolffian ducts $(\mathrm{w} d)$, on the other hand, are very large and are much more clcarly distinguishable from the Wolffian tubules than in the preceding sections. The Wolffian ridges (ir) are very marked projections on the sides of the body, and in a region farther caudad become especially developed as the posterior appendages, to be described in connection with the following scction. Both spinal ganglia are shown in this figure $(s g)$, and in connection with the left ganglion the spinal nerve $(s n)$, extending ventrally as far as the level of the Wolffian duct. The sympathetic nerve rudiments do not extend so far caudad as the plane of this section. The dorsal end of each muscle plate $(m p)$ is seen, in this and other sections, to be slightly enlarged to form a round knob; this 


\section{The Development of the Alligator 35.5}

knob contains a distinct cavity (not shown in the figure), the myocol.

In Figure I 7 s, owing to the curvature of the body, the plane of the section passes through the body at three places: through the region of the heart and lungs (Fig. I $7 d$ ), through the region of the posterior appendages, and through the tail. In fact, the plane of the section represented by each of the preceding figures cut the embryo in more than one region, but for the sake of simplicity only one region was represented in each figure. In the figure under discussion only the leg and tail regions have been drawn, though the latter region $(t)$, being cut through one of its curves, is seen as an elongated body with a section of the spinal cord, notochord, etc., at each end. Both regions shown in the figure are enclosed in the same fold $(a)$ of the amnion. Of the structures in the clorsal side of the larger or more anterior part of this figure nothing need be said. The most striking feature of the section is the presence of the large posterior leg rudiments $(p a)$. As was noted in the preceding figure, they are, as usual, mercly local enlargements or projections of the mesoblast (covered, of course, with ectoblast) of the Wolffian ridge. They are, as shown in this section and in the surface view of this stage (Fig. I 7 ), bluntly pointed projections from the sides of the body. The anterior appendage seems to be slightly more developed than the posterior, as was noted in describing the 


\section{I6 The Alligator and Its Allies}

surface view of the cmbryo. The digestive tract is cut through its extreme posterior end, in the region that may be termed the cloaca $(\mathrm{cl})$, for into it at this point the Wolffian ducts open (wdo). As the narrow cloacal chamber is followed toward the tail, it becomes still smaller in diameter, ard the ventral depression or cleft seen in this figure gradually becomes deeper until its walls are continuous with the ectoderm that covers the ventral projection of mesoderm between the hind legs; no actual opening to the exterior is present, however. There is a space of about twenty-five or thirty sections (in a series of eight hundred) between the posterior ends of the Wolffian bodies and the cloacal openings of the Wolffian ducts. The body cavity $(b c)$ and the posterior cardinal veins $(p c)$ are very small in this region, as might be expected.

\section{STAGE $\mathrm{XV}$}

\section{Figure i8 (Plate XXIV.)}

Only the head of this embryo is represented, as the general state of development is about the same as in the preceding stage.

The chief object in making the figure is to show the five gill clefts $\left(g^{1}-^{5}\right)$. The fifth cleft, though small and probably not open to the exterior, is quite distinct in this embryo. The writer would feel more doubt of its being a true, though rudi- 


\section{The Development of the Alligator 317}

mentary, gill cleft had not Clarke (I7) found a fifth pair of clefts in his material. The nasal pit has advanced in development somewhat and shows the beginning of the groove that connects it with the mouth. In this figure the crescentic hyomandibular cleft shows its connection with the groove between the mandibular and the hyoid folds.

\section{STAGE XVI}

\section{Figure I9 (Plate XXIV.)}

This embryo is only slightly more developed than the preceding. Body flexure is so great that the forebrain and tail nearly touch. Only the anterior three gill clefts are visible. The maxillary process $(m x)$ is longer and more narrow; the mandibular fold has not changed appreciably. The nasal pit $(n)$ is now connected by a distinct groove with the stomodæum. The appendages have increased in size, the posterior $(p a)$ being the longer. The anterior appendage $(a \alpha)$ is distinctly broadened to form the manus, while no sign of the pes is to be seen at the extremity of the posterior appendage. The heart $(h t)$ is still very prominent. The stalk of the umbilicus $(u)$, which is quite narrow, projects from the ventral wall in the region between the heart and the hind legs. The tail is of considerable length and is closely coiled. 


\section{I 8 The Alligator and Its Allies}

\section{STAGE XVII}

Figures 20-20j (Plates XXV., XXVI.)

The superficial changes noted in this stage chiefly concern the head, which has increased considerably in length (Fig. 20). The curvature of the body is slightly more marked, and the tail is more tightly coiled at the end. There are still signs of three gill clefts. The maxillary process (mx) is long and narrow, while the mandibular arch $(m d)$ is still short and broad. The frontonasal region has greatly incrcased and has the aquiline profile noted by Clarke. The nasal groove has disappeared, and there remains the small opening $(n)$ at the side of the fronto-nasal region, near the end of the still separate maxillary process. The umbilicus is in about the same condition as in the preceding stage, but the heart is less prominent. The outline of the manus ( $m a$ ) is more definite, and the extremity of the posterior appendage is distinctly flattened out to form the rudimentary pes $(p e)$. The position of the elbowjoint in the anterior appendage is seen at the end of the reference line $a a$.

Typical transverse sections of this stage are shown in Figures $20 a-j$.

Figure $20 a$ is a section through the middle region of the head, cutting the hindbrain on one side and the forchrain on the other. The walls of the brain show rather more histological differen- 


\section{The Development of the Alligator 319}

tiation than was seen in the preceding sections, though this cannot be shown under the low magnification used. The hindbrain $(h b)$, which is cut near its anterior border, exhibits the usual membranous dorsal and thick ventral walls. The forebrain is here seen as three distinct cavitiesa median third ventricle ( $\left.t i^{\prime}\right)$, with a thick ventral wall, and a thin dorsal wall critended to form a large paraphysis $(c p i)$, and two lateral ventricles $(c h)$, the cavities of the cerebral hemispheres, whose walls are quite thick except on the side next the third ventricle. The sections of this series being slightly oblique, the eye is here cut on the right side only, where it is seen as a large, semicircular cavity (e) with thick, dense walls. The mesoblast, in which several blood-vessels $\left(b i^{\prime}\right)$ are scen, exhibits three distinctareas-a median, lighterzone, with a more dense area on either side. The significance of this variation in the density of the mesoblast is not apparent.

Figure $20 b$ is only a few sections posterior to the section just described. It is drawn chiefly to show the appearance of the forebrain, the other structures being about as in the preceding figure, exceps that both eyes (c) are here represented. The section passes through the wide opening between the third $(t v)$ and the lateral ventricles $(c h)$ and cuts the anterior edge of the pincal body ${ }^{\mathrm{I}}(e \mathrm{pi})$. The

: Subsequent investigation showed that the structure here described as the pineal body is, in reality, the paraphysis; the pineal body is absent in $A$. mississippiensis. 
paraphysis is very large and is directed backward instead of forward, as is usually the case among the lower vertebrates (if the alligator may be so classed). It is shown in Figure $\mathrm{I} 7 \mathrm{a}$ of a preceding stage and will be again shown in a sagittal section to be described later. The same areas of more dense and less dense mesoblast noted in the preceding figure are seen here.

Figure 20c, though still in the head region, shows several features that were not seen in the preceding figures. On the left of the hindbrain $(h b)$ the auditory vesicle $(o)$, which is now considerably more advanced than in earlier figures, is seen as a larger, flask-shaped cavity and a smaller, round one. Between the larger cavity and the hindbrain is the root of a cranial nerve $(\mathrm{cn})$, apparently the eighth, since in another section it comes in close contact with the wall of the larger part of the auditory vesicle just mentioned. On the right side, ventral to the hindbrain, another and much larger nerve $(\mathrm{cn})$ is seen. Nearly in the center of the figure is seen a small, irregular, thick-walled cavity $(p)$; this is the pituitary body, and its connection with the roof of the pharynx may easily be made out in another section. The mesoblast in this region of the sections contains numerous large and small bloodvessels and exhibits certain denser areas which probably represent the beginnings of the cranial cartilages. No sign of the forebrain is seen (the plane of the section passing in front of that region), 
The Development of the Alligator 32I

except that the tip of the wall of one of the cerebral hemispheres $(c h)$ is cut. The left nasal chamber (n) is shown: it will be noted again in the following section. The eye on the right side shows no remarkable features; its lens $(\ln )$ is large and lies well back of the lips of the optic cup, which may now be called the iris (ir). A thin layer of mesoblast has pushed in between the lens and the superficial ectoderm to form the cornea, and the outer wall of the optic cup is now distinctly pigmented. The inner wall of the optic cup is beginning to differentiate into the retinal elements. The eye on the left side is cut farther from its central region and has a very different appearance from the eye just described. This unusual appearance is due to the fact that the section passed through the choroid fissure, which is very large and seems to be formed by the pushing in of the walls of the cup and not by a mere cleft in these walls. This fissure is hardly noticeable in the stage preceding the present, and in a stage slightly older it has disappeared; so that it would seem to be a very transient structure. It apparently is formed at about the time that the optic stalk, as such, disappears. It is in the region of the choroid fissure, if not through it, that theoptic nerve (on) enters the eye. Through the fissure also enters a vascular tuft of mesoblast $(p t)$ which may be seen projecting into the optic cup after the disappearance of the fissure. This loop of blood-vessels is doubtless the pecten. 
Figure $20 d$ represents a section through the hindbrain $(h b)$, pharynx $(p h)$, and tip of the snout. On either side of the hindbrain are a convoluted auditory vesicle $(o)$, and several blood-vessels and nerves, while ventral to it is seen the anterior end of the notochord $(n t)$, around which the mesoblast is somewhat more dense than elsewhere. The pharynx $(p h)$ sends out toward the surface a narrow gill cleft $\left(\mathrm{g}^{\prime}\right)$ in the neighborhood of each auditory vesicle. These clefts connect with the exterior by very narrow slits, not seen in the plane of this section. The opposite end of the pharynx, as seen in this figure, opens on the left $(p n)$ into the nasal chamber. The nasal cavity on the right is cut in such a plane that it shows neither its external nor its pharyngeal opening. The nasal passages are here fairly long and nearly straight chambers; their lining epithelium is quite thick in the middle region, but becomes thinner where it merges into the epithelium of the pharynx at one end, and into the superficial epithelium at the other end. The unusual appearance of the eye (e), on the right side of the figure, is due to the fact that the plane of the section cut tangentially through the extreme edge of the eye in the region of the choroid fissure.

Figure $20 e$ is only a short distance posterior to the preceding. On the left side the pharynx $(p h)$ is connected with the exterior through the stomodæum, and on the right the hyomandibular cleft $\left(g^{\prime}\right)$ iscut almost through its opening to the exterior. 


\section{The Development of the Alligator 323}

The auditory vesicle $(o)$ on the right is cut near its middle region, while that on the left is barely touched by the plane of the section. The notochord $(n t)$, with its condensed area of mesoblast, is somewhat larger than in the preceding section. The nasal canal on the right $(n)$ is cut through neither anterior nor posterior opening, while on the left side the canal shows the anterior opening (an).

Figure 2of, which is in the region of the posterior part of the pharynx and the anterior part of the heart, shows some rather unusual conditions.

The spinal cord $(s c)$ and notochord $(n t)$, with the faintly outlined condensations of mesoblast in their region, need no special description. The pharynx $(p h)$ is here reduced to an irregular, transversely elongated cavity, the lateral angles of which are connected on each side with the exterior through a tortuous and almost closed gill cleft $(g)$, which must be followed through many sections before its inner and outer openings may be determined. Dorsal to the pharynx numerous bloodvessels $(b v)$, both large and small, may be secn, while ventral to it is noticed a faint condensation of mesoblast $(l a)$, in the form of an inverted $\mathrm{T}$, the anlage of the laryngeal structures. The ventral portion of the figure is made up of a nearly circular thin-walled cavity, the pericardium ( $p r)$. Most of the pericardial cavity is occupied in this section by the thick-walled ventricle $\left(\tau^{n} n\right)$, above which is the bulbus (b) and the tip of the auricle (aut). The 


\section{The Alligator and Its Allies}

bulbus is nearly circular in outline, though its cavity is very irregular. A few sections anterior to this, the opening of the bulbus into the ventricle is seen.

In Figure $20 \mathrm{~g}$ the section represented is only a short distance posterior to the one represented by Figure $20 f$. The mesoblastic structures in the neighborhood of the spinal cord (sc) and notochord $(n t)$ will be described in connection with the next figure, where they are more clearly defined. The œsophagus $(o e)$-or posterior end of the pharynx, whichever it may be called-is here a crescentic slit, with its convex side upward; ventrally it opens by a narrow glottis into the trachea $(t a)$. The trachea is surrounded by the same condensed area of mesoblast $(l a)$ that was mentioned in connection with the preceding figure, but the condensation is here more marked. From the bulbus $(b)$ an aortic arch (ar) extends upward for a short distance on the right side, while to the left of the œsophagus an aorticarch (ar) is cut through the upper part of its course. Ventral to the bulbus the ventricle ( $(\mathrm{m})$ ) and two auricles $(a u)$ are seen surrounded by the pericardial wall.

Figure $20 h$ is in the region of the liver $(l i)$, which has about the same position in relation to the auricles (au) that was occupied by the ventricle in the last figure. The auricles are connected with each other by a wide passage. The trachea $(t a)$ and the œsophagus (oe) are entirely distinct from each other; the former is a small, nearly circular hole, while the lumen of the latter is obliterated and 


\section{The Development of the Alligator 325}

its walls form a solid, bow-shaped mass of cells. Since there is a narrow space between this mass of cells and the surrounding mesoblast, it might be thought that the lumen of the œsophagus had been closed by the simple shrinkage of its walls; higher magnification, however, fails to show any sign of a collapsed lumen. It is doubtless the problematic and temporary closure of the osophagus that is noticed in other forms. On each side of the œsophagus, in close relation with the anterior cardinal vein $(a c)$, is noticed a nerve $(c n)$ cut through a ganglionic enlargement. When traced forward these nerves are seen to arise from the region of the medulla, and when followed caudad they are found to be distributed chiefly to the tissues surrounding the newly formed bronchi; they are doubtless the tenth cranial nerves. On the right side of the figure the close connection of this nerve with the near-by gill cleft is seen. Above the paired aortæ $(a o)$ the sympathetic nerves (sy) will be noticed. The mesoblast surrounding the spinal cord (sc) and notochord $(n t)$ is distinctly condensed (more so than the figure shows) to form what may be called the centrum $(c)$ and neural $\operatorname{arch}(n a)$ of the vertebræ. The arch, owing to the slight obliquity of the section, shows here only on one side. The spinal cord is not yet completely enclosed by the neural arches. The muscle plates $(m p)$ are in close connection with the rudiments of the vertebræ just mentioned. The spinal cord 


\section{The Alligator and Its Allies}

(sc) is here differentiated into three areas-a dense, deeply stained area immediately around the neurocœl; a less dense area of cells surrounding the inner area and extending ventralward as a rounded projection on each side; and an outer layer, with few or on nuclei, surrounding the inner two layers except on the dorsal side.

In Figure $20 i$ the size and complexity of the figure are due, it will be easily understood, to the fact that the plane of the section passed through the curve of the body, thus practically cutting the embryo in two regions - an anterior, where the lungs (lut) and liver (li) are seen, and a posterior, where the Wolffian bodies (wt) are present. The spinal cord and the surrounding structures have almost the same characteristics at both ends of the figure, except that the primitive spinal column is rather more distinct in the posterior end of the section. The posterior cardinal veins $(p c)$, Wolffian ducts $(w d)$, and Wolffian bodies $(w t)$ are also prominent structures of this end of the figure, the last being made up of a great number of tubuies. The extreme anterior ends of the Wolffian bodies are seen in the other half of the section in the upper angles of the body cavity, dorsal to the lung rudiments $(l u)$. Filling most of the body cavity $(b c)$ and making up the greater part of the middle of the figure are the liver ( $l i)$, now a very large organ; the stomach $\left(i^{\prime}\right)$, also quite large; the pancreas (pan), a small body lying near the stomach; and the lungs 


\section{The Development of the Alligator}

(lu), which here consist of several thick-walled tubes, surrounded by lobes of mesoblast. The other features of the figure need no special mention.

Figure $20 j$ is through the base of the posterior appendages $(p a)$, in which the cartilages are already being outlined by condensations of mesoblast. The intestine $(i)$ is cut in two regions-at a more anterior point, where it is seen as a small, circular hole surrounded by mesoblast and hung by a narrow mesentery, and through the cloacal region, the larger and more ventral cavity, into which the Wolffian ducts $(w d)$ open a short distance caudad to this section. The blood-vessels present a rather curious appearance. A short distance anterior to this point the aorta has divided into three, or it might be said that it has given off two, large branches. These two branches, one on either side near the posterior cardinal vein, pass toward the ventral side of the embryo on each side of the cloaca and end at about the region represented by the present figure. The small portion of the aorta that remains after the giving off of the two branches just described continues, as the caudal artery $(c a)$, into the tail; it is a small vessel just under the notochord, and gives off small, paired branches at regular intervals toward the vertebral region. The posterior cardinal veins $(p c)$, posterior to the openings of the Wolffian ducts into the cloaca, unite to form a large caudal vein lying just ventral to the caudal artery. 


\section{STAGE XVIII}

\section{Figure 2 I (Plate xxvir.)}

This embryo, as may be seen, for example, by the form of the appendages, is slightly further developed than the one represented in Figure 20. The figure is from a photograph of a living embryo as it lay in the egg, a portion of the shell and shell membranes having been removed. The embryo, which lies on its left side, is rather faintly outlined because of the overlying allantois. The allantois has been increasing rapidly in size, and is here so large that it extends beneath the cut edges of the shell at all points except in the region in front of the head of the embryo, where its border may be seen. Its blood-vessels, especially the one that crosses the head just back of the eye, are clearly shown in the figure, and in the living specimen, when filled with the bright red blood, they form a most beautiful demonstration. As in the chick, the allantois lies close beneath the shell membranes and is easily torn in removing them.

\section{STAGE XIX}

\section{Figure 22 (Plate xxvii.)}

Figure 22 is a photograph of a somewhat older embryo, removed from the egg and freed of the fetal membranes. The appendages show the position of both elbow and knee joints, and in the 


\section{The Development of the Alligator 329}

paddle-shaped manus and pes the digits may be faintly seen. The tail is very long and is spirally coiled, the outer spiral being in contact with the frontal region of the head. The jaws are completely formed, the upper projecting far beyond the lower. The elliptical outline of the eyes is noticeable, but the lids are still too little developed to be seen in this figure. The surface of the embryo is still smooth and white.

\section{STAGE XX}

Figures $23-23 b$ (Plate xxvit.)

In this surface view (Fig. 23) several changes are seen, though no very great advance in development has taken place. The outlines of the digits (five in the manus and four in the pes) are now well defined; they even project slightly beyond the general outline of the paddle-shaped part. The tail has begun to straighten out, and it now extends across the front of the face. The lower jaw has increased in length, but is still shorter than the upper. The eyelids, especially the upper, are beginning to be discernible in surface view. Though still without pigment, the surface of the body is beginning to show by faint transverse lines the development of scales; these lines are most evident in this figure in themiddle region of the tail, just before it crosses the nose.

A sagittal section of the entire embryo (except 


\section{0 \\ The Alligator and Its Allies}

the tail) of this age is shown in Figure 23a. In the head region the section is nearly median, while the posterior part of the body is cut slightly to one side of the middle line. At the tip of the now well-developed snout is seen one of the nostrils (an), cut through the edge; its connection with the complicated nasal chamber $(n)$ is not here seen, nor is the connection of the nasal chamber with the posterior nares $(p n)$. The pharynx $(p h)$, is anteriorly connected with the exterior through the mouth $(\mathrm{m})$ and the nares, while posteriorly it opens into the œsophagus (oe); the trachea $(t a)$, though distinct from the œsophagus, does not yet open into the pharynx. In the lower jaw two masses of cartilage are seen, one near the symphysis $(m k)$ and one near the wall of the trachea, doubtless the rudiment of the hyoid. The deep groove back of the Meckel's cartilage $(m k)$ marks the tip of the developing tongue, which here forms the thick mass on the floor of the mouth cavity. Dorsal to the pharynx a mass of cartilage (se) is developing in the sphenethmoid region. This being a median section, the ventricles of the fore$(f b)$, mid- $(m b)$, and hindbrain $(h b)$ are seen as large cavities, while the cerebral hemispheres $(c h)$ appear nearly solid, only a small portion of a lateral ventricle showing. The paraphysis $(e p i)$ is cut a little to one side of the middle and so does not show its connection with the brain. At the base of the brain the infundibulum $(i n)$ is seen as an elon- 


\section{The Development of the Alligator 33I}

gated cavity whose ventral wall is in close contact with a group of small, darkly staining alveoli $(p)$, the pituitary body. Extending posteriorly from the pituitary body is a gradually thickening mass of cartilage $(b p)$, which surrounds the anterior end of the notochord $(n t)$ and may be called the basilar plate. In its anterior region, where the section is nearly median, the spinal column shows its canal, with the enclosed spinal cord, while toward the posterior end of the figure the vertebræ are cut to one side of the middle line, and hence show the neural arches $(n a)$ with the alternating spinal ganglia $(s g)$. Near the posterior end of the figure the pelvic girdle $(p l)$ is seen. The largest organ of the embryo, as seen in this section, is the heart, of which the ventricle $\left(\mathrm{a}^{\prime} \mathrm{n}\right)$ seems to be closely surrounded, both in front and behind, by the auricles (au). The liver (li) is the large, reticular mass back of the heart. Dorsal and anterior to the liver is the lung ( $l u$ ), now of considerable size and development. The enteron is cut in several places $(o e, i)$ and its walls are beginning to show some differentiation, though this cannot be seen under the magnification here used. One of the Wolffian bodies is seen as a huge mass of tubules (wt) extending from the pelvic region, where the mass is greatest, to the region of the lungs. The Wolffian tubules stain darkly and the whole structure forms a very striking feature of the section. Dorsal to the posterior end of the Wolffian body is a 
small, oval mass of very fine tubules $(k)$, which do not stain so darkly as do the Wolffian tubules; this mass is apparently the beginning of the permanent kidney, the metanephros. Its tubules, though their origin has not been determined, seem to be entirely distinct from the tubules of the Wolffian body.

A single vertical section through the anterior part of the head of an embryo of this age has been represented in Figure $23 b$. On the right side the plane of the section cut through the lens of the eye $(l n)$; on the left side the section was anterior to the lens. The upper $(u l)$ and lower $(l l)$ eyelids are more evident here than in the surface view. Owing to the hardness of the lens, its supporting structures were torn away in sectioning. The vitreous humor is not represented in the figure. The superior ( $u r$ ) and inferior $(l r)$ recti muscles are well shown on the right side; they are attached to the median part of a Y-shaped mass of cartilage (se), which may be termed the sphenethmoidal cartilage. Between the branches of this $\mathrm{Y}$-shaped cartilage the anterior ends of the cerebral hemispheres $(c h)$ better called, perhaps, the olfactory lobes-are seen. Between the lower end of the sphenethmoidal cartilage and a dorsally evaginated part of the pharynx are two small openings $(p n)$; when traced forward these tubes are found to open into the convoluted nasal chamber, while a short distance posterior to the plane of this figure they unite 


\section{The Development of the Alligator 333}

with each other and open almost immediately into the pharynx. The rather complicated structures of the nasal passages of the alligator have been described by the writer in another paper (57). In the lower jaw the cartilage $(m k)$ is seen on either side and several bands of muscle are developing in the mesoblast. Two deep grooves give form to what may be called the rudimentary tongue $(t n)$. In both jaws one or two tooth rudiments (to) may be distinguished as small invaginations of ectoderm.

\section{STAGE XXI}

\section{Figure 24 (Plate xxvir.)}

In this stage the curvature of the body and tail is less marked than was seen in the last surface view. The body has increased greatly in size, so that the size of the head is relatively not so great. The size of the eye in relation to that of the head is much diminished also. The five anterior and four posterior digits are well formed, and their claws are of considerable size, though of course not present on all the digits. The outlines of scales may be traced from the tip of the tail to the skull; they are especially prominent along the dorsal profile. The skin is just beginning to show traces of pigment, which is, however, not shown in the photograph. The umbilical stalk is seen projecting with a loop of the intestine from the abdominal wall; this is shown more clearly in the next stage. 


\section{The Alligator and Its Allies}

The embryo now begins to exhibit some of the external characteristics of the adult alligator.

\section{STAGE XXII}

Figure 25 (Plate xxviil.)

This embryo needs no particular description. It has reached in its external appearance practically the adult condition, although there is still considerable yolk (not shown in the figure) to be absorbed, and the embryo would not have hatched for many days. Pigmentation, begun in the last stage, is now complete. The umbilical stalk is clearly seen projecting from a large opening in the body wall. The long loop of the intestine that extends down into the yolk sac is here evident, and it is hard to understand how it can all be drawn up into the body cavity when the umbilical stalk is withdrawn. No sharp shell-tooth at the tip of the snout, such as is described by Voeltzkow (78) in the crocodile, is here seen.

\section{STAGE XXIII}

Figure 26 (Plate XxviiI.)

This figure shows the relative sizes of the justhatched alligator and the egg from which it came. It also shows the position of the young alligator in the egg, half of the shell having been removed for that purpose. The blotchy appearance of the 


\section{The Development of the Alligator 335}

unopened egg is due chiefly to stains produced by the decayed vegetation of the nest. At hatching the young alligator is about $20 \mathrm{~cm}$. long, nearly three times the length of the egg; but the tail is so compressed that, though it makes up about half of the length of the animal, it takes up very little room in the egg.

\section{SUMMARY}

Owing to the fact that the embryo may undergo considerable development before the egg is laid, and also to the unusual difficulty of removing the very young embryos, the earlier stages of development are very difficult to obtain.

The mesoderm seems to be derived chiefly by proliferation from the entoderm, in which way all of that anterior to the blastopore arises. Posterior to the blastopore the mesoderm is proliferated from the lower side of the ectoderm in the usual way. No distinction can be made between the mesoderm derived from the ectoderm and that derived from the entoderm.

The ectoderm shows during the earlier stages a very great increase in thickness along the median longitudinal axis of the embryo.

The notochord is apparently of entodermal origin, though in the posterior regions, where the germ layers are continuous with each other, it is difficult to decide with certainty. 


\section{The Alligator and Its Allies}

The medullary folds have a curious origin, difficult to explain without the use of figures. They are continuous posteriorly with the primitive streak, so that it is impossible to tell where the medullary groove ends and the primitive groove begins, unless the dorsal opening of the blastopore be taken as the dividing point.

The amnion develops rapidly, and entirely from the anterior end.

The blastopore or neurenteric canal is a very distinct feature of all the earlier stages up to about the time of closure of the medullary canal.

Preceding the ordinary cranial flexure there is a sort of temporary bending of the head region, due apparently to the formation of the head-fold.

During the earlier stages of development the anterior end of the embryo is pushed under the surface of the blastoderm, and is hence not seen from above.

Body torsion is not so definite in direction as in the chick, some embryos lying on the right side, others on the left.

Of the gill clefts, three clearly open to the exterior and probably a fourth also. A probable fifth cleft was seen in sections and in one surface view.

The first trace of the urinary system is seen as a dorsally projecting, solid ridge of mesoblast in the middle region of the embryo, which ridge soon becomes hollowed out to form the Wolffian duct. 


\section{The Development of the Alligator}

The origin of the hypophysis and paraphysis is clearly seen; the latter projects backward.

No connection can be seen between the first rudiments of the sympathetic nerves and the central nervous system.

The lumen of the œsophagus is for a time obliterated as in other forms.

The choroid fissure is a very transitory but wellmarked feature of the eye.

LETTERING FOR ALL FIGURES ON PLATES VI.-XXVIII.

$a$, head-fold of amnion.

$a a$, anterior appendage.

$a c$, anterior cardinal vein.

$a l$, allantois.

$a n$, anterior nares.

ao, aorta.

$a o p$, area opaca.

$a p$, area pellucida.

$a r$, aortic arch.

$a u$, auricle.

$b$, bulbus arteriosus.

$b c$, body cavity.

$b l p$, blastopore.

$b p$, basilar plate.

$b v$, blood-vessel.

$c$, centrum of vertebra.

$c a$, caudal artery.

ch, cerebral hemisphere.

$c l$, cloaca.

$c n$, cranial nerve.

$c p$, posterior choroid plexus.

$c v$, cardinal veins.

$d c$, ductus Cuvieri.

$e$, eye.

$e c$, ectoderm.

$e c^{\prime}$, thickening of ectoderm.

$e n$, entoderm. $e n^{\prime}$, endocardium.

ent, enteron.

$e p$, epidermal layer of ectoderm.

epi, paraphysis.

$e s$, embryonic shield.

$f$, fronto-nasal process.

$f b$, forebrain.

$f g$, foregut.

$g^{x_{-}}$, gill clefts.

$g f^{2}-6$, gill folds.

$g l$, glomerulus.

$h$, head-fold.

$h b$, hindbrain.

$h t$, heart.

$i$, intestine.

$i$, stomach.

in, infundibulum.

ir, iris.

it, iter.

$k$, kidney (metanephros).

$l$, remains of groove between secondary folds.

$l a$, larynx (cartilages of).

$l i$, liver.

$l l$, lower lid of eye.

ln, lens.

$l r$, inferior rectus muscle of eye. 


\section{The Alligator and Its Allies}

$l u$, lungs.

$l v$, lens vesicle.

$m$, mouth.

ma, manus.

$m b$, midbrain.

$m c$, medullary canal.

$m e^{\prime}$, tip end of medullary canal.

$m d$, mandibular fold.

mes, mesoderm.

mes', myocardium.

$m f$, medullary fold.

$m g$, medullary groove.

$m k$, Meckel's cartilage.

$m p$, muscle plate.

ms, mesentery.

$m v$, meatus venosus.

$m x$, maxillary fold.

myc, myocœl.

$n$, nasal invagination or cavity. $n a$, neural arch of vertebra.

$n c$, neurenteric canal.

$n l$, nervous layer of ectoderm.

$n t$, notochord.

$o$, ear vesicle.

$o c$, optic cup.

oe, œesophagus.

on, optic nerve.

os, optic stalk.

$o v$, optic vesicle.

$p$, pituitary body.

$p a$, posterior appendage.

pan, pancreas.

$p c$, posterior cardinal vein.

pe, pes.

$p g$, primitive groove.

$p h$, pharynx.

$p l$, pelvis.

$p n$, posterior nares. $p r$, pericardial cavity.

$p s$, primitive streak.

$p t$, pecten.

$r t$, retina.

$s$, somites.

$s c$, spinal cord.

se, sphenethmoid cartilage.

$s f$, secondary fold.

$s g$, spinal ganglion.

sm, splanchnic mesoblast.

$s n$, spinal nerve.

so, somatic mesoblast.

$s t$, stomodæum.

$s y$, sympathetic nervous system.

$t$, tail.

ta, trachea.

$t g$, thyroid gland.

th, thickening and posterior limit of $s f$.

$t n$, tongue.

to, tooth anlage.

$t r$, truncus arteriosus.

$t v$, third ventricle of brain.

$t v^{\prime}$, third ventricle of brain.

$u$, umbilical stalk.

$u l$, upper lid of eye.

ur, superior rectus muscle of eye. v'-"."', first, second, and third cerebral vesicles.

$v a$, vascular area.

ขm, vitelline membrane.

$v n$, ventricle of heart.

ขv, vitelline blood-vessels.

wd, Wolffian duct.

wdo, opening of Wolffian duct.

wr, Wolffian ridge.

$w t$, Wolffian tubules.

$y$, yolk.

\section{EXPLANATION OF FIGURES I-26 ON PLATES VI.-XXVIII.}

All of the figures, with the exception of the photographs and those copied by permission from S. F. Clarke, were drawn under a cameralucida. 


\section{The Development of the Alligator}

The magnification of each figure, except those from Clarke, is indicated below.

The photographs were made by the author, and were enlarged for reproduction by the photographic department of the Smithsonian Institution. The other surface views were made, under the author's direction, by Miss C. M. Reese.

With the exception of Stage III., all of the figures of any one stage are given the same number, followed where necessary by a distinguishing letter, so that it is possible to tell at a glance which section and surface views belong together. The transverse sections are all cut in series from anterior to posterior.

Figure I. Surface view of egg. $\times \frac{2}{3}$.

Ia. Egg with part of the shell removed to show the chalky band in the shell membrane. $\times \frac{2}{3}$.

Figures 2 and $2 a$. Dorsal and ventral views respectively of the blastoderm before the formation of the notochord, medullary folds, etc. After Clarke.

$2 b-2 f$. Transverse sections of an embryo of the age represented in Figures 2 and $2 a$. $\times 43$.

3 and $3 a$. Ventral and dorsal views respectively of an embryo a few days older than that represented in Figures 2 and 2a. After Clarke.

$3^{b-3 m}$. Transverse sections of an embryo of the age shown in Figures 3 and $3 a . \times 43$.

Figures $3 n$ and 30 . Two sagittal sections of an embryo of the same stage as Figures 3 and $3 a . \times 43$.

4 and $4 a$. Dorsal and ventral views respectively of a slightly older embryo than the one shown in Figures 3 and $3 a$. Figure $4 a$ shows only the head region. After Clarke.

5 and $5 a$. Dorsal and ventral views respectively of an embryo of almost the same age as the preceding, to show the further development of the medullary folds. After Clarke.

Figure 6. Dorsal view of an embryo only a day or two older than the preceding. After Clarke.

Figures $6 a-6 i$. A series of transverse sections of this stage. $\times 43$.

Figures $7 a-7 h$. A series of transverse sections of an embryo slightly older than the one shown in Figures $4-6 . \times 43 . \quad$ (No surface view of this stage is figured.)

8 and $8 a$. Dorsal and ventral views respectively of an embryo with five pairs of mesoblastic somites. $\times 20$. (Drawn by transmitted light.) 
$8 b$ and $8 c$. Two sagittal sections of an embryo of this stage. $\times 43$.

Figures $8 d-8 j$. A series of transverse sections of the embryo represented in Figures 8 and $8 a . \quad \times 43$.

$9 a-9 m$. A series of transverse sections of an embryo somewhat more advanced in development than the one represented in the last series. $\quad \times 43$.

Figures ro and roa. Dorsal and ventral views respectively of an embryo with eight pairs of mesoblastic somites. $\times 20$. (Drawn chiefly by transmitted light.)

Figure II. Dorsal view of an embryo with fourteen pairs of mesoblastic somites. The area pellucida and the developing vascular area are shown, the latter having a mottled appearance. The pushing of the head under the blastoderm is also shown. $\times 20$. (Drawn chiefly by transmitted light.)

FIGURES II $a-1$ I $k$. A series of transverse sections of an embryo of this stage. $\times 43$.

Figure I2. Dorsal view of an embryo with about seventeen pairs of mesoblastic somites. Part of the area pellucida is represented. (Both transmitted and reflected light were used in making the drawing.) $\times \mathrm{I} 3$.

Figures 12a-12g. A series of transverse sections of an embryo of this stage. $\times 43$.

Figure 13. Surface view of an embryo with about twenty pairs of mesoblastic somites. $\times$ (about) I5. (Drawn with both reflected and transmitted light.)

Figures $\mathbf{1}_{3}{ }^{a-1} 3 f$. A series of transverse sections of an embryo slightly more developed than the one shown in Figure 13. $\times 20$.

FigURE I3g. A sagittal section of an embryo of about the age of the one represented in Figure $13 . \times 20$.

14. Head of an embryo with one pair of gill clefts; ventrolateral view. $\times \mathrm{r} 3$.

15. Profile view of the head of an embryo with three pairs of gill clefts. $\times \mathrm{I}_{3}$.

Figures I5a-15e. A series of transverse sections of an embryo of about the age of the one represented in Figure 15. $\times 20$.

FIGURE I5 $f$. A horizontal section through the anterior region of an embryo of the age of that shown in Figure $15 . \times 20$.

I6. Surface view in profile of an embryo with four pairs of gill clefts. $\times$ (about) 12 . 


\section{The Development of the Alligator}

Figures $16 a-16 f$. A series of transverse sections of an embryo of the approximate age of the one represented in Figure 16. $\times 20$.

Figure I6g. A sagittal section of an embryo of the age (possibly slightly younger) of the one represented in Figure 16. $\times 20$.

17. Surface view in profile of an embryo at the time of origin of the limbs. $\times$ (about) 5 .

Figures I 7a-I7g. A series of transverse sections of an embryo of the age of the one represented in Figure $17 . \times 7$.

FIGURE I 8. Surface view in profile of the head of an embryo slightly larger than, though of about the same state of development as, the one represented in Figure I7. Reproduced here chiefly to show the gill clefts. $X$ (about) 3 .

19. Surface view of an embryo somewhat more developed than the one just described. $\quad \times$ (about) 3 .

Figure 20. Surface view of an embryo older than the one represented in Figure 19; with well-developed manus and pes. $\times$ (about) 5 .

Figures 20a-20j. A series of transverse sections of an embryo of the age of the one represented in Figure $20 . \times 7$.

Figure 21. A photograph of a living embryo in the egg, showing the allantois, yolk mass, etc. The embryo is somewhat more developed than the one shown in Figure 20. $\times \frac{2}{3}$.

22. A photograph of a still larger embryo, removed from the shell and freed from the fetal membranes. $\times$ (about) I.

23. A photograph of a still more advanced embryo, in which the digits are quite evident and the scales are beginning to show. $\times$ (about) $I$.

23a. A sagittal section of an embryo of the age of the one represented in Figure 23; the tail has not been shown in this figure. $\times$ (about) 3 .

23b. A vertical section through the head of an embryo of about the size (perhaps slightly smaller) of the one shown in Figure 23. $\times$ (about) 3 .

24. A photograph of an older embryo in which the pigmentation of the scales is evident, though not shown in the figure. $\times$ (about) $\mathrm{I}$.

25. A photograph of an embryo in which the pigmentation and the development of the body form are practically 


\section{The Alligator and Its Allies}

complete. The allantois, unabsorbed yolk, etc., have been removed. $\times$ (about) $3 / 4$.

26. A photograph of a just-hatched alligator, of an alligator egg, and of a young alligator in the egg just before hatching. $X$ (about) $\frac{3}{7}$. 

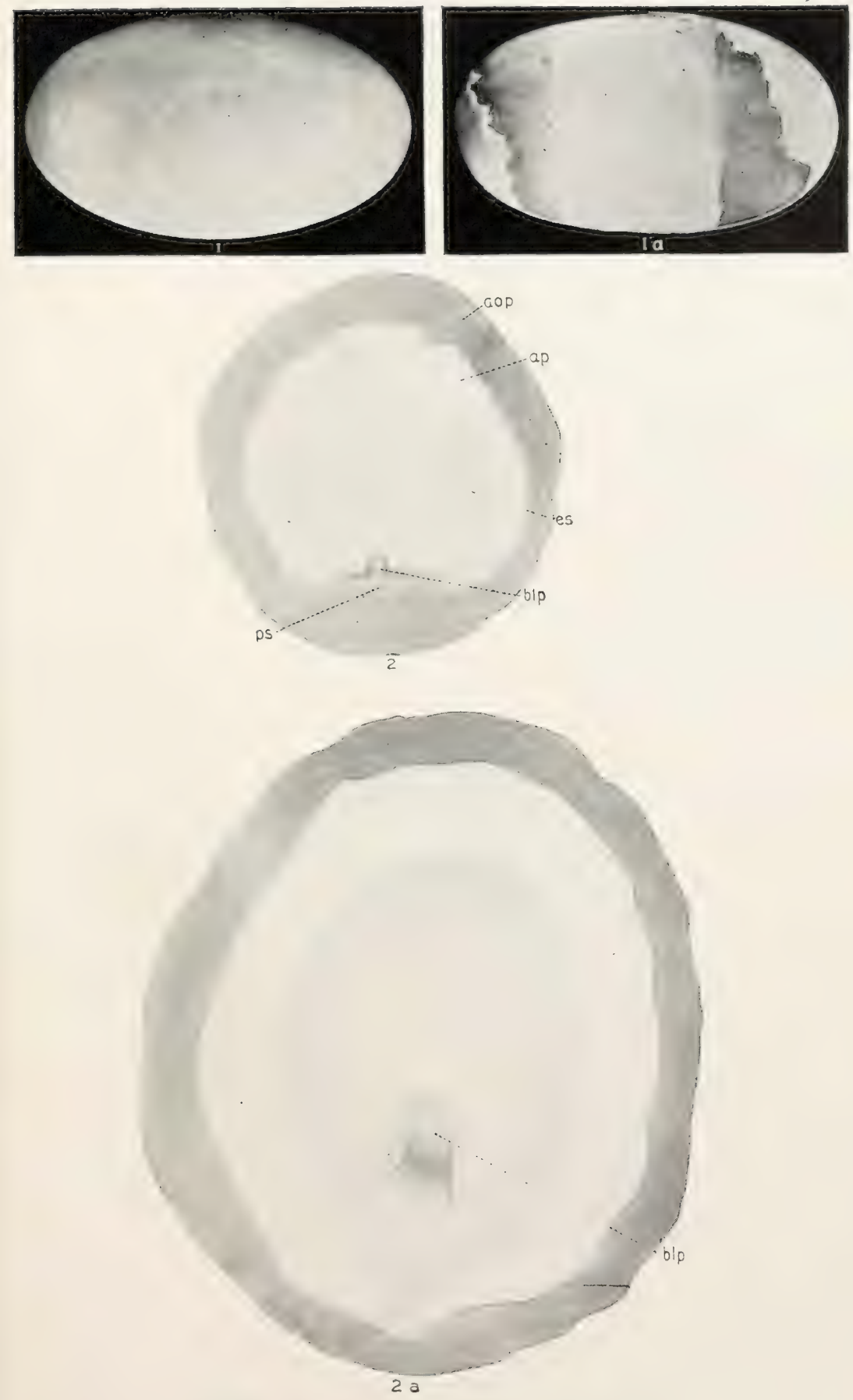

Plate VI. I, Ia, The EgG; 2, $2 a$, Stage I. 



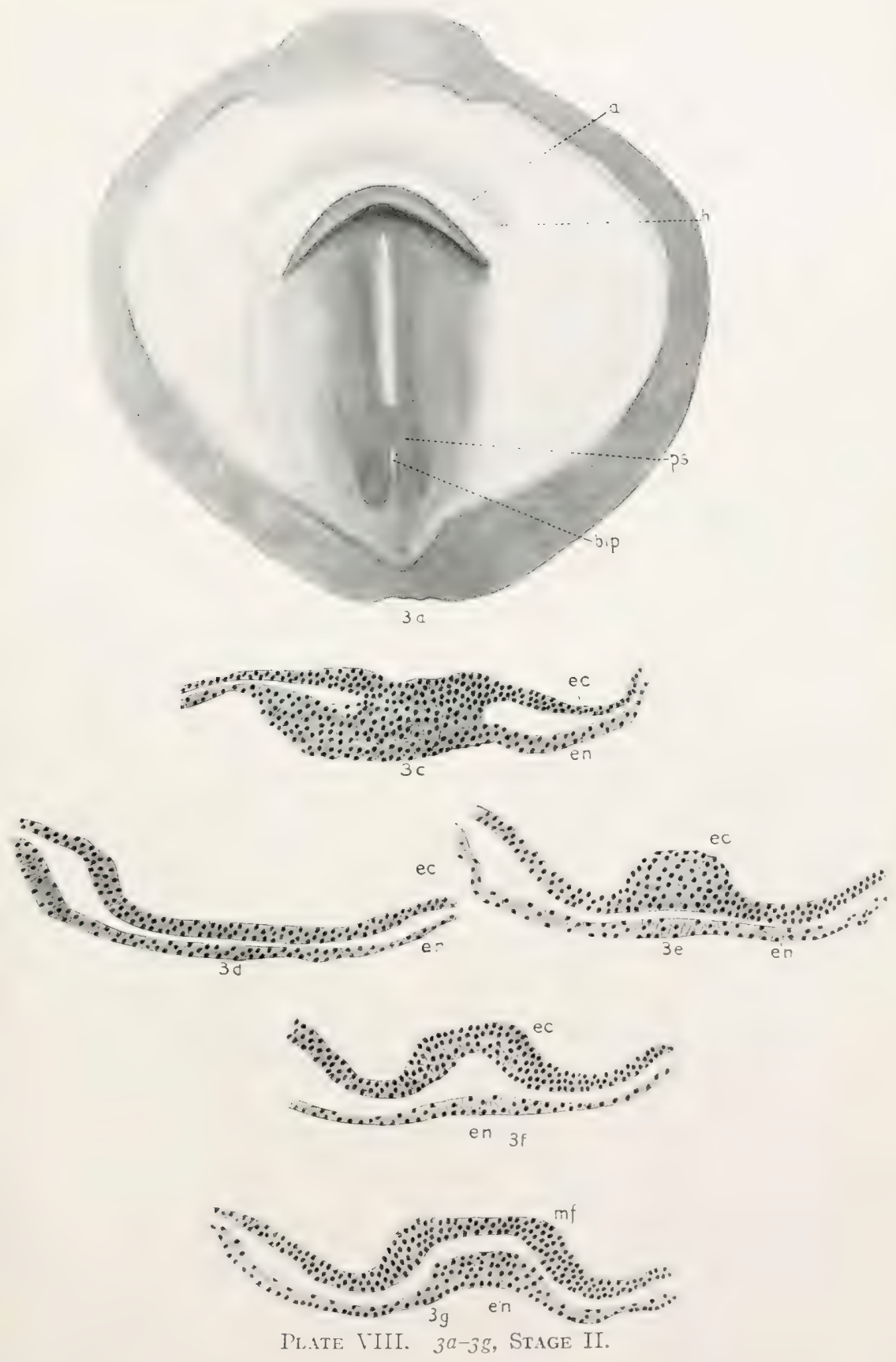


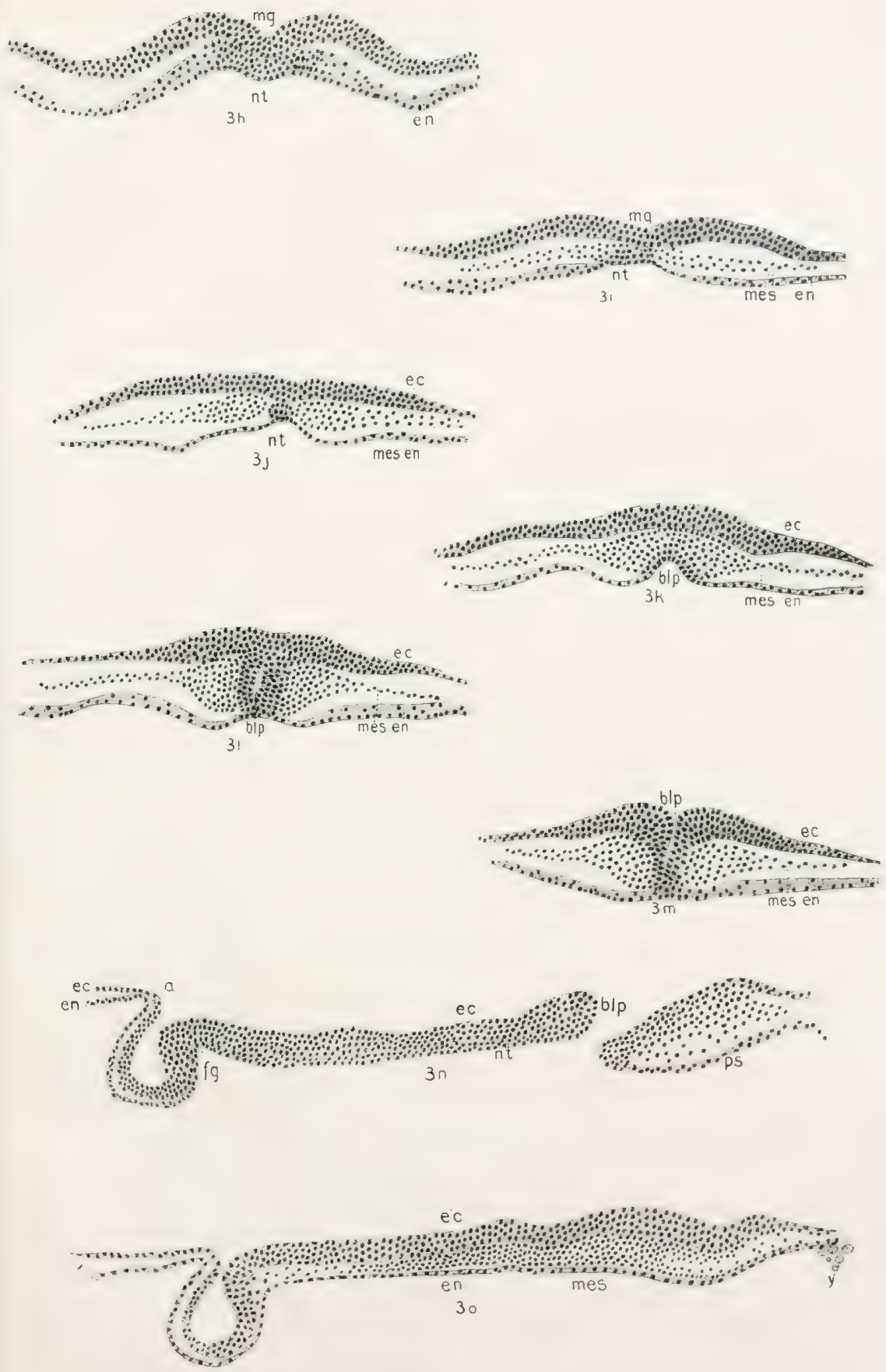

Plate IX. $3 h-30$, Srage II. 


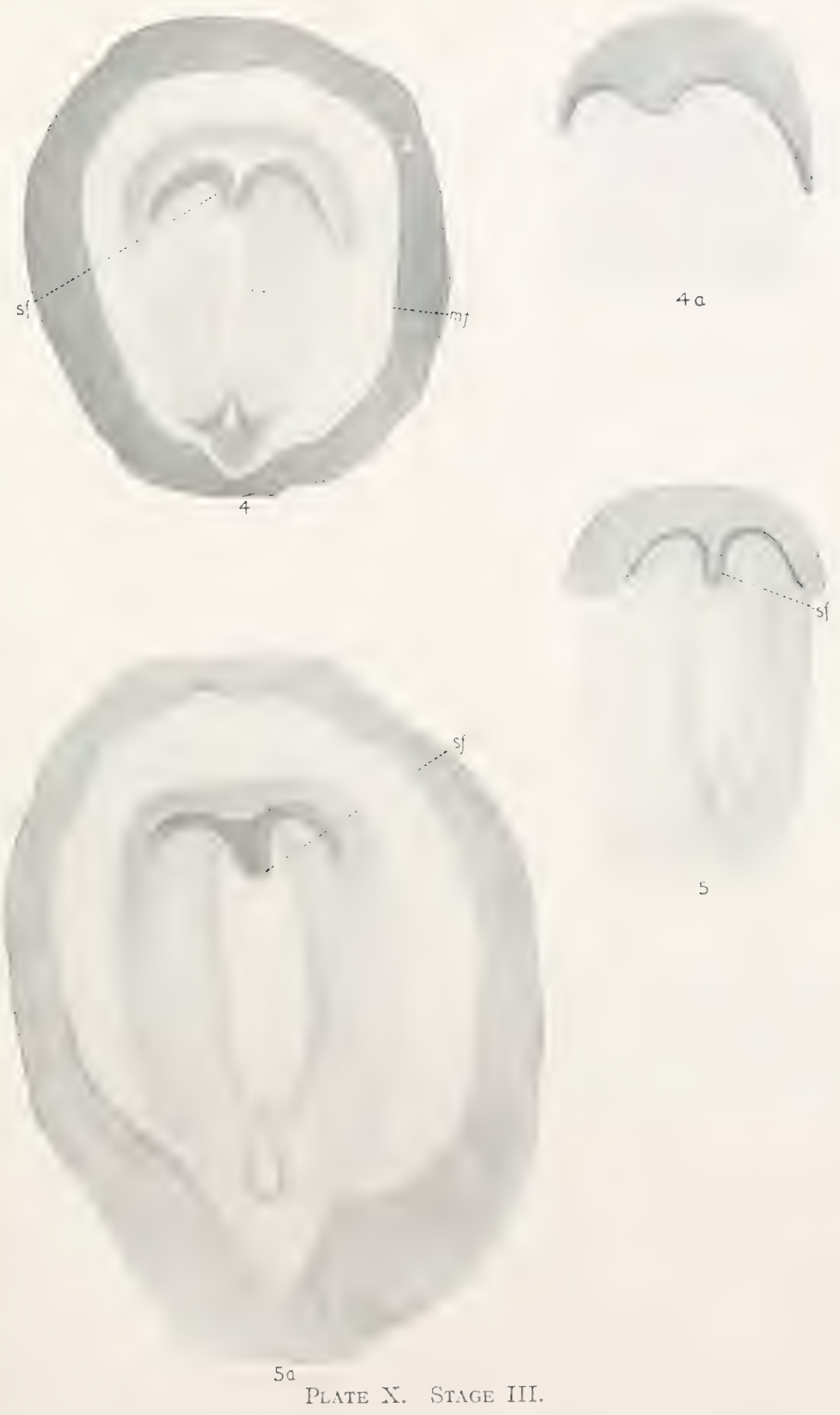


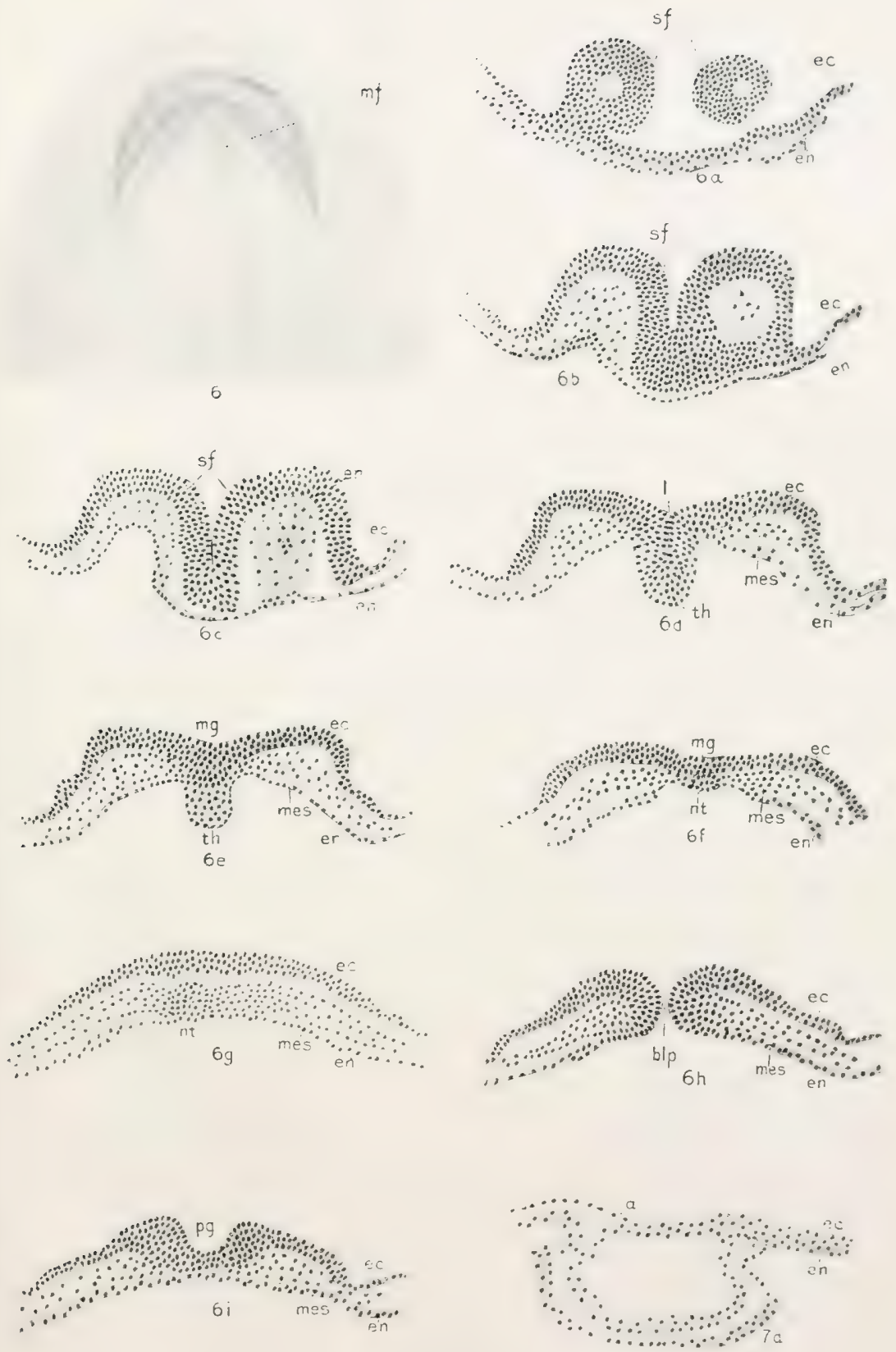

Ph.ite Xi. 6-ji, Situgi: III; $; a$, Stage IV. 


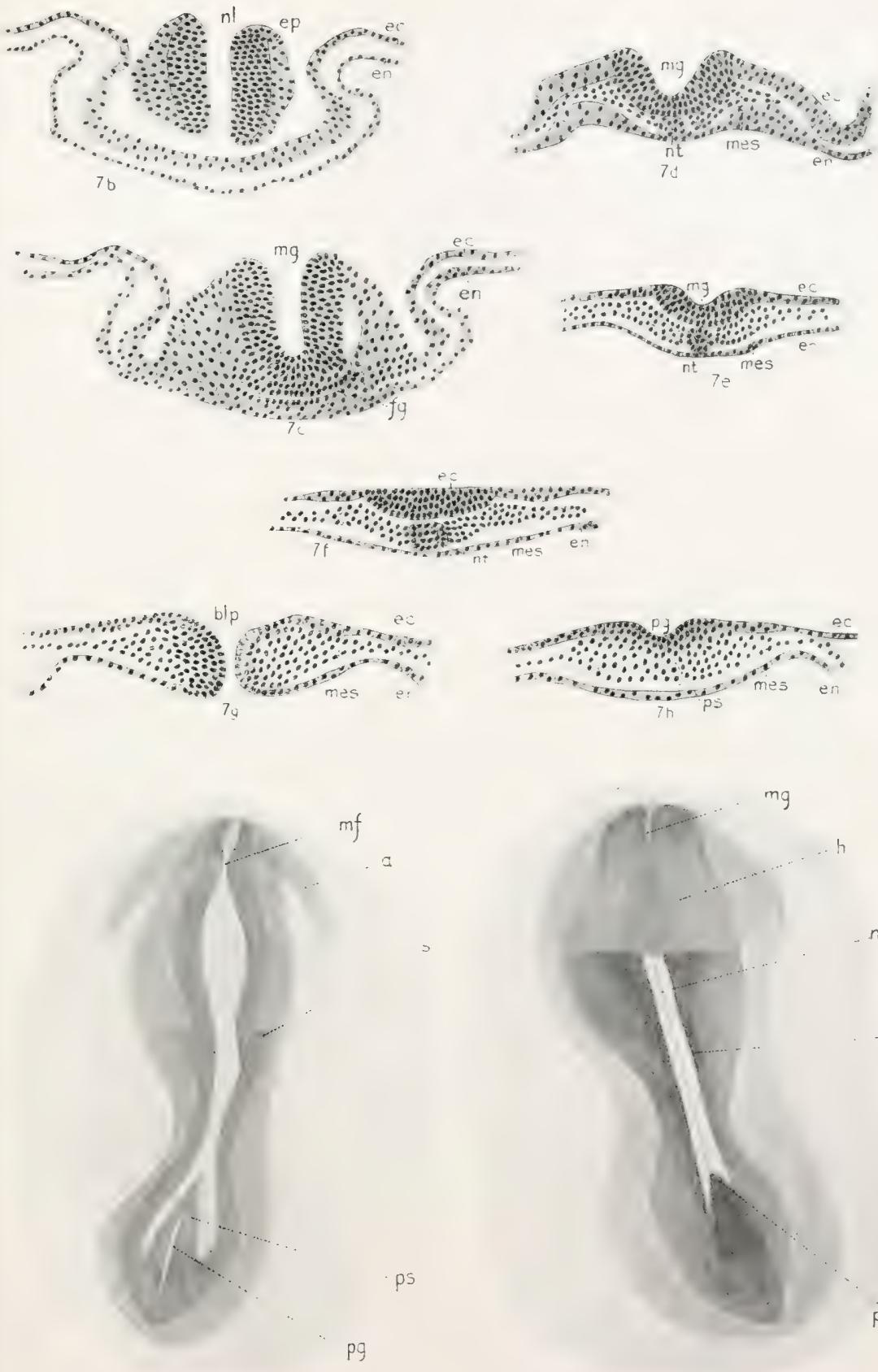


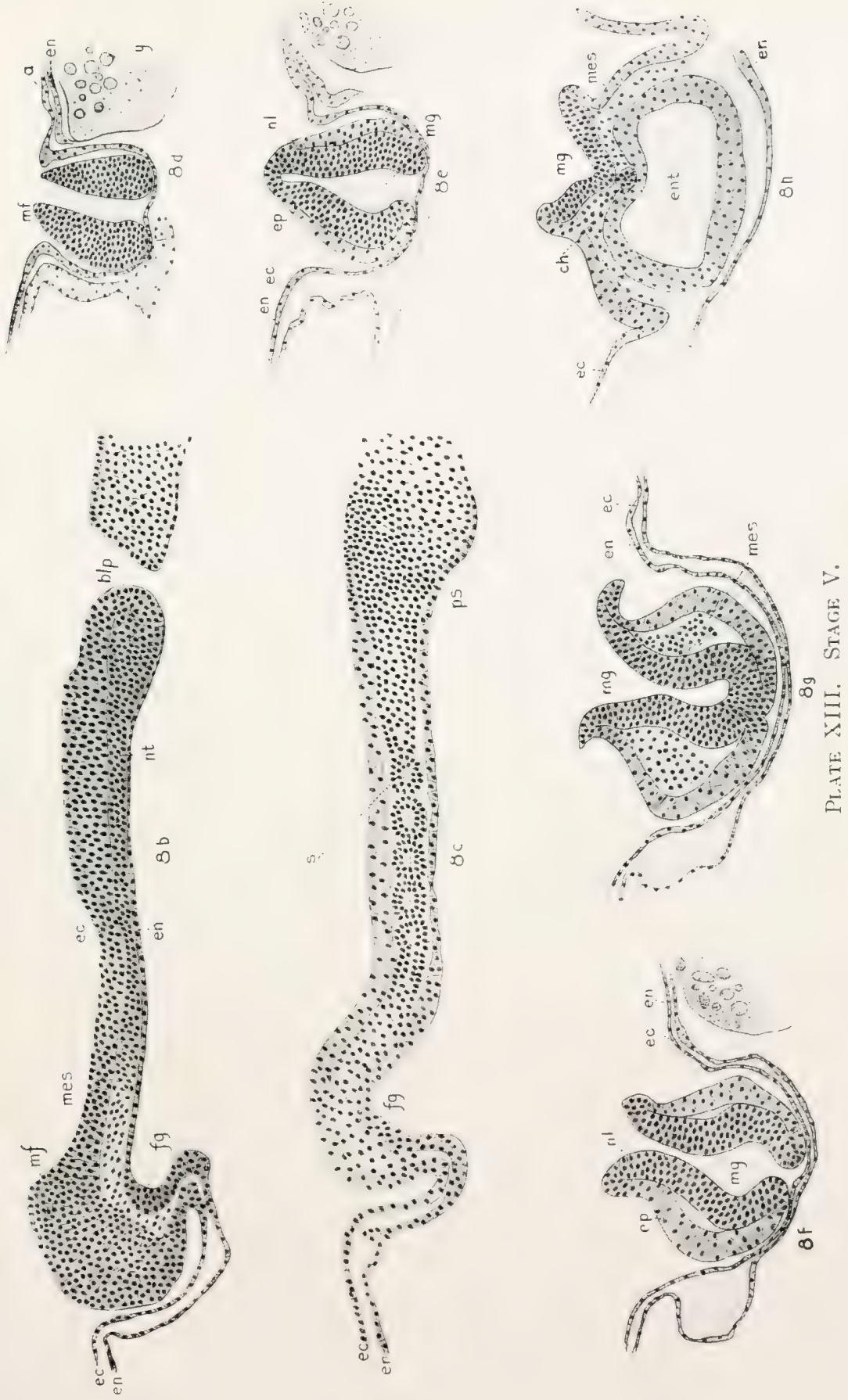


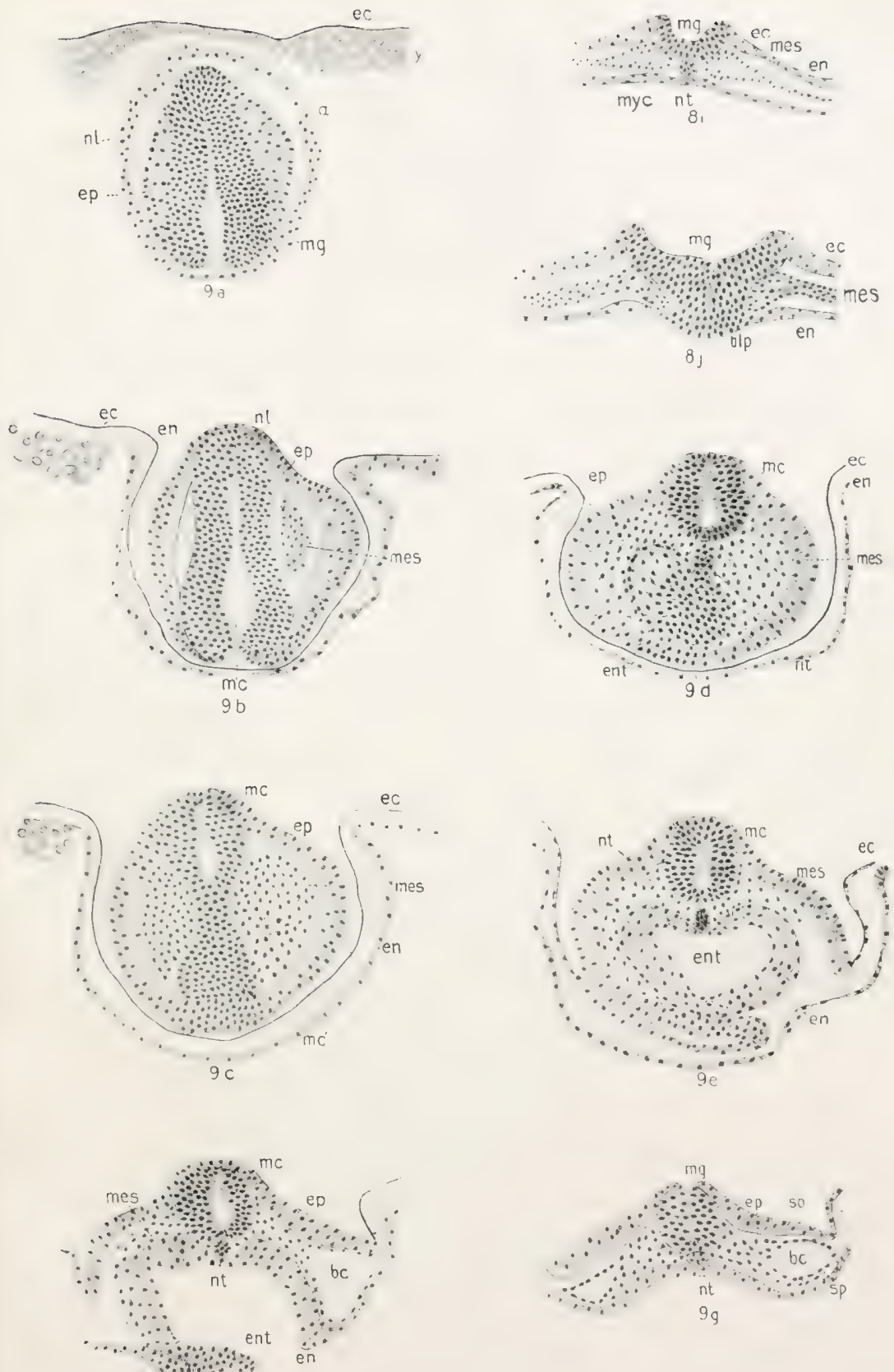

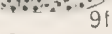

Plate Xil. Si-Sj, Stage V; $q a-g g$, Stage VI. 


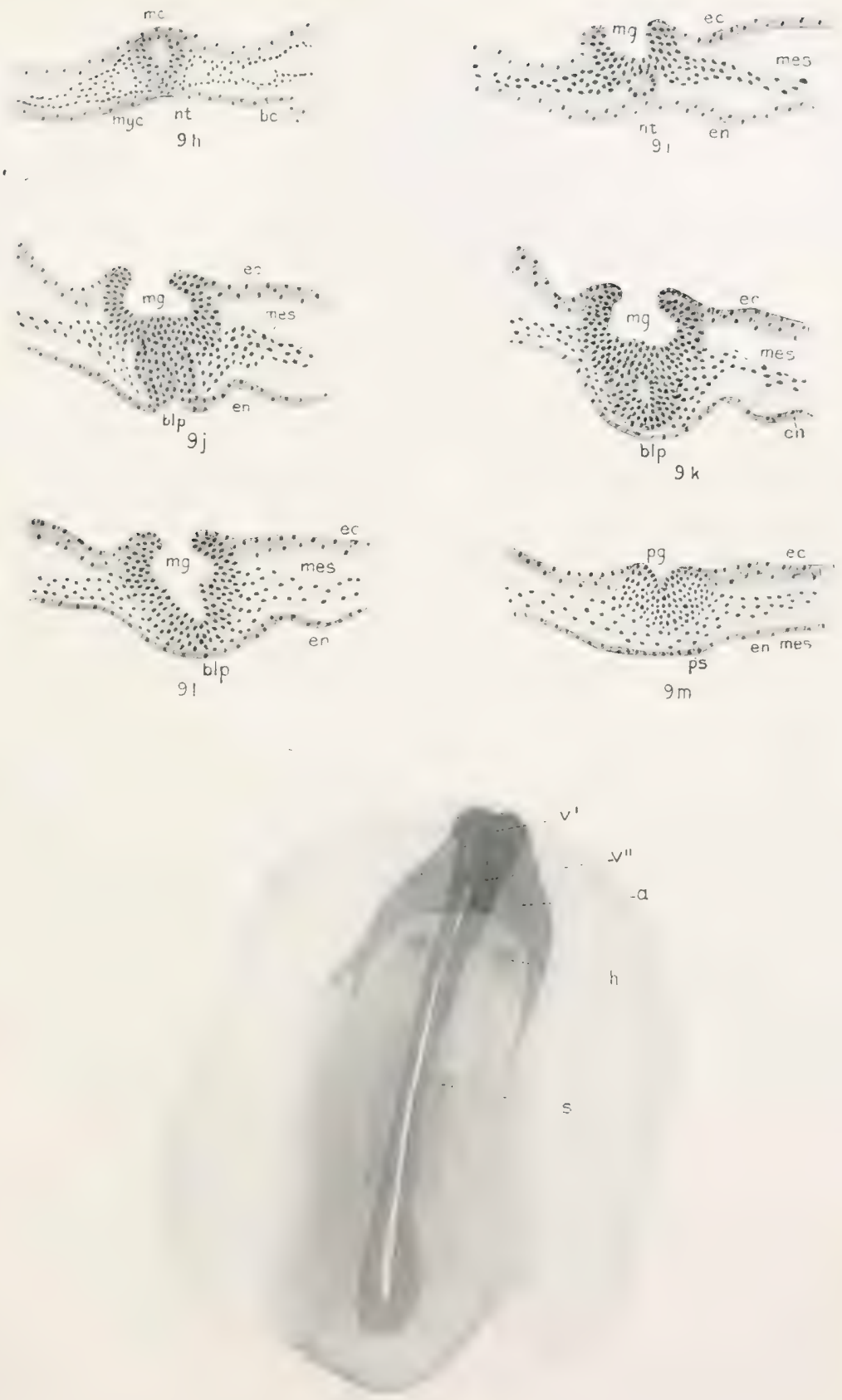

10

Plate XV. gh-gm, Stage VI; io, Stage Vil. 

$10 \mathrm{a}$
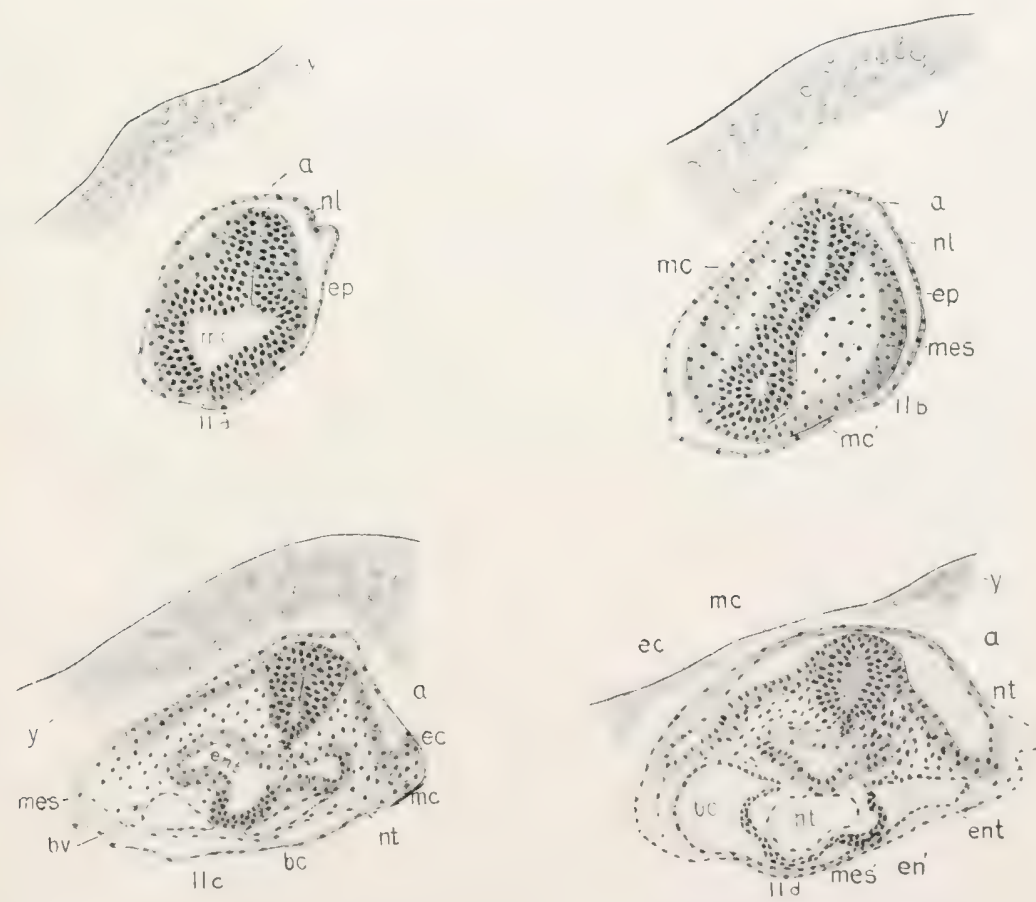

Plate XVI, hoa, Srige VII; II $q-I I d$, Stage Vili. 


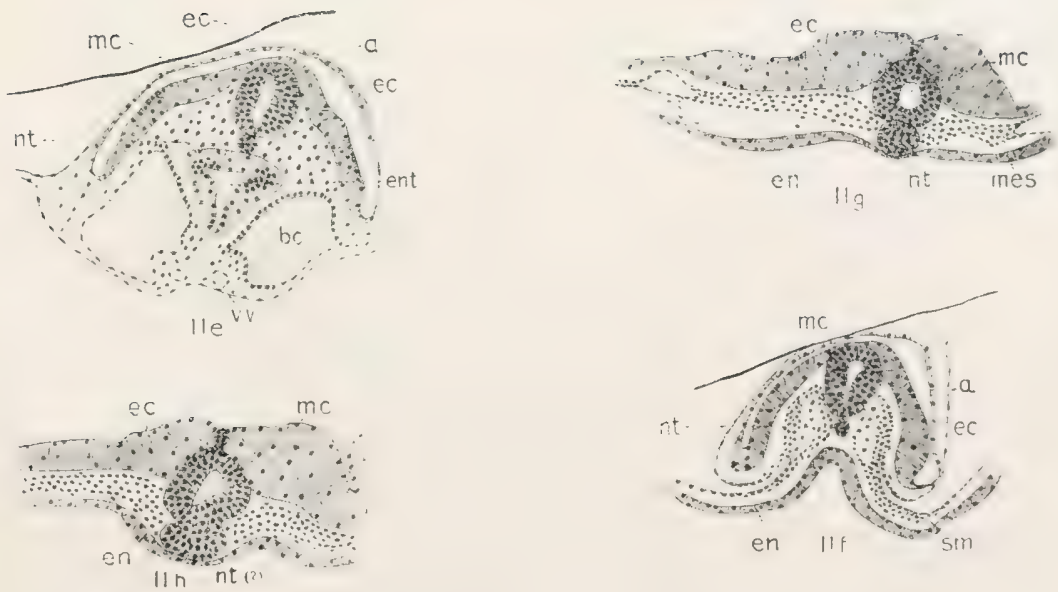

Plate IVII. Stage ViII. 


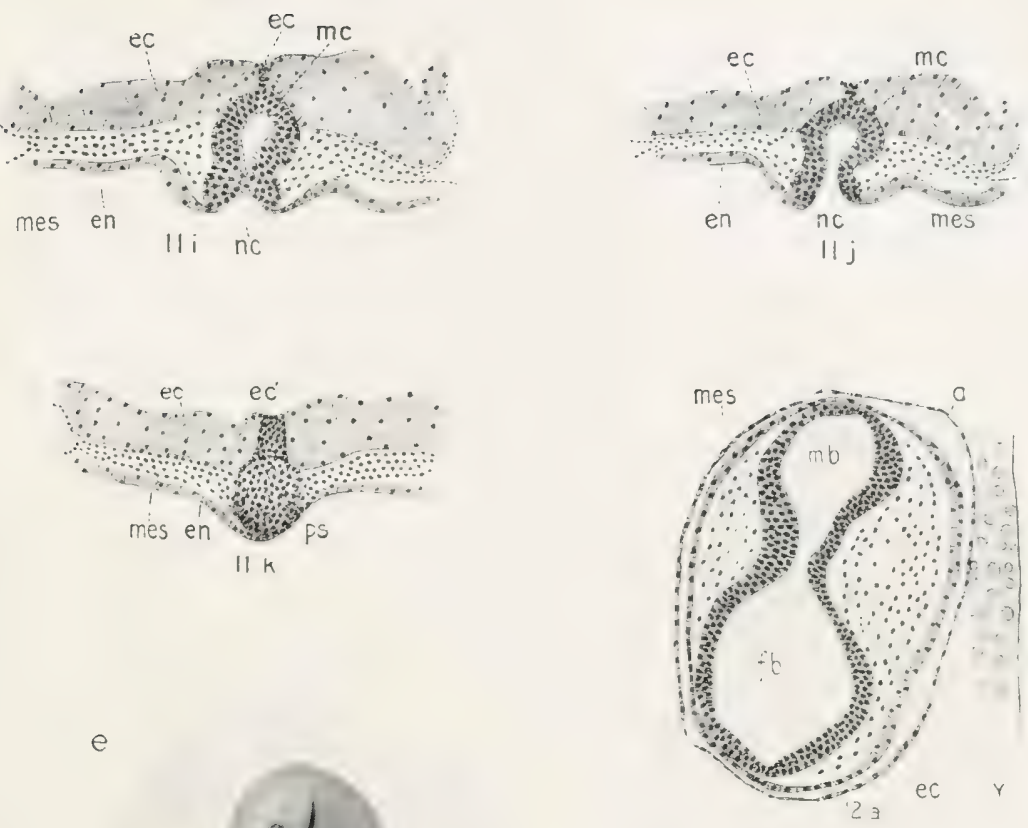

ht. in

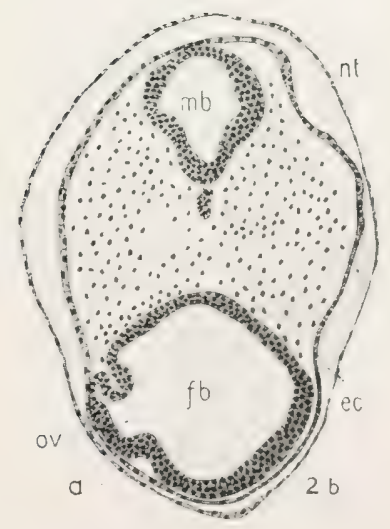

12

Plate init. iti-tik, Stage ViII; $12-I 2 b$, Stage IX. 


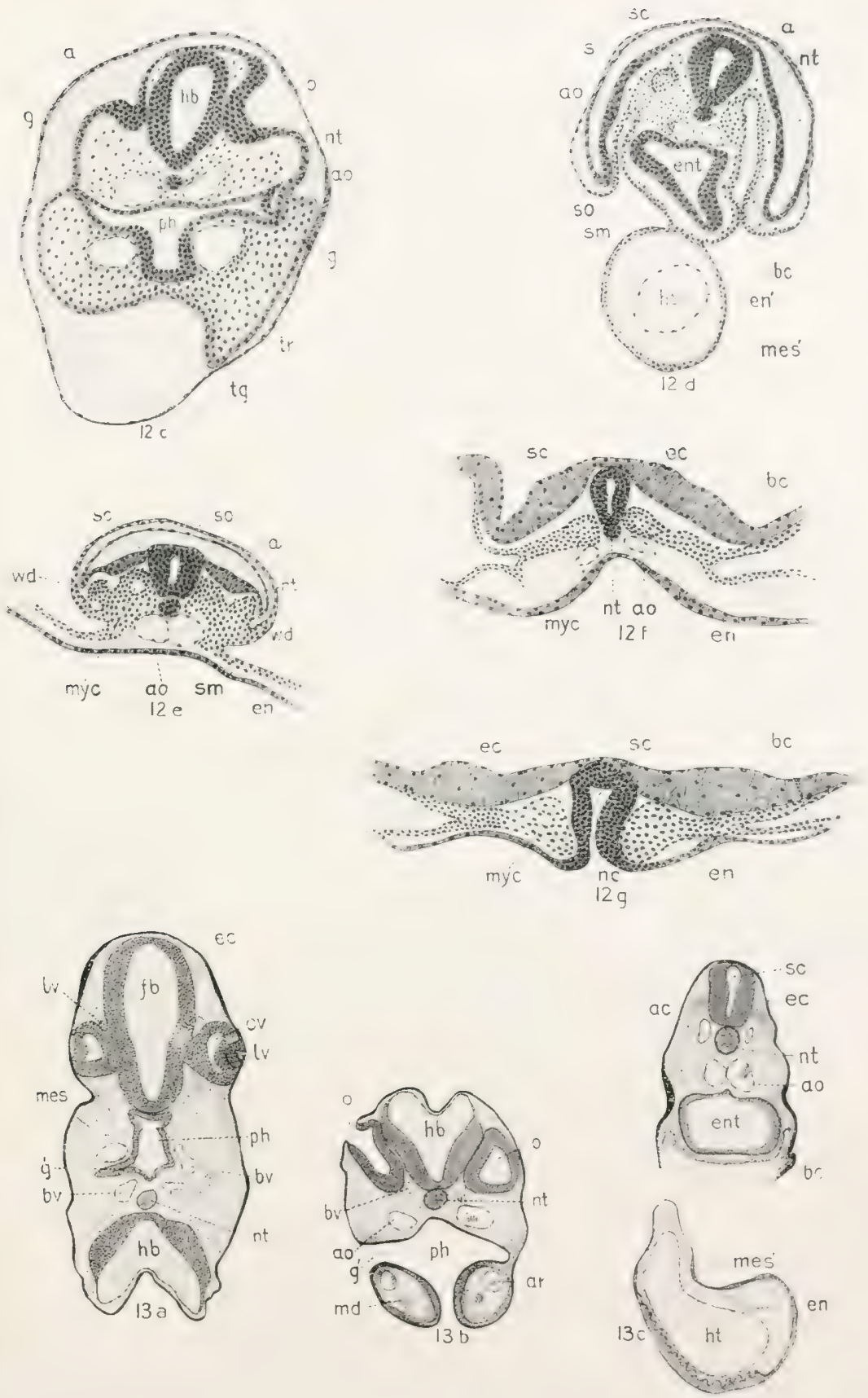

Plite XIX. I $2 c-12 g$, Stage IX; $13 a-13 c$, Stage X. 




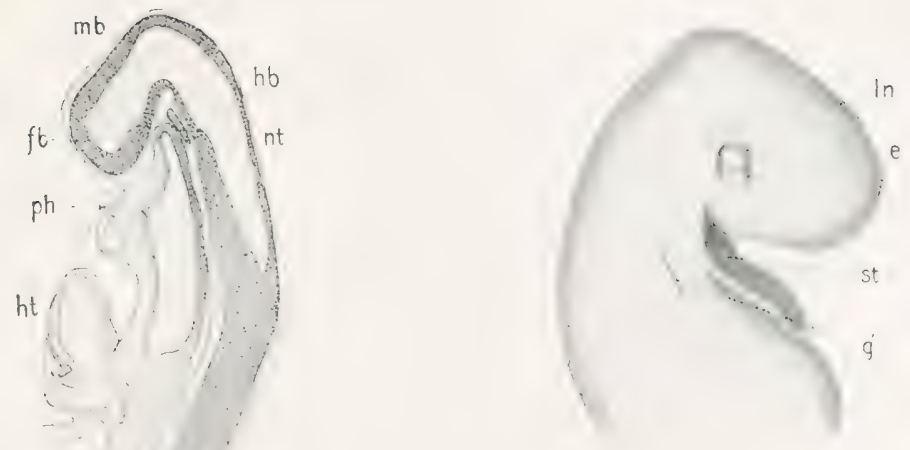

a.

a
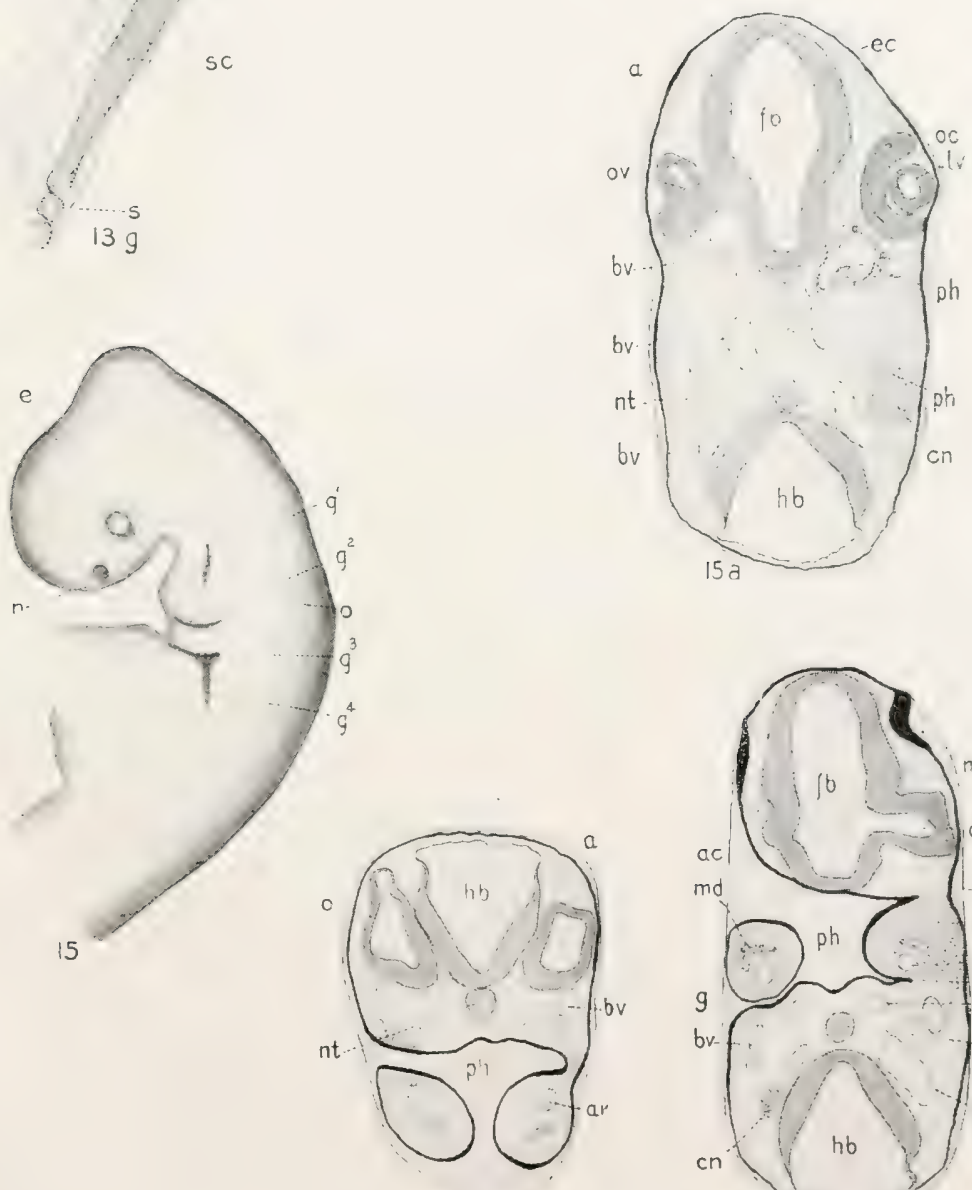

$15 \mathrm{c}$

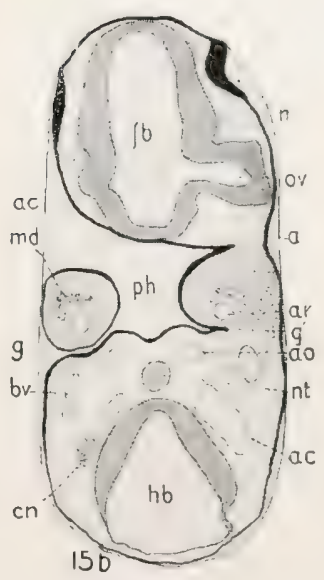

Plate XXi. i3g, Stage X; 14 , Stage XI; I5-15c, Stage Xil. 


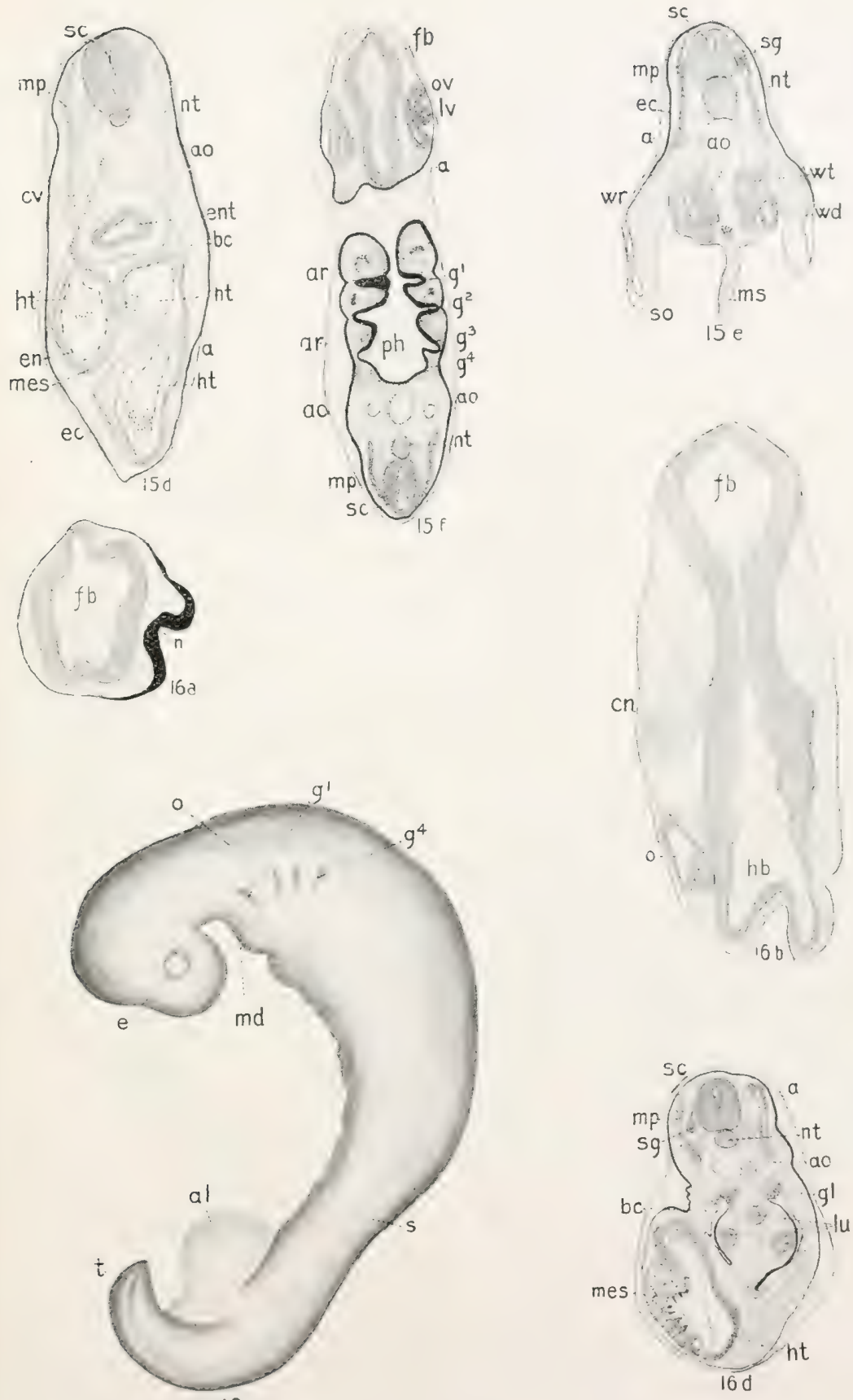

Plate XXII. I5d-I5f, Stage Xil; i6-I6d, Stage Xili. 


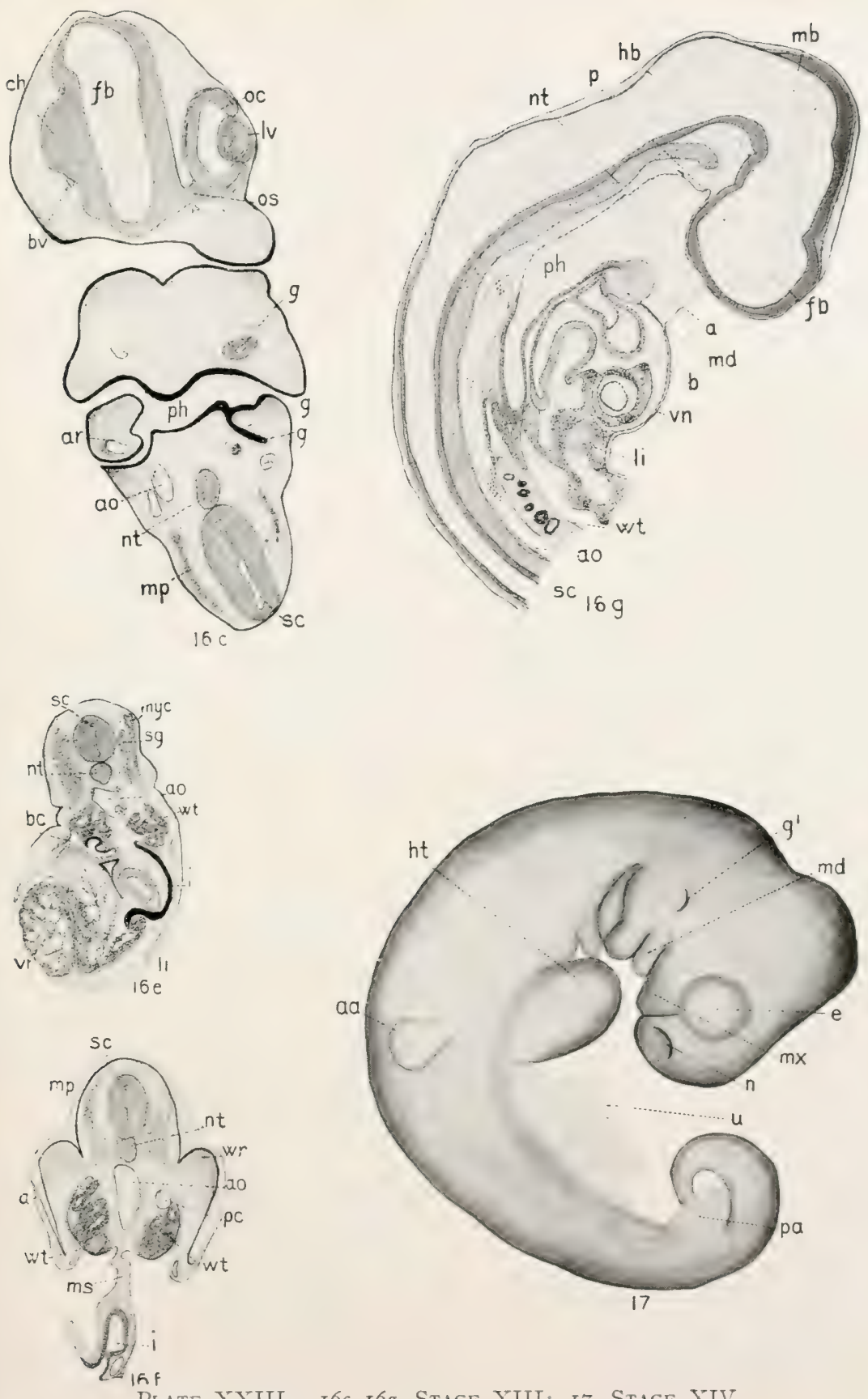

Plate Xxill. i6c-I6g, Stage Xili; 17 , Stage XIV. 



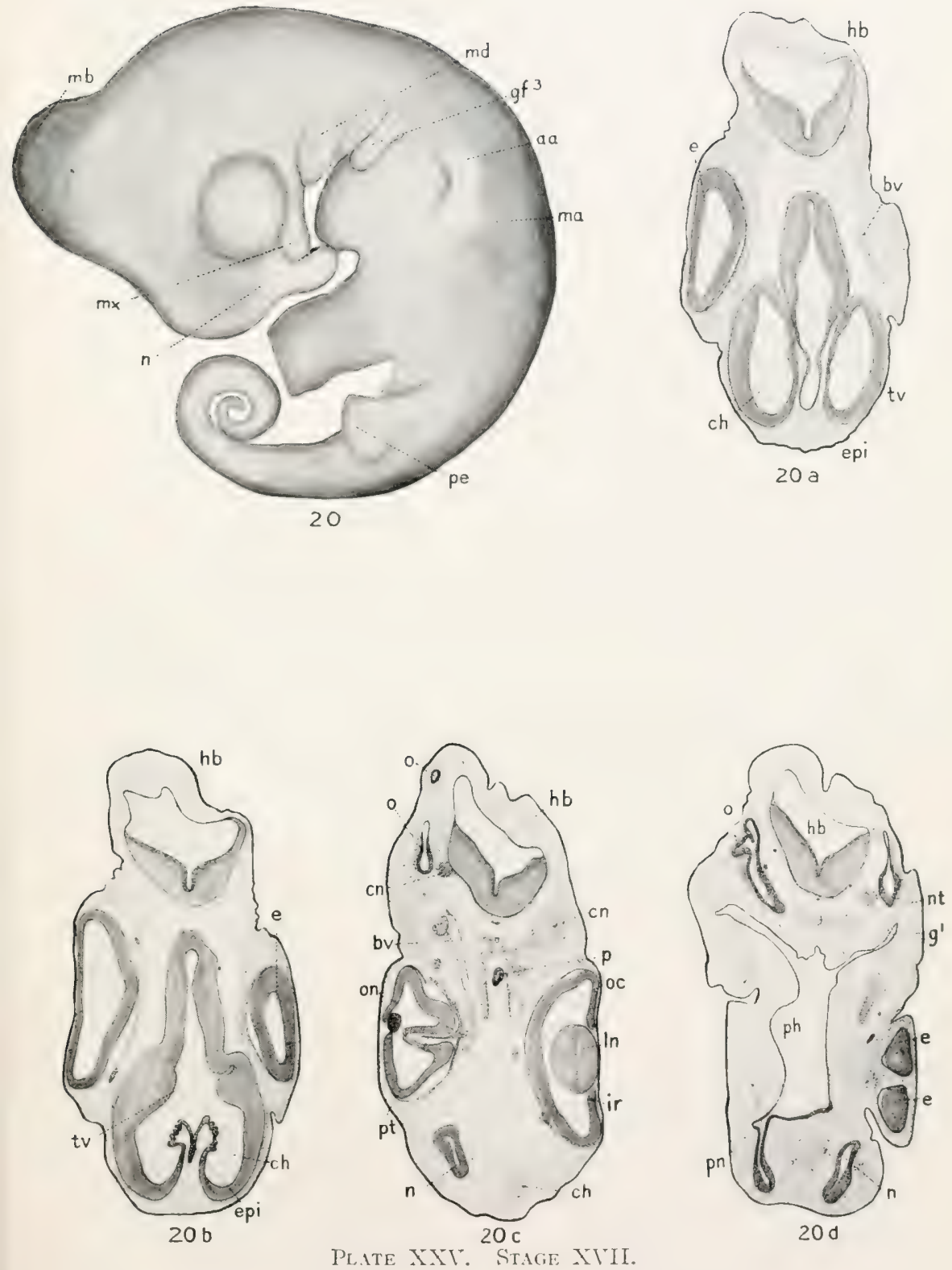


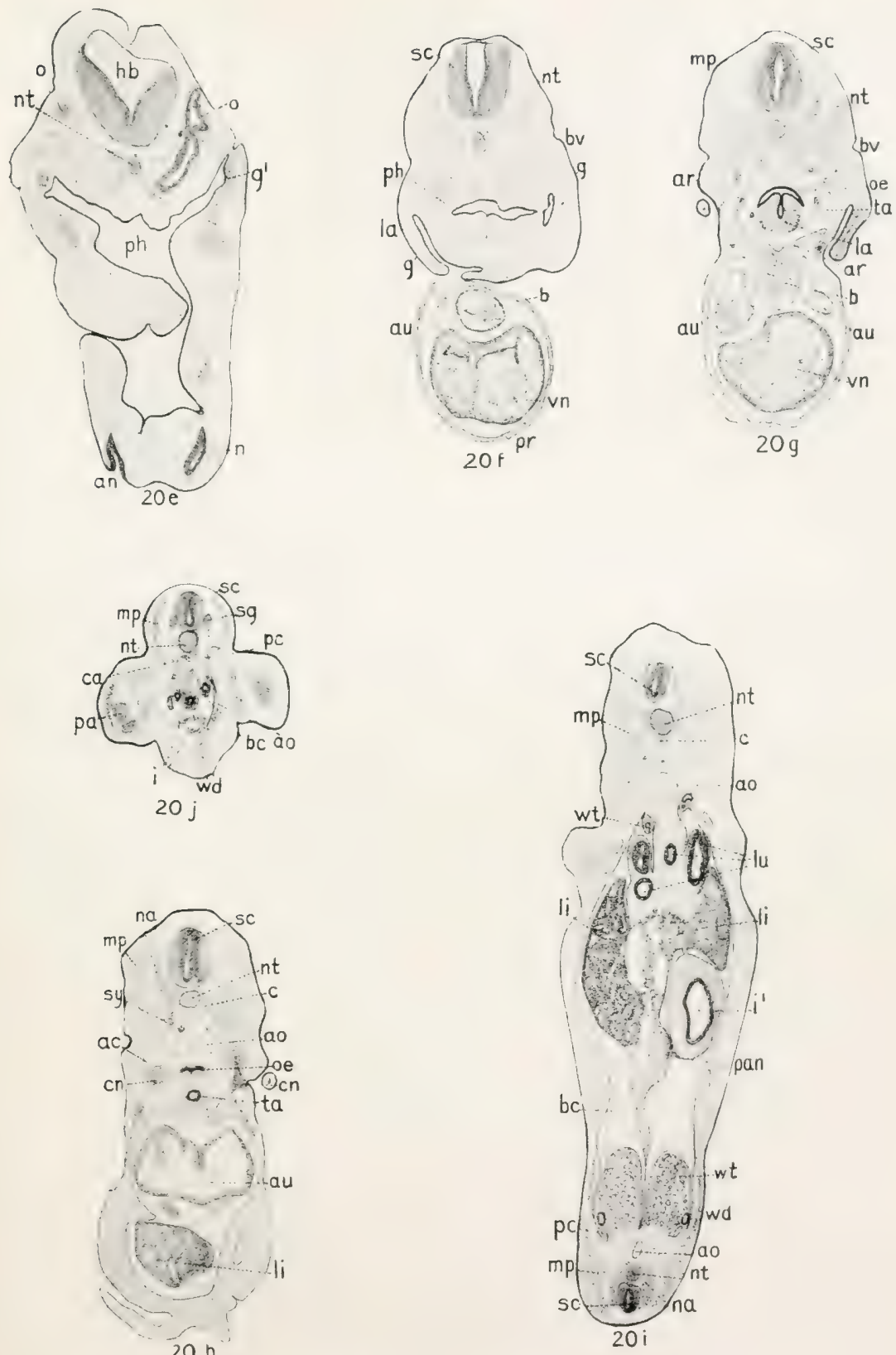

Plate Mirt, St.age Miri 


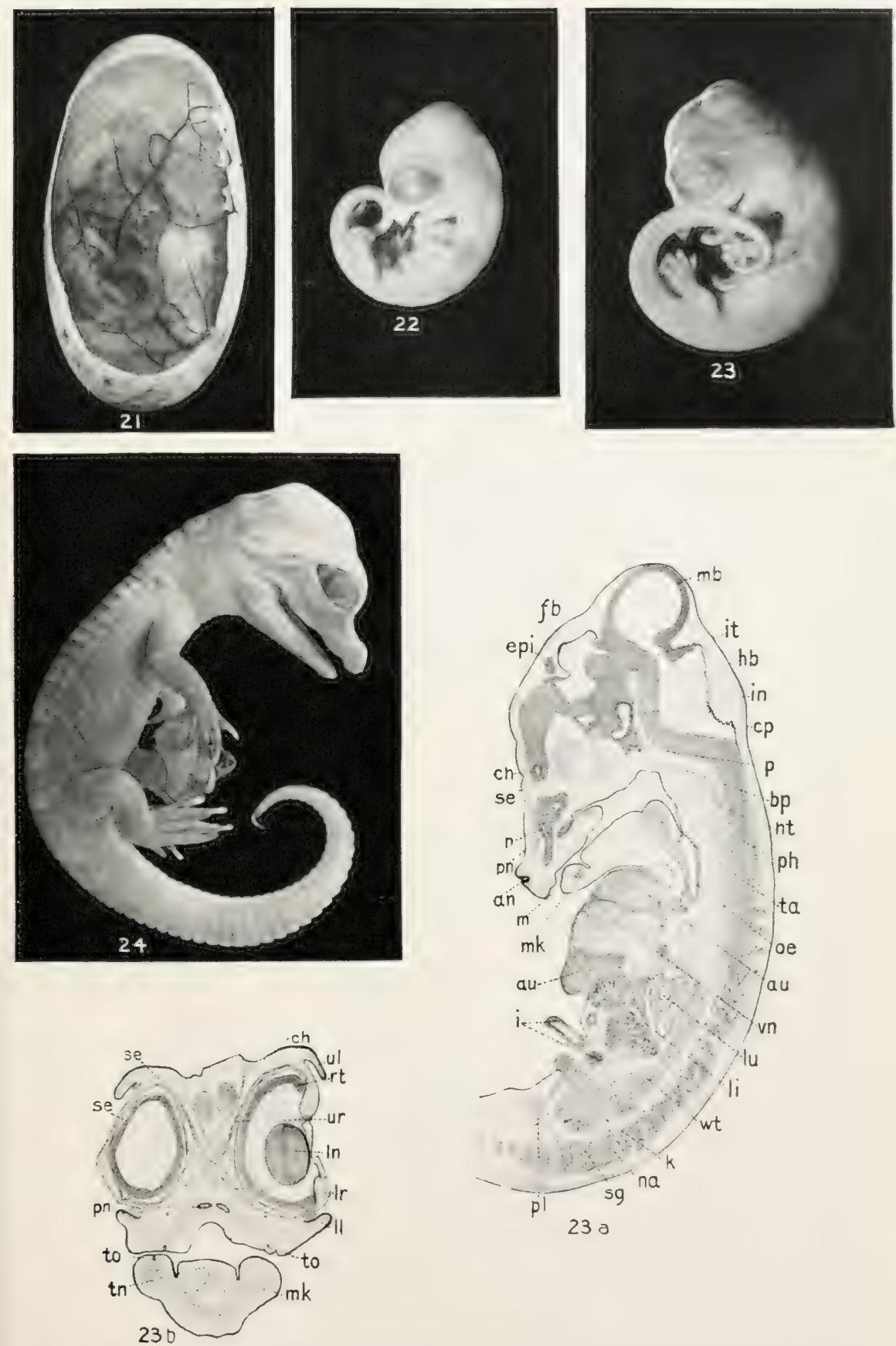

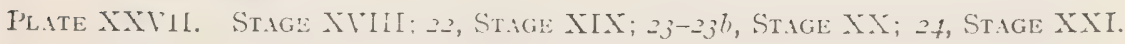




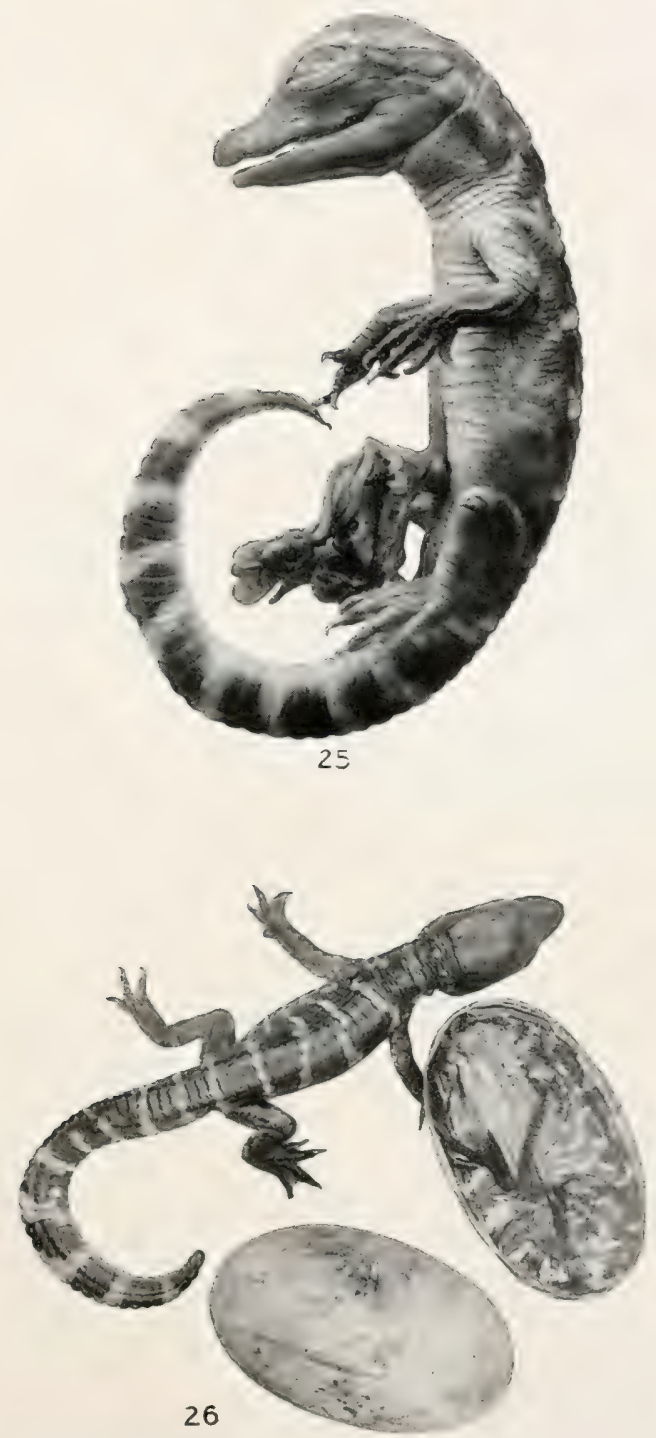

Peate XXViII. 25, Stage XXII, Alligator Embryo; 26, Stage XXIII, Alligator Just Hatched and Relative Size of EGG. 



\section{BIBLIOGRAPHY}

I. Adams, A. L., The Wanderings of a Naturalist in India. Edinburgh, 1867.

2. Anderson, A., "An Account of the Eggs and Young of the Gavial (G. gangeticus)," Proc. Zoöl. Soc., I 875, p. 2.

3. Balfour, F. M., Comparative Embryology, vol. 2.

4. Battersby, J., "Crocodile's Egg with Solid Shell," Nature, vol. 48 , no. 1237 , p. 248 .

5. Bischoff, "Über den Bau des Crocodilherzens, besonders von $C$. lucius," J. Müller's Archiv, 1836 .

6. Boake, Bancroft, "The Nest of the Crocodile," Zoölogist, vol. 5, I870, pp. 2002-4.

7. Boettger, O., Katalog d. Reptilien-Samml. im Mruseum d. Senckenbergischen Gess., Frkft., 1893.

8. Boutan, Louis, Le Crocodile des Marias (C. palustus), Mission Scientifique Permanente d'Exploration en Indo-China Décades Zoologique, Hanoi, 1906.

9. Brand, , "Sur le ductus caroticus du Caiman," Bull. Acad. St. Petersburg, vol. 17, p. 307, 1872.

Io. Brehms, Thierleben, vol. 4, pp. 498-572, I912.

II. Bronn, H. G., Klassen und Ordnungen des Thier-Reichs, vol. 63, "Reptilien 2, Eidechsen und Wasserechsen."

12. BRüHL, C. B., Das Skelet der Krokodiliner, dargestellt in 20 Tafeln, I 862.

12a. Butler, G. W., "On the Subdivision of the Body Cavity in Lizards, Crocodiles, and Birds," Proc. Zoöl. Soc., London, pt. 4, I 889 .

13. Butrmann, H., De musculis Crocodili, Diss. inaugur., Hallæ, I826.

14. Cambridge Natural History (Gadow), vol. on 1 mphibia and Reptiles, pp. 430-472, I90I.

15. Chaffanjon, M. J., "Observations sur 1'Alligator Mississippiensis," Ann. de la Soc. Linn. de Lyon, vol. 28, pp. 83-96, I88 I.

16. Clarke, S. F., "The Nest and Eggs of the Alligator, A. lucius, Cuv.," Zool. Anz., II. jahrg., no. 290, pp. 568-70, 1888. 


\section{The Alligator and Its Allies}

17. Clarke, S. F., "The Habits and Embryology of the American Alligator," Jour. Morph., vol. 5, pp. 182-214, 1891.

18. Claus and Sedgwick, Elementary Textbook of Zoölogy. 1884.

19. Cope, E. D., Checklist of North American Batrachia and Reptiles. Washington, 1875 .

19a. Davenport, C. B., "Note on the Carotids and Ductus Botalli of the Alligator," Bull. Mus. Comp.Zoöl., Harvard, vol. 24, pp. 45-51, I893.

20. Ditmars, R. L., The Reptile Book. New York, 1907.

21. - Reptiles of the World. New York, I910.

22. Dumeril, A., and Bocourt, . . études sur les reptiles et les batraciens du Mexique. Paris, I870-82.

23. Duvernoy, "Note sur le structure du cœur des Crocodiliens," Jour. de l' Institute, 1838.

24. Ersler, P., "Zur Kenntniss der Histologie des Alligatormagens," Archiv. f. Mik. Anat., vol. 34, pp. I-Io, T. I., 1889.

25. Fauvel, An account of the Chinese alligator (title of paper not known), J. China Asiat. Soc., vol. 13, pp. 1-36, 1879.

26. Feilden, H. W., "The Nest of the Alligator," Zoölogist, 2 sr., vol. 5 , pp. 2090-92, 1870 .

27. Felix, W., Head-Kidney in the Crocodile. 1897.

28. Gadow, Hans, "On the Modification of the First and Second Visceral Arches, with Especial References to the Homologies of the Auditory Ossicles," Phil. Trans., vol. I79B, pp. 45I-85, T. $71-74$.

29. - "Untersuchungen über die Bauchmuskeln der Crocodile, Eidechsen u. Schildkröten," Morph. Jahrb., vol. 7, pp. 57-100, I88I.

29a. Geofrroy, E., "Observations anatomiques sur le Crocodile du Nil," Ann. Mus. Nat., vol. 2, pp. 45-47, 1803.

30. Giebel, C. G., "Das Skelet des westafrik. Crocodilus cataphractus," in dessen Zeitschrift f. d. ges. Naturw., p. 105, 1877.

31. HaIr, , A thesis in the Univer. of Edinburgh (title not known), referred to by Haughton in Ann. and Mag. Nat. Hist., below.

32. Hasse, C., "Das Gehörorgan der Crocodile," in seine Anat. Studien, p. 679, I 87 I.

33. - "Das Gehörorgan der Crocodile," in dessen Anat. Studien, p. 679,1873 (possibly same as no. 32 ).

34. Haughton, S., "On the Muscular Anatomy of the Crocodile," Proc. of the Royal Irish Acad., vol. 9, pt. 3, Dublin, 1866.

35. - "On the Muscular Anatomy of the Alligator," Annals and Mag. of Nat. Hist., 4 th sr., vol. 1, pp. 282-92, 1868. 


\section{Bibliography}

36. Herrick, C. L., "The Brain of the Alligator," Cincinnati Acad. Nat. Hist., 1890.

36a. Hertwig, O., Handbuch der vergleichenden und experimentallen Entwickelungslehre der Wirbelthiere, vol. 2, Jena, 1906.

37. Hornaday, W. T., The American Natural History, pp. 317-22, 1904.

38. Howes, G. B., "On the Probable Existence of a Jacobson's Organ among the Crocodilia," Proc. Zoöl. Soc. London, pp. I48-59, Feb., I 89 I.

39. Huxley, Thos., "On the Dermal Armor of Jacare and Caiman, with Notes on the Specific and Generic Characters of Recent Crocodilia," Jour. of the Proc. of the Linn. Soc., I 859.

40. JaCQuart, H., "Sur plusieurs points du système veincux abdominal du Caiman à museau de brochet (Alligator lucius)," Compt. Rendus Acad.Sc. Paris, T. 47, pp. $829 \mathrm{ff}, \mathrm{I} 858$.

4I. Kingsley, J. S., Comparative A natomy of Vertehrates. Phila., I9I 2. 42. v. Klein, F., "Beiträge zur Osteologie der Crocodilenschädel," Jahreshefte des Vereins $f$. vaterländ. Natur. in Württemberg, I9 Jahrg., p. I0, I863.

43. KükenthaL, W., "Zur Entwickelung des Handskelettes des Krokodiles," Morph. Jahrb., vol. 19, pp. 42-55, 1892-93.

43a. Lydekker, Rich., New Natural History, vol. 5, 1901.

44. MAXER, ,"Bemerkungen über den Schädel von Gavialis Schlegelii u. Crocodilus raninus," A rchiv.f. Naturg., p. 312, I 858.

45. Meek, Alex., "On the Occurrence of a Jacobson's Organ, with Notes on the Development of the Nasal Cavity, the Lachrymal Duct, and Harderian Gland in Crocodilus porosus," Jour. Anat. and Physiol., London, vol. 27, pp. 151-160, T. 10, 1892.

45a. Meek, Alex., "On'the Morphogenesis of the Head of the Crocodile," Jour. Anat. and Physiol., vol. 45, pp. 357-77, I9I I.

45b. Milani, A., "Beiträge zur Kentniss der Reptilienlunge (alligator and crocodile)," Zool. Jahrb., vol. 10, pp. 133-56, I897.

45c. Miller, W. S., "The Structure of the Lung," Jour. Morph., vol. 8, p. I7I, I893.

46. Oldenburg, Hy., "Giving some Account of the Present Undertakings, Studies, and Labours, of the Ingenious in many considerable parts of the World," Philos. Trans., vol. I, Anno 1665 and 1666, p. 703 .

47. PanizzA, , "Sulla struttura del cruore e della circolazione del sangue del Crocodilus lucius," Biblioteca Italiana, vol. 6o, 1887 (?).

48. PARKeR, W. K., On the Structure and Development of the Skull 


\section{The Alligator and Its Allies}

in the Crocodile, London, I882; rev. Trans. Zoöl. Soc. London, vol. II or I2, pp. 263-310; Nature, vol. 26, pp. 252-54, I 882 .

49. PARKer and Haswell, Text-book of Zoölogy. $\mathbf{I} 897$.

50. Peters, W., "Über das Gehōrknöchelchen und den Meckel'schen Knorpel bei den Crocodilen," Monatsb. der königl. preuss. Akademie der Wiss. zu Berlin, p. 529, I 868.

51. _- "Über die Höhlen des Unterkiefers bei den Crocodilen," ibid., p. 15,1870

52. Poelmann, C., "Note sur le système circulatoire des Crocodiliens," Bull. de l'Acad. Belgique, vol. 21, pp. 67-72, I854; L'Institute, vol. 23, p. 213,1854 .

53. RABL-RüCKHARD, "Das Centralnervensystem des Alligators," Zeitsch. f. Wiss. Zool., vol. 30, pp. 336-73, 1878.

54. Ratuke, C., Untersuchungen über dic Entwickelung und den Körperbau der Crocodile. Braunschweig, I 866.

55. ReEse, A. M., "The Nasal Passage of the Florida Alligator," Proc. Phila. Acad. Nat. Sci., pp. 457-64, rgor.

56. _- "Artificial Incubation of Alligator Eggs," Amer. Nat., vol. 35, no. 4II, pp. 193-95, March, I90I.

57. _ "A Double Embryo of the Florida Alligator," Anat. Anz., vol. 28 , nos. 9 and 10, pp. 229-3I, 1906.

58. — "The Development of the American Alligator," Smithsonian Misc. Coll., no. I79I, pp. I-66, 1908.

59. __ "The Breeding Habits of the Florida Alligator," ibid., no. I696, pp. 38 I-86, I907.

6o. - "The Home of the Alligator," Pop. Sc. Monthly, pp. 36572, Oct., 1910.

6I. _- "Development of the Digestive Canal of the American Alligator, Smith. Misc. Coll., no. 1946, pp. I-25, I9Io.

62. _- "The Development of the Brain of the American Alligator: The Paraphysis and Hypophysis," Smith. Misc. Coll., no. I922, pp. I-20, 1910.

63. — "The Histology of the Enteron of the Florida Alligator," Anat. Record, vol. 7, no. 4, pp. 105-29, April, I9I3.

64. - "The Vascular System of the Florida Alligator," Proc. Phila. Acad. Nat. Sc., pp. 413-25, 1914.

65. RösE, C., "Über die Zahnentwickelung der Krokodile," Verhandl. d. anat. Gesellsch., Jena, vol. 6, pp. 225-27, 1892; also Morph. A rb., Jena, vol. 3, pp. 195-228, 1893-4.

66. —_ "Über die Verwachsung von retinierten Zähnen mit den Kieferknochen," Anat. Anz., pp. 82-89, 8 Jahr, I893. 


\section{Bibliography}

67. RösE, C., "Über đas rudimentäre Jacobsonschen Organ der Kro kodile und des Menchen," Anat. Anz., pp. 458-72, 8 Jahr, I 893 .

68. _- "Über die Nasendrüse und die Gaumendrüsen von Crocodilus poroso," Anat. Anz., vol. 8, pp. 745-5I, I 893.

69. - - "Über die Zahnleiste und die Eischweile der Sauropsiden," Anat. Anz., vol. 7, pp. 748-64, 1892.

7o. Schwalbe, G., "Über Auricular höcker bei Reptilien, ein Beitrag zur Phylogenie des Äusseren Ohres," Anat. Anz., vol. 6, pp. 43-53, 1891 .

71. Sclater, W. L., List of the Reptiles and Batrachians of S. Africa. 1898.

72. Sluiter, E. P., "Das Jacobsonsche Organ von Crocodilus porosus (Schn.)," Anat. Anz., vol. 7, pp. 540-45, I892.

73. Sигтн, H. M., "Notes on the Alligator Industry," Bull. U. S. Fish Com., vol. II, pp. 343-45, I89I.

74. Stevenson, C. W., "Utilization of the Skins of Aquatic Animals; Leather from Alligator Skins," Report of Com. Fish and Fisheries for 1902, pp. 342-46, 1904.

75. Tennent, Sir J. E., Sketches of the Natural History of Ceylon. London, I86I.

76. Van Bemmelen, J. F., "Die Visceraltaschen und Aortenbogen bei Reptilien und Vögeln," Zool. Anz., vol. 9, pp. 528-32, 543-46, 1886.

76a. Virchow, Hans, "Ueber die Alligatorwirbelsãule," Archiv. fur Anat., parts 2 and 3, pp. 103-I42, I9I4.

77. Voeltzkow, A., "On the Oviposition and Embryological Development of the Crocodile," translated in Ann. Nat. Hist., vol. 9 , pp. 66-72, r891.

78. — "Biologie und Entwickelung der äusseren Körperform von Crocodilus madagascariensis Grand," Abhandl. Senckenberg Naturf. Gesell., vol. 26, part I, pp. I-I49, I889.

79. Voeltzkow, M. (?), "Beiträge zur Entwichelungsgeschichte der Reptilien, I-IV (Crocodilus madagascariensis und Podocnemis madagascariensis)," ibid., vol. 26, 1889.

8o. Vrolik, "Sur le coeur du Caiman à museau de Brochet (Crocodilus lucius)," Het. Institute, I84ז.

81. Waytallingam, S., "Notes on the Breeding of Crocodilus palustris." Proc. Zoöl. Soc. London, pp. 186-87, I880.

82. Wiedersheim, R., Comparative Anatomy of Vertebrates. 1899.

83. — "Beiträge zur Entwickelungsgeschichte des Urogenitalapparatus der Krokodile und Schildkröten," Verhndl. der 1o internat. Med. Cong. Berlin, vol. 2, pt. I, pp. 132-34, 1891; 


\title{
348 The Alligator and Its Allies
}

\author{
Anat. Anz., 5 Jahrg., pp. 337-44, I89o.
}

84. Williston, S. W., Water Reptiles of the Pastand Present. Chicago, I9I4.

85. ZIEGLER, H. E., Lehrbuch dervergleichenden Entwickelungsgeschichte der niederen Wirbelthiere. Jena, 1902.

86. ZuckerhandL, E., "Zur Anatomie und Entwickelungsgeschichte der Arterien des Unterschenkels und des Fusses," Anat. Hefte, pt. I, vol. 5, pp. 207-9 I, I895 (?).

87. _ “Zur Anatomie des Vorderarmes" (2d part), ibid., pp. 157$205, \mathbf{I} 895$.

88. - "Description anatomique de trois crocodiles envoyés de Siam par les Pères Jésuites," Mémoires de l'académie Royale des sciences, vol. 3, part 2, p. 266.

89. - - Description anatomique d'un crocodile, ibid., part 3, p. 173. 


\section{INDEX}

Abdominal aorta and branches, 2 I 2

Abdominal ribs, 80

Acetabulum, 85

Air chamber of egg, 228

Albumen of egg, 229, 230

Allantois, 299, 300, 328

Alligator, 6

abundance of, 8

American, 3

and cane rat, 28

and muskrat, 28

attack from, I4

bellowing of, 18

catching of, 34

cave of, 12

Chinese, 38

Cyanocephalus, I Io

daylight hunting of, 33

dealers in, 34

derivation of name of, 40

differs from crocodile, 7

digging from cave, 33

distribution of, ro

economic importance of, 26

eggs used as food, 35

feeding of, 12

fire hunting of, 32

habitat of, 8

hatching of, for sale, 35

hibernation of, 12,13

hides, annual output of, 28 for card cases, etc., 30

chief centers for, 27

damaged in removal, $3 \mathbf{I}$

Floridian, 28, 29

highest priced, 32

length and width of, 30

from Louisiana, 28, 29, 30

methods of cutting, 3I

Mexican, 29, 30

removal of, 3 I salting of, $3 \mathrm{I}$

shipment of, 3 I

from South and Central America, 27, 28

from Southern States, 28

varieties of, 29

value of different sizes of, 28 , 29

value to hunter of, 28

hole, I I

hunting, 32

Joe, 9

killing of, 33

for sport, 27

laws for protection of, 28

leather, first used, 26

for shoes, 27

imitation, 32

present use of, 32

meat, preparation of, 35

smoking of, 36

use as focd, 35

mississippiensis, 3,7

raw hides, selling of, 32

sale of live, 34

sinensis, 3,16

the stuffing of, 34

swimming of, 13,14

tanned hides, sale of, 32

teeth, sale of, 34

value of, 34

trail, II, I3

unknown to ancients, 40

use of tail, I4

value of live, 34

Alligatoridx, I

Amnion, 236, 247, 251, 259, 266, $267,268,269,270,274,275$,

$278,290,334$

Ampullæ, 149

Ancestry, 4

Annulus tympanicus, 149 
Aortic arches, 203, 296, 299

Appendages, development of, 308 , $315,317,327,328$

Appendicular skeleton, 8 I

Area opaca, 233

Area pellucida, 233

Arkansas Alligator Farm, 20 I

Arterial system, 212

first reference to, 44

Arteries, of anterior region, 215 , 216

brachial, 218

caudal, 216

cervical, 220

cloacal, 3 I 6

coeliac, 212

collateralis colli, 217,2 I9

common carotid, 219,221

crural, 2 I6

dorsal aorta, 2 I 2

fibular, 2 I 4

first hæmorrhoidal, 216

gastric, 2 I 2

gastro-hepatico-intestinal, 2 I 2

iliac, 2 I 4

inferior dental, 223

injection of, 201

internal carotid, 70, 221

internal mammary, 2 I 7

ischiadicæ, 214

lingual, 220

lumbar, 2 I 3

mandibular, 220

mesenteric, 2 I 3

œsophageal, 217

pancreo-intestinal, 2 I 2

pelvic, 2I 4, 2 I 6

pleural, 217

of posterior region, $2 \mathrm{I} 3$

primary carotid, $203,218,220$

pulmonary, 203

radial, 2 I 8

rectal, 216

right subclavian, 203, 216

sciatic, 2 I 4

second hæemorrhoidal, 2I6

spleno-intestinal, 212

subclavian, left, 2 I9

subscapular, 217

superior dental, 223

thoracic, 2 I 8

thyroid, 217 tibial, 214

ulnar, $2 \mathrm{I} 8$

urogenital, 2 I 4

vertebral, 217

Arytenoid cartilage, 147

Atlantosaurus, 4

Atlas, 53

Auditory capsule, 72

Auditory vesicle, 274, 277, 286, $294,297,302,309,320,322$

Auricles, 204

Axis, 54

Bartram's account, 8

Basilar plate, 33I

Belly skin, 3I

Belodon, 5

Bile duct, 154

Bird and crocodile, 40, 4 I

Blastopore, 233, 234, 235, 236 , $240,246,249,250,252,257,263$, 264,272

Body cavity, development, 279, $28 \mathrm{I}, 287$

Body flexure, 307, 317, 318

Bones, alisphenoid, 68

angular, 76

of anterior limb, 82

articular, 75

basilingual plate, 76

basioccipital, $67,68,72$

basisphenoid, 67

calcaneum, 88

centrale, 84

clavicle, 82

coracoid, 8 I, 82

coranoid, 75

dentary, 74

epiotic, 73

epipubis, 86

episternum, 82

exoccipital, 70

fibula, 87

fibulare, see calcaneum

of foot, 88

frontal, 60

humerus, 82

hyoid, 76

ilium, 84

integumental, 50

interclavicle, $8 \mathbf{I}$

ischium, 85 
Bones-Continued

jugal, 62, 67

lachrymal, 62

malar, 62

maxilla, 6I, 64

mesethmoid, 72

metacarpals, 84

nasal, 60

opisthotic, 73

palatine, 65

parietal, 59

of pelvic girdle, 84

pisiform, 83

of posterior limb, 84

postfrontal, 59

prefrontal, 60

premaxilla, 6I, 63

pro-otic, 73

pterygoid, 66, 70

pubis, 86

quadrate, 62, 69

quadratojugal, 64,67

radius, 83

scapula, $8 \mathrm{I}$

splenial, 75

squamosal, 59

supra-angular, 75

supraorbital, 62

suprascapula, 8I

tarsalia, 88

tibia, 87

tibiale-centrale, 88

transpalatine, 66

ulna, 83

ulnare, 80

vomer, 72

Brain, I32

Breeding habits of alligator, 18

Bronchial rings, 199

Buttons, 27

Caiman, 36

of Amazon, 37

banded, 3

black, 3,36

latirostris, 3

niger, 3,7

palpebrosus, 3

round-nosed, 3

sclerops, 3

species of, 37

spectacled, 3,37 teeth of, 36

trigonotus, 3

ventral armor of, 36

Capitulum of rib, 78

Carpus, 83

Cauda equina, I3I

Cement, 65

Centrum, development of, 325

Cerebellum, I32, I33

Cerebral hemispheres, I32, I33, I34 development of, 302, 309, 310 , 332

Cerebral peduncles, I33, I34

Cerebral vesicles, 266, 273, 319

Cervical cord, 132

Chalky band of egg, 229

Chewing muscles, 90

Chinese alligator, 3

Chorda tympani, I37

Choroid, I 47

Choroid fissure, 32 I, 322, 337

Clarke, S. F., 226, 227, 228, 230, $231,232,233,236,243,247$, $250,274,293,317,318$

Classification, I

Claws, 46, 84 development of, 333

Cleavage of mesoblast, 263

Clitoris, 196

Cloaca, I 55 embryonic, 316,327

Cloacal glands, 156

Cocoa, Fla., 27

Columella, 74, I49

Conjunctiva, 136

Conjunctival gland, r 46

Conus arteriosus, 203

Copulation of crocodile, 195

Copulatory organs, 194

Cornea, I46 development of, 32 I

Corn marks, 29, 30

Cornua of hyoid, 76

Corpora cavernosa, 194

Cranial cartilages, 320

Cranial flexure, $273,276,283,29$ I

Cranial nerves, $132,135,302,320$, 325

Cranium, $5^{8}$

Cricoid cartilage, 197

Crocodile-Crocodilus, 6 African, 39 
Crocodile-Continued

African, caves of, 4 I

distribution of, 40

egg laying of, 4I

held sacred, 40

in Madagascar, 40

mentioned by Herodotus, 40

Voeltzkow's account, 40

American, 2, 37

colors of, 39

distribution of, 38

Ditmars' experience, 38

range of, 37

cataphractus, 2

Cuban, 2, 39

derivation of name of, 40

Guatemala, 2

intermedius, 2,39

johnstoni, 2

Madagascar, 2

eggs of, 228

hatching of, $4 \mathrm{I}$

nest of, 4 I

man-eating, 40, 43

marsh, or mugger, 42

moreletti, 2

Nile, 2 I, 39

niloticus, 2,39

Orinoco, 2, 39

palustris, 3,42

migration of, 42

porosus, 2

rhombiferus, 2, 39

robustus, 2

rough-backed, 3

salt-water, $2,4^{2}$

in captivity, 43

habitat, 43

size of, 42

skeleton of, 5 I

sharp-nosed, 2

Siamese, 2

swamp, 3

Crocodilia, I

Crocodilidæ, $1,2,3$

Deaths by crocodiles in Africa, 40 in India, 43

Deltoid ridge, 83

Dentine, 65

Dermal skeleton, 47

Diaphragm, I 5
Digestive system, 152

Digestive tract, fixation of, I 59 histology of, I 89 outline of, 158

Digits, development of, 329, 332

Dinosauria, 4

Dorsal aorta, development of, 277 , 278,327

Dorsal fissure, I31, I32, I33

Dorsal shield, 47

Drum, I48, I49

Ductus Cuvieri, $3 \mathbf{I} 2$

\section{Ear, 147,148}

Ectoderm, 233

Eggs, 227, 231

artificial incubation of, 24

incubation of, 22

number of, per nest, 2 I , 22, 23

shape of, 228

shell of, 228

size of, $25,227,228$

taken from oviduct, 24

variation in size of, 26

weight of, 25

Elizabeth Thompson Science Fund, 226

El lagarto, 40

Embryo, development of, 231

earliest stages of, 232, 233

position of, 230

removal of, from egg, 23I

stages: I., 233; II., 235; III., 240; IV., 247; V., 249; VI., 257; VII., 266; VIII., 267; IX., 273; X., 282; XI., 293; XII., 293; XIII., 300; XIV., 307; XV., 316; XVI., 317; XVII., 318; XVIII., 328: XIX., 328; XX., 329; XXI., 333; XXII., 334; XXIII., 334

Embryology, summary of, 335

Enamel, 65

Endoskeleton, 50

Enteron, development of, 26I, $262,269,27$ I, 278, 287

Entoderm, 234

Epidermal skeleton, 46

Epiglottis, $197^{\circ}$

Episternum, 8I

Epitrichial cells, 48 


\section{Index}

Eustachian tube, 72, I49

Everglades, 10, 220

External auditory meatus, 70, 73, 148

External mandibular foramen, 75

Extracolumellar cartilage, 74

Eye, 144 glands of, I 44

Eyeball, I 46

Eyelids, I 44 development of, 329,332

Feeding of alligators, 15

Fenestra ovalis, 73

Fissura ventralis, $13 \mathbf{I}$

Food of alligators, I5

Foramen ovale of skull, 68

Forebrain, 274, 276, 284, 29I, $294,302,308,319$

Foregut, 240, 248, 252, 297

Foreskin, I95

Fort Pierce, Fla., 27

Fourth ventricle, 132

Fronto-nasal region, 3 I 8

Fundic region of stomach, I52

Gastroliths, 44, 45, I53

Gavial, 6 food of, 44

Indian, distribution of, 43 eggs and nest of, 44 meaning of, 44

Gavialidæ, 1,3

Gavialis gangeticus, 2 character of, 43,44 size of, 43

Genital ducts, 156

Gcographical distribution of Crocodilia, 6

Gescmackwärzchen, I65

Gharial, 44

Gill clefts, 277, 283, 285, 293, 294, 299, 301, 302, 303, 316, 317, 318, 323,336

Gizzard, I 53

Glans penis, 195

Glenoid cavity, 8 I

Glomeruli, 304

Glottis, development of, 324

Growth of alligators, I6
Hallux, 88

Harderian gland, I36, I 45

Head-fold, 233, 236, 237

Heart, 202, 204 development of, $267,270,279$, $283,287,297,303,310$

Hindbrain, 277, 284, 294, 308, 319

Histology of enteron, I57 of integument, 48

Horn alligator, 31

Horny layer, 48

Hyoid, I5 I development of, 330

Hyomandibular cleft, 286, 307, 309,322

Hypophysis, 53, I33

development of, 306, 320, 33I, 337

Incubation, period of, 25

Infundibulum, I33, I34 development of, 330

Integument, histology of, 48

Internal auditory meatus, 73

Internal mandibular foramen, 76

Intestine, I 54 development of, 289

Iris, 146 development of, 32 I

Jacksonville, Fla., 34

Kidneys, 192

Kissimmee, Fla., 27

Labyrinth, $\mathbf{1} 48$

Lachrymal canal, I45

Lachrymal gland, I44, I45

Lake Kissimmee, ro

Lake Worth, 37

Large intestine, epithelium of, 187 histology of, 186 see Rectum

Larynx, 197 develcpment of, 323

Lateral disks of stomach, I53

Lateral ventricle, developing, 319

Laying season of alligator, 18

Lens, 147

Lens vesicle, $276,284,294,302$, $309,321,332$

"Leviathan" of Book of Job, 40 
Liver, 154

development of, $304,307,312$, 326

Lower jaw, 74

Lungs, I99, 200

capillaries of, 200

development of, $303,304,312$, $33 \mathrm{I}$

Mandible, 74

Mandibular fold, 296, 301, 308, 317,318

Manus, $84,317,318,329$

Mating season of alligator, 19

Maxillary process, 30I, 308, 317, 318

Meatus venosus, 3 I2

Meckel's cartilage, 330

Medulla, I32

Medullary, canal, 254, 255, 258, $259,260,262,267,268,269$, $270,271,272,275,282,29 \mathrm{I}$

Medullary folds, 250, 25I, 253, $254,256,258,265,266,291$ origin of, 336

Medullary groove, 236, 237, 238, $24 \mathrm{I}, 242,244,245,248,250$, $253,255,256,263,265,3 \mathrm{I} 3$, $334,336,337$

Medullary plate, 249

Melbourne, Fla., 27

Mesentery, development of, 299

Mesoderm, 234

Metanephros, 332

Miami, Fla., 27

Midbrain, 275, 276

Middle ear, I49

Mouth, I50

Muscles:

abdominal, 112

ambiens, 118

anconæus, 104

atlanti-mastoideus, 96

capiti-sternalis, 96

caput coraco-scapulare, I05

caput humerale mediale, 106

caput humerale posticum, I05

caput humeri laterale, I05

caput scapulare laterale, 104

carpo-metacarpalis, II I

carpo-metacarpalis V., III

carpo-phalangei, ro9, I I0 carpo-phalangeus, III

carpo-phalangeus primus digiti V., III

caudali-ilio-femoralis, 120

caudi-femoralis, I2I

cerato-hyoideus, 93

cervicalis adscendens, 96

collo-capitis, 94

collo-occipitis, 96

collo-scapularis superficialis, 97

collo-squamosus, 95

collo-thoraci-suprascapular is

profundus, $9^{8}$

coraco-antebrachialis, IOI

coraco-brachialis, I0I

coraco-ceratoideus, 92

costo-coracoideus, 93, 99

costo-scapularis, 94

costo-vertebralis lateralis, 94

costo-vertebralis medialis, 94

deltoideus scapularis infericr, 103

diaphragmatic, I I 5

dorsalis scapulæ, I03

of dorsal neck region, 94

dorso-humeralis, 102

dorso-scapularis, 97

episterno-ceratoideus, 92

epistropheo-vertebralis, 95

extensor hallucis proprius, I29

extensor ilio-tibialis, II 8

extensor longus digitorum, 125

of eyeball, 146

femoro-tibialis, I I9

flexor digitorum brevis, 128

flexor longus digitorum, I27

flexor tibialis externus, 122

flexor tibialis internus, 122

of forearm, 107

gastrocnemius, 126

humero-antebrachialis inferior, IO2

humero-carpi-radialis, 108

humero-carpi-ulnaris, 108

humero-metacarpalis, I08

humero-radialis, 106

humero-radialis brevis, 108

humero-radialis internus, 107

humero-radialis lateralis, $\mathbf{1 0 9}$

humero-radialis longus, 107

humero-radialis medialis, I09

humero-ulno-phalangei, 1 I0 
Muscles-Continued

ilio-femoralis, 120

ilio-fibularis, I 19

ilio-ischio-caudalis, 130

intercostales, II 5

intermaxillaris, 9I

interosseus cruris, $\mathbf{1 2 8}$

ischio-femoralis, 123

latus colli, 92

maxillo-coracoideus, 93

maxillo-hyoideus, 93

metacarpo-phalangeus, I I I

metacarpo-phalangeus I., digiti V., I I 2

obliquus abdominis externus, I 2

obliquus abdominis internus, I 3

occipito-cervicalis medialis, 94

occipito-epistropheus, 96

occipito-maxillaris, 91

pectoralis, I0o

pectoralis minor, I00

peroneus anterior, 125

pisiformi phalangeus primus digiti V., I I I

of posterior appendages, II 8

pterygo-maxillaris, 9I

pubi-ischio-femoralis externus, 123

pubi-ischio-femoralis internus, I 24

pubi-ischio-femoralis posterior, I 24

quadratus lumborum, I I 5

rectus abdominis, II 3

rectus internus, I 15

rectus lateralis, I I 4

rectus ventralis, $I_{3} 3$

retractor oculi, $\mathbf{I} 37$

rhomboideus, 99

of scapula, 96

scapulo-humeralis IO3

sphincter colli, 9 I

squamoso-cervicalis medialis, 9.5

sterno-atlanticus, 97

subscapularis, I04

supracoracoideus, Ioo

of tail, 129

temporalo-maxillaris, 90

teres major, 103 tibialis anticus, 125

tibialis posticus, 128

transversus abdominis, I I3

ulno-carpi-radialis, 109

ulno-radialis, 107

of ventral side of neck, 9I

Muscle plates, 289, 297, 3 I I, 325

Musk glands, I 56

Myocardium, development of, 305

Myocœl, 256, 280, 281, 282, 31 I

Nasal passages, I 5I

Nasal pit, 294, 307, 310, 317, 322, 330

Nephrostome, 290

Nerves

abducens, I33, I34, I35, I37

acoustic, $\mathbf{I} 33, \mathbf{I} 37$

alveolar branch, inferior, I36

axillaris, $\mathbf{1} 4 \mathrm{I}$

brachialis longus inferior, I4I

brachialis longus superior (radialis), I4I

brachial plexus, distribution of, 140

coraco-brachialis, I4I

crural and ischiadic plexuses, I 42, I 43

cutaneus brachii et antebrachialis medialis, I $4 \mathbf{I}$

cutaneus pectoralis, I 4 I

dorsalis scapulæ (posterior), I $\mathbf{4} \mathbf{I}$

facial, I33, I37

frontal branch, 136

glossopharyngeal, I34, I 37

hypoglcssal, 68, I34, I38

latissimi dorsi, I4I

nasal branch, I36

oculomotor, $68,133,134,135$

olfactory, I35

optic, $68,134,135$

pectoralis, I4I

pneumcgastric, see vagus

postsacral, I 42,143

presacral, I $42, \mathbf{1} 43$

sacral, 143

scapulo-humeralis profundus, I 4 I

spinal (I-4), I38, I39, I40

subscapularis, I 4 I

supracoracoideus, I 40

teres major, I4I

thoraci inferiores, I 40 
Nerves-Continued

trigeminal, 68, I33, I35, I36, 137

trigeminal, inferior maxillary branch, I36

trigeminal, ophthalmic branch, I36

trigeminal, superior maxillary branch, I36

trochlear, 133

vagus, $68,134,137$

Nervous epithelium of ear, I 49

Nervous layer of ectoderm, 259, 268

Nervous system, I3I

Nest of alligator, compactness of, 2 I

construction of, 2 I

form of, 2 I

location of, $2 \mathrm{C}$

size of, 2 I

temperature in, 24

Neural arches, development of, 325,331

Neural groove, see Medullary groove

Neurenteric canal, 264, 267, 272, $275,282,336$

New York Zoölogical Park, crocodilians in, 39

Nictitating membrane, I44

Notochord, 236, 238, 245, 248, $249,25 \mathrm{I}, 255,256,260,263$, $266,269,270,285,295,306$, 335

Nuchal shield, 47

\section{Obex, 133}

Oblique muscles, I46

Odontoid process, 52,54

CEsophagus, I 5 I, I 52, 324, 330

cilia of, I 74

epithelium of (feeding), I73

epithelium of (hibernating), I 72

histology of, 168

transsections of (figures), I69, 170

Okefinokee, 10, 226

Olfactory bulb, I32, 133

Olfactory lobes, development of, 332
Olfactory tract, $132,133,134$

Olivary enlargement of œesophagus, I 5 I

Optic chiasma, I34

cup, 302, 309, 310, 321

lobes, I 32, I 33, I 35

nerve, development of, 32 I

stalk, 302

tracts, I34

vesicle, $274,276,282,294$

Oral cavity, I 50

Ora serrata, 147

Osteolæmus tetrapis, 3

Otic vesicle, see Auditory vesicle

Outer ear, $\mathrm{r}_{4} 8$

Ova, 193

Ovary, 193

Oviducts, I56, I93, I94

Palm Beach, Fla,, 9

Pancreas, 154

development of, 326

Papillæ of tongue, I 50

Paraphysis, I32, I33

development of, $319,320,330$

Pecten, I 47, 32I

Pectoral girdle, $8 \mathrm{I}$

Penis, shaft of, 194

Pericardium, 323

Periotic capsule, 73

Pes, 317, 318, 329

Petromyzon marinus, I 57

Pharynx, development of, 277, 285, 292, 295, 299

Pigment, 333,334

Pineal body, I32, 319

Pits in scales, 49

Pituitary body, see Hypophysis

Plover and crocodile, 40

Posterior cardinal vein, development of, 298

Postorbital bar, 60

Prickle cells, 49

Primitive groove, 246, 249, 250, $256,265,267$

Primitive spinal column, 326

Primitive streak, 233, 240, 246, $249,250,256,265,267,275$

Procolia, I

Pulp cavity of tooth, 65

Pupil, I46 
Recessus cavi tympani, 149

Recessus scalæ tympani, I49

Rectum, 155 transsection of (fig.), I86

Rectus muscles of eye, I46 development of, 332

Respiratory organs, 197, 200; (fig.) I98

Rete Malpighii, 48

Retina, I47 development of, 32 I

Retractor oculi muscle, I46

Ribs, 77

Rima auditoria, I 48

Ring muscle, 157

Roof of mouth, 165 covering of (fig.), 166 glands of, 167 papillæ of, 167

Saccus naso-lachrymalis, $\mathbf{1 4 6}$

Scales, development of, 333

Sclera, 146

Scutes, 47

Semicircular canals, I49

Semilunar valves of stomach, 154

Sexual characteristics, I9

Sexual maturity, I7

Shell membrane, 228

Shell-tooth, 334

Sinus venosus, 202

Size of alligator, 16 at hatching, 16

Skeleton, 46, 50

Skin, 87

Skull, 58

dorsal aspect of, 59

lateral aspect of, 67

posterior aspect of, 70

sagittal section of, 72

ventral aspect of, 63

Smaller part of stomach, I53

Small intestine, I54 histology of, 179,186 mucosa of (fig.), I 84 transsection of (figs.), I8I, I82, I 83,185

Smithsonian Institution, 226, 227

Somatapleure, 279

Somites, 25I, 252, 256, 266, 267 , $274,282,292,300$

Special sense organs, 144
Spinal cord, I3I, 290, 291, 298, 311,325

development of, 298

Spinal ganglion, development of, 299, 31 I, 312, 31 4, 33 I

Spinal nerves, I 38

Splanchnopleure, 279

Stenosauria, I

Sternum, 77,80

Stomach, 152, I 53

development of, 305,326

glands of, 177,179

histology of, I 74

transsection of (fig.), 176

Stomodæum, 317, 322

Stratum corneum, 48

Supratemporal fossa, 57

Sympathetic nerves, 314, 325, 337

Systemic arch, 203

Tail, 317, 318, 329

Tailfold, 274

Tapetum lucidum, 146

Tarsus, 88

Taste papillæ, I65

Tear dots, 145

Teeth, 47,64

Teleosauria, I

Temperature range in swamps, 23

Tendon Achilles, I26, 127

Testes, 194

Thoracic ribs, 78

Thyroid gland, development of, 78,269

Tomistoma schlegeli, 2 skeleton of, $5 \mathrm{I}$

Tongue, I 50 covering of (fig.), I60, I6I

development of, 333

epithelium of, I6I

glands of, I60, I62, I63, I64

histology of, I 57

papillæ of, 160,165

Tooth, development of, 333

socket of, 64

structure of, 65

Torsion of body, 274,336

Trachea, 197

development of, 324,330

rings of, $\mathrm{x} 98, \mathrm{I} 99$

Trigeminal foramen, 78 
Tuberculum of rib, 78

Tympanic cavity, 70, 73, 148, 149

Umbilical stalk, 300, 308, 317 , $318,333,334$

Ureter, I56, 193

development of, 290

Urogenital organs, 192, 196

Valves of outer ear, $\mathbf{1}_{4} 8$

Vasa deferentia, $\mathbf{1} 56$

Vascular system, 20 I

lettering for, 224

Veins, of anterior region (fig.), 209

anterior vena cava, 208

axillary, 2 Io

brachial, 2 Io

caudal, 207

coronary, 202

external jugular, 2 I I

femoral, 206

hepatic, 202, 205

hepatic portal, 205

iliac, 206

inferior dental, 2 I I

internal epigastric, 206

internal jugular, 208

internal mammary, 208

ischiadic, 207

lingual, 2 I I

mesenteric, 205

muscular, 2 I I

pancreatic, 205

of pes, 207

postbrachial, 2 I0

postcaval, 202, 204

of posterior region, 204

precaval, 202, 208 pulmonary, 203

radial, 2 I I

rectal, 207

renal portal, 207

subclavian, 2 I0

subscapular, 2 Io

superior dental, 2 I I

thoracic, 2 Io

vertebral, 208

Velum palatinum, I5I

Venous system, 204

Ventricle, 203

Vertebræ, cervical, 5I, 52

caudal, 57

lumbar, 56

sacral, 56

Vertebral column, 50

Vertebrarterial canal, 78

Vitelline blood-vessels, 267,283

Vitelline veins, 270

Vitreous humor, 332

Vocal cords, 197

Vocitzkow, A., 228, 230, 231, 232, 334

Voice of alligator, $\mathbf{I} 8$

before hatching, 25

Warts, 49

Wolffian body, 289, 299, 304, $305,307,314,316,326,33 I$, 336

ducts, 280, 28I, 289, 299, 3I4, 316

ridge, $299,306,314$

tubules, 306, 313, 331

Xiphisternal horns, $8 \mathbf{I}$

Yolk of egg, 230 
A Selection from the Catalogue of

\title{
G. P. PUTNAM'S SONS
}

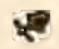 \\ Complete Catalogue sent \\ on application
}





\section{An Introduction to}

\section{Vertebrate Embryology}

Based on the Study of the Frog and the Chick

\section{By}

Albert Moore Reese

Ph.D. (Johns Hopkins)

Associate Professor of Histology and Embryology in Syracuse University and Lecturer in the

College of Medicine

Illustrated. $2 d$ Edition, Revised and Enlarged $\$ 1.50$ net

This work is the result of the need for a concise text-book of Embryology. Professor Reese's volume is intended as an outline from which the student may learn the main facts about Embryology of the two animals in question, and the instructor is supposed, in his lectures, to enlarge upon this outline to any extent he may see fit.

\section{G. P. Putnam's Sons}

New York

London 


\section{Putnam's Science Series}

I. The Study of Man. By A. C. HAdnon.

2. The Groundwork of Science. By St. George Mrvart

3. Rivers of North America. By ISRAel C. Russell.

4. Earth Sculpture; or, The Origin of Land Forms. By James GEIKIE

5. Volcanoes; Their Structure and Significance. Revised Ed. By T. G. BONNEY.

6. Bacteria. By George Newman.

7. A Book of Whales. By F. E. BEDdard.

8. Comparative Physiology of the Brain, etc. By JACQUES LOEB.

9. The Stars. By Simon Newcomb.

I0. The Basis of Social Relations. By Daniel G. Brinton.

II. Experiments on Animals. By STEPHEN PAGET.

12. Infection and Immunity. By George M. Sternberg.

13. Fatigue. By A. Mosso,

14. Earthquakes. By Clarence E. Dutton.

I5. The Nature of Man. By ÉLie Metchnikoff.

16. Nervous and Mental Hygiene in Health and Disease. By AUgust Forel.

17. The Prolongation of Life. By Élie Metchnikorf.

18. The Solar System. By Charles Lane Poor.

19. Heredity. By J. Arthur Thompson, M.A.

20. Climate. By Robert DeCourcy Waro

21. Age, Growth, and Death. By Charles S. Minot.

22. The Interpretation of Nature. By C. Lloyd MORGAN.

23. Mosquito Life. By Evelys Groesbeeck Mitchell.

24. Thinking, Feeling, Doing. By E. W. Scripture.

25. The World's Gold. By L. DE LAunaY

26. The Interpretation of Radium. Revised Ed. By F. SodDY.

27. Criminal Man. By Cesare Lombroso.

28. Social Evil. By E. R. A. Seligman.

29. Microbes and Toxins in Nature. By E. Burnet.

30. Problems of Life and Reproduction. By M. Hartog.

3r. Problem of the Sexes. By J. Finot.

32. The Positive Evolution of Religion. By F. HARRISON。

33. The Science of Happiness. By J. FrNot.

34. Life and Death of the Globe. By A. BERget.

35. Genetic Interpretation. By JAMES MARK BAL.Dwin. 





(6)

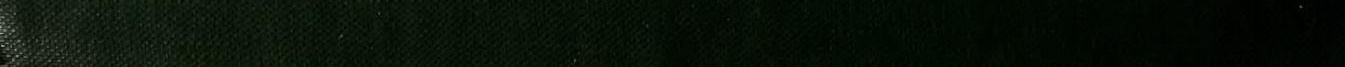

